\title{
TYPHA LATIFOLIA RESPONSE TO OLIGOTROPHIC AND EUTROPHIC NITROGEN AND PHOSPHORUS LOADING RATES UNDER LABORATORY CONDITIONS
}

By

\author{
Mark Henry Tiley \\ Bachelor of Science - Environmental Science and Biology \\ Trent University, 1993 \\ A Thesis presented to Ryerson University \\ In partial fulfillment of the requirements for the degree of \\ Master of Applied Science \\ In the program of \\ Environmental Applied Science and Management
}

Toronto, Ontario, Canada

Date, 2013

○Mark H. Tiley, 2013 


\section{Author's Declaration}

I hereby declare that I am the sole author of this thesis. This is a true copy of the thesis, including any required final revisions.

I authorize Ryerson University to lend this thesis to other institutions or individuals for the purpose of scholarly research

I further authorize Ryerson University to reproduce this thesis by photocopying or by other means, in total or in part, at the request of other institutions or individuals for the purpose of scholarly research.

I understand that my thesis may be made electronically available to the public. 


\title{
TYPHA LATIFOLIA RESPONSE TO OLIGOTROPHIC AND EUTROPHIC NITROGEN AND PHOSPHORUS LOADING RATES UNDER LABORATORY CONDITIONS.
}

\author{
M.A.Sc., 2013. \\ Mark Henry Tiley \\ Environmental Applied Science and Management \\ Ryerson University
}

\begin{abstract}
Typha latifolia is an aggressive rhizomatous emergent wetland plant that can invade wetlands resulting in near monotypic Typha stands. T. latifolia is also one of the most commonly used macrophyte species in constructed wetlands. The hypothesis that elevated nitrogen and phosphorus concentrations observed in nonpoint source runoff increases T. latifolia fitness and potentially $T$. latifolia invasiveness was tested under semi-controlled laboratory conditions. A protocol was developed to propagate $T$. latifolia from seed in low P sediment to simulate an oligotrophic pre-impact reference treatment. Microcosms provided with hypereutrophic levels of $\mathrm{P}$ combined with oligotrophic or eutrophic levels of $\mathrm{N}$ had significantly greater shoot biomass and maximum leaf height compared to oligotrophic $\mathrm{N}$ and $\mathrm{P}$ treatment microcosms. These results indicated that high $\mathrm{P}$ often found in runoff may contribute to $T$. latifolia invasion. We recommend that noninvasive species of macrophytes be used in constructed wetlands to prevent impact to ecologically sensitive areas.
\end{abstract}




\section{Acknowledgements}

Firstly, I would like to thank Dr. Lynda McCarthy for giving me the opportunity to study and work as her graduate student and for providing me with a tremendous learning experience. Her kind support and friendship has helped pull me through some strenuous times. A tremendous thanks goes to Laura Taylor, at the time a Ryerson University undergraduate student working part time, who graciously volunteered on a regular basis through the first summer of intensive experiments and data collection. Thank you to Dr. Andrew Laursen, Ryerson University, for his interest in my research, the lending of his equipment and lab, his assistance with statistical analysis and his friendship. I would like to thank Acorus Restoration for providing wetland flora and useful assistance with regards to propagating T. latifolia from seed. Thank you to Dr. Joy B. Zedler, University of Wisconsin botany professor and wetland restoration ecologist, Dr. S. Galen Smith, emeritus, University of Wisconsin and Dr. Joanna Freedland, geneticist, Trent University, for their advice, wisdom and generous information sharing. Thank you to Aslam Hanief and Jeremy Lau who provided assistance with phosphate, nitrate and ammonia analysis. Thank you to lab partners Dr. Jorge Loyo and Melanie Raby, for helping with data collection and the sharing of their wisdom and chemistry expertise. Thank you to Jessica Stoeckli, Mark Jilles and Darragh McNicholas for assisting with data collection. Thank you to all other graduate and undergraduate students who made my time at Ryerson and enjoyable and highly fulfilling one. Thank you to my father, James H Tiley, for being logistically and emotionally supportive throughout the process. Finally, last but far from least, a tremendous thanks goes to Karen Puddephatt, the chemistry-biology technician who provided a tremendous amount of invaluable help with laboratory technique and statistical software. 


\section{Dedications}

I would like to dedicate this thesis to Manfred Praus who reveled in the outdoors and, in his own way, spiritually connected with all around him. Had he been given the opportunity to find his path, protection for the natural world would have been one of his pursuits. I would also like to dedicate this thesis to my mother who bestowed in me the confidence to prove my true capability. 


\section{Table of Contents}



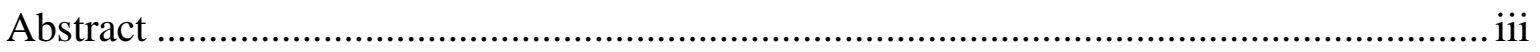

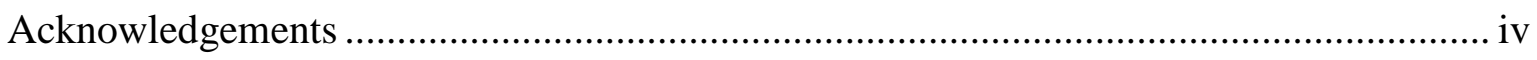

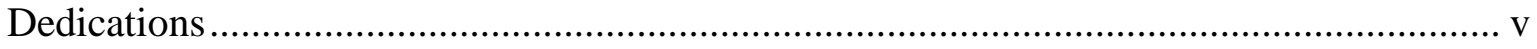

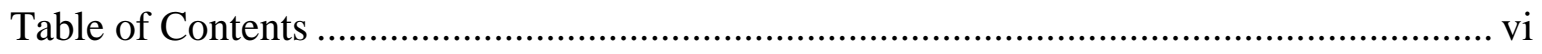

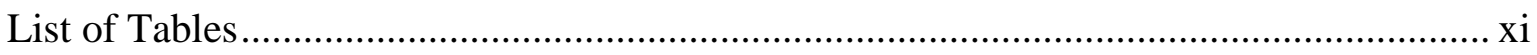

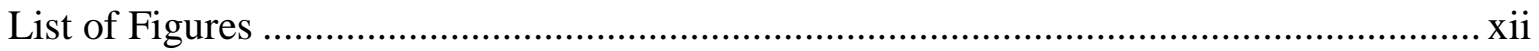

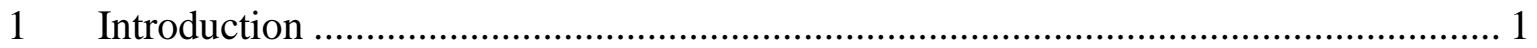

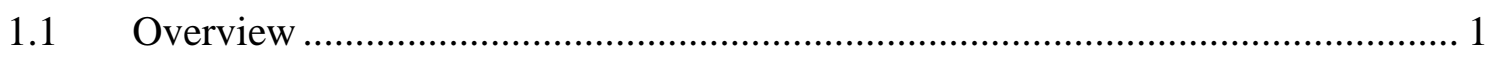

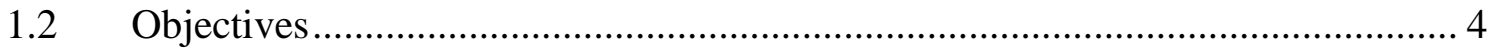

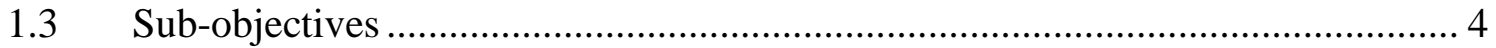



$1.5 \quad$ Typha latifolia Biology and Ecology …………............................................. 11

1.5.1 Distribution and Habitat ............................................................................ 12

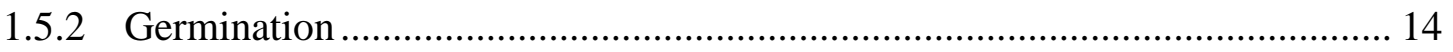

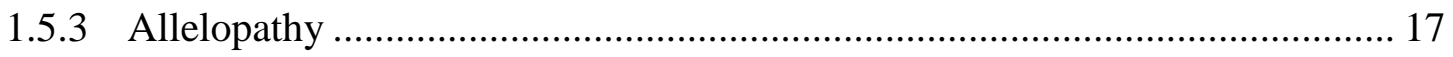

1.5.4 Growth and Vegetative Reproduction ............................................................ 17

1.5.5 The Typha latifolia Life Cycle in Temperate Regions .................................... 18



1.5.7 Nitrogen and Phosphorus Limitation in Typha latifolia .................................. 19

1.5.8 Sexual Reproduction and Genetic Diversity …………................................... 20

1.5.9 Typha latifolia Hybridization with Typha angustifolia .................................... 20

1.5.10 Herbivory and Wildlife Habitat .................................................................. 22

1.6 The History of Typha Invasions in North America............................................ 23

1.6.1 Early Documentation of Typha spp. Invasions and the Development of Control



$1.7 \quad$ Potential Causes of Typha latifolia Invasions ..................................................... 26

1.7.1 Nutrient Loading..................................................................................... 27

1.7.2 Altered Hydroperiod ................................................................................... 31 
1.7.3 Internal Eutrophication and Interaction between Hydroperiod Alternation and

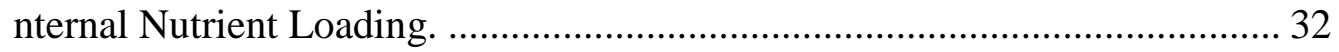

1.7.4 Other Potentially Contributing Factors to Typha Invasion............................ 34

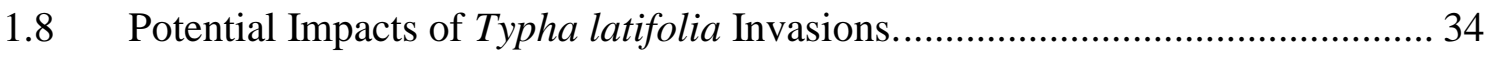

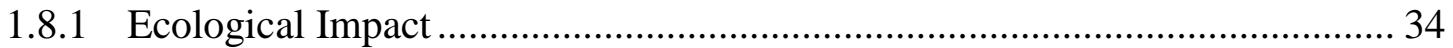

1.9 Limitations of Control Methods for Typha spp ........................................... 35

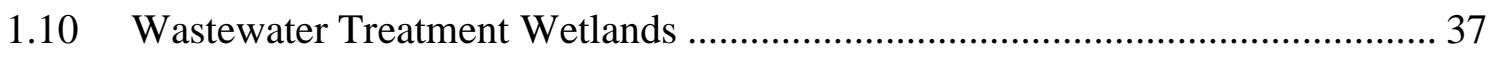

1.10.1 The History of Constructed Wetlands for the Treatment of Wastewater ...... 39

1.10.2 Types of Constructed Wetlands .............................................................. 40

1.10.3 Constructed Wetlands for the Restoration of Eutrophic Systems ................. 42

1.10.4 Nitrogen and Phosphorus Removal Limitations of Constructed Wetlands ... 42

1.10.5 Typha Productivity in Wastewater and Constructed Wetlands Effluent ....... 44

1.10.6 Hybridization and Formation of T. $x$ glauca populations............................ 44

1.11 The Role of Wetland Vegetation in Nitrogen and Phosphorus Removal Processes



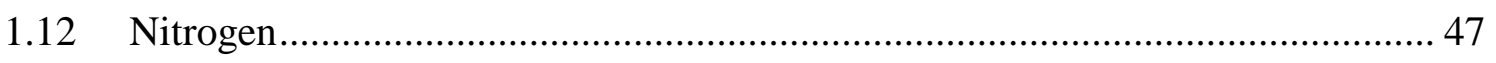



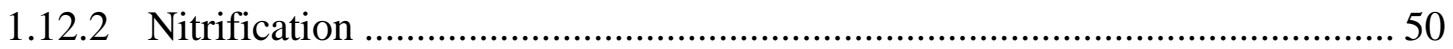

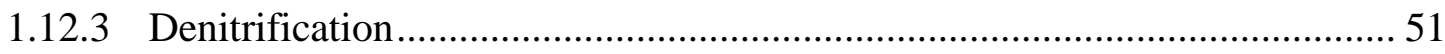

1.12.4 Macrophyte Nitrogen Assimilation and Peat Accretion .............................. 52

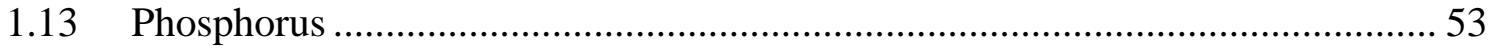

1.13.1 Sedimentation of Particulate Phosphorus .................................................. 56

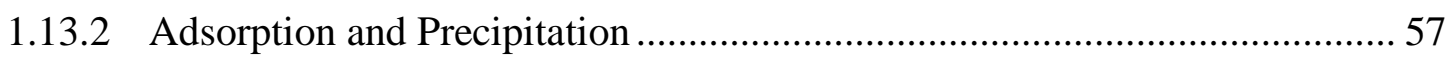

1.13.3 The Influence of Reduction-Oxidation Potential in Phosphorus Removal and

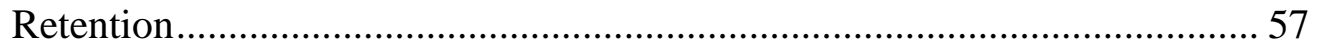

1.13.4 Phosphorus Assimilation by Macrophytes .............................................. 58

1.13.5 Phosphorus Retention by Peat Accretion ................................................. 59

1.14 Phosphorus Removal Limitation in Constructed Wetlands .............................. 60

1.15 Predominant use of Invasive Vegetation in Constructed Wetlands .................. 61

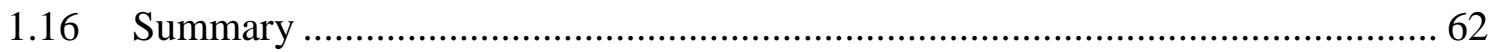

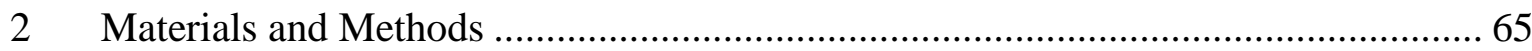




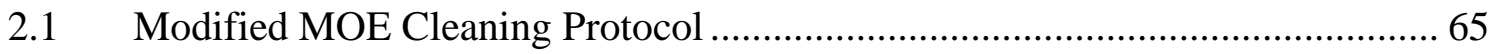



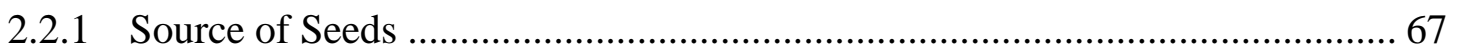

2.2.2 Germination and Experimental Vessels .......................................................... 67



2.2.4 Seedling Response to Phosphorus ................................................................ 69

2.2.5 Percent Germination of Viable Seeds.......................................................... 70

2.2.6 Percent Germination of Seeds added to Reference and P treatment

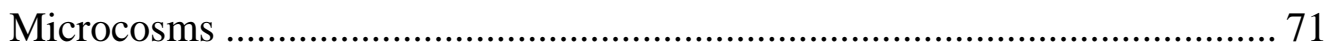

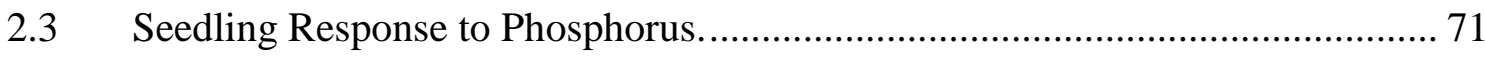

2.3.1 Formulated Sediment................................................................................ 71

2.3.2 Deionized Water Extractible Phosphate Method............................................ 72

2.3.3 Formulated Sediment Top Soil Selection.......................................................... 77

2.3.3.1 Sediment Preparation and Percent Moisture Content ................................... 78

2.3.4 Environmental Conditions .......................................................................... 79

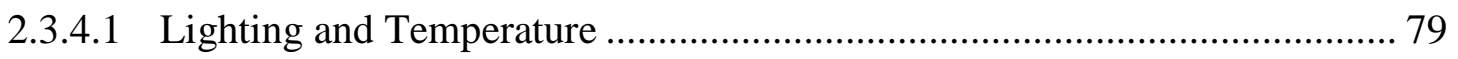

2.3.4.2 Soil Moisture Monitoring ........................................................................ 80

2.3.5 Seedling Addition to Experimental Vessels ………….................................. 81

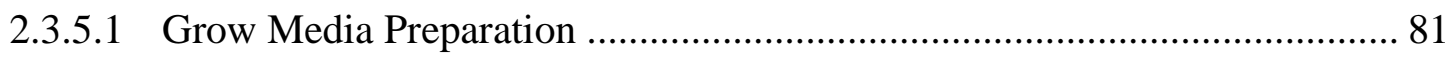

2.3.6 Watering Regimen and Grow Media Addition.............................................. 83

2.3.7 Pore Water Sampling ............................................................................... 84

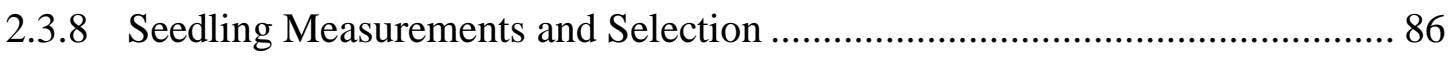

2.4 Typha latifolia response to Phosphorus and Nitrogen Experiment..................... 87

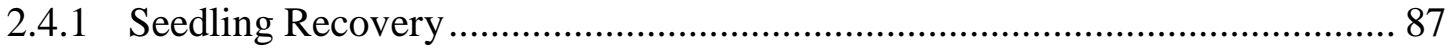

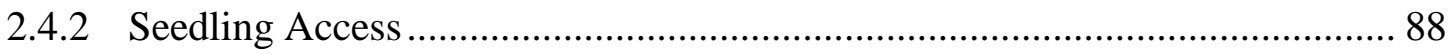

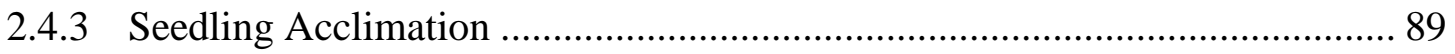

2.4.3.1 Formulated Sediment Preparation ............................................................. 89

2.4.4 Seedling Transplanting ........................................................................... 90

2.4.5 Grow Media and Watering Regimen ......................................................... 92

2.4.6 Environmental Conditions ............................................................................ 93

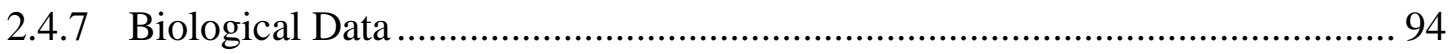


2.5 Typha latifolia Response to Oligotrophic and Eutrophic N and P Loading Rates

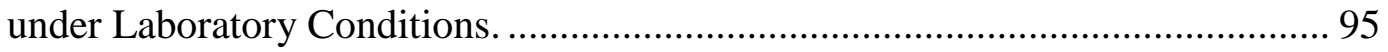

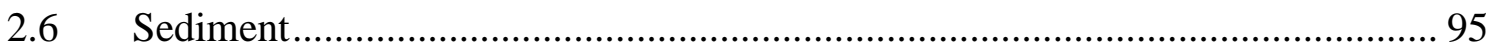



2.7.1 Grow Media and Watering Regimen ....................................................... 96

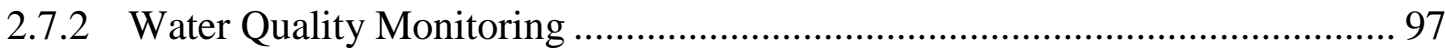

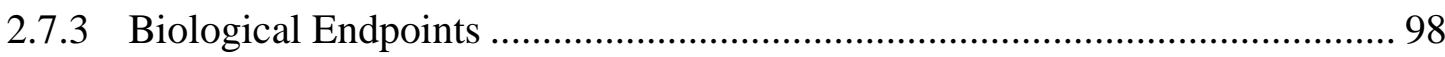

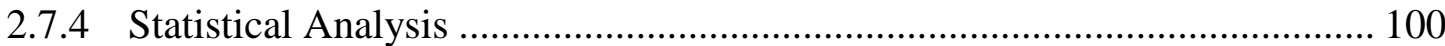

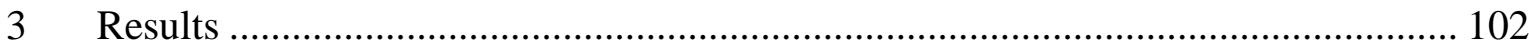

3.1 Typha latifolia Post Germination Response to 0, 50, 100 and $300 \mu \mathrm{g} \mathrm{PO}_{4}-\mathrm{P} / \mathrm{L}$

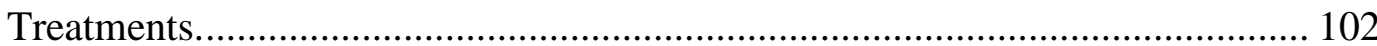

3.1.1 Environmental Conditions .................................................................. 102

3.1.2 Viable Seed Identification ................................................................. 103

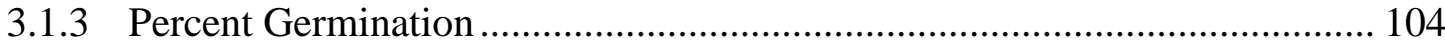

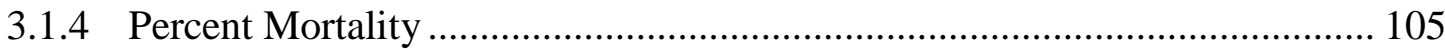

3.1.5 Growth and Biomass ....................................................................... 106

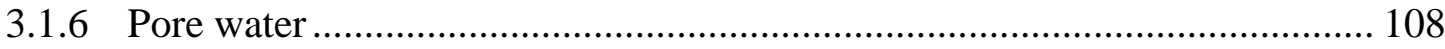

3.2 Typha latifolia Response to Oligotrophic and Eutrophic N and P Loading Rates..

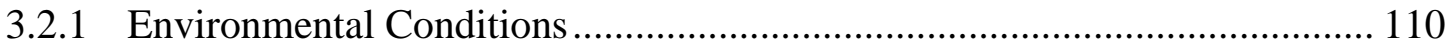

3.2.2 Basic Water Quality Parameters........................................................... 110

3.2.3 Pre-treatment Shoot Height, Total Leaf Length and Shoot Density

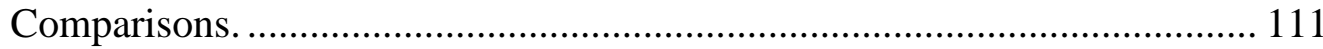

3.2.4 Growth Expressed as Total Leaf Length in Response to N and P Treatments....

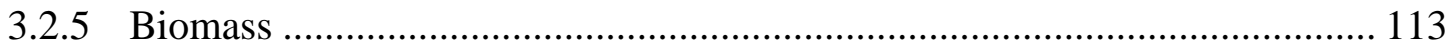



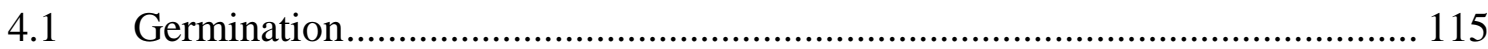

4.2 A Protocol for Examining Typha latifolia Response to Phosphorus Loading. . 117

4.3 Typha latifolia Response to Oligotrophic and Eutrophic N and P Loading Rates.. 
4.4 Recommendations for Further Study ................................................... 122

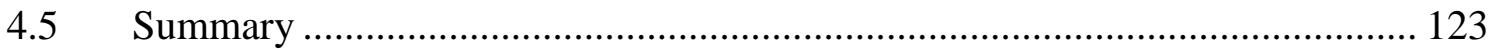

4.5.1 Typha latifolia Nitrogen and Phosphorus Limitation and Constructed Wetland Use for Ecological Protection and Restoration........................................ 124

4.5.2 The Use of Constructed Wetlands for the Protection and Restoration of Aquatic Ecosystems ................................................................... 125

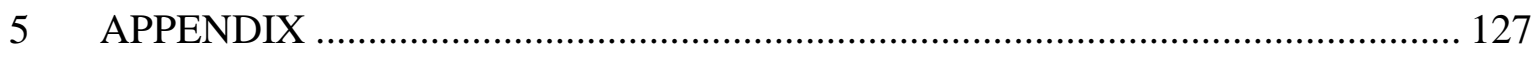

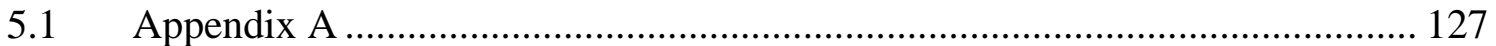

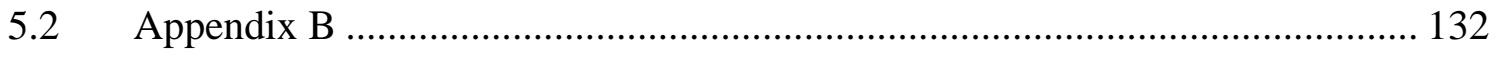

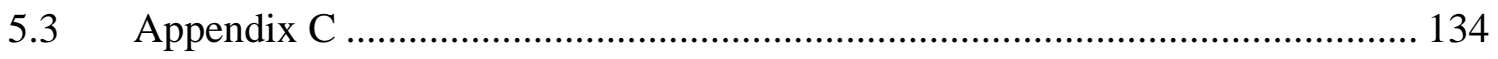

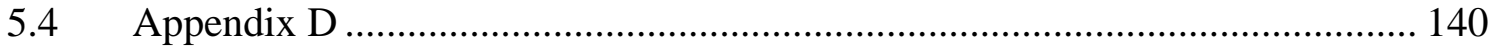

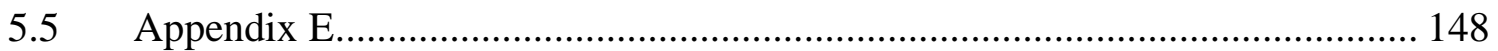

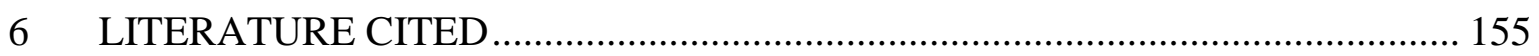




\section{List of Tables}

Table 1. Non-invasive and invasive herbaceous wetland plant species identified as suitable

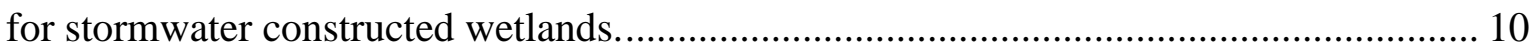

Table 2. Trophic status of freshwater ecosystems based on TN and TP concentrations. .. 29

Table 3. Total phosphorus concentrations in relation to freshwater trophic status as defined by Environment Canada (2004).

Table 4. $\mathrm{N}$ and $\mathrm{P}$ treatment concentrations used in controlled and semi-controlled experiments conducted to determine response in Typha latifoli and Typha x glauca biomass and competitive hierarchy.

Table 5. The modified grow media used in the Typha latifolia post germination response to phosphorus loading adopted from Weng et al. (2006). Micronutrients were made and

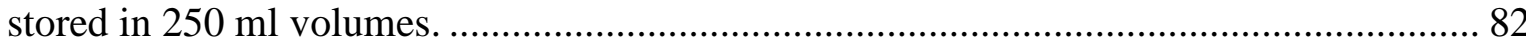

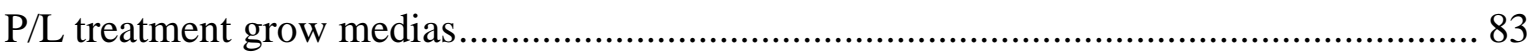

Table 7. Percent germination of seeds classified as nonviable. ................................... 104

Table 8. Percent germination of Typha latifolia seeds classified as viable.................... 104

Table 9. Basic water quality parameters monitored monthly for the duration of the

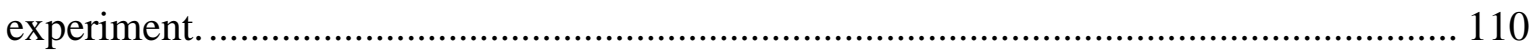

Table 10. Mean weekly growth rate expressed as change in TLL over the course of the experiment. 


\section{List of Figures}

Figure 1. Typha spp. Monospecific stand, Highway 28, Kawartha Lakes Region, Southern Ontario, June 2012.

Figure 2. Sexually mature Typha latifolia illustrating the staminate (male) spike and

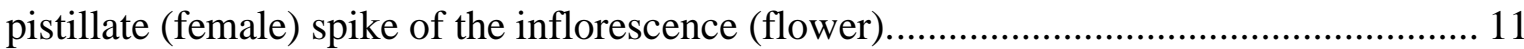

Figure 3. Typha latifolia, Typha angustifolia and Typha domingensis distributions in North America.

Figure 4. Typha latifolia carpodia and mature viable seed from the same inflorescence.. 14 Figure 5. Typha latifolia seed structures for developing immature seed (a) and mature seed (b).

Figure 6. The expansion of Typha angustifolia and Typha x glauca in North America.... 21

Figure 7. Wildlife habitat enhancement performed in 1946 through Typha latifolia removal (above) and re-seeding with wild rice (below)

Figure 8. Ashbridges Bay wetland in 1909 before the completion of the Main Treatment

Plant

Figure 9. Floating vegetation (a), surface flow (b) subsurface horizontal flow (c) and subsurface vertical flow (d) constructed wetlands. 41

orizontal view (Left). Magnification X 2 ........................................................................ 45

Figure 11. Nitrogen transformations in constructed wetlands. ............................................ 49

Figure 12. Phosphorus tranformations in constructed wetlands. ……………………...... 55

Figure 13. An internal view of the Typha latifolia inflorescence used for all germination trials and experiments illustrating the plumage (blue arrows) and seeds (green arrow)..... 66 Figure 14. The ripe Typha latifolia inflorescence used for all germination and rearing trials

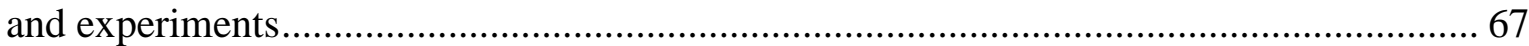

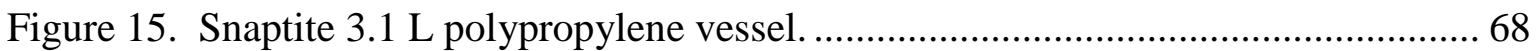

Figure 16. Microcosm vessels with black duct tape covering the lower $6 \mathrm{~cm}$ of each vessel and identifying labels after the removal of Typha latifolia shoots.

Figure 17. Light sensor attached to styrofoam to determine light intensity immediately prior to seeds being added.

Figure 18. Flow chart summarizing the Deionized Water Extractible Phosphate Method.73 
Figure 19. The $18.9 \mathrm{~L}$ sediment mixing bucket. ..................................................... 78

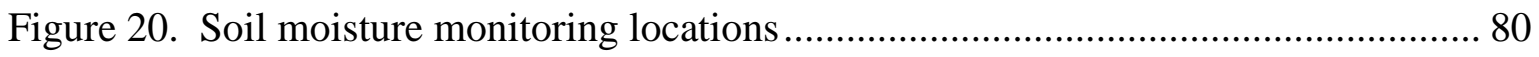

Figure 21. Typha latifolia recovering shoots being grown hydroponically in grow media on August 31, 2012 after removed from sediment, August 16 to 19, 2012 .................... 87

Figure 22. Cart being pulled out from underneath light bank 3 to access microcosms.... 88 Figure 23. Genet roots being gently laid on granite stones. Note the digital balance used to measure the weight of the genet and, immediately afterward, used to add $725 \mathrm{~g}$ of formulated sediment as DW. 91 Figure 24. A representative senescent leaf showing green pigment and counted as a green leaf. 94

Figure 25. Measuring light intenstity under LB3 with an extension on May 08, 2013.... 96 Figure 26. Root mass soaking to facilitate sediment removal. 99 Figure 27. Observed minimum and maximum laboratory air temperatures collected beneath the light bank used to determine Typha latifolia post termination response to $\mathrm{P}$ treatments.

Figure 28. Total percent germination over a six day period for Typha latifolia seeds observed in each of the four $\mathrm{PO}_{4}-\mathrm{P}$ treatment microcosms. 105 Figure 29. Post germination percent Typha latifolia mortality from June 01 to August 16, 2012 106

Figure 30. Typha latifolia mean height to tallest leaf over a twelve week period from the time of germination. 107 Figure 31. Typha latifolia biomass (wet weight) after 12 weeks from germination....... 107 Figure 32. Microcosm pore water $\mathrm{PO}_{4}$ concentrations observed on August 09 and 10... 109 Figure 33. Pore water concentrations from microcosms sampled on August 13. 109 Figure 34. Growth in response to $\mathrm{N}$ and $\mathrm{P}$ treatments expressed as change in TLL over time. $\mathrm{N}$ and $\mathrm{P}$ treatment additions began at the start of week 2 . 112 Figure 35. Shoot biomass, root biomass, total biomass and root to shoot ratio observed for low and high $\mathrm{N}$ and $\mathrm{P}$ treatments. 


\section{INTRODUCTION}

\subsection{Overview}

The shift from diverse wetland ecosystem communities to monotypic stands of Typha latifolia and other Typha species has been documented since at least since the 1940's (Addy and MacNamara, 1948). Typha spp. invasions have often been attributed, in whole or in part, to cultural eutrophication (e.g., Moore et al., 1989; McJannet et al., 1995; Galatowitsch et al. 1999; Chow-Fraser, 2005; Shih and Finkelstein, 2008). Galatowitsch et al. (1999) however noted that the scientific evidence supporting the eutrophication hypothesis to explain Typha spp. invasions in the northern US and Canada was "scant". The establishment and dominance of natural wetlands high in nutrients by T. latifolia (and other Typha species) is well documented (e.g., Grace and Wetzel, 1981a; Steward et al., 1997; Chow-Fraser, 2005). However, as the contribution of other factors such as climate, habitat disturbance, water level and hydroperiod, competition and herbivory may contribute significantly to T. latifolia establishment and invasion, field observations generally provide suggestive evidence that T. latifolia establishment and invasions occur under relatively high nutrient availability. Furthermore, Grace (1987) observed T. latifolia dominance under moderate (mesotrophic) surface water nutrient conditions in a reservoir suggesting that high nutrient loading may not be a requisite for T. latifolia invasion. The controlled and semi-controlled experiments conducted to determine Typha spp. response to N and P treatments (Shipley and Keddy, 1988; Wetzel and van der Valk, 1998; Keddy et al., 2000; Woo and Zedler, 2002) used N and P treatments that exceeded levels observed in even the most polluted natural wetlands. There is therefore uncertainty regarding the contributions of elevated $\mathrm{N}$ and $\mathrm{P}$ concentrations characteristic of environmentally relevant nonpoint source effluent.

Despite a general awareness of the benefits natural and constructed wetlands provide summarized later, there is a lack of awareness or consideration regarding the potential impacts of intentionally planting Typha latifolia and other invasive species commonly used in constructed 
wetlands for wastewater and stormwater treatment. Few authors have identified the risks of planting constructed wetlands with invasive species. Livingston (1989) stated in the oft-cited Hammer (1989) that the use of T. latifolia and other Typha species in constructed wetlands was "unacceptable". Similarly, Taylor (1992) raised concerns regarding the potential impacts of utilizing T. latifolia and other invasive species in constructed wetlands. Despite these warnings Typha has continued to be the most commonly used macrophyte species in constructed wetlands in North America and second only to Phragmites australis, also an invasive in North America, in European constructed wetlands despite the availability of noninvasive species that in some cases have been shown to be as or more effective in removing $\mathrm{N}$ and/or P (e.g. Neil and Graham, 1989; White et al., 2000).

There is a real disconnect between the objectives of constructed wetland practitioners, ecologists and land managers. The first criterion stated by Tanner (1996) for identifying species of vegetation for use in constructed wetlands was as follows:

"No significant weed or disease risks or danger to the ecological or genetic integrity of surrounding natural ecosystems".

Scholz (2006) recommended in his book Wetland Systems to Control Urban Runoff, published in the UK, that vegetation used in constructed wetlands should have "ecological adaptability" and not pose a "weed risk". Scholz (2006) then described the merits of utilizing $T$. latifolia and $P$. australis in constructed wetlands, two of the most invasive wetland species in North America. Kadlec and Wallace (2009) stated that the most suitable species of vegetation for constructed wetlands are aggressive rhizomatous species that have rapid grow rates, can rapidly infill newly built wetlands and can tolerate water level fluctuations and pollutants - traits often characteristic of invasive species.

In continuing with this disconnect, up to $80 \%$ of total annual budgets available for wildlife and nature preserve management in the US has been allocated to the control of invasive species, particularly invasive plants (D'Antonio and Meyerson, 2002). In 1998, over $90 \%$ of the $\$ 32$ to \$42 million US Federal annual budget available for the protection of species listed under the 
Federal Endangered Species Act was allocated to invasive species control (Wilcove \& Chen 1998).

Yet there has been recent interest in expanding the use of constructed wetlands to the watershed scale to remove N and P (Boesch et al., 2001; Arheimer and Wittgren, 2002; Zedler, 2003; Woo, 2009; Gren, 2010; Kim, 2010) and pilot studies have been conducted to evaluate constructed wetlands using $T$. latifolia as a restoration technique for recovering eutrophicated aquatic ecosystems (Li et al., 2008; Ham et al., 2010; Özkundack et al., 2010). Additionally, the constructed wetland N and P removal rates reported in Vymazal (2007) are too low to prevent ecological impact to receiving aquatic systems and can also fail to meet regulatory water quality standards (Vymazal, 2007; Lee et al., 2009). The ecological risk of using invasive species in constructed wetlands combined with high $\mathrm{N}$ and $\mathrm{P}$ in both influent and effluent therefore needs to be adequately addressed in constructed wetland design.

Lastly, research conducted to identify plant species most suitable for use in constructed wetlands, including native noninvasive species (e.g. Tanner, 1996), has been inconclusive due, at least in part, to low levels of experimental unit replication, inconsistent methodologies and the use of plants of variable age and fitness (Brisson and Chazarenc, 2009). The propagation of plants from seed is therefore a requirement to ensure consistent age and fitness for effective hypothesis testing. However, little information is provided in published research on plant propagation protocols. The majority of published research on Typha spp. response to $\mathrm{N}$ and $\mathrm{P}$ have relied on shoots produced from rhizome (root stalk), often of unknown history (e.g. Weng et al., 2006). The three studies located in the primary literature that propagated T. latifolia from seed (Ye et al, 1997; Wetzel and van der Valk, 1998; Kercher and Zedler, 2004) provided incomplete details on germination and propagation protocols. In order to identify native noninvasive species suitable for use in constructed wetlands and to identify nitrogen $(\mathrm{N})$ and phosphorus $(\mathrm{P})$ loading rates which significantly increase $T$. latifolia biomass and potentially invasiveness, a standardized protocol for propagating $T$. latifolia from seed under low nutrient reference conditions is needed. 


\subsection{Objectives}

1. Develop a protocol for rearing Typha latifolia from seed to adult stages under laboratory conditions to enable hypothesis testing based on data collected from plants of known history, uniform age and comparable fitness;

2. Conduct controlled, rigorous experiments with sufficient replication to further existing knowledge on the effects of environmentally relevant $\mathrm{N}$ and $\mathrm{P}$ loading rates on $T$. latifolia survival, growth and biomass;

\subsection{Sub-objectives}

1. Determine the feasibility of conducting future competition and nutrient removal experiments between $T$. latifolia and the native non-invasive species such as Schoenoplectus acutus and Schoenoplectus tabernaemontani under laboratory conditions;

2. Based on literature review, present supporting evidence for the hypothesis that native, non-invasive wetland macrophytes would provide $\mathrm{N}$ and $\mathrm{P}$ removal rates comparable to currently used invasive species and raise the issue of invasive species use in constructed wetlands to encourage research to determine the feasibility of utilizing non-invasive species in constructed wetlands for $\mathrm{N}$ and $\mathrm{P}$ removal. 


\subsection{Background}

It should be emphasized here that it is not the intention of the author to impress upon the reader that $T$. latifolia is inherently invasive. The evidence overwhelmingly suggests that $T$. latifolia becomes invasive due to anthropogenic habitat or environmental alteration and/or degradation of wetland ecosystems and should therefore be viewed as an indicator of ecological health. T. latifolia may play an essential role in ecosystems that have remained relatively unimpacted and under such conditions should be viewed as a vital component of the ecosystem. The ecological significance of T. latifolia as well as that of Typha angustifolia and Typha $x$ glauca should also be carefully assessed in impacted areas. T. $x$ glauca is a dominant emergent species of vegetation in the severely degraded Cootes Paradise wetland (Chow-Fraser et al., 1998) likely because they are one of the few species capable of surviving in that heavily polluted and hydrologically altered system (T. Theÿsmeÿer, Royal Botanical Gardens, personal communication). The habitat they provide may be critical to a variety of waterbirds and wildlife species. Despite the severe habitat degradation, Cootes Paradise is still supports species of conservation concern (listed and rare species) (Court and Bowman, 2011) and has been designated as the second important waterfowl staging area in Lake Ontario (Painter et al., 1988) with Typha spp. likely contributing significantly to the persistence of a number of wildlife species in Cootes Paradise.

T. latifolia (common cattail, broadleaf cattail) is an aggressive rhizomatous wetland plant that is native to parts of Central and North America, Europe, Asia and Africa (Grace and Harrison, 1986) and has been introduced to many other parts of the world (Invasive Species Specialist Group, 2013). T. latifolia (along with other Typha species (spp.)) is one of the most

productive plants known (Wetzel, 1983). Capable of rapid growth and vegetative reproduction from rhizome (underground stem), T. latifolia can achieve heights of 1 to 3 meters, very high biomass and produce 20,000 - 200,000 seeds from a single inflorescence (flower) (e.g. Yeo, 1964; Grace and Harrison, 1986).

These traits under certain conditions appear to enable T. latifolia to outcompete other plants and form dense monotypic stands with impoverished biodiversity (e.g. Curtis, 1959; 
McNaughton, 1966; Linde et al., 1976; Grace and Harrison, 1986; Moore et al., 1989; Wetzel and van der Valk, 1998; Drohan et al., 2006; Sullivan et al., 2010; Asomoah and Bork, 2010; Invasive Species Specialist Group, 2013) (Figure 1). Pollen records indicate that the range of $T$. latifolia has been expanding in North America since the mid to late 20th century likely in response to habitat disturbance and habitat degradation associated with human development and land use (e.g. Shih and Finkelstein, 2008; Olson et al., 2009). Over the last two to three decades, T. latifolia has often been defined as an invasive species in North America where it is native (e.g. Grace and Harrison, 1986; Livingston, 1989; Taylor, 1992; Kercher and Zedler, 2004; Bourgeois et al., 2012). Kercher and Zedler (2004) defined invasive plants as follows:

"Species or strains that rapidly increase their spatial distribution by expanding into existing plant communities".



Figure 1. Typha spp. Monospecific stand, Highway 28, Kawartha Lakes Region, Southern Ontario, June 2012.

Photo by Mark Tiley. 
Under this definition, invasive species include native species such as $T$. latifolia that have displayed invasive characteristics in response to habitat disturbance or environmental change. Invasive species are of major environmental concern globally. Organizations and programs such the World Conservation Union's Global Invasive Species Program, the U.S. National Invasive Species Council, the Ontario Phragmites Working Group and the recently terminated Alien Species Partnership Program have been formed in efforts to combat invasive species (Houlahan and Findlay, 2004).

The mechanisms that contribute to Typha spp. invasiveness, discussed later, have been studied for nearly three decades (e.g. Wilcox et al., 1984; Wilcox et al., 2008). However, disentangling the confounding mechanisms contributing to Typha invasion has proven illusive and a consistent challenge to researchers that have attempted to identify the role of invasive species in native species decline (Gurevitch and Padilla, 2004).

There is strong evidence indicating that $\mathrm{P}$ loading is a major contributor to Typha domingensis invasions in the Florida Everglades (e.g. Davis, 1991; Reddy et al., 1993; Newman et al., 1996; Noe et al., 2001). Most wetlands of all types are generally $\mathrm{N}$-limited and reduced wetland species diversity in Europe has commonly been associated with increases in $\mathrm{N}$ and both elevated $\mathrm{N}$ and $\mathrm{P}$ have been associated with low plant species diversity in North American wetlands (Bedford et al., 1999). Similarly James et al. (2005) found an inverse relationship between winter nitrate $\left(\mathrm{NO}_{3}^{-}\right)$levels and submergent plant species diversity in United Kingdom lakes.

The effects of high $\mathrm{P}$ and $\mathrm{N}$ loading in degraded aquatic ecosystems are however often confounded by altered hydroperiod (e.g. Davis, 1991; Drohan et al. 2006; Boers et al., 2007) and elevated levels of other nutrients and stressors such as potassium $(\mathrm{K})$ and calcium $(\mathrm{Ca})$, organic matter, suspended sediments, metals, industrial chemicals and other invasive species (e.g Cyprinus carpio (common carp)), (e.g. Painter et al., 1988; Martín and Fernández, 1992; ChowFraser et al., 1998; Smolders et al., 2006). Other contributing factors to Typha invasions may also include increased levels of carbon dioxide $\left(\mathrm{CO}_{2}\right)$ (Sullivan et al., 2010), global warming, reduced grazing pressure and fire suppression. How ecosystem changes associated with 
eutrophication, such as altered nutrient cycling, $\mathrm{pH}$, redox conditions, microbial communities and species composition and interaction, may contribute to Typha invasions have also not been addressed.

The relative importance of $\mathrm{N}$ and $\mathrm{P}$ to $T$. latifolia biomass production and invasion is also unclear. The need to address the uncertainty regarding the importance of environmentally relevant $\mathrm{N}$ and $\mathrm{P}$ concentrations on $T$. latifolia productivity for the protection and restoration of natural wetlands is obvious. There is a timely need to quantify T. latifolia response to environmentally relevant $\mathrm{N}$ and $\mathrm{P}$ levels as the building of remedial wastewater constructed wetlands (hence forth referred to as constructed wetlands) at the local scale has been suggested and/or assessed as a means of restoring eutrophicated inland freshwater ecosystems (e.g. Li et al., 2008, Ham et al., 2010; Özkundack et al., 2010). Boesch et al.(2001); Arheimer and Wittgren, (2002); Zedler, 2003; Woo, (2009); Gren, (2010) and Kim, (2010) have recommended or investigated the use of constructed wetlands at the watershed scale for the protection and restoration of coastal marine ecosystems. T. latifolia and other invasive species (e.g. Phragmites australis, Phalaris arundinacea, Typha angustifolia) are commonly used in constructed wastewater and stormwater remedial wetlands, all of which have been shown to increase biomass in response to elevated nutrient levels (e.g., Grace and Wetzel, 1981c; Weisner, 1993; Mal and Narine, 2004; Drohan et al., 2006; Martina and von Ende, 2008). Phragmites australis australis, the European genotype of Phragmites australis ( $P$. australis americanus is the native genotype), is also highly invasive in North America (Galatowitsch et al., 1999; Mal and Narine, 2004; Gilbert, 2012). The use T. latifolia and other invasive species in constructed wetlands may provide the high nutrient conditions often associated with Typha invasions.

To date, there is no evidence to indicate a macrophyte species effect on the pollutant removal performance of natural wetlands (reviewed by Nichols, 1983) and operational wastewater and stormwater remedial constructed wetlands (reviewed by Brix, 1994; Brix and Schierup, 1989; Brix, 1997; Brisson and Chazarenc, 2009; Marchand et al., 2010). Brisson and Chazarenc (2009) did not observe a consistently superior species based on their literature review and were therefore unable to provide generalizations in regards to nutrient removal efficiencies of particular wetland plant species. Studies comparing the relative metals removal capabilities of 
individual species in small-scale experiments have also been inconclusive (Marchand et al., 2010). Non-invasive species of vegetation have been used successfully in both constructed wastewater treatment wetlands (e.g. Kadlec and Wallace, 2009) and natural wetlands used to treat wastewater (e.g. White et al., 2000). Neil and Graham (1989) observed the non-invasive native bulrush Schoenoplectus tabernaemontani (formerly S. validus) to be generally more effective in the overall removal of all water quality parametrs tested, including $\mathrm{P}$ and $\mathrm{N}$, than the invasive T. angustifolia although the experimental mesocosm wetlands planted with $S$. tabernaemontani had a 5 day (d) - 7.5 d longer retention time. Taylor (1992) provided a list of species considered suitable for constructed wetlands in Ontario Canada which included both invasive and non-invasive species (Table 1).

The results from several studies involving the same species comparisons conducted to identify the relative pollutant removal capabilities for a given macrophyte species were sometimes conflicting (Brisson and Chazarenc, 2009). Brisson and Chazarenc (2009) noted that major differences in methodology between studies including the size and type of vessels, the age and condition of the plants used and a low level of replication were common limitations. Several authors have propagated T. latifolia from seed for research purposes (e.g. Ye et al., 1997; Wetzel and van der Valk, 1998; Kercher and Zedler, 2004). However, a detailed protocol for rearing $T$. latifolia and noninvasive native wetland plants used in constructed wetlands (e.g. Schoenoplectus spp.) from seed was not found in the peer-reviewed literature. In order to ensure plants of the same age and fitness are available for hypothesis testing, a standardized protocol for rearing wetland plants from seed is needed given that nurseries may not have the means or capacity to provide disease-free and pest-free plants of consistent age and fitness.

In order to provide the reader with background information on how constructed wetlands remove $\mathrm{N}$ and $\mathrm{P}, \mathrm{N}$ and $\mathrm{P}$ removal pathways and the relative importance of direct plant uptake are provided in later sections of the Introduction. 
Table 1. Non-invasive and invasive herbaceous wetland plant species identified as suitable for stormwater constructed wetlands.

Modified from Taylor (1992).

\begin{tabular}{|c|c|c|}
\hline Species & Common Name & Comments \\
\hline Cephalanthus occidentalis & Buttonbush & \\
\hline Saggitaria latifolia & Common arrowhead & \\
\hline Phalaris ardundinacea & Reed canary grass & $\begin{array}{l}\text { Highly invasive in many wetlands, } \\
\text { streams, waterways }\end{array}$ \\
\hline $\begin{array}{l}\text { Schoenoplectus spp. (formerly } \\
\text { Scirpus) }\end{array}$ & Bulrush & \\
\hline Carex spp. & Sedges & \\
\hline Acorus calamus & Sweet flag & \\
\hline Potamogeton crispus & Curly-leaved pond weed & $\begin{array}{l}\text { Submergent aquaitic introduced invasive } \\
\text { from Eurasia }\end{array}$ \\
\hline Leersia oryzoides & Rice cutgrass & \\
\hline Nuphar variegata & Bulhead lily & \\
\hline Eleocharis acicularis & Spikerush & \\
\hline Pontederia cordata & Pickerel weed & \\
\hline Sparganium eurycarpum & Giant bur-reed & \\
\hline Typha latifolia & $\begin{array}{l}\text { Common cattail, broad } \\
\text { leaf cattail }\end{array}$ & $1.5-3 \mathrm{~m}$ tall invasive marsh plant \\
\hline Typha angustifolia & Narrow leaf cattail & $1.5-3 \mathrm{~m}$ tall invasive marsh plant \\
\hline $\begin{array}{l}\text { Phragmites australis } \\
\text { americanus }\end{array}$ & $\begin{array}{l}\text { Common reed - North } \\
\text { American genotype }\end{array}$ & $\begin{array}{l}\text { Considered much less vigorous than the } \\
\text { Eurasian subspecies }\end{array}$ \\
\hline Phragmites australis australis. & $\begin{array}{l}\text { Common reed - Eurasian } \\
\text { genotype }\end{array}$ & $\begin{array}{l}\text { Highly invasive in North America, } 2-6 \mathrm{~m} \\
\text { tall }\end{array}$ \\
\hline Elodea canadensis & Elodea & Submerged aquatic \\
\hline
\end{tabular}




\subsection{Typha latifolia Biology and Ecology}

Kadlec and Wallace (2009) defined natural wetlands as land areas that are sufficiently wet during parts of the year which enable wetland plants to occur. Under this definition, wetland habitat includes marshes, swamps, fens, bogs, sloughs, wet riparian zones and shallow depression or pocket wetlands. T. latifolia is an herbaceous monocotyledon obligate wetland plant belonging to the Typhaceae family which comprises the genus Typha (cattails) and Sparganium (bur-reeds) (Figure 2). Obligate species are defined here as species that occur only in a specific type of habitat or condition. The earliest fossils of Typhaceae date to approximately 90 million years ago during the late Cretaceous period (Bremner, 2002), coinciding with the emergence of the first flowering plants. T. latifolia is the only extant native Typha species in the northern US and Canada (Smith, 1967; Grace and Harrison, 1986).

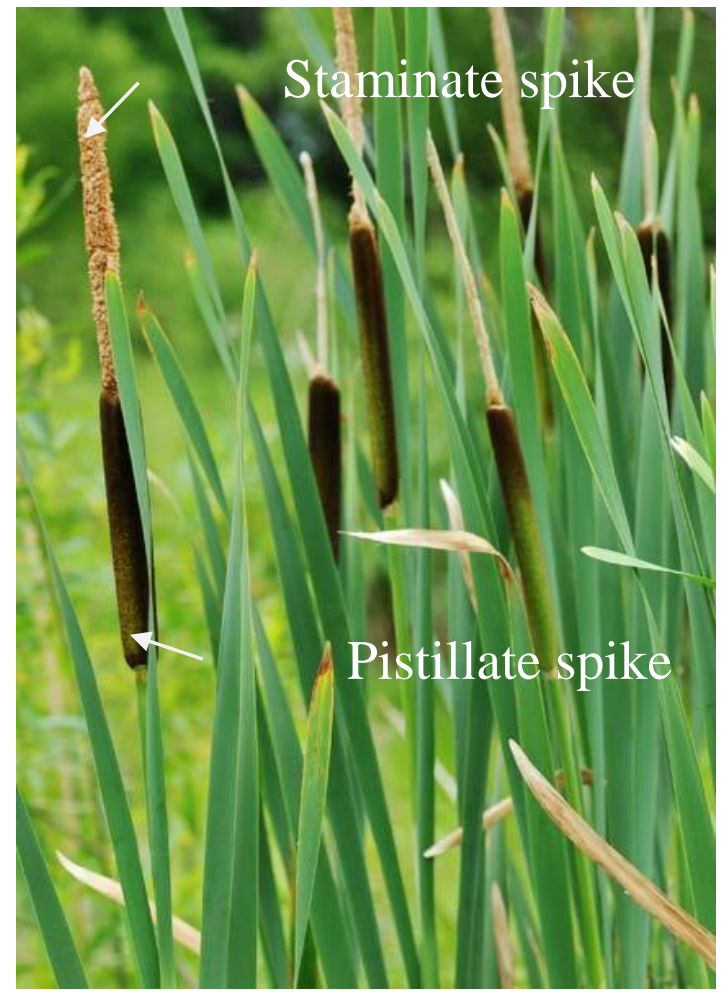

Figure 2. Sexually mature Typha latifolia illustrating the staminate (male) spike and pistillate (female) spike of the inflorescence (flower).

From http://www.iowaplants. com/flora/family/Typhaceae/typha/t_latifolia/Typha_latifolia.html 


\subsubsection{Distribution and Habitat}

T. latifolia is native to the Americas, Eurasia, and Africa and has been introduced to many other parts of the world including New Zealand, Hawaii and Australia where it is often invasive or a nuisance (Invasive Species Specialist Group, 2013). T. latifolia occurs in climates ranging from tropical to northern-temperate, dry to humid and at elevations from sea level to $2125 \mathrm{~m}$ (7000 ft) (Grace and Harrison, 1986). T. latifolia currently ranges throughout most of North America and its range historically overlapped with that of the native Typha domingensis in the southern U.S (Smith, 1967) (Figure 3). Since the mid-nineteenth century, the introduced Typha angustifolia has rapidly expanded it's range westward from the northeast coast of the US into the historical range of $T$. latifolia. T. latifolia and $T$. angustifolia hybridize to form the natural hybrid Typha x glauca which has a similar range to that of T. angustifolia (Galatowitsch et al., 1999).

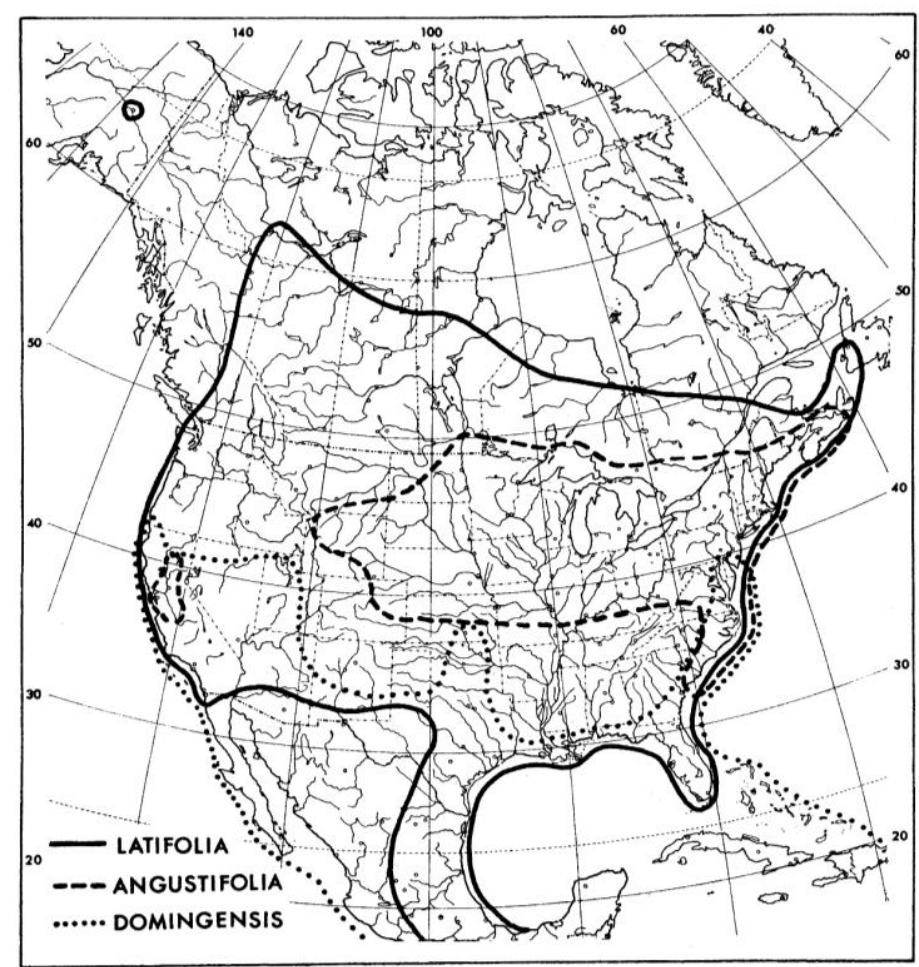

Figure 3. Typha latifolia, Typha angustifolia and Typha domingensis distributions in North America.

From Smith (1967), data from Hotchkiss and Dozier (1949). 
T. latifolia can establish in virtually any type of exposed substrate that remains sufficiently wet during most of the growing season (Grace and Harrison, 1986). Observations by Grace and Wetzel (1981b) and Grace (1985) that seeds germinate well in wet exposed sediment is consistent with the hypothesis that physical disturbance of vegetative cover (e.g. Shih and Finkelstein, 2008) and lower water levels that expose sediment are required for new Typha spp. stands to establish from seed. T. latifolia can tolerate moderate salinities (Hotchkiss and Dozier, 1949; Smith, 1967) but may be outcompeted by the more salt-tolerant T. angustifolia and T. $x$ glauca in roadside ditches where salinities can be elevated where de-icing road salt is applied (Grace and Harrison, 1986; Olson et al., 2009). It is reported in Smith (1967) to be the only acid-tolerant species of Typha. Jensen and Brix (1996) found T. latifolia seedlings grew rapidly at $\mathrm{pH} 5.0$ and were able to tolerate a $\mathrm{pH}$ of 3.5 for several days before showing signs of stress. $T$. latifolia are shade-tolerant, capable of growing in wooded areas affected by tree canopy cover (Grace and Wetzel, 1981a). Arbuscular mycorrhizae colonize T. latifolia roots providing mineral nutrients in exchange for photosynthate (Ray and Inouye, 2006) which may enable $T$. latifolia to survive in acidic low-nutrient soils. Arbuscular mycorrhizae are mycorrhizae (fungus) which penetrate the cortex of plant roots.

The presence of T. latifolia in nutrient enriched systems is well document as previously indicated. T. latifolia also occurs in pristine wetlands within the circumpolar boreal regions (Bourgeois et al. 2012) and has been documented in Sifton Bog, Ontario, since the 1920's (City of London and the Upper Thames River Conservation Authority, 2009) indicating that $T$. latifolia can establish under conditions of low nutrient availability where they generally occur in isolated stands. Steward et al. (1997) noted that T. latifolia were restricted to areas of the Florida Everglades that had been impacted by anthropogenic nutrient loading possibly due to their exclusion by the competitive dominance of Cladium jamaicense in unimpacted oligotrophic areas. Grace (1987) observed T. latifolia dominance under moderate (mesotrophic) surface water nutrient conditions suggesting that factors other than high nutrient loading contribute to $T$. latifolia competitive dominance. 


\subsubsection{Germination}

T. latifolia seeds are approximately 1.5 millimeters $(\mathrm{mm})$ in length (Grace and Harrison, 1986) and weigh $9 \pm 1$ micrograms $(\mu \mathrm{g})$ with all plumages and appendages removed (Shipley and Keddy, 1988). Fine hairs attached to the seed appendages facilitate wind dispersal (Yeo, 1964) (Figure 5b). Typha spp. are unique in that non-viable seeds termed carpodia ( $p l .=$ carpodium) or pistillodia by Krattinger (1975) (Figure 4, Figure 5) are produced (Hotchkiss and Dozier, 1949; Yeo, 1964), the evolutionary significance of which is unknown (Dr. S. G. Smith, emeritus, University of Wisconsin, personal communication).

Germination under natural conditions appears to occur under suitable light and moisture conditions that can occur at any time from spring through fall (Grace and Harrison, 1986). Moist soil conditions were stated by Grace and Wetzel (1981b) as a requirement for germination although submerged seeds also germinate (Sifton, 1959; Yeo, 1964; Bonnewell et al., 1982; Grace, 1985). Grace (1985) observed a decreasing germination rate along a moisture gradient with distance from the water table. Sifton (1959) observed a higher germination rate in seeds submersed compared to seeds germinated on a moistened artificial substrate under laboratory conditions.



Figure 4. Typha latifolia carpodia and mature viable seed from the same inflorescence. Photo by Mark Tiley. 

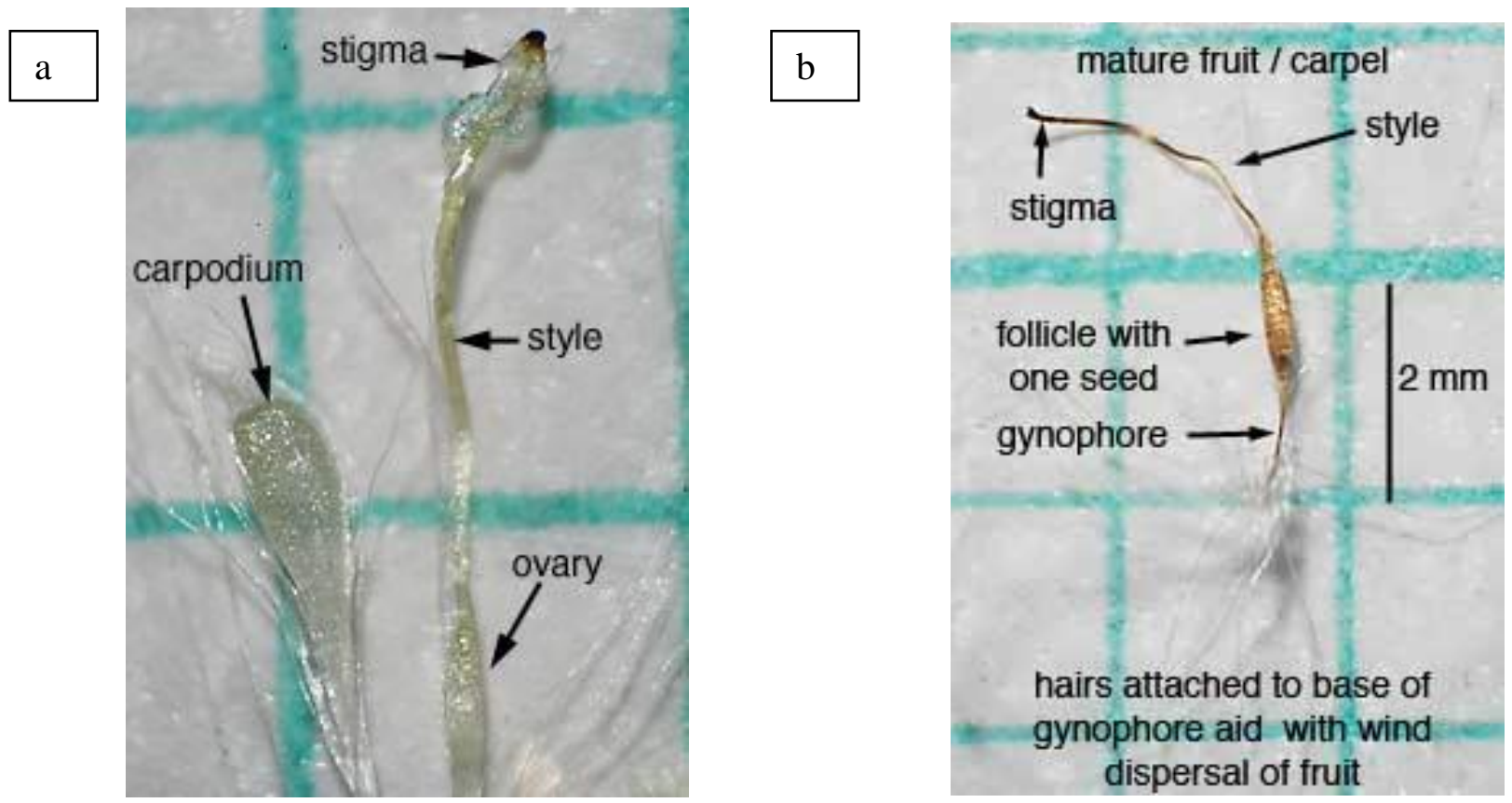

Figure 5. Typha latifolia seed structures for developing immature seed (a) and mature seed (b).

From http://www.iowaplants. com /flora/family/Typhaceae/typha/t_latifolia/Typha_latifolia.html

Yeo (1964) observed that seeds germinated at a depth of 76.2 centimeters $(\mathrm{cm})$ (maximum depth of the vessel) were able to grow leaves that reached the water surface. Both Yeo (1964) and Grace (1985) noted that submerged seeds that germinated produced floating leaves before generating erect leaves that grew above the water surface. Yeo (1964) noted that seeds germinated in moist soil grew "leathery" leaves that differed morphologically from the leaves produced by submerged seeds.

\subsubsection{Germination Under Laboratory and semi-controlled Conditions}

Previous studies that investigated T. latifolia percent germination generally involved the quantification of only seeds that sank when placed in water with the floating material, assumed to be remnants of flower parts and nonviable seeds, being removed (e.g. Yeo, 1964; McNaughton, 1968; Bonnewell et al., 1982). Percent germination near or at 100 percent (\%) has often been observed under laboratory conditions (e.g. Morinaga, 1926; Sifton, 1959; McNaughton, 1968; Bonnewell et al., 1982; Grace 1983; Bourgeois et al., 2012). However, Yeo (1964) observed a very low percent germination (0 - $15.7 \%)$ and Stewart et al. (1997) observed 
a relatively low percent germination of 30 to $40 \%$ for $T$. latifolia seeds collected from the Florida Everglades and germinated in environmental chambers (light intensities of 10, 764 or 32, 292 lux) and a shade house using paper towel and peat sediment as substrate. Yeo (1964) was later able to achieve $100 \%$ germination using the same seeds by applying pressure to rupture the seed coat to expose a circular opening. Bourgeois et al., (2012) observed a maximum percent germination of $36 \%$ on seeds grown on peat moss under controlled conditions.

\subsubsection{Temperature effect on Seed Germination under Laboratory Conditions}

McNaughton (1966) did not observe germination below $18^{\circ} \mathrm{C}$ in seeds collected from populations ranging from Texas to North Dakota. Sifton (1959) and Bonnewell et al., (1982) observed a low germination rate at 15 degrees Celsius $\left({ }^{\circ} \mathrm{C}\right)$ for seeds collected in Minnesota and a reduced time to maximum germination $(48 \mathrm{hrs})$ at $32^{\circ} \mathrm{C}$. Bonnewell et al., (1982) observed that the maximum percent germination of submerged seeds occurred at dissolved oxygen (DO) levels of between 2.3 milligrams per litre $(\mathrm{mg} / \mathrm{L})$ and $4.3 \mathrm{mg} / \mathrm{L}$ below or above which percent germination was significantly lower. Sifton (1959) stated that the required light intensity for germination is low and observed $0-10 \%$ (average of $5 \%$ ) germination in total darkness (layers

of paper wrapped around the seed-containing vessel. Seeds held in total darkness exposed to alternating temperature treatments $\left(15-30^{\circ} \mathrm{C}, 15-35^{\circ} \mathrm{C}, 20-35^{\circ} \mathrm{C}\right)$ resulted a germination rate of up to $97.2 \%$. The observations obtained by Sifton (1959) indicated that T. latifolia seeds are capable of germination under low light conditions, including total darkness, which may provided a significant competitive advantage with the ability to germinate under shaded conditions.

\subsubsection{Seed Tolerance to $\mathrm{pH}$ and Sedimentation}

Little information was found on the effects of $\mathrm{pH}$ on T. latifolia germination. Bourgeois et al. (2012) found evidence to suggest that the low $\mathrm{pH}$ found in moss cover grown on commercial peat (3.7) significantly reduced T. latifolia germination compared to seeds exposed to a $\mathrm{pH}$ of 4.3 grown on natural peat with a moss cover.

Percent germination for T. latifolia seeds subjected to burial by sediment was not located in the literature. (Wang et al., 1994) observed $>70 \%$ germination at the sediment surface and $<20$ 
$\%$ when buried by $4 \mathrm{~mm}$ of sediment for T. $x$ glauca seeds. Similarly, Galiano and van der Valk (1986) observed $72 \%$ germination for T. $x$ glauca seeds at the sediment surface, $10 \%$ germination with seeds buried by $1 \mathrm{~mm}$ of sediment and $0 \%$ germination with seeds buried by 2 mm of sediment.

\subsubsection{Allelopathy}

There is conflicting evidence as to whether T. latifolia release allelotoxins hypothesized by McNaughton (1968) to be a competitive strategy for preventing the establishment of new $T$. latifolia genotypes. McNaughton (1968) observed a slight negative effect on the percent germination of seeds subjected to marsh water collected from a mature T. latifolia stand and a significant reduction in germination when seeds were subjected to water squeezed from sediments in which adult $T$. latifolia were growing. Seeds that germinated in aqueous leaf extract did not grow beyond a tiny radicle. Grace (1983) observed no effect on T. latifolia seed germination following exposure to adult $T$. latifolia soil substrate and $T$. latifolia leaf litter extract but did observe a lower germination rate in seeds exposed to moulds which became established in the cultures.

\subsubsection{Growth and Vegetative Reproduction}

Newly established seedlings under natural conditions are capable of spreading rapidly and prolifically by rhizome (Grace and Harrison, 1986). A rhizome is an underground stem or shoot that later turns upward, penetrating through the sediments to access sunlight at which point is referred to as an aerial shoot or a ramet. A single plant germinated from seed is capable of producing a network of rhizomes reaching $58 \mathrm{~m}^{2}$ over a two-year period (Grace and Wetzel, 1981b). Yeo (1964) observed astounding growth over a single 7 month growing period (April 01 - November 01) where rhizome expansion from a single seed uninhibited by competition or physical obstruction reached a diameter of $3.05 \mathrm{~m}$ and vegetatively produced 34 aerial shoots (ramets or "suckers") ranging in height from $46 \mathrm{~cm}$ to $122 \mathrm{~cm}$.

Yeo (1964) observed that when the parent shoot produced from seed reaches approximately $30.0 \mathrm{~cm}$, the base of the shoot forms a crown at which point growth slows. The 
first rhizomes are produced shortly thereafter when parent shoots reach heights of approximately $36-46 \mathrm{~cm}$. After $30-61 \mathrm{~cm}$ of lateral growth, the rhizomes turned upward to form an aerial shoot. The genet consists of the parent ramet produced from seed and all vegetatively produced ramets (Grace and Wetzel, 1981b). T. latifolia aerial shoots can grow to depths of 1m but may be restricted to shallower waters through competition with T. angustifolia (Grace and Wetzel, 1981b; Weisner, 1993).

The leaf high amount of leaf litter and dead root mass produced by T. latifolia may significantly increase the organic matter of sediments and provide a further source of nutrients. Angeloni et al. (2006) observed greater than 10-fold higher $\mathrm{N}$ and $\mathrm{P}$ concentrations within the sediments of an expanding T. $x$ glauca stand compared to the adjacent sediments where noninvasive native plant species occurred. The production of high amounts of leaf litter can completely blanket the sediments (personal observation) which may prevent the germination or vegetative regeneration of other plant species. The manipulation experiment conducted by Jordan et al. (1990) observed reduced T. angustifolia production after three years receiving three times the amount $T$. angustifolia litter compared to the unaltered reference condition. Van der Valk (1986) observed greater species richness and shoot density were greater in plots cleared of T. $x$ glauca and P. australis litter compared to treatments that received a blanket of T. $\mathrm{x}$ glauca litter.

\subsubsection{The Typha latifolia Life Cycle in Temperate Regions}

Northern US populations translocate photosynthate to the rhizomes beginning in mid to late summer for over-winter storage with rhizome maximum biomass being achieved by late fall (Grace and Harrison, 1986; Garver et al., 1988). Garver et al. (1988) observed that in a Minnesota T. latifolia stand, 35 to $44 \%$ of $\mathrm{P}$ in shoot tissue had been translocated to the rhizomes by late fall, $75 \%$ of which was retained to the following spring.

Growth from rhizome in the spring in a Minnesota population was reported by Dubbe et al. (1988) to begin in early May. Initial growth from rhizome with growth continues until mid to late summer (Grace and Harrison, 1986; Garver et al., 1988) at which point flowering may occur at the expense of vegetative production (Grace and Wetzel, 1981a). Rhizomes connecting ramet 
clones die after 2 - 3 years (Kuhen et al., 1999) and typically die after flowering (Grace and Wetzel, 1981a).

\subsubsection{Phenotypic Variability}

T. latifolia displays considerable phenotypic variability depending on habitat and environmental conditions (Grace and Harrison, 1986). Grace and Wetzel (1981a) did not observe differences in overall biomass between three $T$. latifolia populations occurring adjacent to the same lake based on meristem $\mathrm{N}$ and $\mathrm{P}$ tissue content, an indicator of $\mathrm{N}$ and $\mathrm{P}$ availability within the surrounding environment, but did observe significant differences in phenotypic expression associated with $\mathrm{N}$ and $\mathrm{P}$ allocation. The woods biotype growing under tree and shrub canopy had the highest meristem nutrient levels and was thus considered to be non-nutrient limited but had the largest leaf volume: dry mass ratio and was therefore considered to be lightlimited. Despite having access to unlimited nutrient resources, the woods biotype did not allocate any photosynthate to sexual reproduction (no inflorescences were produced) (Grace and Wetzel, 1981a).

The T. latifolia population occurring within a marsh (cattail marsh biotype) and sheltered from wind and waves also did not produce inflorescences and was considered $\mathrm{N}$-limited based on tissue N content (Grace and Wetzel, 1981a). The T. latifolia population growing in exposed open water habitat was considered to be both $\mathrm{N}$ and $\mathrm{P}$ co-limited yet was the only population to produce inflorescences (11\% of all ramets). Individuals within the open water population that did not produce inflorescences had twice the vegetative biomass compared to individuals that produced inflorescences. N-P-K nutrient additions applied to the same populations in a separate experiment under field conditions had no effect on the woods biotype but resulted in a fivefold increase in biomass in the open-water biotype (Grace and Wetzel, 1981a).

\subsubsection{Nitrogen and Phosphorus Limitation in Typha latifolia}

The relative observed importance of $\mathrm{N}$ and $\mathrm{P}$ to $T$. latifolia growth, biomass and reproductive potential (fecundity) differs between studies. Field experiments by Grace (1988) observed an increase in $T$. latifolia biomass in response to increased soil $\mathrm{N}$ but no response was 
observed in response to increased sediment $\mathrm{P}$ which suggested $\mathrm{N}$ limitation. Conversely, Boyd and Hess (1970) observed a significant correlation between surface water $\mathrm{PO}_{4}-\mathrm{P}(200-320 \mu \mathrm{g}$ $\mathrm{PO}_{4}-\mathrm{P}$ ) and $\mathrm{T}$. latifolia standing crop whereas no correlation was observed between standing crop and surface water $\mathrm{NO}_{3}-\mathrm{N}(10-450 \mu \mathrm{g} \mathrm{NO}-\mathrm{N})$. Grace and Wetzel (1981a) observed possible differences in $\mathrm{N}$ and $\mathrm{P}$ limitation between three cattail stands occurring within the same wetland system depending on site-specific substrate $\mathrm{N}$ and $\mathrm{P}$ availability and other site-specific factors such as wind exposure and light availability.

\subsubsection{Sexual Reproduction and Genetic Diversity}

Stigmas are receptive one to two days before pollen is released from the staminate spike. Pollen is released over a $1-2$ day period in which self-pollination can occur (Grace and Harrison, 1986; Zhang et al., 2008). It has been hypothesized that stigmas remain receptive for up to 1 month to enable out-crossing (Grace and Harrison, 1986). Conversely, Krattinger (1975) observed that self-pollination was highly favoured with the majority of pollen falling directly from the male staminate spike onto the female flower below. All studies that have investigated the genetic traits of T. latifolia populations have found little to no genetic variation within populations and between populations within river drainage systems (e.g. Keane et al., 1999; Lamote, 2005; Zhang et al., 2008). The low genetic diversity is likely the result of selfpollination and the vegetative production of clones (Zhang et al., 2008).

\subsubsection{Typha latifolia Hybridization with Typha angustifolia}

Typha angustifolia, an invasive either introduced from Europe in the nineteenth century or historically restricted to the Northeast coast of the United States, has also been used in North American constructed wetlands (Neil and Graham, 1989; Selbo and Snow, 2004). The range of Typha angustifolia has expanded rapidly across North America since approximately 1860 (Galatowitsch et al., 1999; Shih and Finkelstein, 2008) (Figure 6). T. angustifolia often crosspollinates with $T$. latifolia where the two species are sympatric producing the natural hybrid Typha x glauca (Smith, 1967; Waters and Shay, 1990; Galatowitsch et al., 1999; Shih and Finkelstein, 2008; Olson et al., 2009). 
T. $x$ glauca is considered to be more invasive than either of the parent species (Galatowitsch et al. 1999; Fieswyk and Zedler, 2007; Olson et al., 2009) and has, over several decades, become the dominant species at many sites in the Lower Great Lakes region formerly occupied by T. latifolia (Kirk et al., 2011) and is believed to have displaced T. latifolia and other species in many of the Great Lakes coastal wetlands (e.g. Frieswyk and Zedler, 2007; Wilcox et al., 2008). T. x. glauca was reported as becoming increasingly abundant in both North American and European prairie wetlands (Waters and Shay, 1992) and is now the most common large macrophyte in the North American prairie pothole region (Linz and Homan, 2011).

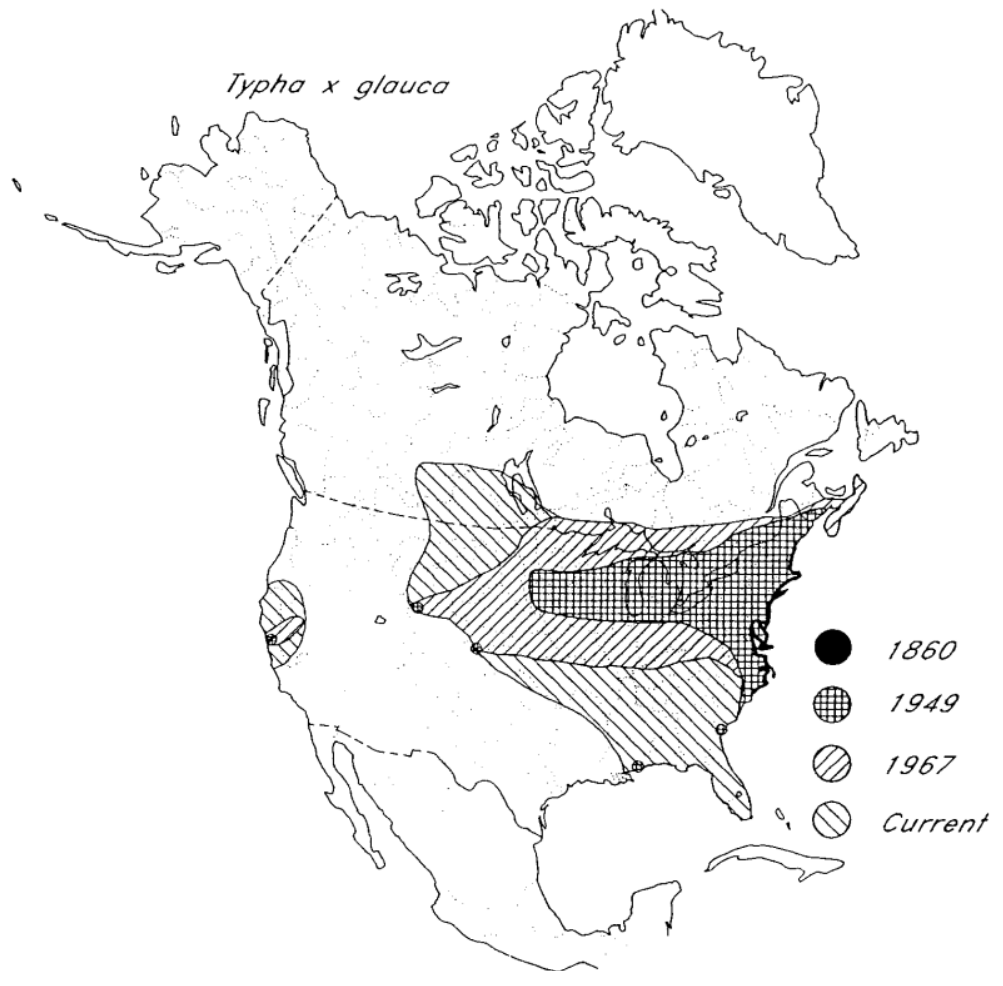

Figure 6. The expansion of Typha angustifolia and Typha $x$ glauca in North America. From Galatowitsch et al., 1999.

The expansion of T. angustifolia and T. x glauca across North America has often been attributed to the high salinities that are less favourable or intolerable to $T$. latifolia, altered hydroperiod, high nutrient loading and habitat disturbance (e.g. Grace and Harrison, 1986; Galatowitsch et al., 1999; Woo and Zedler, 2002; Frieswyk and Zedler, 2007; Boers et al., 2007; Boers and Zedler, 2008). T. x glauca is generally considered to be largely sterile (e.g. Smith, 
1967; Galatowitsch et al., 1999). However, Bedish (1967) observed a T. x. glauca percent germination of $48 \%$, Wang et al. (1994) up to $81 \%$ and Galiano and van der Valk (1986) up to $75 \%$ germination with all three studies being conducted under greenhouse conditions. Bedish (1967) observed no T. x glauca germination under field conditions using seeds from the same inflorescence as used in his greenhouse experiments and on the same natural wetland soil. The spread of T. x glauca through seed dispersal is therefore at least a possibility.

\subsubsection{Herbivory and Wildlife Habitat}

Muskrat (Ondatra zibethicus) can be defined as a keystone wetland species as their grazing can profoundly affect wetland plant species distribution and diversity, habitat structure and heterogeneity, avian abundance and diversity, nutrient cycling and macroinvertebrate diversity and distribution (e.g. Errington et al., 1963; de Szalay and Cassidy, 2001; Roberts and Crimmins, 2010) which may interact significantly with a variety of fish and wildlife species. Roberts and Crimmins (2010) documented a $75 \%$ reduction in muskrat harvest rates in eastern North America since 1986. Roberts and Crimmins (2010) further recommended that a regional assessment of muskrat populations be conducted to determine whether a true decline in muskrat populations is occurring so that management efforts could be implemented to reverse declines which may be necessary to protect remaining functional wetland ecosystems.

T. latifolia is known to be an important if not primary diet of muskrat (Beule, 1979; Campbell and MacAarthur, 1997; Mirka et al., 1996). Muskrat herbivory was considered by van der Valk and Davis (1978) to have a major effect on Typha abundance and wetland plant community structure in the Prairie region. Curtis (1959) noted that Typha spp. densities were absent or rare in marshes where muskrat populations were high. Bedish (1967) experienced the decimation of some T. $x$ glauca experimental plots, including the digging and consumption of buried rhizomes, to muskrat herbivory. A possible reduction in muskrat abundance which may have been caused by the loss of wetland habitat and land use development (e.g., Whillans, 1982; Curtis, 1989; Snell, 1989; Dahl \& Johnson, 1991) and may therefore be a contributing factor in Typha invasions. 
Grazing pressure on Typha by other vertebrate herbivores is generally considered to be light although elk and moose (Stevens and Hoag, 2000) and deer (Beule, 1979) graze newly emerging shoots during the spring and geese feed on roots (Stevens and Hoag, 2000). Seeds are generally not considered palatable due to the plumage but do provide food for several duck species. A variety of insects feed on the various T. latifolia structures (Grace and Harrison, 1986). The near total loss of T. latifolia stands to the cattail armyworm (Simyra henrici) in constructed wetlands was reported in Taylor (1992) and Ye et al. (2001).

\subsection{The History of Typha Invasions in North America}

\subsubsection{Early Documentation of Typha spp. Invasions and the Development of Control Methods}

The shift from a dominance of Zizania aquatica (wild rice) to T. latifolia in the Cootes Paradise wetland approximately coincides with initial European settlement and probably in response to deforestation, increased sediment deposition and nutrient loading (Chow-Fraser, 2005). It is therefore likely that T. latifolia. invasions have occurred throughout the species' range where disturbance and nutrient loading associated with human settlement has occurred.

The first document found describing a Typha invasion in North America was reported by Addy and MacNamara (1948) which documented the loss of shoreline bird nesting habitat, open water waterfowl habitat and wildlife food plants to Typha encroachment (Figure 7). Addy and MacNamara (1948) provided four methods for removing Typha: (1) raising water levels (drowning); (2) explosives (dynamite) to open channels and create new ponds; (3) removal by hand and (4) cutting. Other early documents related to Typha control cited in Beule (1979) included Heath and Lewis (1957); Martin et al., (1957) and Steens et al. (1959).

The study by Beule and Janisch (1973) (unpublished) was possibly the first scientific study conducted that assessed a Typha invasion in a conservation context where the objective of experiments were to identify methods for recovering lost wetland habitat and wildlife diversity. Shortly after, Beules' manual titled Control and management of cattails in southeastern Wisconsin wetlands, published in 1979, provided various techniques for controlling Typha, some 
of which were based on the information presented in Linde et al (1976). Beule (1979) continues to be commonly cited in the peer-reviewed literature and has undoubtedly contributed much to wetland restoration efforts.



Figure 20. Cattail control plot, Patuxent Research Refuge, Maryland. Plants cut July 19, 1946 just after flowering and followed by a slight cutting of volunteers one month later. (Photograph by F. M. Uhler.)

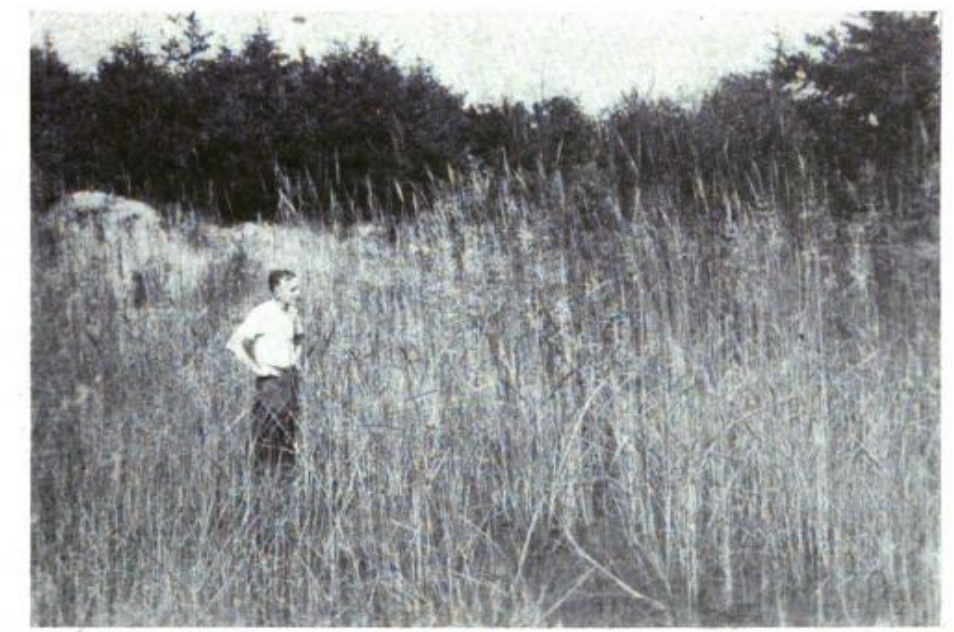

Figure 21. Stand of wildrice on August 6, 1947 growing in place of caltails in Figure 20. Wildrice seed sown Sept. 11, 1946 after the cattail was mowed. (Photograph by F. M. Uhler.)

Figure 7. Wildlife habitat enhancement performed in 1946 through Typha latifolia removal (above) and re-seeding with wild rice (below).

From Addy and MacNamara, 1948. 
Wilcox et al. (1985) was the earliest peer-reviewed publication located in the primary literature that investigated the potential causes of a Typha invasion. The study used a combination of air photo interpretation and field sampling to quantify the expansion of Typha into grass-sedge meadow over a 44 year period within Cowles Bog National Natural Landmark, Indiana. The sedge-grass habitat had received Federal protection as a significant natural feature.

Results indicated that T. latifolia and T. angustifolia occurring in isolated stands increased in area slightly from 2 hectares (ha) in 1938 to 7 ha by 1970. By 1982 the Typha stands had merged to form large stands totaling 37.2 ha at the expense of the native sedge-grass habitat. Wilcox et al. (1985) attributed the cause of the Typha invasion to increased and stabilized water levels associated with seepage from diked fly-ash settling ponds constructed upslope of Cowles Bog in the mid-1960s and in 1971. It was hypothesized that the altered hydrology created habitat conditions that increased Typha sexual reproductive success and rhizomatous expansion and as new Typha stands became established, sedge-grass meadow species were shaded out.

Wilcox et al. (1985) predicted that the remaining sedge-grass meadow would eventually be lost as the control techniques such as herbicide application and flooding provided in Beule (1979) were deemed infeasible or likely to be ineffective. The study by Wilcox et al. (1985) is probably the first scientific study to document the loss of a unique ecosystem and possibly species extirpation as a result of a Typha invasion.

From 1947 - 1971 T. x glauca and T. angustifolia increased from $30 \%$ sub-dominance to covering $80 \%$ of the Horicon Marsh Wetland Area (HMWA) wetland in Wisconsin (Beule, 1979). This major loss in wildlife habitat resulted in the first long-term study of Typha invasion by Linde et al., (1976). Started in 1969, the purpose of the study was to (1) identify the most effective Typha control measures and (2) determine strategies for maximizing wildlife habitat value and biodiversity. The study produced, along with extensive data on Typha phenotypic and life history characteristics, recommendations for future control such as cutting in late June when carbohydrate stores are at their lowest and immediately before new shoots are capable of significant photosynthesis. Though the study did not discuss causation of the Typha invasion, it 
was the first major body of work to raise awareness regarding the impacts of Typha in an ecological context.

\subsection{Potential Causes of Typha latifolia Invasions}

Nutrient loading and altered hydroperiod (increased and/or stabilized water levels, unnatural water level fluctuations) or their combined effects are considered to be the primary stressors contributing to Typha invasions (e.g. Wilcox et al., 1985; Woo and Zedler, 2002; Bradley and Wolf, 2005; Boers and Zedler, 2008; Samoah and Bork, 2010). Separating the effects of elevated and stabilized water levels and nutrient availability may be challenging in the case of wetlands subjected to elevated or stabilized water levels. Natural decreases in water levels during dry seasons and drought periods result in the oxidization of dewatered sediments which can increase P retention due to the increased availability of oxidized iron (Fe) which precipitates $\mathrm{P}$ (discussed further below). Artificially prolonged inundation or water level stabilization can result in the development of anaerobic conditions in the sediments. The release of bioavailable N, P and K may reach levels high enough to degrade surface water quality and alter wetland vegetation community and function, including wetlands not subjected to elevated external nutrient loading rates - a process termed internal eutrophication (Koerselman et al., 1993; reviewed by Smolders et al., 2006). Kercher and Zedler (2004) were the authors found in the literature on causation of T. latifolia invasion to consider the potential interaction between altered hydroperiod and nutrient availability to explain Typha invasions in North America.

Typha spp. are generally considered to be resistant to a variety of stressor such as pollution, sedimentation and moderate water level fluctuations which may exclude other less tolerant species or provide Typha spp. with a competitive advantage. Other confounding stressors often mentioned in study site descriptions in studies that have examined Typha invasions such as the presence of other invasive species, sedimentation, industrial chemical contaminants and physical habitat disturbance (e.g. Wei and Chow-Fraser, 2006) have generally not been quantified or included in analysis. Discussion in the following section is therefore primarily limited to the effects of nutrient loading and altered hydroperiod largely due to a lack of data relating other potential stressors to Typha invasions. 


\subsubsection{Nutrient Loading}

\subsubsection{Evidence from Field Research under Natural Conditions}

Field studies that have examined the effects of increased nutrient availability on North American Typha spp. have generally observed an increase in biomass with increased nutrient availability. Dubbe et al. (1988) observed a parallel relationship between soil N, P and potassium (K) uptake and biomass production in T. latifolia, T. angustifolia and T. x glauca. Moore et al., 1989 observed an inverse relationship between wetland plant species biodiversity and soil nutrient levels with rare species occurring only in wetlands with a low standing crop (biomass $/ \mathrm{m}^{2}$ ) and comparatively low soil nutrient levels. Vegetation standing crop was also inversely related to species diversity with Typha stands having the highest standing crop and the lowest plant species biodiversity. Woo and Zedler (2002) documented increases in T. $x$ glauca biomass planted in sedge-grass meadow in response to commercial lawn fertilizer additions whereas native sedges (Carex spp.) showed no response to the fertilizer treatments.

The substantial research conducted in the Florida Everglades provides strong support for the eutrophication hypothesis. The shift from Cladium jamaicense (sawgrass), a keystone species adapted to low nutrient conditions (Steward and Ornes, 1975), to Typha domingensis has been commonly associated with P inputs derived from agricultural and stormwater runoff although increased, stabilized water levels are also believed to been a contributing factor (e.g. Davis, 1991; Reddy et al., 1993; Newman et al., 1996; Noe et al., 2001). Cladium jamaicense can store excess nutrients for later use during periods of nutrient scarcity (Newman et al., 1996) and is thus well adapted to the oligotrophic conditions present in unimpacted areas of the Florida everglades (Craft and Richardson, 1993; 1998; Noe et al., 2001). T. domingensis can rapidly assimilate nutrients into tissue biomass, a characteristic of all Typha species (e.g. Dubbe et al., 1988). T. domingensis invasions observed in wetland cells impacted by nutrient loading suggests that $T$. domingensis out-competes other species adapted to nutrient-poor conditions or that are less competitive under high nutrient availability. Similarly, Drohan et al. (2006) attributed a $T$. latifolia invasion to a combination of nutrient loading as a result of cattle grazing and altered hydroperiod resulting from the damming effect of a road which increased and stabilized water levels. 
The lowest $\mathrm{P}$ treatment found in the literature used to determine Typha response to $\mathrm{P}$ loading was by Newman et al. (1996) who applied "low" 50 $\mu \mathrm{g} / \mathrm{L}$ P (eutrophic levels according to Environment Canada (2004) and the EPA) as a reference to compare to $100 \mu \mathrm{g} / \mathrm{L} \mathrm{P}$ (hypereutrophic levels) with both treatments being achieved by diluting marsh water to determine the competitive response of $T$. domingensis. No data was found in the primary literature that documented the response of Typha spp. to oligotrophic nutrient levels in surface water or oligotrophic loading rates. Data on T. latifolia survival, growth and competitiveness under oligotrophic conditions could serve as a reference for historically natural oligotrophic systems that have become mesotrophic or eutrophic.

\subsubsection{Typha spp. response to high nutrients under Controlled and Semi-Controlled Conditions}

The TP and TN concentrations reported in Wetzel (1983) obtained from freshwater lakes and reservoirs and used to define the trophic status in freshwater ecosystems in general are presented in Table 2. Environment Canada definitions for freshwater trophic status (Environment Canada, 2004) are provided in Table 3. The United States Environmental Protection Agency (EPA) classification method established freshwater trophic status based on several parameters including total phosphorus (TP), chlorophyll a and water transparency but does not incorporate $\mathrm{N}$ concentrations. Oligotrophic, mesotrophic, eutrophic and hypereutrophic TP levels according to EPA classification are $0-12,12-24,24-96$ and $96-384 \mu \mathrm{g}$ TP/L respectively. Controlled and semi-controlled experiments conducted under laboratory conditions with artificial light (Wetzel and van der Valk, 1998), under greenhouse conditions (Shipley and Keddy, 1988; Woo and Zedler, 2002) and in an outdoor setting (Keddy et al., 2000) to determine Typha spp. response to elevated levels of $\mathrm{N}$ and $\mathrm{P}$, measured as function of shoot height and/or biomass, and competitive hierarchy (relative competitiveness compared to other species) have involved loading rates that in general far exceed levels observed in even the most polluted natural wetlands (Table 4). All studies observed increased biomass or size with increased nutrient availability; however; as results have limited environmental relevance, there is still uncertainty as to how $T$. latifolia responds to $\mathrm{N}$ and $\mathrm{P}$ loading rates typically observed in eutrophicated natural wetlands. 
Table 2. Trophic status of freshwater ecosystems based on TN and TP concentrations.

From Wetzel (1983). a = EPA classification for hypereutrophic status.

\begin{tabular}{|c|c|c|c|c|}
\hline Parametr & Oligotrophic & Mesotrophic & Eutrophic & Hypereutrophic $^{\mathrm{a}}$ \\
\hline \multirow{4}{*}{ Total P $(\mu \mathrm{g} / \mathrm{L})$} & Mean & Mean & Mean & Mean \\
\hline & 8.0 & 26.7 & 84.4 & $\geq 96^{\mathrm{a}}$ \\
\hline & Range & Range & Range & Range \\
\hline & $3.0-17.7$ & $10.9-95.6$ & $16-386$ & $750-1200$ \\
\hline \multirow{4}{*}{ Total N ( $\mu \mathrm{g} / \mathrm{L})$} & Mean & Mean & Mean & Mean \\
\hline & 661 & 753 & 1875 & - \\
\hline & Range & Range & Range & Range \\
\hline & $307-1630$ & $361-1387$ & $393-6100$ & - \\
\hline
\end{tabular}

Table 3. Total phosphorus concentrations in relation to freshwater trophic status as defined by Environment Canada (2004).

\begin{tabular}{|l|c|}
\hline Trophic Status & Total Phosphorus $(\boldsymbol{\mu g} / \mathbf{L})$ \\
\hline Ultra oligotrophic & $<4.0$ \\
\hline Oligotrophic & $10-20$ \\
\hline Mesotrophic & $20-35$ \\
\hline Meso-eutrophic & $35-100$ \\
\hline Eutrophic & $>100$ \\
\hline Hypereutrophic & \\
\hline
\end{tabular}


Table 4. $\mathbf{N}$ and $P$ treatment concentrations used in controlled and semi-controlled experiments conducted to determine response in Typha latifoli and Typha $x$ glauca biomass and competitive hierarchy.

\begin{tabular}{|c|c|c|c|}
\hline Authors & $\begin{array}{l}\text { Typha } \\
\text { Species }\end{array}$ & $\mathbf{N}$ & $\mathbf{P}$ \\
\hline $\begin{array}{l}\text { Shipley and } \\
\text { Keddy (1988) }\end{array}$ & T. $x$ glauca & $630 \mu \mathrm{g} \mathrm{NO}{ }_{3}-\mathrm{N} / \mathrm{L}$ & $\begin{array}{l}\text { Low Treatment: } \\
155 \mu \mathrm{g} \mathrm{PO} \mathrm{PO}_{4}-\mathrm{P} / \mathrm{L} \\
\text { High Treatment: } \\
1550 \mu \mathrm{g} \mathrm{PO}_{4}-\mathrm{P} / \mathrm{L}\end{array}$ \\
\hline $\begin{array}{l}\text { Keddy et al ., } \\
(2000)\end{array}$ & T. $x$ glauca & $630 \mu \mathrm{g} \mathrm{NO}_{3}-\mathrm{N} / \mathrm{L}$ & $\begin{array}{l}\text { Low Treatment: } \\
155 \mu \mathrm{g} \mathrm{PO} \mathrm{PO}_{4}-\mathrm{P} / \mathrm{L} \\
\text { High Treatment: } \\
1550 \mu \mathrm{g} \mathrm{PO}_{4}-\mathrm{P} / \mathrm{L}\end{array}$ \\
\hline $\begin{array}{l}\text { Wetzel and van } \\
\text { der Valk (1998) }\end{array}$ & T. latifolia & $2000 \mu \mathrm{g} \mathrm{NO}_{3} / \mathrm{g}$ soil & $\begin{array}{c}5 \times 10^{3} \mu \mathrm{g} \text { available } \mathrm{P} / \mathrm{g} \\
\text { soil } \\
\text { High Treatment: } \\
20 \times 10^{3} \mu \mathrm{g} \text { available } \mathrm{P} / \mathrm{g}\end{array}$ \\
\hline $\begin{array}{l}\text { Woo and Zedler } \\
(2002)\end{array}$ & T. $x$ glauca & $\begin{array}{c}\text { Treatment Range: } \\
70-2240 \times 10^{3} \mu \mathrm{g} \\
\mathrm{NH}_{4} \mathrm{NO}_{3}-\mathrm{N} / \mathrm{L}\end{array}$ & $\begin{array}{c}\text { Treatment Range: } \\
20-640 \times 10^{3} \mu \mathrm{g} \\
\mathrm{PO}_{4}-\mathrm{P} / \mathrm{L}\end{array}$ \\
\hline
\end{tabular}

Documented total phosphorus (TP) observed in the highly degraded Cootes Paradise, a coastal wetland that has received point source pollution from a sewage treatment plant since 1919, agricultural and stormwater runoff and combined sewer overflows (Warren, 1950; Painter et al., 1988; Chow-Fraser et al., 1998) has in recent years averaged $210 \mu \mathrm{g} \mathrm{TP} / \mathrm{L}$ (Court and Bowman, 2011). Mayer et al. (2008) documented TP levels of 1,655-1,987 mg/kg in Cootes Paradise sediment. Surface water TP and sediment TP levels in sections of the Point Pelee National Park Typha wetland located in Southwestern Ontario, Canada, and impacted by agricultural land use were $233 \mu \mathrm{g} \mathrm{TP} / \mathrm{L}$ and, depending on the sampling site, just over or below $1200 \mathrm{mg} \mathrm{TP} / \mathrm{kg}$ of sediment at the sediment/surface water interface. 


\subsubsection{Altered Hydroperiod}

A primary objective of this study was to specifically examine the effects of eutrophic $\mathrm{N}$ and $\mathrm{P}$ levels on T. latifolia and under continuous, stabilized water levels (a change in water level by no more than approximately $4 \mathrm{~cm}$ ). Several authors have attributed Typha invasions to stabilized and increased water levels (e.g. Wilcox et al., 1985; Bradley and Wolf, 2005; Boers et al., 2007; Wilcox et al., 2008); however, the effects of stabilized water level was not an objective of this study. Seasonal water level fluctuations that follow an historic cycle contribute to wetland plant diversity by preventing the drying of sediments and encroachment by terrestrial tree and shrub species. Seasonal water level fluctuations also maintains habitat heterogeneity, facilitates expansion of sedge-grass meadow and replenishes the seed bank (Frieswyk and Zedler, 2007). Additionally, periodic flooding creates habitat for subdominant species by killing competitively superior plant species such as Typha (Keddy and Reznicek, 1986). Many nonrhizomatous annual wetland species re-establish only from seed and therefore requires seasonally low water levels and exposed sediments for seed germination and seedling survival (e.g. Keddy and Reznicek, 1986; Court and Bowman, 2011). Stabilized water levels can therefore promote competitively dominant Typha spp. that can maintain populations through vegetative regeneration from rhizome. Artificially maintained water levels at higher elevations can also result in the expansion of invasive wetland species inland (Wilcox et al., 2008).

Research that has attempted to disentangle the individual effects of altered hydroperiod and nutrient loading where the two stressors co-occur to explain Typha invasion causation was not found in the literature. Wilcox et al., (1985) and Wilcox et al., (2008) who attributed Typha invasion to stabilized high water levels did not quantify nutrient levels. Boers et al. (2007) who attributed T. x glauca encroachment in a restored wetland to altered hydroperiod considered observed TP concentrations of $193-492 \mu \mathrm{g} / \mathrm{L}$ to be low and not a contributing factor in the expansion of T. $x$ glauca; however, these TP levels far exceed the > 100 $\mathrm{g}$ TP/L minimum concentration considered hypereutrophic according to Environment Canada (2004). 


\subsubsection{Internal Eutrophication and Interaction between Hydroperiod Alternation and Internal Nutrient Loading.}

Eutrophication can occur in aquatic systems not subjected to elevated external anthropogenic sources of $\mathrm{P}$ due a process termed internal eutrophication (Koerselman et al., 1993; reviewed by Smolders et al., 2006) involving elevated levels of sulfur (S), alkalinity and possibly increased $\mathrm{NO}_{3}{ }^{-}$which results in the transformation of existing unavailable $\mathrm{P}$ within sediments to bioavailable $\mathrm{P}$ and reduced sediment $\mathrm{P}$ retention capacity.

Increased deposition of sulfur $(\mathrm{S})$ derived from the combustion of fossil fuels (e.g. coal) and gaseous ammonium $\left(\mathrm{NH}_{3}\right)$ and ammonium sulfate aerosols have resulted in elevated levels of $\mathrm{S}$ and $\mathrm{N}$ in soils, surface water and groundwater in Europe and the mobilization of $\mathrm{PO}_{4}{ }^{3-}$, due to increased levels of $\mathrm{FeS}_{\mathrm{x}}$ which reduces $\mathrm{Fe}$ availability for $\mathrm{P}$ retention and possibly due to competition between $\mathrm{PO}_{4}{ }^{3-}$ and $\mathrm{SO}_{4}{ }^{2-}$ for cation binding sites. Under anaerobic conditions the production of $\mathrm{H}_{2} \mathrm{~S}$ (Eq. 1) can result in the formation of FeS, further reducing Fe availability for $\mathrm{P}$ retention. To date, the significance of $\mathrm{S}$ deposition as a contributor to eutrophication in North America and Typha invasion has received very little attention.

Eq. 1. Reduction of $\mathrm{SO}_{4}{ }^{2-}$ to $\mathrm{H}_{2} \mathrm{~S}$

$$
\mathrm{SO}_{4}{ }^{2-}(\mathrm{aq})+10 \mathrm{H}^{+}(\mathrm{aq})+8 e^{-}(\mathrm{aq}) \rightarrow \mathrm{H}_{2} \mathrm{~S}(\mathrm{~g})+4 \mathrm{H}_{2} \mathrm{O}(\mathrm{l})
$$

Oxidizing conditions in exposed sediments during naturally reduced water levels, including periodic draught conditions, can facilitate the removal of $\mathrm{S}$ through oxidization to soluble $\mathrm{SO}_{4}{ }^{2-}$ and subsequent removal via wetland outflow during re-inundation (Smolders et al., 2006). Artificially high or stabilized water levels may therefore also contribute to internal eutrophication. Boers and Zedler (2008) observed increased biomass and a higher P tissue content in T. x. glauca grown in microcosms subjected to continuous inundation which they attributed to internal eutrophication and greater $\mathrm{P}$ bioavailability. The elimination of natural water level fluctuations results in prolonged anaerobic conditions within sediments and the reduction of $\mathrm{Fe}$ hydroxides to soluble $\mathrm{Fe}^{2+}$ cation which has a lower $\mathrm{P}$ retention ability than $\mathrm{Fe}^{3+}$ 
due to a lower electrical charge difference between the $\mathrm{PO}_{4}{ }^{3-}$ anion and $\mathrm{Fe}$ oxides and hydroxides (Eq. 2) (Smolders et al., 2006):

Eq. 2. Reduction of iron oxide-hydroxide to $\mathrm{Fe}^{2+}$

$$
\mathrm{FeOOH}(\mathrm{aq})+3 \mathrm{H}^{+}(\mathrm{aq})+e^{-} \rightarrow \mathrm{Fe}^{2+}(\mathrm{aq})+2 \mathrm{H}_{2} \mathrm{O}(\mathrm{l})
$$

Acidic conditions produced in anoxic sediments as a result of anaerobic microbial organic acid production reduce the decomposition rate of organic matter. An increase alkalinity as a result of oxygen release into the rhizosphere by macrophytes described further in Section 1.11 and the oxidization of $\mathrm{SO}_{4}{ }^{2-}$ and denitrification, depending on the specific chemical and/or microbial process consumes $\mathrm{H}^{+}$and/or produces $\mathrm{OH}^{-}$(Smolders et al., 2006). The release of oxygen into the rhizosphere can result in the neutralization of acids which inhibit decomposition and therefore can increase the mineralization rate of organic matter to bioavailable $\mathrm{NH}_{4}{ }^{+}, \mathrm{PO}_{4}{ }^{3-}$ and other nutrients. $\mathrm{HCO}_{3}{ }^{-}$may also compete for cation binding sites (Smolders et al., 2006). Increases in alkalinity may occur due to changes in surface water and groundwater hydrology and possibly some industrial and land use practices may therefore contribute to Typha invasion through internal eutrophication.

Smolders et al. (2006) identified increased $\mathrm{NO}_{3}{ }^{-}$concentrations in surface and groundwater derived from agricultural fertilizers as a potential cause of internal eutrophication due to (1) increased availability of an electron acceptor for the microbial decomposition of organic matter; (2) the oxidization of pyrite $\left(\mathrm{FeS}_{2}\right)$ by $\mathrm{NO}_{3}{ }^{-}$to $\mathrm{SO}_{4}{ }^{2-}$ in ground water and subsequent discharge into surface water which may increase the bioavailable $\mathrm{P}$ in wetland sediments. The production of $\mathrm{OH}^{-}$through ammonia ionization from $\mathrm{NH}_{3}$ to $\mathrm{NH}_{4}{ }^{+}$(Eq. 4) and nitrate dissimilation (Kadlec and Wallace, 2009) may also increase alkalinity and therefore the decomposition rate of organic matter. Conversely, $\mathrm{NO}_{3}{ }^{-}$may inhibit internal eutrophication as it is a preferred $e^{-}$acceptor over Fe and may therefore increase Fe availability for P retention (Smolders et al., 2006).

Internal eutrophication may not occur in all wetlands subjected to altered hydroperiod. (Koerselman et al., 1993) hypothesized, based on their lab results, that internal eutrophication 
may be dependent on surface water chemistry, sediment characteristics (organic content, nutrient levels, buffering capacity) and elevated temperatures (global warming) which increases microbial metabolism and the mineralization rate of organic matter. To quantify the effects of internal eutrophication on Typha invasions, nutrient levels in pore water would need to be quantified in relation to timing, extent and duration of inundation. Pore water is defined as the water that occurs within the interstitial spaces between sediment particles. T. latifolia and other emergent macrophytes and under most conditions submergent species obtain nutrients almost exclusively from pore water (Bole and Allan, 1978; Carignan and Kalff, 1980; Reddy and D’Angelo, 1997).

\subsubsection{Other Potentially Contributing Factors to Typha Invasion}

Other potentially contributing factors to Typha invasions may also include increased levels of carbon dioxide $\left(\mathrm{CO}_{2}\right)$ (Sullivan et al., 2010) which would increase available carbon for biomass production, global warming, reduced (muskrat) grazing pressure and fire suppression. How ecosystem changes associated with eutrophication such as altered nutrient cycling, $\mathrm{pH}$, sediment redox conditions, microbial communities and species composition and interaction may contribute to Typha invasion have not been assessed.

\subsection{Potential Impacts of Typha latifolia Invasions.}

\subsubsection{Ecological Impact}

Despite the protection natural wetlands now receive (e.g. the North American Wetlands Protection Act; Wetlands Reserve Program (US)), habitat degradation continues in which invasive species are a major contributor (e.g., Drexler and Bedford, 2002; Gilbert, 2012). Ecological impacts includes losses of native and ecologically significant vegetation (e.g., listed

species, species of conservation concern, ecotypes such as sedge-meadow habitat, plants adapted to nutrient-poor conditions (e.g., sawgrass (Cladium jamaicense), isoetid submergent plants), shoreline bird breeding habitat, waterfowl breeding and open water rearing habitat (Addy and MacNamara, 1948; Curtis, 1959; Linde et al., 1976; Beule, 1979; Newman et al., 1996;

Smolders et al., 2002; Asamoah and Bork, 2010; Meyer et al., 2010). The significance of effect 
of Typha invasions upon macroinvertebrate, fish, amphibian and reptile populations was not located in the peer-reviewed literature but has likely been significant given that losses in plant species richness and diversity likely equates to losses in critical habitat for wildlife dependent on wetlands. Typha spp. have high transpiration rates (Otis, 1914) and Typha invasion has been shown to reduce open water habitat (e.g. Addy and MacNamara, 1948; Beule, 1979; Linde et al, 1976; Mitch 2000) accelerating the transition from wetland to terrestrial habitat (e.g. Wilcox et al., 1985). Gilbert (2012) has documented turtle mortality caused by the drying of wetland habitat resulting from transpiration through dense stands of invading Pragmites australis australis in southern Ontario.

Efficient piscivores (predatory fish) such as northern pike (Esox lucius) can be effective in controlling benthivorous and zooplanktivorous fishes such as common carp (Cyprinus carpio) and alewife (Alosa pseudoharengus). Reductions in zooplanktivorous fishes can enable largebodied and efficient zooplankton grazers such as Daphnia spp. to increase in number and size to lower phytoplankton biomass and return turbid algae-dominated eutrophicated systems to a clear-water macrophyte-dominated state (e.g. Shapiro, 1990; Donk et al., 1990; Meijer et al., 1995; Lougheed et al., 2004). Sedges such as Schoenoplectus spp. and Carex spp. provide important spawning habitat for northern pike (Cooper et al., 2008) whereas Casselman and Lewis (1996) observed limited use of Typha by spawning pike.

\subsection{Limitations of Control Methods for Typha spp.}

A common method for controlling Typha is the application of chemical herbicides such as glyphosate (e.g. Linz and Homan, 2011). However, acute toxicity effects and physiological abnormality in chronic toxicity tests were observed in several life-history stages of four Ontario frog species to which Howe et al. (2004) attributed the combined effects of the surfactant carrier chemicals and the glysophate compound found in common commercially-sold herbicides (e.g. Roundup Original $^{\circledR}$ ). Alternative methods to chemical herbicides such as direct physical removal, water level manipulation (drowning and/or desiccation) and controlled burns could have minor to severe impacts on other plant and animal species occurring within the same wetland depending on the method, extent and duration of removal, habitat requirements of individual species and specific life history stages affected at the time of removal. Typha removal 
in its self would be a disturbance and would thus create an opportunity for the establishment of additional invasive species. A labour-intensive but low-impact method for reducing Typha abundance involves the bending or cutting of shoots below the water surface approximately 3 times per growing season which deprives roots of oxygen and eventually kills the plant (Sale and Wetzel, 1983). This method could however significantly reduce the amount of oxygen within the rhizosphere if cutting is done on a large scale. Additionally, the creation of reducing conditions within the sediment as a result of cutting could potentially result in the mobilization of sediment-bound P.

Potential biological control agents of Typha spp. have not been adequately evaluated. Beule (1979) noted that deer ate young Typha shoots developing in exposed mud flats and muskrats that gained access to cut areas of dense Typha stands were able to increase the area of open-water habitat through grazing. Curtis (1959) observed none to low numbers of Typha where muskrat population density was high. Muskrat introductions, if proven successful, may offer the most ecologically sound method of effective Typha control; however, there is also the potential for introducing disease and impact to other animal and plant species. The release of cattail armyworm is also a possible option; however, as with muskrat introductions, a substantial investment would be necessary for adequate evaluation and risk assessment.

Typha control programs can be economically driven. Unsustainable financial losses to sunflower growers in the prairie pothole region to consumption by pest bird species that nest and roost in Typha was estimated to be in the range of $\$ 4$ million to $\$ 11$ million dollars annually (Peer et al., 2003). The widespread establishment and dominance of Typha spp. has provided habitat for millions of red-winged blackbirds, common grackle and yellow-winged blackbirds which feed on sunflower seeds (Linz and Homan, 2011).

Regardless of the removal method used, re-planting with carefully selected non-invasive species would be necessary to prevent or reduce re-colonization by Typha and other invasive species. The difficulty, expense and potential impacts associated with Typha control emphasizes the need to implement preventative measures by reducing disturbances that contributes to Typha invasions. 


\subsection{Wastewater Treatment Wetlands}

Hammer et al. (1989) defined wastewater constructed wetlands (hence-forth referred to as constructed wetlands) as man-made or converted natural wetlands which are used to remove pollutants by the physical, chemical and biological processes that occur within wetland ecosystems. Widely accepted as a cost-effective means of removing surface water pollutants, the number of constructed wetlands $(\mathrm{CW})$ has steadily increased globally in all climactic regions since the 1970's (Brix and Schierup, 1989; Kadlec and Wallace, 2009). Requiring only inexpensive and locally available materials, low technology and minimal operating skills, constructed wetlands are particularly well suited to smaller municipalities, rural communities and third world nations which have an availability of affordable lands and/or lack the monetary resources needed to build and operate technologically sophisticated and expensive wastewater treatment plants (WWTP) and the necessary sewage and stormwater conveyance infrastructure (Brix and Schierup, 1989; Kadlec and Wallace, 2009).

Constructed wetlands can also provide a practical and cost-effective means of treating nonpoint source runoff from urban, agricultural, rural and industrial lands (e.g. Taylor, 1992), areas where WWTP and conveyance systems may be impractical or cost-prohibitive. Constructed wetlands have also been developed for individual industrial operations such as olive mill, tannery, mining and slaughter house effluent (e.g. White et al., 2000; Calheiros et al., 2009; Marchand et al., 2010; Yalcuk et al., 2010) and individual households (Fraser et al., 2004) where early interception and treatment of wastewater can potentially provide greater environmental protection at an affordable cost to both industry and society.

Constructed wetlands can be effective in removing pathogens (bacteria such as E.coli and fecal coliforms, helminthes, protozoans, fungi and viruses), organic matter and therefore BOD, COD, suspended sediments, nutrients, metals and toxic industrial and organic chemicals in all seasons and in a variety of climates. A tremendous volume of research now exists on constructed wetland design and performance from sources ranging from household grey water, sewage, industrial effluent, acid mine drainage and urban and agricultural runoff (EPA, 2000; Fraser et al., 2004; Kadlec and Wallace, 2009). 
Constructed wetlands have been built across Canada and by 1997 two wetlands had been constructed in subarctic regions and eight in the boreal forest region of the Yukon and the North West Territories. Pollutant removal has been effective during the winter months (Pries, 1997); however, pollutant removal processes can cease if the wetland freezes completely (Kadlec and Wallace, 2009).

Pollutant removal performance has varied from poor to excellent with key factors being pollutant loading rate, hydraulic retention time and wetland area (see reviews by Nichols, 1983; Brix and Schierup, 1989; Taylor, 1992; Brix, 1997; Reddy et al., 1999; Sheoran and Sheoran, 2006; Vymazal, 2007; Lee et al., 2009; Marchand et al., 2010). The life expectancy of constructed wetlands varies depending on a number of factors including loading rate, the size of the wetland, the physical and geochemical characteristics of the substrate and the microbial communities which are essential for transforming pollutants into non-harmful forms. Constructed wetlands designed for industrial use may provide effective removal capacity for a decade whereas wetlands receiving Municipal wastewater may last for centuries (Pries, 1997).

Constructed wetlands could also potentially serve as mitigation for the loss of natural wetlands (Brix, 1997) as the loss of wetlands in North America has been extensive. In Southern Ontario 70 to $100 \%$ of natural wetlands has been lost depending on the region (Whillans, 1982; Curtis, 1989; Snell, 1989). Approximately $90 \%$ of wetlands have been lost primarily to agriculture in the prairie pothole region (Dahl and Johnson, 1991). The building of constructed wetlands in developed areas at a watershed scale could therefore potentially serve to restore natural flood control processes, improve stream and river hydrology and ground water recharge, promote riparian vegetation recovery which in turn could improve water quality, improve aquatic habitat and increase biological diversity. Constructed wetlands designed for wastewater treatment can also provide ancillary benefits including the creation of fish and wildlife habitat, recreational and educational opportunities and aesthetic value (e.g., Taylor, 1992; Brix, 1997; EPA, 2000; Kadlec and Wallace, 2009).

Emergent vegetation produced in wetlands has been used to manufacture various types of building materials (Maddison et al., 2009) and as fertilizer and biofuel (Agricultural Wetland 
Research Network, 2011). With a predicted shortage of phosphate rock in the near future (Cordell et al., 2009; Elser and Bennett, 2011) the harvesting and subsequent utilization of emergent vegetation and the $\mathrm{P}$ that that accumulates within constructed wetlands sediments could provide a means of $\mathrm{P}$ recovery.

\subsubsection{The History of Constructed Wetlands for the Treatment of Wastewater}

Natural wetlands have been used as convenient disposal sites for wastewater ever since effluent has been collected. Several North American wetlands have been receiving sewage for over 100 years (Kadlec and Wallace, 2009). The wetland formerly located in Ashbridges Bay, Toronto Ontario, Canada (Figure 8) historically received conveyed stormwater runoff and wastewater from animal and livestock holding areas (Bonnell and Fortin, 2009) and later from the Main Treatment Plant which became operational in 1910 (City of Toronto, 2013a). The Cootes Paradise marsh located within the tri-city area of Hamilton, Burlington and Dundas, Ontario, Canada, has been the repository for the Dundas Sewage Treatment Plant since 1919 (Painter et al., 1988). Beining and Otte (1997) observed significant removal of arsenic (As) and Zinc $(\mathrm{Zn})$ by a natural wetland in Ireland that had been receiving drainage from an abandoned mine since 1824.

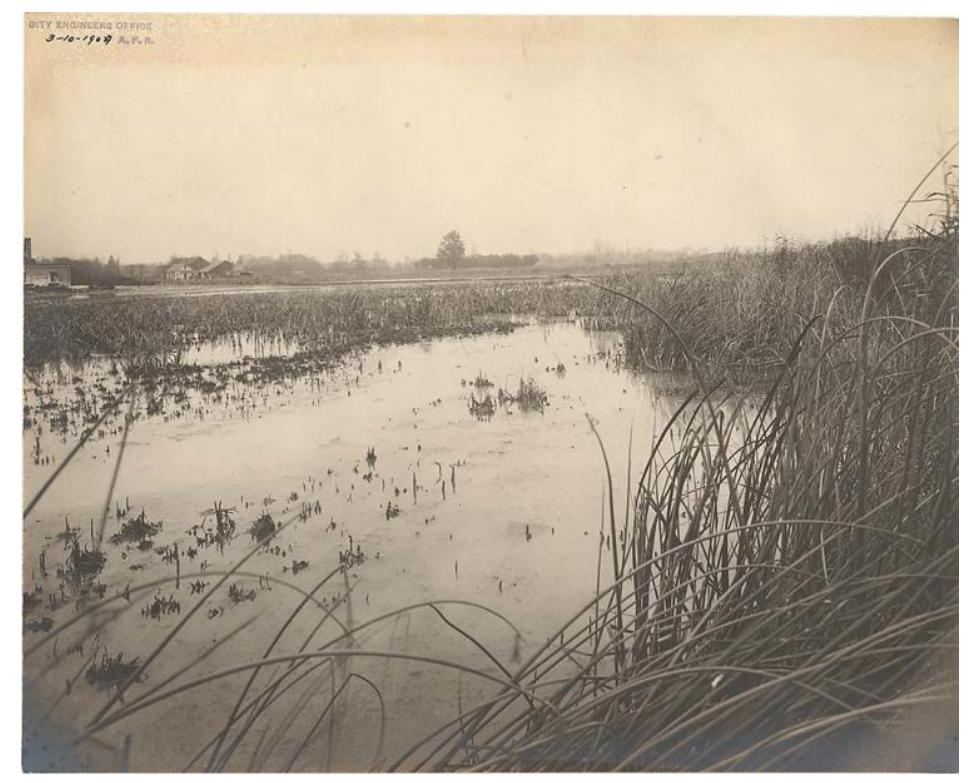

Figure 8. Ashbridges Bay wetland in 1909 before the completion of the Main Treatment Plant.

Courtesy of City of Toronto Archives. 
Wetlands have been constructed as aquaculture ponds, rice paddies, ornamental wetlands, road-side ditches etc, all of which have been built for centuries (Taylor, 1992). Dr. Käthe Seidel (1907-1990) has been credited with conceiving the idea of constructing wetlands for wastewater treatment (Kadlec and Wallace, 2009). Dr. Reinhol Kickuth, a colleague of Dr. Seidel, has also been credited with contributing to Dr. Seidel's pioneering research (Lee et al., 2009) which began in 1952 at the Max Planck Institute in West Germany. By the 1960’s Dr. Seidel's work had confirmed the effectiveness of constructed wetlands as an effective pollutant removal technique. Research on wastewater treatment constructed wetlands began in the western hemisphere in 1971 by Dr. Robert Kadlec at the University of Michigan (Kadlec and Wallace, 2009).

\subsubsection{Types of Constructed Wetlands}

Constructed wetlands can be classified as free surface flow constructed wetlands (FWS) which resemble natural marshes (EPA, 2000; Kadlec and Knight, 2009) and subsurface constructed wetlands (SSFCW) which can be further classified as vertical flow (VF) and horizontal flow (HF) designs (e.g. Vymazal and Kropfelova, 2011) (Figure 9). Floating vegetation wetlands (FVW) are used in tropical climates and typically use water hyacinth (Eichhornia crassipes) which has been shown to have a higher capacity for removing nutrients compared to rooted macrophytes (Vymazal, 2007). As floating vegetation wetlands are not relevant to $T$. latifolia invasion and temperate climates, literature referenced in this thesis pertain primarily to FWS and secondarily to VF and VH wetlands.

In SSFCW effluent enters directly into the substrate and vegetative root systems (Van de Moortel et al., 2009; Yalcuk et al., 2010). VF and HF wetlands are designed for specific hydraulic loading rates, thus are not capable of treating stormwater runoff or dynamic flow changes. Though young SSFW with sufficient $\mathrm{P}$ adsorption sites can be effective in removing $\mathrm{P}$ (Vrhovsek et al., 1996), the primary limitation of SSFCW designs for P removal is the inability to accrete peat biomass (Vymazal, 2007). Peat is partially decomposed plant matter which can retain nutrients and other pollutants. Peat accretion and subsequent burial is now generally accepted as the only long- term P removal mechanism in FWS (discussed in a later section). 

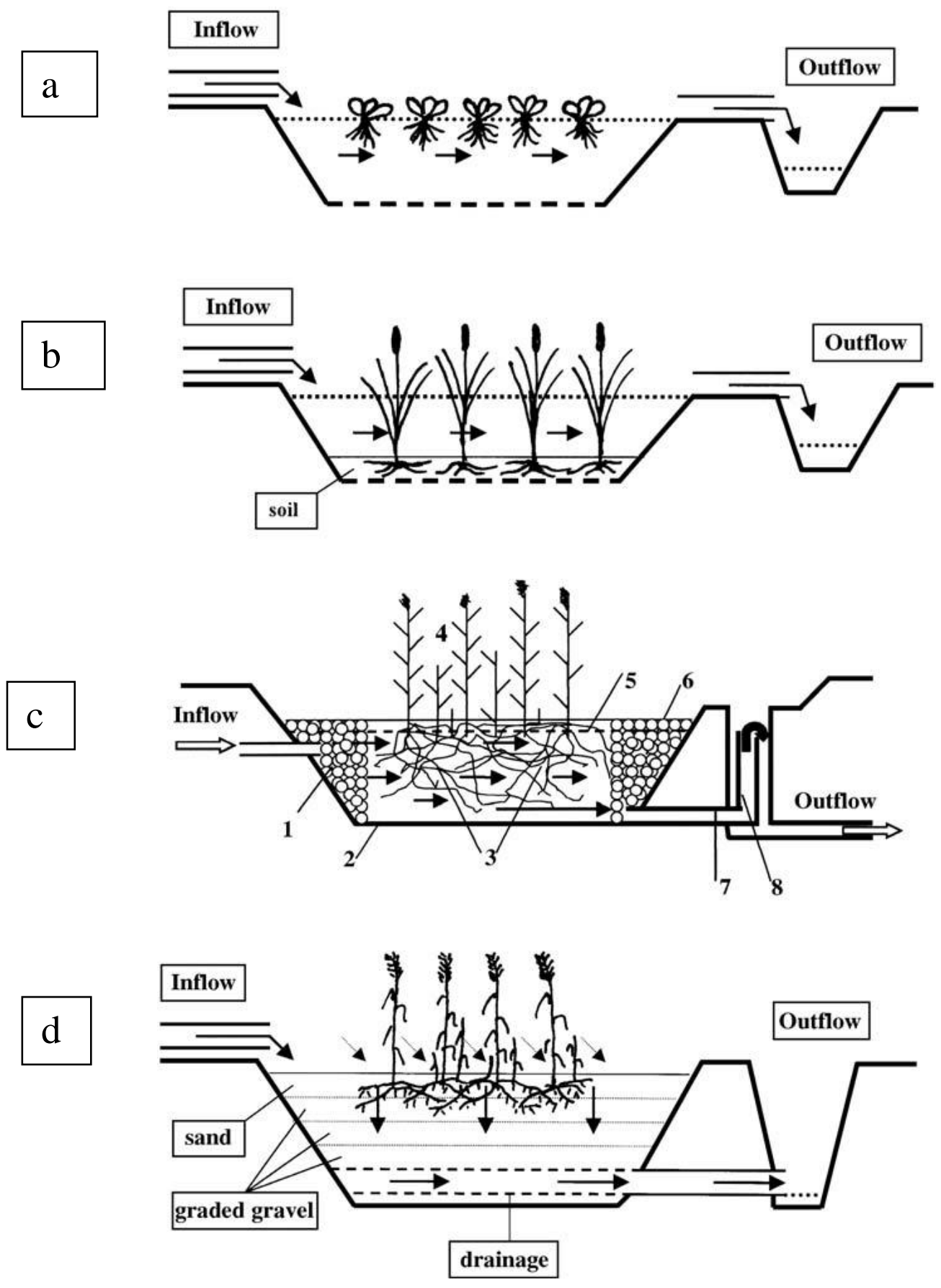

Figure 9. Floating vegetation (a), surface flow (b) subsurface horizontal flow (c) and subsurface vertical flow (d) constructed wetlands.

From Vymazal (2007).

In SSFCW wetlands vegetation is planted into topsoil which is not inundated, therefore significant peat accretion, which develops from the decomposition of wetland vegetation, does 
not occur (Vymazal, 2007). VF constructed wetlands are effective at oxidizing $\mathrm{NH}_{4}{ }^{+}$to $\mathrm{NO}_{3}{ }^{-}$but have low ability to remove $\mathrm{NO}_{3}{ }^{-}$(Vymazal, 2007) possibly due to higher aerobic conditions within the sediments. Thus, hybrid constructed wetland systems which combine both VF and HF wetlands have been utilized to achieve adequate $\mathrm{N}$ removal (Kadlec and Wallace, 2009).

\subsubsection{Constructed Wetlands for the Restoration of Eutrophic Systems}

The use of constructed wetlands for restoring eutrophicated freshwater ecosystems has long been considered (e.g. Boyd, 1970; Yount and Crossman, 1970; Brix and Schierup, 1989; Theÿsmeÿer et al., 1999). Feasibility or pilot studies on the potential suitability of constructed wetlands for the restoration of eutrophicated lakes, either as a stand-alone strategy or in combination with other restoration efforts, have recently been conducted by Li et al. (2008), Ham et al. (2010) and Özkundack et al. (2010). There has also been some interest in developing constructed wetlands at the watershed scale to provide flood control and nutrient removal services to prevent or reverse the impacts of eutrophication on coastal marine ecosystems (e.g. Boesch et al., 2001; Arheimer and Wittgren, 2002; Zedler, 2003; Woo, 2009; Gren, 2010 and Kim, 2010). If constructed wetlands are developed at the watershed scale to reduce non-point source pollution, the risk of spreading invasive species to ecologically sensitive areas may therefore increase. Ecologically sensitive areas are defined here as areas or ecosystems that support endemic, rare, threatened, endangered species or species of special concern, unique or important ecosystems including wetlands classified as significant or high biological diversity warrant protection (Environment Canada, 2013).

\subsubsection{Nitrogen and Phosphorus Removal Limitations of Constructed Wetlands}

It is generally known that $\mathrm{P}$ removal capacity often declines as constructed wetlands age and P binding sites become saturated (e.g. Richardson, 1985; EPA, 2000, Vymazal, 2007). The TP objective for surface waters set by the Ontario Ministry of Environment in Ontario (MOE) is as low as $20 \mu \mathrm{g}$ TP/L for lakes during the growing season, depending on the historic lake trophic status, and $30 \mu \mathrm{g}$ TP/L for streams (MOE et al., 2010). Vymazal (2007) provided the TP removal rates for 85 mature surface flow wetlands. The mean TP concentration in influent was $4.4 \mathrm{mg} \mathrm{P} / \mathrm{L}$ and the mean TP in effluent was $2.15 \mathrm{mg}$ P/L for a mean removal rate of $48.8 \%$. 
The data presented in Vymazal (2007) indicates that at typical P loading and removal rates, constructed wetlands, using currently technology, are unable to reduce P to levels that would ensure no ecological impact unless to receiving water bodies. Even if effluent becomes sufficiently diluted, the tendency for particulate $\mathrm{P}$ to settle at inflow outfall areas suggests that even if effluent $\mathrm{P}$ eventually becomes diluted to low levels, localized impacts and the establishment of invasive species may still occur within the inflow area of receiving aquatic systems. The mean $\mathrm{P}$ loading rate in the influent for 251 constructed wetlands reviewed by Vymazal (2007) was 151.3 grams (g) P/square meter $\left(\mathrm{m}^{2}\right) /$ year (yr) with a mean removal of $47.9 \%$ giving a mean of $86.25 \mathrm{~g} \mathrm{P} / \mathrm{m}^{2} / \mathrm{yr}$ in effluent (ranging from $54-127 \mathrm{~g} \mathrm{P} / \mathrm{m}^{2} / \mathrm{yr}$ which is nearly seven times greater than the mean TP loading rate of $13.1 \mathrm{~g} \mathrm{P} / \mathrm{m}^{2} / \mathrm{yr}$ observed by Jeppensen et al. (1991) for shallow culturally eutrophicated lakes in Denmark indicating that effluent from constructed wetlands used for nutrient removal would, in most cases, still contain ecologically impacting levels of $\mathrm{P}$.

Similarly, N removal performance by constructed wetlands is variable and sometimes does not meet water quality objectives or standards (reviewed by Lee et al., 2009). James et al. (2005) found that diverse submergent plant communities in the UK occurred only in lakes with $\mathrm{NO}_{3}-\mathrm{N}$ levels of $1-2 \mathrm{mg} / \mathrm{L}$, a concentration that is likely unachievable for most constructed wetlands, particularly those subjected to moderate to high loading rates. Based on data presented in Vymazal (2007) the typical $\mathrm{N}$ removal rate for mature wetlands was $40-55 \%$ at a mean influent loading rate of $792.5 \mathrm{~g} \mathrm{~N} / \mathrm{m}^{2} / \mathrm{yr}$ (ranging from 466 to $1222 \mathrm{~g} \mathrm{~N} / \mathrm{m}^{2} / \mathrm{yr}$ ) giving a mean of $409 \mathrm{~g} \mathrm{~N} / \mathrm{m}^{2} / \mathrm{yr}$ constructed water effluent (ranging from $219-592 \mathrm{~g} \mathrm{~N} / \mathrm{m}^{2} / \mathrm{yr}$ ). Jeppensen (1991) observed a loading rate of $142.0 \mathrm{~g} \mathrm{~N} / \mathrm{m}^{2} / \mathrm{yr}$ for shallow lakes impacted by cultural eutrophication in Denmark which is substantially less than the $\mathrm{N}$ loading in constructed wetland effluent documented by Vymazal (2007). As the majority of natural wetland ecosystems are $\mathrm{N}$ limited (Bedford et al., 1999) and constructed wetlands can only remove a percentage of the $\mathrm{N}$ loading, constructed wetland effluent would likely contain $\mathrm{N}$ concentrations sufficiently elevated to impact receiving aquatic ecosystems and potentially contribute to the establishment and expansion of invasive species unless the effluent is substantially diluted immediately by a receiving water body. 


\subsubsection{Typha Productivity in Wastewater and Constructed Wetlands Effluent}

Several studies have documented increased $T$. latifolia biomass in wetlands subjected to wastewater effluent or levels characteristic of wastewater entering constructed wetlands and drainages (e.g. Martín and Fernández, 1992; Weng et al., 2006; Maddison et al., 2009). Martín and Fernández (1992) documented a significant increase in T. latifolia biomass within a river channel receiving secondarily treated wastewater with mean concentrations of $6.4 \mathrm{mg} \mathrm{PO}_{4}-\mathrm{P} / \mathrm{L}$, $11.6 \mathrm{mg} \mathrm{NH}_{4}-\mathrm{N} / \mathrm{L}$ and $6.4 \mathrm{mg} \mathrm{NO}-\mathrm{N} / \mathrm{L}$, which far exceeds hypereutrophic levels, as well as elevated levels of magnesium $(\mathrm{Mg})$, potassium $(\mathrm{K})$ and calcium $(\mathrm{Ca})$. The research documenting high Typha production within constructed wetlands (Maddison et al., 2009) simulated constructed wetlands influent (Weng et al., 2006) or in downstream wetlands receiving wastewater effluent (Martín and Fernández, 1992;) suggests that Typha could establish highly productive monotypic stands in constructed wetland effluent given suitable hydrology and substrates.

\subsubsection{Hybridization and Formation of $T$. $x$ glauca populations.}

There is the potential risk that constructed wetlands planted with $T$. latifolia will hybridize with the expanding T. angustifolia and form new highly invasive T. $x$ glauca populations. The only document found that had tested for hybridization in a constructed wetland planted with both T. latifolia and T. angustifolia was by Selbo and Snow (2004). Although no evidence of hybridization was found, there appears to be a reasonably high probability that future hybridizations will occur in or adjacent to constructed wetlands planted with T. latifolia.

\subsection{The Role of Wetland Vegetation in Nitrogen and Phosphorus Removal Processes - An Overview}

The first objective of this section is to summarize the most significant contribution of aquatic macrophytes to $\mathrm{N}$ and $\mathrm{P}$ removal processes in constructed wetlands. Only the most important removal pathways are discussed in detail. Diagrams depicting the numerous $\mathrm{N}$ and $\mathrm{P}$

pollutant are provided for completeness in order to illustrate to the reader the overall complexity of pollutant pathways within constructed wetlands. The second objective of this section is to 
present evidence to support of the hypothesis that, given that the direct macrophyte uptake of nutrients represents a comparatively minor removal pathway, constructed wetlands planted with native non-invasive plant species should provide comparable nutrient removal performance to constructed wetlands planted with invasive species. Constructed wetlands planted with noninvasive native species should therefore offer effective water treatment services without the ecological risks associated with planting constructed wetlands with invasive species. A detailed discussion on the pollutant removal processes in wetlands for other contaminant types including suspended solids, organic matter, sulfur, metals, halogens and organic chemicals is beyond the scope of this thesis.

Wetlands are effective as pollutant-removing systems owing to their high productivity and the combination of aerobic and anaerobic sediments in which emergent wetland vegetation play a critical role (reviewed by Nichols, 1983; Brix, 1994; Brix and Schierup, 1989; Brix, 1997). Wetland emergent plants are uniquely adapted to survive in flooded anoxic sediments owing to their internal aerenchyma system. Aerenchyma tissue in Typha spp consists of air-filled spaces (lucunar) within leaves (Figure 9) and rhizomes that enables gas exchange to occur between the roots and the atmosphere (e.g. Sale and Wetzel, 1983; Tornbjerg et al., 1994). In T. latifolia (and

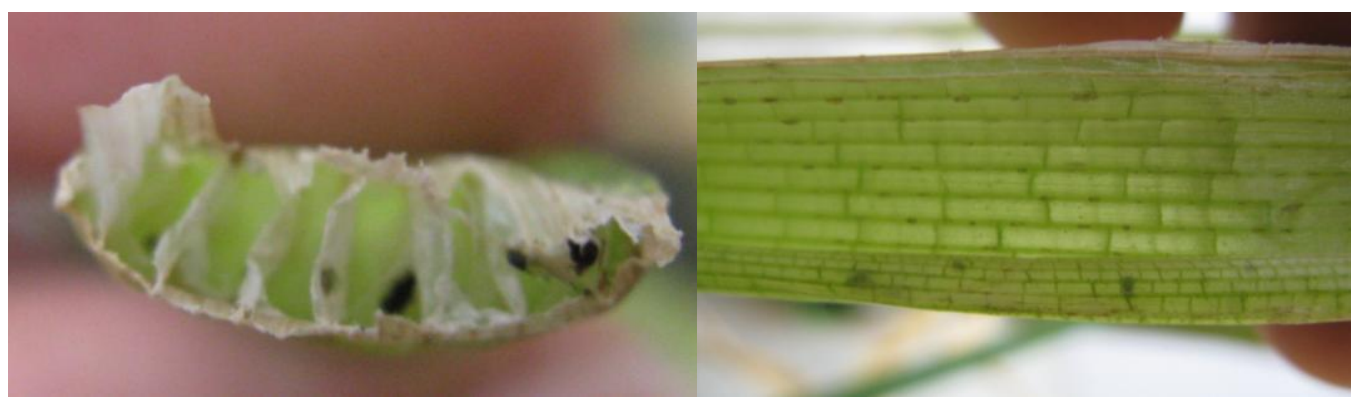

Figure 10. Typha latifolia leaf aerenchyma tissue from a leaf cross sectional (right) and horizontal view (Left). Magnification X 2.

Photos by Mark Tiley.

T. angustifolia), air enters through the stomata of middle-aged leaves against a small pressure gradient and then diffuses through the leaf blade and rhizome aerenchyma into root tissue through which excess oxygen escapes into the sediments (Tornbjerg et al., 1994). 
The amount of oxygen escape into the rhizosphere depends on the oxygen demand of the sediments, oxygen concentration within the plant and roots and root age. Older root tissue becomes impermeable to gas exchange in order to maximize oxygen transport to the root apical meristem; thus, oxygen escape occurs primarily at the root tip (Brix, 1994). Gases produced by respiration and metabolism and gases which diffuse into the root system from the sediments $\left(\mathrm{CO}_{2}, \mathrm{NH}_{3}, \mathrm{H}_{2} \mathrm{~S}\right)$ pass through old or damaged leaves (Tornbjerg et al., 1994). More oxygen enters the roots than is needed and diffuses through root tissue into the rhizosphere where it becomes available to aerobic microbial communities within the rhizosphere (Sale and Wetzel, 1983; Kadlec and Wallace, 2009). Dead culms (flowering stems) and leaves enables gas exchange to continue through the winter months, which is essential for rhizome survival (Linde et al., 1976) and enables aerobic microbial transformation of pollutants to continue throughout the year.

The dense macrophyte root systems provide increased surface area for the colonization of microbial communities involved in the transformation of organic matter and nutrients $(e . g$. Brix, 1994; Vymazal, 2007), toxic industrial organic contaminants (Reddy and D'Angelo, 1997) and metals. Metals undergo similar chemical and biological transformations through the formation of compound complexes, hydrolysis microbial oxidation and microbial and plant uptake and assimilation as to other contaminants (Sheoran and Sheoran. 2006; Marchand et al., 2010). Plant photosynthates leached from roots and decaying vegetation are the primary carbon sources for pollutant-transforming microbes which are critical to the pollutant-removal performance of constructed wetlands (e.g. Brix, 1994; Kadlec and Wallace, 2009). Root penetration loosens sediments and after death and decay, leaves channels (macropores) which increases hydraulic conductivity and the ability for water to be channel through the root bed (Brix, 1994). Macropores may increase microbial surface area, oxygenation of the sediments and dispersal of nutrients and contaminants and therefore increase pollutant removal efficiency.

Dead plant matter provides adsorptive surface area for microbes, nutrients, metals and some organic industrial compounds. Peat can contain a significant amount of absorbed and adsorbed nutrients and contaminants. The burial or retention of peat within the sediments (peat accretion) is the only long-term removal pathway for P (e.g. Nichols, 1983; Vymazal, 2007). 
Under anaerobic conditions, anaerobes reduce the $\mathrm{pH}$ of the sediments through the production of organic acids which slows the decomposition rate of organic matter and therefore increases $\mathrm{P}$ retention (Smolders et al., 2006). Dead plant matter has a cooling effect during the summer and can prevent the sediment from freezing during the winter months (Brix, 1997). Tall species such as Phragmites, Typha spp. and Schoenoplectus spp. can also reduce algal production through shading which can improve water quality (Brix, 1997).

In addition to providing greater ancillary benefits including wildlife habitat, education, recreation and aesthetics, a greater plant species diversity in constructed wetlands may also increase pollutant removal capability owing to species-specific differences in pollutant tolerances, disease and insect infestations (Brix and Scheirup, 1989; Taylor, 1992; Kadlec and Wallace, 2009). Engelhardt and Ritchie (2001) found higher TP removal rates in microcosms containing higher submergent plant species diversity compared to single-species controls. A higher level of increased biodiversity would also provide greater resilience to variations in water levels, episodic weather events and herbivore pest out-breaks and thus provide some insurance against poor pollutant - removal performance or failure (Taylor, 1992; Kadlec and Wallace, 2009).

\subsection{Nitrogen}

Sources of anthropogenic $\mathrm{N}$ include sewage effluent, urban and agricultural runoff, crop and garden fertilizers. Atmospheric nitrogen oxide pollutants $\left(\mathrm{NO}\right.$ and $\left.\mathrm{NO}_{2}\right)$ produced by the combustion of fossil fuels can enter aquatic ecosystems via atmospheric dry deposition or washout (Kelly et al., 1990; Camargo et al., 2005). Increased levels of nitric acid $\left(\mathrm{HNO}_{3}\right)$ and $\mathrm{NO}_{3}{ }^{-}$derived from the oxidation of increased nitric acid deposition can result in elevated nitrate levels in lakes and lower pH (Kelly et al., 1990), potentially increasing the bioavailability of toxic metals and $\mathrm{P}$. Unionized ammonia $\left(\mathrm{NH}_{3}\right)$, formed by the hydrolysis of urea and decomposition of amino acids, is highly toxic to fish and other aquatic organisms (Kadlec and Wallace, 2009). Ammonium or ionized ammonia $\left(\mathrm{NH}_{4}{ }^{+}\right), \mathrm{NO}_{2}{ }^{-}$and $\mathrm{NO}_{3}{ }^{-}$ions can also be toxic to aquatic animals and humans (reviews by Ip et al., 2001; Camargo et al., 2005). 
The eutrophication of estuarine and marine coastal ecosystems in response to elevated $\mathrm{N}$ loading largely derived from agricultural fertilizer is well documented (e.g. Boesch, 2001; Zedler, 2003; Smith and Schindler, 2009). Wetland ecosystems are often N limited (Bedford et al., 1999) and high $\mathrm{N}$ loading can also contribute to the eutrophication of other freshwater ecosystems (Elser et al., 1990; González et al., 2005) thus effective removal of $\mathrm{N}$ from various anthropogenic sources is often a primary objective of constructed wetlands (Sauders and Kalff, 2001; Kadlec and Wallace, 2009). $\mathrm{NH}_{4}{ }^{+}$and $\mathrm{NO}_{3}{ }^{-}$are generally the only bioavailable forms of $\mathrm{N}$ which can be assimilated into aquatic macrophyte and algal biomass. The increased growth of $\mathrm{N}$ fixing cyanobacteria (heterocyst-forming blue-green algae) under high P availability may potentially also increase the amount of atmospheric $\mathrm{N}$ transfer into surface waters where it can be oxidized into bioavailable nitrate $\left(\mathrm{NO}_{3}{ }^{-}\right)$, further increasing algal production and the negative effects of eutrophication (Smith and Schindler, 2009).

$\mathrm{N}$ removal processes in wetlands includes ammonification, ammonia volatilization, nitrification, aerobic and anaerobic denitrification, anaerobic ammonia oxidization and reduction of $\mathrm{NO}_{2}{ }^{-}$to $\mathrm{N}_{2}$ (anammox), adsorption to peat, permanent burial of organic $\mathrm{N}$, and uptake of $\mathrm{NO}_{3}{ }^{-}$ and $\mathrm{NH}_{4}{ }^{+}$by macrophytes, algae and microbes (e.g., van Kessel, 1978; Wetzel, 1983; Vymazal, 2007; Kadlec and Wallace, 2009) (Figure 11). The mean $\mathrm{NO}_{3}{ }^{-}$removal rate of surface flow and horizontal subsurface flow wetlands was $47.4 \%$ with a mean inflow influent concentration of 5 mg $\mathrm{NO}_{3}-\mathrm{N} / \mathrm{L} . \mathrm{NO}_{3}{ }^{-}$actually increased in vertical flow subsurface wetlands which are not considered effective for $\mathrm{NO}_{3}{ }^{-}$removal (Vymazal, 2007). The mean $\mathrm{NH}_{4}{ }^{+}$removal rates reported in Vymazal (2007) for 295 constructed wetlands of all types except floating vegetation wetlands was $62.52 \%$ with a mean influent concentration of $35.6 \mathrm{mg} \mathrm{NH}_{4}{ }^{+}-\mathrm{N} / \mathrm{L}$. The removal rates for both $\mathrm{NO}_{3}{ }^{-}$and $\mathrm{NH}_{4}{ }^{+}$are thus insufficient to prevent ecological impact to receiving systems unless further treatment or significant dilution occurs.

The primary contribution to $\mathrm{N}$ removal by wetland vegetation is physical whereby macrophytes reduce water velocity which increases the sedimentation rate (deposition to the sediments) of particulate inorganic and organic $\mathrm{N}$ allowing ammonification, nitrification, denitrification and burial processes to permanently remove N. Macrophytes also increase the surface area for N-removing biofilms which achieve greater biomass on solid surfaces such as 
live and dead vegetation (Craft and Richardson, 1993; Saunders and Kalff, 2001). As is the case for $\mathrm{P}$, the removal rate of $\mathrm{N}$ is determined by hydraulic loading rate (Brix and Schierup, 1989).

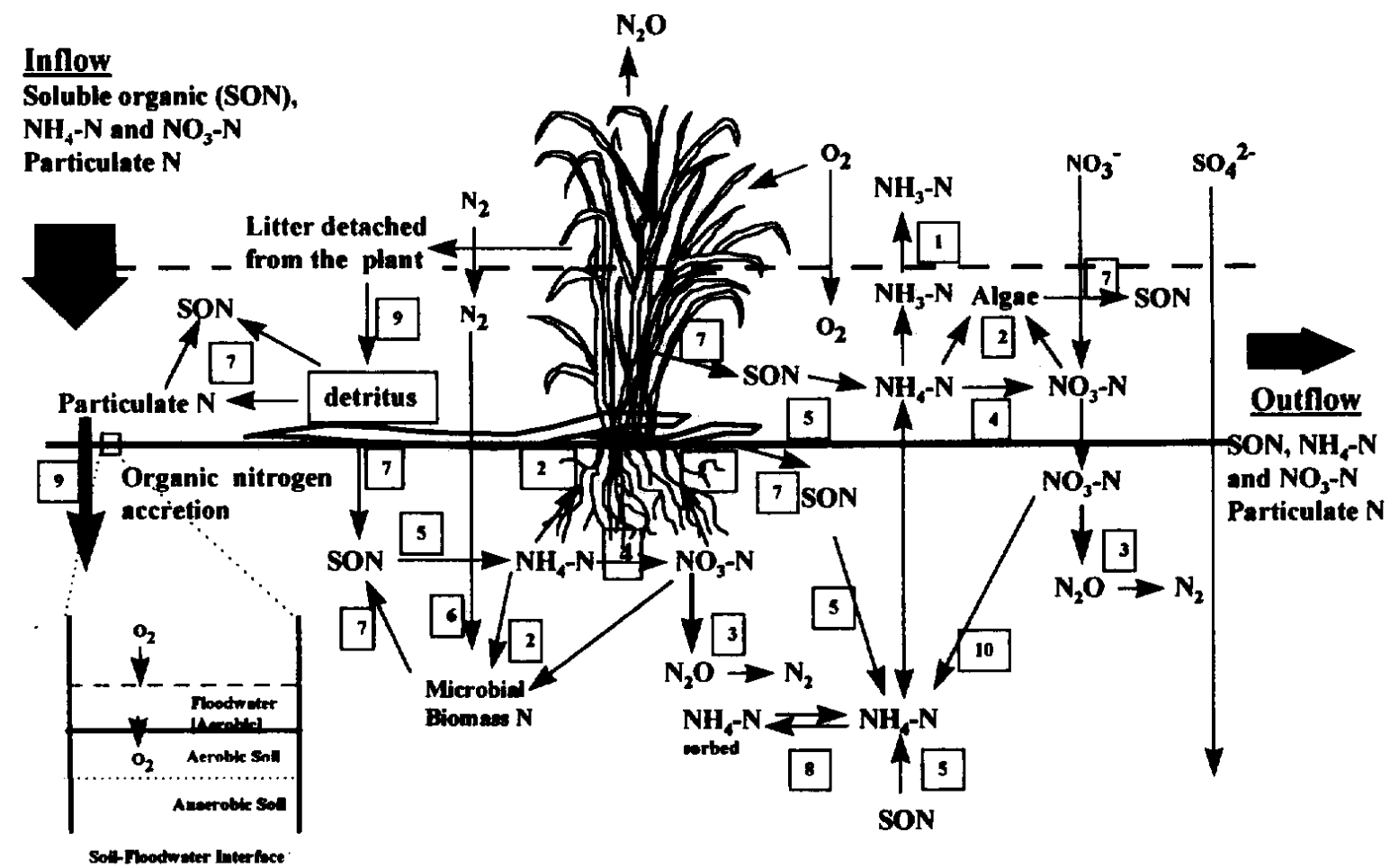

Figure 11. Nitrogen transformations in constructed wetlands.

(1) volatilization, (2) plant and microbial uptake, (3) denitrification, (4) nitrification, (5) mineralization, (6) nitrogen fixation, (7) fragmentation and leaching, (8) sorption and decomposition, (9) burial and (10) nitrate reduction to ammonium.

From Reddy and D'Angelo. 1997.

\subsubsection{Ammonification}

$\mathrm{NH}_{3}$ is rapidly converted to $\mathrm{NH}_{4}{ }^{+}$under conditions of moderate $\mathrm{pH}$ and temperatures < $30^{\circ} \mathrm{C}$ which predominate in wetlands (Kadlec and Wallace, 2009). $\mathrm{NH}_{3}$ concentrations can however rapidly accumulate under anoxic conditions (Wetzel, 1983); or at very high $\mathrm{pH}(>9.0)$ and temperatures of approximately $30^{\circ} \mathrm{C}$ (Kadlec and Wallace, 2009). In constructed wetlands where high $\mathrm{NH}_{3}$ does not pose a threat to fish and other aquatic organisms, submergent 
macrophytes can be used to elevate $\mathrm{pH}$ by consuming $\mathrm{CO}_{2}$ during photosynthesis and increase the amount of $\mathrm{N}$ removed by $\mathrm{NH}_{3}$ volatilization (Brix and Schierup, 1989).

The ammonification process (Eq. 3 and Eq. 4) begins with the release of unionized and volatile ammonia $\left(\mathrm{NH}_{3}\right)$ as a result of organic $\mathrm{N}$ decomposition by chemotropic and heterotrophic microorganisms under both aerobic and anaerobic conditions (Kadlec and Wallace, 2009).

Eq. 3. Ammonification (e.g. urea breakdown).

$\mathrm{NH}_{2} \mathrm{CONH}_{2}(\mathrm{aq})+\mathrm{H}_{2} \mathrm{O}(\mathrm{l}) \rightarrow 2 \mathrm{NH}_{3}(\mathrm{~g})+\mathrm{CO}_{2}(\mathrm{~g})$

Eq. 4. Ammonia ionization/deionization.

$\mathrm{NH}_{3}(\mathrm{~g})+\mathrm{H}_{2} \mathrm{O}(\mathrm{aq}) \rightleftharpoons \mathrm{NH}_{4}^{+}(\mathrm{aq})+\mathrm{OH}^{-}(\mathrm{aq})$

\subsubsection{Nitrification}

Nitrification is the oxidation of reduced forms of $\mathrm{N}$ which largely occurs under aerobic conditions and is the primary mechanism for reducing $\mathrm{NH}_{4}{ }^{+}$in wetlands. Nitrification of $\mathrm{NH}_{4}{ }^{+}$ (Eq. 5 and Eq. 6) involves the successive oxidation of $\mathrm{NH}_{4}{ }^{+}$to intermediate $\mathrm{NO}_{2}{ }^{-}$and finally $\mathrm{NO}_{3}{ }^{-}$by aerobic chemoautotrophic and heterotrophic bacteria for adenosine triphosphate (ATP) production and assimilation of $\mathrm{CO}_{2}$ for growth. As the nitrification of ammonia consumes $\mathrm{CaCO}_{3}$, alkalinity decreases along with a reduction in $\mathrm{pH}$ (Kadlec and Wallace, 2009).

Eq. 5: Nitriation by Nitrosomonas

$$
\mathrm{NH}_{4}^{+}(\mathrm{aq})+3 \mathrm{O}_{2}(\mathrm{~g}) \rightarrow 4 \mathrm{H}^{+}(\mathrm{aq})+2 \mathrm{NO}_{2}^{-}(\mathrm{aq})+2 \mathrm{H}_{2} \mathrm{O}(\mathrm{l})
$$


Eq. 6. Nitrification by Nitrobactor

$2 \mathrm{NO}_{2}^{-}(\mathrm{aq})+\mathrm{O}_{2}(\mathrm{~g}) \rightarrow 2 \mathrm{NO}_{3}^{-}(\mathrm{aq})$

The oxidation of $\mathrm{NH}_{4}{ }^{+}$to intermediate nitrite $\left(\mathrm{NO}_{2}^{-}\right)$is primarily by Nitrosomonas bacteria followed by further oxidation to $\mathrm{NO}_{3}{ }^{-}$primarily by Nitrobacter bacteria with oxygen as the terminal electron $\left(e^{-}\right)$acceptor (Wetzel, 1983). Oxygenation of the rhizosphere by macrophytes increases nitrification by stimulating the growth of nitrifying bacteria within the sediments. $\mathrm{NO}_{3}{ }^{-}$ within the aerobic zone of the sediments then diffuses into the oxygen-scarce facultative anaerobe and anoxic obligate microbial zones where denitrification and permanent removal of $\mathrm{N}$ occurs (e.g. Reddy and D’Angelo, 1997; Kadlec and Wallace, 2009).

\subsubsection{Denitrification}

Denitrification (nitrate dissimilation) is the conversion of $\mathrm{NO}_{3}{ }^{-}$to $\mathrm{N}_{2}$ gas by denitrifying facultative heterotrophic organisms, particularly those that are anaerobic (e.g. Pseudomonas, Vibrio, Aeromonas, Bacillus, Thiobacillus, Nitrosomonas) (Eq. 7) which utilize nitrate as a terminal $e^{-}$acceptor. Denitrification by heterotrophic bacteria requires a carbon energy source generally in the form of organic matter (Vymazal, 2007) (Eq. 8) which, in constructed wetlands, can be provided by decomposing plant tissue and other organic molecules produced by macrophytes. Autotrophic ( $\mathrm{CO}_{2}$ fixers) Thiobacillus denitrificans can reduce $\mathrm{NO}_{3}{ }^{-}$to $\mathrm{N}_{2}$ by utilizing elemental sulfur $\left(\mathrm{S}^{\mathrm{o}}\right)$, sulfide $\left(\mathrm{S}^{2-}\right)$, thiosulfate $\left(\mathrm{S}_{2} \mathrm{O}_{3}{ }^{2-}\right)$ and sulfite $\left(\mathrm{SO}_{2}{ }^{3-}\right)$ as terminal $e^{-}$ acceptors (Kadlec and Wallace, 2009). Denitrification under anaerobic conditions can also occur in the absence of a carbon source through the reduction of $\mathrm{NO}_{2}{ }^{-}$to $\mathrm{N}_{2}$ by the oxidation of ammonia by the bacteria Planctomycetes and Nitrosomas eutropha (Eq. 9) (Kadlec and Wallace, 2009).

Eq. 7: Denitrification:

$2 \mathrm{NO}_{3}^{-}(\mathrm{aq}) \rightarrow 2 \mathrm{NO}_{2}^{-}(\mathrm{aq}) \rightarrow 2 \mathrm{NO}(\mathrm{aq}) \rightarrow \mathrm{N}_{2} \mathrm{O} \rightarrow \mathrm{N}_{2}(\mathrm{~g})$ 
Eq. 8. Denitrification with methanol (Kadlec and Wallace, 2009).

$2 \mathrm{NO}_{3}{ }^{-}(\mathrm{aq})+0.833 \mathrm{CH}_{3} \mathrm{OH}(\mathrm{aq}) \rightarrow 0.5 \mathrm{~N}_{2}(\mathrm{~g})+0.833 \mathrm{CO}_{2}(\mathrm{~g})+1.167 \mathrm{H}_{2} \mathrm{O}(\mathrm{l})+\mathrm{OH}^{-}(\mathrm{aq})$

Eq. 9. Anaerobic ammonia oxidation (anammox) (Kadlec and Wallace, 2009)

$$
\mathrm{NH}_{4}{ }^{+}(\mathrm{aq})+\mathrm{NO}_{2}^{-}(\mathrm{aq}) \rightarrow \mathrm{N}_{2}(\mathrm{~g})+2 \mathrm{H}_{2} \mathrm{O}(\mathrm{l})
$$

Denitrification is the primary $\mathrm{N}$ removal mechanism in lakes, streams and wetlands (Saunders and Kalff, 2001). Denitrification predominantly occurs under anoxic conditions but can also occur under aerobic conditions (Wetzel, 1983; Kadlec and Wallace, 2009).

Denitrification interacts with other pollutant removal processes by generating alkalinity through the production of $\mathrm{OH}^{-}$which raises $\mathrm{pH}$ and thereby affecting the decomposition rate of organic matter and the cycling and motility of metals (Marchand et al., 2010) and P (Smolders et al., 2006).

\subsubsection{Macrophyte Nitrogen Assimilation and Peat Accretion}

Aquatic macrophyte species obtain $\mathrm{N}$ largely from sediment pore water although submergent species of vegetation can obtain a small amount of $\mathrm{N}$ from surface water (Reddy and D’Angelo, 1997). Most plant species can store and rapidly assimilate either $\mathrm{NO}_{3}{ }^{-}$or $\mathrm{NH}_{4}{ }^{+}$into plant tissue (Hirel and Lea, 2001). Direct ammonia uptake is more efficient for plant growth as energy is required for the successive reduction of $\mathrm{NO}_{3}{ }^{-}$to $\mathrm{NO}_{2}{ }^{-}$and $\mathrm{NH}_{4}{ }^{+}$(e.g. Wetzel, 1983; Hirel and Lea, 2001; Vymazal, 2007). The selection of either $\mathrm{NO}_{3}{ }^{-}$or $\mathrm{NH}_{4}{ }^{+}$by macrophytes is often determined by availably with nitrate reductase and nitrite reductase enzymes being produced when $\mathrm{NO}_{3}{ }^{-}$is more abundant (Vymazal, 2007; Kadlec and Wallace, 2009). Although T. latifolia is capable of assimilating either $\mathrm{NO}_{3}{ }^{-}$or $\mathrm{NH}_{4}{ }^{+}$Brix et al. (2002) observed greater $T$. latifolia growth in plants fed $\mathrm{NH}_{4}{ }^{+}$compared to plants provided with $\mathrm{NO}_{3}{ }^{-}$.

The amount of $\mathrm{N}$ uptake by macrophytes and algae is considered to be minor relative to $\mathrm{N}$ loading rates typically received by both natural (Nichols, 1983) and constructed wetlands (e.g. Mustafa et al., 2011). Mustafa et al. (2011) reported that $\mathrm{N}$ uptake by T. latifolia accounted for 
$<1 \%$ of $\mathrm{N}$ removed by a constructed wetland over a 12 month period. Emergent rhizomatous vegetation translocate a significant amount of carbohydrate and nutrient from the shoots to the rhizomes for overwinter storage (e.g. Dubbe et al., 1988); however, similar to submergent vegetation, the amount of $\mathrm{N}$ retained within the rhizome structure is relatively minor (Brix, 1997; Sauders and Kalff, 2001; Mustafa et al., 2011). While macrophyte N retention can be significant during the growing season (Brix, 1997; Kadlec and Wallace, 2009) most of the assimilated N is re-released after the growing season through decomposition following death (Vymazal, 2007; Kadlec and Wallace, 2009).

Retention by peat accretion in constructed wetlands is restricted to surface flow wetlands and is generally considered to be low (Vymazal, 2007). Accreted peat generally contains < $5 \%$ N (Kadlec and Wallace, 2009). Kadlec and Wallace (2009) reported that the removal of N through peat accretion was in the order of $10 \mathrm{~g} \mathrm{~N} / \mathrm{m}^{2} / \mathrm{yr}$ which may be of significance for constructed wetlands subjected to very low loading rates but insignificant in wetlands subjected loading rates typically received by constructed wetlands. Recall that the mean TN influent loading rate for 254 constructed wetlands of all types presented in Vymazal (2007) was $792.5 \mathrm{~g}$ $\mathrm{N} / \mathrm{m}^{2} / \mathrm{yr}$.

\subsection{Phosphorus}

$\mathrm{P}$ is generally the nutrient most limiting to algal production in freshwater ecosystems and the primary cause of freshwater eutrophication (e.g., Schindler, 1974; 1977; Reddy et al., 1999; Smith and Schindler, 2009). P limitation has also been observed in estuarine ecosystems during certain times of the year (Boesch et al., 2001). Anthropogenic P enters aquatic ecosystems in sewage effluent from wastewater treatment plants, combined sewer overflows, agricultural runoff containing livestock waste, fertilizer and farm field soils, stormwater runoff containing garden fertilizers and particulate $\mathrm{P}$ and atmospheric deposition of particulate $\mathrm{P}$ (wind-blown soil,

dust, pollen and plant parts). Evidence of P loading in sediment cores collected from the Bay of Quinte dates to the late $17^{\text {th }}$ century coinciding with early European settlement (Ahl, 1988). Ahl (1988) attributed increased P levels in centuries old Northern European sediments in remote areas of low human population density to the aerial transport of eroded agricultural soils. 
$\mathrm{P}$ fractions differ greatly in ecological significance. Total phosphorus (TP) represents all fractions of $\mathrm{P}$ including dissolved, particulate, organic and inorganic forms. Approximately 90 $\%$ of $\mathrm{P}$ in unpolluted freshwater systems occurs in unavailable organic forms (Wetzel, 1983; EPA, 2000). Orthophosphate $\left(\mathrm{PO}_{4}{ }^{3-}\right)$ is the only readily bioavailable fraction (e.g. Wetzel, 1983; Bostrom et al., 1988; Correll, 1998) and the most ecologically significant owing to its' rapid utilization by algae and aquatic plants (e.g. Rigler, 1964; Schachtman et al., 1998; Jarvie et al. 2006). The commonly sampled soluble reactive phosphate (SRP) fraction represents $\mathrm{PO}_{4}{ }^{3-}$ and the fraction of organic $\mathrm{P}$ that can be rapidly converted to $\mathrm{PO}_{4}{ }^{3-}$ by bacteria (Wetzel, 1983).

The major P removal pathways in constructed wetlands are sedimentation of particulate inorganic and organic $\mathrm{P}$, co-precipitation and retention of $\mathrm{PO}_{4}{ }^{3-}$ with $\mathrm{Fe}, \mathrm{Al}$ and $\mathrm{Ca}$ cations to the sediments, macrophyte uptake, burial and peat accretion (e.g. Brix, 1994; Richardson, 1985; Vymazla, 2007) (Figure 12).

The removal of $\mathrm{P}$ to protect receiving aquatic ecosystems and meet water quality standards and guidelines is often a primary consideration in constructed wetland design (e.g. Cameron et al., 2003; Maddison et al., 2009; Vohla et al., 2011); thus, the P removal efficiencies of constructed wetland designs under various hydraulic and nutrient loading rates has been extensively researched (e.g.; White et al., 2000; Cameron et al., 2003; Song et al., 2006; Maddison, et al., 2009; Slayton, 2009; reviewed by Vymazal, 2007; Vohla et al., 2011). The amount of $\mathrm{P}$ in wastewater or stormwater influent entering constructed wetlands is often orders of magnitude higher than natural wetlands (Vymazal, 2007). Thus, to enable $P$ in surface water to diffuse into constructed wetland sediments where $\mathrm{P}$ has already accumulated, surface water $\mathrm{P}$ must be high as observed by Patrick and Khalid (1974).

P removal efficiencies in constructed wetlands are variable. Vymazal (2007) found that the typical rate of total phosphorus (TP) removal by mature constructed wetlands ranged between $41-60 \%$. Newly constructed wetlands typically achieve higher P retention with removal rates of over $90 \%$ being documented (e.g. Cameron et al., 2003) owing to the greater availability of sediment P adsorption sites (Kadlec and Wallace, 2009). Slayton (2009) reported that the average TP removal rate by the 1190 ha Orlando Easterly Wetlands (OEW), a natural 
wetland subjected to seasonal changes in hydraulic and nutrient loading rates, averaged $67.71 \%$ over a 17 year period. The TP removal efficiency for 326 constructed wetlands of all types was reviewed by Vymazal (2007) where influent TP ranged from $3.8-10.5 \mathrm{mg} P / \mathrm{L}$ and averaged $6.8 \mathrm{mg}$ P/L. Mean effluent TP was $3.4 \mathrm{mg} \mathrm{P} / \mathrm{L}$ for a mean removal rate of $48 \%$. Recalling that the mean TP concentration for eutrophic lakes and reservoirs presented in Wetzel (1983) was $0.084 \mathrm{mg} \mathrm{P} / \mathrm{L}$ and EPA guidelines define $0.096 \mathrm{mg} \mathrm{P} / \mathrm{L}$ as an indication of hyereutrophic levels, the TP in both the influent and effluent of constructed wetlands is far above levels typical of even the most polluted of natural aquatic ecosystems. The EPA (2000) considered constructed wetlands to have low $\mathrm{P}$ retention capacity and unsuitable for $\mathrm{P}$ management to protect surface waters. Similarly, Richardson (1985) also observed low P removal capacity in various types of natural wetland systems relative to terrestrial soil and recommended that peat wetlands not be considered as effective $\mathrm{P}$ sinks for water quality management purposes.

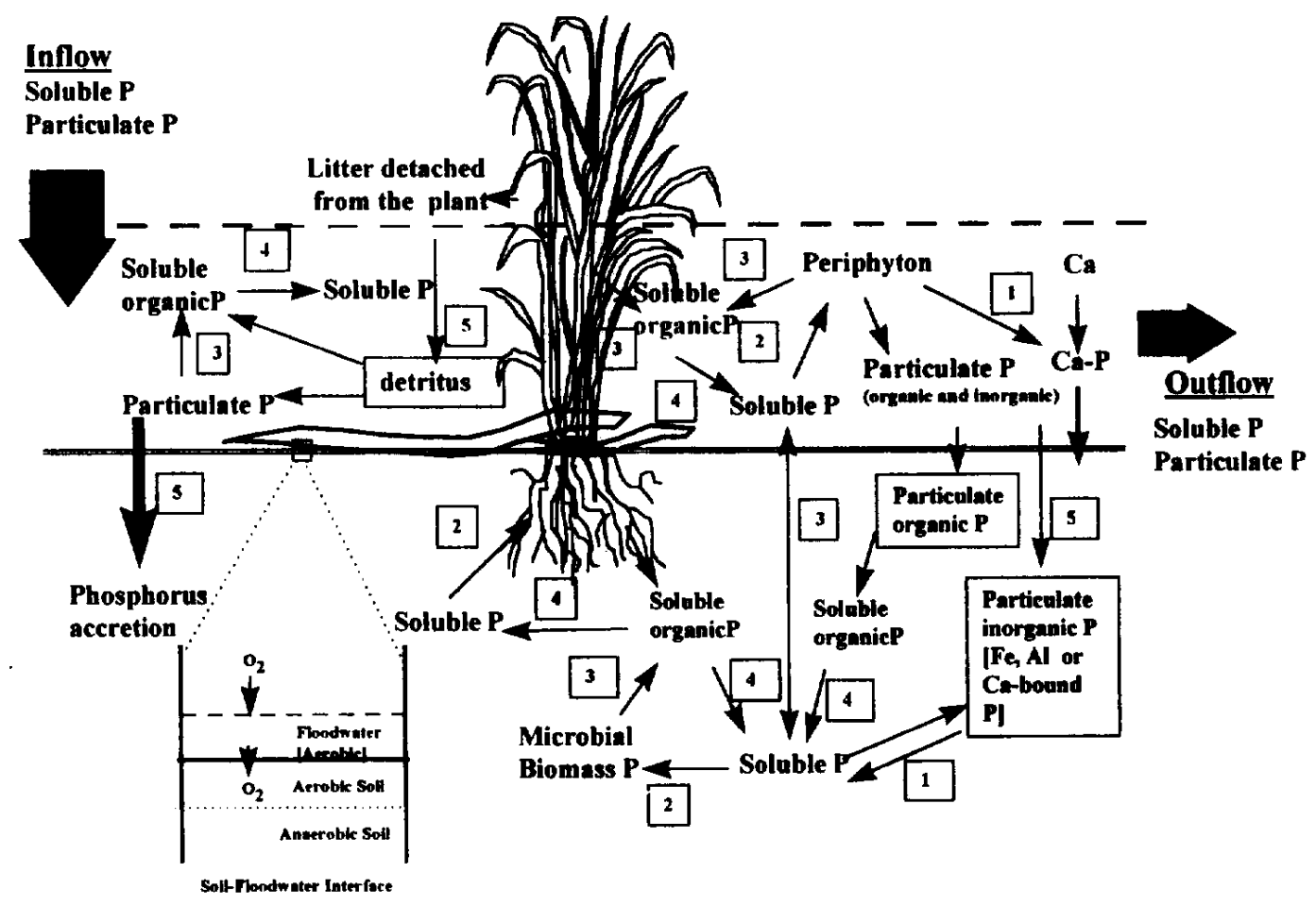

Figure 12. Phosphorus tranformations in constructed wetlands.

(1) adsorption and desorption, (2) plant and microbial uptake, (3) fragmentation and leaching, (4) mineralization and (5) sedimentation and burial.

From Reddy and D'Angelo. 1997. 
Microbial populations can provide short-term $\mathrm{P}$ storage but are generally regarded as insignificant in P retention within constructed wetlands owing to their low biomass and rapid turnover rate (e.g., Nichols, 1983; Vymazal, 2007). Similarly, average annual P retention by periphyton and phytoplankton, although potentially significant during the growing season, is also generally considered to be insignificant due to low biomass and high turnover rate. Microbial $\mathrm{P}$ absorption and assimilation may however be more significant in natural wetlands and constructed wetlands that receive low nutrient loading. Reddy et al. (1999) cited two studies where $60 \%$ of $\mathrm{P}$ in the treatment wetlands was retained by microbial uptake and assimilation where P loading was low.

The only gaseous phases of $\mathrm{P}$ that are known to form in wetlands are phosphine $\left(\mathrm{PH}_{3}\right)$ and disphosphine $\left(\mathrm{P}_{2} \mathrm{H}_{4}\right)$ which are believed to form under highly reducing conditions (Kadlec and Wallace, 2009). The mechanisms responsible for phosphine formation in wetlands are unknown. The research reviewed in Kadlec and Wallace (2009) found that most phosphine remained trapped within wetland sediments and then at very low concentrations $(<1 \mu \mathrm{g} / \mathrm{L})$. However, at a sediment concentration of $2.2 \mathrm{~g} \mathrm{P} / \mathrm{kg}$ (very high for natural wetlands) a loss rate of $5.7 \%$ of $\mathrm{P}$ ( $38 \mathrm{mg} \mathrm{P} / \mathrm{m}^{2} / \mathrm{yr}$ ) was explained by volatilization. The significance of $\mathrm{P}$ loss to volatilization remains unknown and to date has been ignored with respect to $\mathrm{P}$ removal by wetlands (Kadlec and Wallace, 2009).

\subsubsection{Sedimentation of Particulate Phosphorus}

Suspended solids (SS) which includes all forms of inorganic and organic settleable, supracolloidal, colloidal and soluble solids ranging from $1 \mu \mathrm{m}$ to $>100 \mu \mathrm{m}$ (EPA, 2000) is commonly the dominant source of total phosphorus (TP) in aquatic ecosystems (Ahl, 1988) and the primary form of $\mathrm{P}$ in agricultural runoff (e.g. Cooke and Williams, 1973, Jarvie et al., 2006). Sediment $\mathrm{P}$ levels are typically highest in the influent outfall area for both natural and constructed wetlands where the majority of SS settle to the substrate (e.g. White et al., 2000; Mayer et al., 2006; Kadlec and Wallace, 2009). Constructed wetlands are consistently effective in reducing SS (Kadlec and Wallace, 2009) with nearly $100 \%$ being removed if sufficient retention time is provided (Verhoeven and Meuleman, 1999; EPA, 2000; Cameron et al., 2003). The physical removal of SS and particulate $\mathrm{P}$ by wetlands is enhanced by the attenuation of 
inflow velocities by ponded water, course substrate material and wetland vegetation, each of which contributes to filtering, interception, aggregation and sedimentation by gravitational forces (EPA, 2000; Kadlec and Wallace, 2009). However, the $41-60 \%$ P removal rate suggests that some of the particulate $\mathrm{P}$ is transformed into dissolved $\mathrm{P}$ which is transported via effluent out of the wetland.

\subsubsection{Adsorption and Precipitation}

The voluminous body of literature on phosphate $\left(\mathrm{PO}_{4}{ }^{3-}\right)$ removal, cycling and storage in wetlands has identified coprecipitation with the cations, oxides and hydroxides of $\mathrm{Al}$ and $\mathrm{Fe}$ at neutral to acidic conditions as the most important factors in $\mathrm{PO}_{4}{ }^{3-}$ removal (e.g., Nichols, 1983; Reddy and D'Angelo, 1997). As most wetlands have a slightly acidic to neutral pH (Kadlec and Wallace, 2009), $\mathrm{PO}_{4}$ adsorption to $\mathrm{Al}$ and $\mathrm{Fe}$ are generally considered to be the primary factors in $\mathrm{PO}_{4}{ }^{3-}$ retention in both natural and constructed wetlands. Richardson (1985) found that sediment $\mathrm{Al}$ concentration explained $87 \%$ of the variation in $\mathrm{P}$ retention for fen, bog, swamp and marsh wetlands while multiple regression analysis showed little effect of Fe and other variables. Sakadevan and Bavor (1998) also found Al to be the most important determinant of P removal in constructed wetlands but that Fe also played a significant role. Battay et al. (2002) documented significant $\mathrm{P}$ retention on the surfaces of $\mathrm{Fe}, \mathrm{Mn}$ and $\mathrm{Al}$ hydroxide plaques that formed on the surface of macrophyte roots. The significance of root plaque formation and $\mathrm{P}$ retention is unknown. Phosphate adsorption to $\mathrm{Ca}$ and $\mathrm{Mn}$ cations and positively charged silica and clay cation exchange sites are the primary $\mathrm{P}$ removal and retention mechanisms under alkaline conditions (e.g. Nichols, 1983; Danen-Louwerse et al., 1993; Brix, 1997; Reddy and D’Angelo, 1997; Reddy et al., 1999; Gray et al., 2000; Vymazal, 2007; Vohla et al., 2011).

\subsubsection{The Influence of Reduction-Oxidation Potential in Phosphorus Removal and Retention}

Sediment reduction and oxidation (redox) potentials are considered to be the primary determining factors in $\mathrm{P}$ retention in constructed and natural wetlands. In aerobic surface waters the movement of $\mathrm{P}$ is generally unidirectional into the sediments (Wetzel, 1983). Under anaerobic conditions the reduction of $\mathrm{Fe}^{3+}$ and $\mathrm{Mn}^{4+}$ is believed to result in the release of Fe and 
Mn bound P (Patrick and Khalid, 1974). A thin oxic layer at the sediment/water interface of usually no more that $1 \mathrm{~cm}$ in thickness can prevent or inhibit P release into the water column (Wetzel, 1983). Aerobic conditions within the rhizosphere can also increase P retention within the sediments through $\mathrm{P}$ co-precipitation with $\mathrm{Fe}, \mathrm{Al}, \mathrm{Mn}, \mathrm{Ca}, \mathrm{Mg}$, clay and colloids in pore water (e.g. Wetzel, 1983; Danen-Louwerse, 1993; Van de Moortel et al., 2009, Yates and Prasher, 2009).

Differences in root oxygen escape between macrophyte species may be a significant factor in $\mathrm{P}$ retention whereby greater oxidizing conditions within the sediments would increase Fe availability therefore P retention capacity. Szögi et al. (2004) observed considerably higher oxidizing conditions over a 12 month period in a wetland planted with Schoenoplectus compared to a Typha wetland receiving the same effluent. Neil and Graham (1989) found Schoenoplectus tabernaemontani to be more effective at $\mathrm{P}$ removal than Typha angustifolia which may have been due to higher oxidizing conditions within the $S$. tabernaemontani rhizosphere.

\subsubsection{Phosphorus Assimilation by Macrophytes}

Davis (1982) cited in Reddy et al., (1999) observed that only $2-4 \%$ of $\mathrm{P}^{32}$ added to surface water was eventually absorbed by Typha domingensis. Submergent macrophytes have been shown to obtain some $\mathrm{P}$ from surface water under eutrophic conditions; however, the majority of $\mathrm{P}$ is still obtained from the sediments (Bole and Allan, 1978; Carignan and Kalff, 1980). During the growing season, direct plant uptake in constructed wetlands can remove a significant amount of $\mathrm{P}$, but the proportion of $\mathrm{P}$ removed under typically high $\mathrm{P}$ loading rates is generally considered small to minor compared to sedimentation, precipitation and burial within the sediments (Brix and Schierup, 1989; Brix, 1997;Vymazal, 2007; Mustafa \& Miklas Scholz, 2011). The proportion of surface and sediment water $P$ retained within wetland vegetation following senescence and death is generally minor (Brix, 1997; Vymazal, 2007). Mustafa et al. (2011) reported that $<1 \%$ of the P loading was retained by T. latifolia over a 12 month period.

After death, approximately 35 to $75 \%$ of the $\mathrm{P}$ assimilated within plant tissue is rereleased during decomposition in natural wetlands (Nichols, 1983). The seasonal effect of $\mathrm{P}$ retention by macrophytes is well illustrated in the review by Nichols (1983) where a Typha stand 
subjected to storm sewer water retained $83 \%$ of influent P during the summer, only $1 \%$ in the fall and $8 \%$ in the spring giving a $10 \%$ removal rate overall.

\subsubsection{Phosphorus Retention by Peat Accretion}

Peat accretion is generally accepted as the only long-term $\mathrm{P}$ retention mechanism in constructed wetlands (e.g. Nichols, 1983; Reddy and D’Angelo, 1997; Vymazal, 2007; Mustafa et al., 2011). Acidic conditions in the deeper anoxic sediments as a result of organic acid production by anaerobic bacteria reduce the decomposition rate of organic matter potentially resulting in the permanent burial of organically-bound P (Smolders et al., 2006). Conversely, bicarbonate alkalinity produced within the rhizosphere through macrophyte metabolism can buffer against organic acid production associated with microbial decomposition and reduce acidity and thus increase microbial biomass and the mineralization of organic $\mathrm{P}$ into bioavailable P (Smolders et al., 2006).

Natural wetland peat generally contains very low amounts of P levels with P commonly representing $<0.1 \%$ of peat biomass (Nichols, 1983). Peat accretion data presented in Richardson (1985) indicated a range of 0.005 to $0.24 \mathrm{~g} \mathrm{P} / \mathrm{m}^{2} \cdot \mathrm{yr}$ in natural wetlands. Peat in constructed wetlands contains much higher levels of $\mathrm{P}$ due to much higher $\mathrm{P}$ loading rates (Vymazal, 2007). 1.6g P/ $\mathrm{m}^{2} \cdot \mathrm{yr}$ has been reported under nutrient-rich conditions for a Phragmites stand and $1.95 \mathrm{~g} \mathrm{P} \mathrm{m}^{2} \cdot \mathrm{yr}$ has been reported for a Schoenoplectus fluviatilis stand (Kadlec and Wallace, 2009). The amount of P removed in peat however is still very low relative to the total P loading rate over a 12 month period. Macrophyte Harvesting for Phosphorus Removal

The harvesting of above-ground macrophyte biomass has been suggested as a means of reducing nutrients in eutrophicated systems by several authors (e.g. Boyd, 1970, Yount and Crossman; 1970, Brix and Schrierup, 1989; Vyamzal, 2007; Maddison et al., 2009). However, P yields by macrophyte harvesting is generally low as is the proportion of $\mathrm{P}$ removed relative to loading rate (Vyamzal, 2007), is costly and requires specialized equipment (Kadlec and Wallace, 2009: 363). Vymazal (2004, 2007) suggested that under relatively low loading rates for constructed wetlands of $<20 \mathrm{~g} \mathrm{P} / \mathrm{m}^{2} / \mathrm{y}$, macrophyte harvesting could potentially be effective in 
reducing $\mathrm{P}$ in eutrophicated systems. Selective harvesting for $\mathrm{P}$ recovery could also provide a means of maintaining optimal macrophyte density and diversity as well as a means of removing unwanted invasive species.

Typha spp. is currently being harvested where the Red River empties into Lake Winnipeg after which it is made into biofuel pellets (Austin, 2011). The high nutrient-containing ash produced from the pellet burning is being used as a crop fertilizer. In Estonia, Typha chips and inflorescences are used in cost-efficient building blocks and clay plaster respectively, with the former also increasing the insulation value of the blocks (Maddison et al., 2005). Organic matter and vegetation from the constructed wetland described in Maine et al. (2009) was used as fertilizer and compost for ornamental plants. It is recommended that harvested vegetation be tested for toxic pollutants if the harvested material is to be used for further uses such as green fertilizer, biofuels or building materials where further release of toxic metals and chemicals is possible.

\subsection{Phosphorus Removal Limitation in Constructed Wetlands}

There is a finite $\mathrm{P}$ removal capacity in constructed wetlands and natural wetlands used for wastewater treatment as on-going $\mathrm{P}$ loading reduces or saturates the availability of $\mathrm{Fe}, \mathrm{Al}, \mathrm{Ca}$ and other P sediment adsorption sites over time (EPA, 2000; White et al., 2000; Vymazal, 2007; Kadlec and Wallace, 2009). Constructed wetlands may also lose $\mathrm{P}$ removal capacity during winter ice-over when the diffusion of atmospheric oxygen into the surface water ceases. The biological oxygen demand (BOD) associated with the decomposition of vegetation and other forms of organic matter may consume all available oxygen during ice-over periods resulting in anoxic conditions throughout the sediments and water column resulting in the mobilization of $\mathrm{P}$ into surface water (Wetzel, 1983). Retention within the sediments is also partially determined by $\mathrm{pH}$ where high $\mathrm{pH}$ and low $\mathrm{pH}$ can result in the solubilization of $\mathrm{Al}$ and $\mathrm{Fe}$ bound $\mathrm{P}$ (Wetzel, 1983). There may therefore be a trade-off between maximizing peat accretion by increasing acidity and the loss of $\mathrm{Al}$ and $\mathrm{Fe}$ binding sites to $\mathrm{Al}$ and $\mathrm{Fe}$ solubilization. Artificial Substrates for Phosphorus Removal 
There has been a considerable body of work in assessing the $\mathrm{P}$ retention capabilities of various types of substrates ranging from natural material (e.g. apatite, sand, gravel, peat), industrial by-products (blast furnace slag, fly ash, iron ore) and manmade material (e.g. Alunite,

Filtralite $^{\mathrm{TM}}$, oyster shell) for use in constructed wetlands to improve P removal capability (e.g. Sakadevan and Bavor, 1998; Drizzo et al., 1999; reviewed by Vohla et al., 2011). A very high P retention was often achieved (> $90 \%$ ) for several types of natural and artificial substrates (e.g. Cameron et al., 2003; Vohla et al., 2011). Although most of the data has been collected from small-scale experiments with data available from only a few fully operating constructed wetlands, results appear promising and an overall improvement in P removal may be realized such that the use of constructed wetlands for ecosystem protection and restoration may become more feasible. There is also interest in assessing the feasibility of recycling the adsorbed $\mathrm{P}$ for use as fertilizer (Vohla, et al., 2011).

\subsection{Predominant use of Invasive Vegetation in Constructed Wetlands}

Typha spp and Phragmites australis are by far the most common species of emergent vegetation used in constructed wetlands both in North America and Europe (Vymazal, 2007; Kadlec and Wallace, 2009; Maddison et al., 2009). Brisson and Chazarenc, (2009) and Marchand et al., (2010) questioned the general dependency on these species in the context of pollutant removal efficiency and recommended that further research be conducted to identify plants that may be more effective for removing specific types of heavy metals and nutrients.

T. latifolia is probably the most commonly used species used in the constructed wetland research (e.g. Martín, and Fernández, 1992; Cameron et al., 2003; Weng et al., 2006; Maddison et al., 2009; Calheiros et al., 2009; Yalcuk et al., 2010; Mustafa and Scholz, 2011). Phragmites australis australis (common reed) is the most commonly used macrophyte species used in European constructed wetlands (Brix and Schierup, 1989). While there has been a steadily increasing volume of literature documenting the invasive nature of Typha spp and Phragmites australis australis in North America spanning several decades (e.g. Linde et al., 1976; Beule, 1979; Grace and Harrison, 1986; Galatowitsch et al., 1999; Mal and Narine. 2004; Shih and Finkelstein, 2008), the common use of invasive species such as T. latifolia in constructed 
wetlands and constructed wetlands research has gone almost unquestioned in respect to potential environmental impact with the exception of Livingston (1989) and Taylor (1992).

Based on the lack of evidence to justify the wide-spread use of T. latifolia and other invasive species in constructed wetlands where organic matter and nutrient removal are the primary objectives, vegetation selected for constructed wetlands should be restricted to locally adapted native non-invasive species, particularly in areas where invasive species have not yet had significant impact. Numerous native species used in constructed wetlands have proven to be effective at pollutant removal. White et al. (2000) determined that a 1246 ha restored natural prairie wetland dominated by native vegetation (Schoenoplectus acutus, Stuckenia pectinata L. (formerly Potamogeton pectinatus), Myriophyllum albescens, Potamogeton richardsonii) removed $60 \%$ of $\mathrm{P}$ received from a beef slaughter house and municipal sewage effluent over a five-year period. S. pectinata is native to most of North America and can be invasive in eutrophic conditions but is also an important food plant for wildlife (Casey, 2010).

\subsection{Summary}

The shift from diverse wetland ecosystem communities to monotypic stands of Typha latifolia and other Typha species have often been attributed, in whole or in part, to cultural eutrophication (e.g. Moore et al., 1989; McJannet et al., 1995; Galatowitsch et al. 1999; Shih and Finkelstein, 2008). However, data to support this hypothesis is lacking for T. latifolia and other Typha species occurring in the Northern US and Canada. Although several previous field studies on Typha invasions have found evidence to support the eutrophication hypothesis, the effects of nutrient loading have been difficult to elucidate due to other confounding variables, particularly altered hydroperiod. Additionally, controlled and semi-controlled experiments conducted under artificial light (Wetzel and van der Valk, 1998), in greenhouse (Woo and Zedler, 2002) and in outdoor settings (Shipley and Keddy, 1988; Keddy et al., 2000) to determine Typha spp. response to $\mathrm{N}$ and $\mathrm{P}$ treatments have involved loading rates that in general far exceed levels observed in even the most polluted of natural wetlands.

The need to determine the effects of $\mathrm{N}$ and $\mathrm{P}$ loading at environmentally relevant levels is timely given that there is significant interest in building constructed wetlands for the purpose of 
removing nutrients from non-point sources at the watershed scale. Constructed wetlands technology has continued to emphasize the use of Typha, Phragmites and Scirpus spp. (bulrushes) including Schoenoplectus spp. (Kadlec and Wallace, 2009) in North America, Europe and Asia with the former two species which are commonly known to be invasive. Furthermore, constructed wetlands have a limited capacity to remove both $\mathrm{N}$ and $\mathrm{P}$. The widespread use of constructed wetlands could therefore introduce invasive species to unimpacted areas and, by releasing high levels of $\mathrm{N}$ and $\mathrm{P}$ in effluent, create suitable conditions for invasion by $T$. latifolia and possibly other invasive species. The effectiveness of constructed wetlands for removing $\mathrm{N}$ and $\mathrm{P}$ to prevent impact and cultural eutrophication appears highly limited and improved nutrient management should be emphasized.

There is currently effort underway to genetically engineer $T$. latifolia for use in constructed wetlands (Kadlec and Wallace, 2009). These genetically engineered varieties may introduce foreign genetic material into wild populations and potentially increase their invasiveness or have a negative impact on the survival of wild T. latifolia populations under certain conditions. There may also be risks to the wildlife that consume genetically modified varieties.

The lack of evidence demonstrating that $T$. latifolia and other invasive species commonly used in constructed wetlands are superior to native non-invasive species suggests that noninvasive species can be equally as effective in removing $\mathrm{N}$ and $\mathrm{P}$ without posing a potentially significant environmental risk. The use of native non-invasive species in constructed wetlands, particularly within or adjacent to ecosystems not significantly impacted by Typha latifolia and other invasive species is a preventative measure that must be considered.

The overall objective of this thesis was to test the eutrophication hypothesis by determining the response of $T$. latifolia to $\mathrm{N}$ and $\mathrm{P}$ concentrations representative of unimpacted (oligotrophic) wetlands and to $\mathrm{N}$ and $\mathrm{P}$ concentrations representative of eutrophicated natural ecosystems under semi-controlled laboratory conditions. Sub-objective 1 was to develop a protocol for rearing T. latifolia from seed to adult in order to provide specimens of known history uniform age and equal fitness for effective hypothesis testing. Sub-objective 2 was to determine the feasibility of conducting future experiments with the non-invasive species 
Schoenoplectus acutus and Schoenoplectus tabernaemontani under semi-controlled laboratory conditions for future experiments that could compare nutrient removal capability and competitive ability against $T$. latifolia under various nutrient regimes. Sub-objective 3 was to raise the issue of invasive species use in constructed wetlands and encourage research into the feasibility of utilizing native non-invasive species. 


\section{MATERIALS AND METHODS}

\subsection{Modified MOE Cleaning Protocol}

The procedure for cleaning all glassware and experimental unit vessels followed a modified Ontario Ministry of Environment (MOE) protocol, hence forth known as the Ryerson Protocol offered by K. Puddephatt, as preparation for all trials and experiments to prevent introducing contaminants as a potential source of experimental error, and was as follows:

1. All vessels, seed trays and laboratory equipment including glass and plastic pipettes, volumetric flasks, Petri dishes, graduated cylinders and glass beakers were carefully inspected for cracks, visible remnants of soil, algae or reagent residue and if necessary rinsed with municipal drinking water (MDW).

2. Prior to initial use at the beginning of each experiment all equipment was soaked for at least 15 minutes in Extran ${ }^{\circledR}$ (phosphate-free laboratory glassware washing detergent with nitrilotriacetic acid trisodium salt, $\mathrm{NaOH}$ and $\mathrm{Brij} 35^{\circledR}$ as the active ingredients) to remove all traces of organic contaminants.

3. All seed trays, Petri dishes and vessels used in T. latifolia experiments involving $\mathrm{N}$ and $\mathrm{P}$ treatments were then finger scrubbed with MDW to removal all traces of Extran. Volumetric flasks and graduated cylinders were thoroughly flushed with running MDW.

4. All equipment was then thoroughly rinsed in $10 \% \mathrm{HCl}$ to remove all traces of residue, Extran, monochloramine $\left(\mathrm{NH}_{2} \mathrm{Cl}\right)$ and/or dichloramine $\left(\mathrm{NHCl}_{2}\right)$ and their organic compound complexes $\mathrm{RNH}_{2} \mathrm{Cl}$ and $\mathrm{RNHCl}_{2}$, metals and bases.

5. All items were rinsed three times with distilled water, inverted and allowed to air dry. Any remaining distilled water in volumetric flasks was rinsed with the solvent to be used for reagents used in colourimetric water quality analysis.

6. Following the initial cleaning procedure described above, glassware used for inorganic nutrient analysis or for making T. latifolia grow media was subjected to each of the above steps except for soaking in Extran (step 2). 


\subsection{Germination Protocol}

A major component of this study was the development of a whole lifecycle protocol for Typha latifolia as the existing literature was very depauperate in this aspect. Thus, germination of seeds is the first crucial step. Seeds are removed from the inflorescence by pinching off a small grab of plumage (Figure 13) using a forceps which typically yielded over 300 seeds.

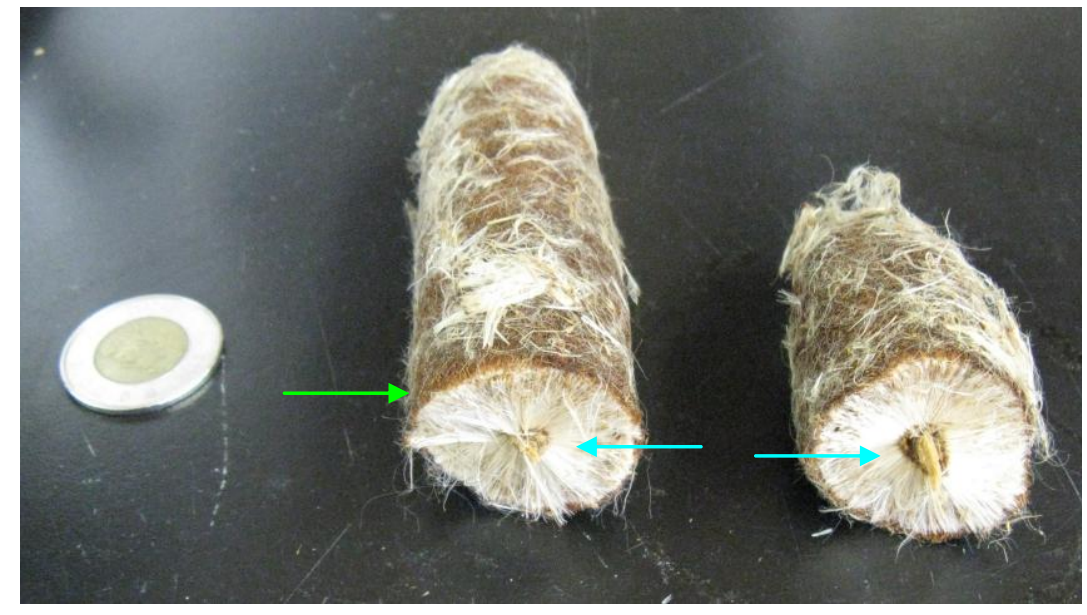

Figure 13. An internal view of the Typha latifolia inflorescence used for all germination trials and experiments illustrating the plumage (blue arrows) and seeds (green arrow).

\section{Photo by Mark Tiley}

Seeds were then placed into the designated vessel or Petri dish containing MDW with sufficient depth to effectively mix and separate individual seeds. Randomly selected seeds intended for one experimental unit vessel were then transferred to a second Petri dish filled to approximately $1.0 \mathrm{~cm}$ using a dissecting needle to which the seeds would stick when wet. The purpose of the transfer of seeds to a second Petri dish was to ensure that the correct number of seeds was transferred to an awaiting experimental unit given that seeds can be difficult to accurately count due to clumping with carpodium and flower parts. Seeds were then individually transferred using the dissecting needle to an awaiting vessel or experimental unit. The process of randomly selecting and transferring seeds was repeated until all experimental units contained the desired number of seeds. 


\subsubsection{Source of Seeds}

A single mature Typha latifolia inflorescence (flower) Figure 14, collected during the fall, 2010, in the Walsingham, Ontario region (Catherine Riley-Arenburg, Acorus Restoration office manager, personal communication) was received by Acorus Restoration and used in all propagation trials and experiments. Acorus Restoration also provided Schoenoplectus acutus and Schoenoplectus tabernaemontani seeds to test the hypothesis that $\mathrm{P}$ removal by a native would be as effective as T. latifolia. Trials to germinate Schoenoplectus seed under artificial light, natural light, on top soil and paper towel substrate and outdoors using seeds exposed to outdoor overwintering conditions were all unsuccessful and will not be detailed here.

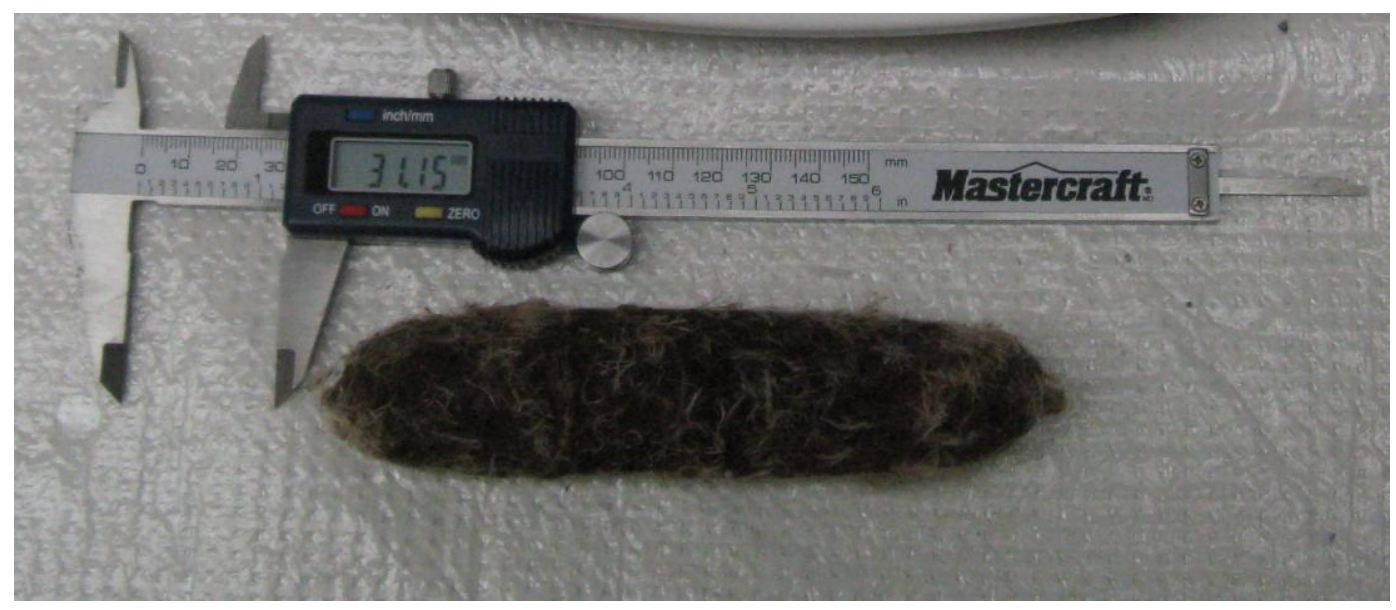

Figure 14. The ripe Typha latifolia inflorescence used for all germination and rearing trials and experiments

\subsubsection{Germination and Experimental Vessels}

Food-grade Snaptite ${ }^{\circledR} 3.1$ liter (L) polypropylene containers (Figure 15) were used as experimental unit vessels for the T. latifolia age 0 to 85 day (d) old seedling response to as 40 units could fit under a bench light bank $242 \mathrm{~cm}$ in length, $67.4 \mathrm{~cm}$ in width and $51.2 \mathrm{~cm}$ to bulb height, henceforth referred to as light bank 1 (LB1), with ten replicates/treatment. The $3.1 \mathrm{~L}$ vessels were also considered suitable for the subsequent $T$. latifolia response to $\mathrm{N}$ and $\mathrm{P}$ experiment as preliminary trials indicated that the interior dimensions of the $3.1 \mathrm{~L}$ vessel $(16.4$ $\mathrm{cm}$ in height, $14.0 \mathrm{~cm}$ wide and $20.0 \mathrm{~cm}$ in length) were easily handled when containing wet sediment and approximately $1 \mathrm{~L}$ of surface water without spilling. The interior dimensions of the 
bottom of the container were $10.0 \mathrm{~cm}$ in width and $16.4 \mathrm{~cm}$ in length. The clear plastic had a negligible effect on photosynthetically active radiation (PAR) with a decrease in 3 microeinsteins per meter squared per second $\left(\mu \mathrm{E} \mathrm{m}^{-2} \mathrm{~s}^{-1}\right)$ observed by holding the Field Scout light meter under a light bank and moving the vessel over the light meter sensor.

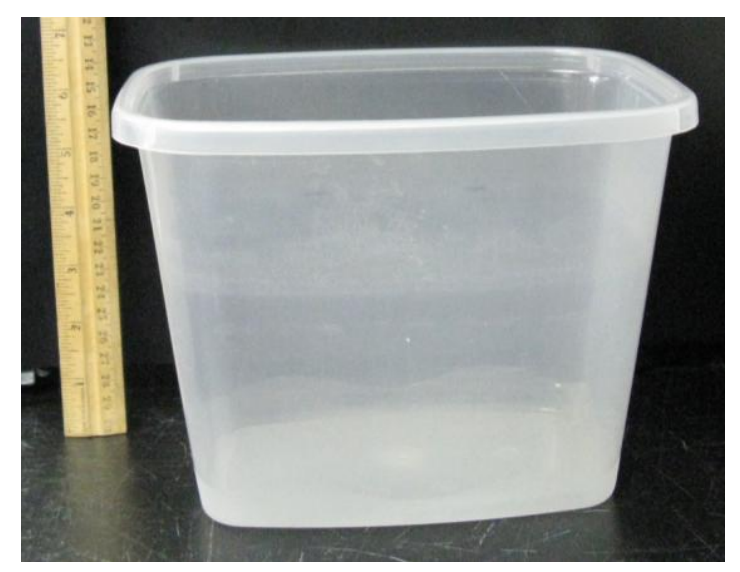

Figure 15. Snaptite 3.1 L polypropylene vessel.

Polypropylene is chemically resistant to organic solvents, acids and bases (Ipex, 2001). Information on the chemical resistance of polypropylene to acids, bases and gases that may be naturally produced in microcosms (e.g. nitric acid $\left(\mathrm{HNO}_{3}\right)$; hydrogen sulfide $\left(\mathrm{H}_{2} \mathrm{~S}\right)$; ammonia $\left(\mathrm{NH}_{3}\right)$ phosphoric acid $\left(\mathrm{H}_{3} \mathrm{PO}_{4}\right)$, in addition to other compounds, was compiled by Ipex Inc., (2001), Borealis (2001) and Engineering Toolbox (2013). A summary of the compounds assessed by Engineering Toolbox (2013) for chemical reactivity between polypropylene and compounds that may occur within microcosm wetlands is provided in Appendix F. Microcosms were defined by Fraser and Keddy (1997) as small ecosystems. In this experiment, each microcosm consisted of a simplified ecosystem consisting of sediment, water, micoflora and microfauna introduced via the sediment, air and water, and the T. latifolia plants.

All labels were removed from newly purchased containers and both containers and lids were washed as per the glassware cleaning protocol before use. The entire bottom $6 \mathrm{~cm}$ of each vessel was covered in black duct tape (Figure 16) to simulate natural conditions by preventing direct light from contacting subsurface sediments on the sides of the container. The addition of 1.205 $\mathrm{ml}$ of water measured using a graduated plastic water jug indicated the $6 \mathrm{~cm}$ mark below which 
black duct tape was applied. All vessels were numbered and randomly assigned to one of the four treatments.

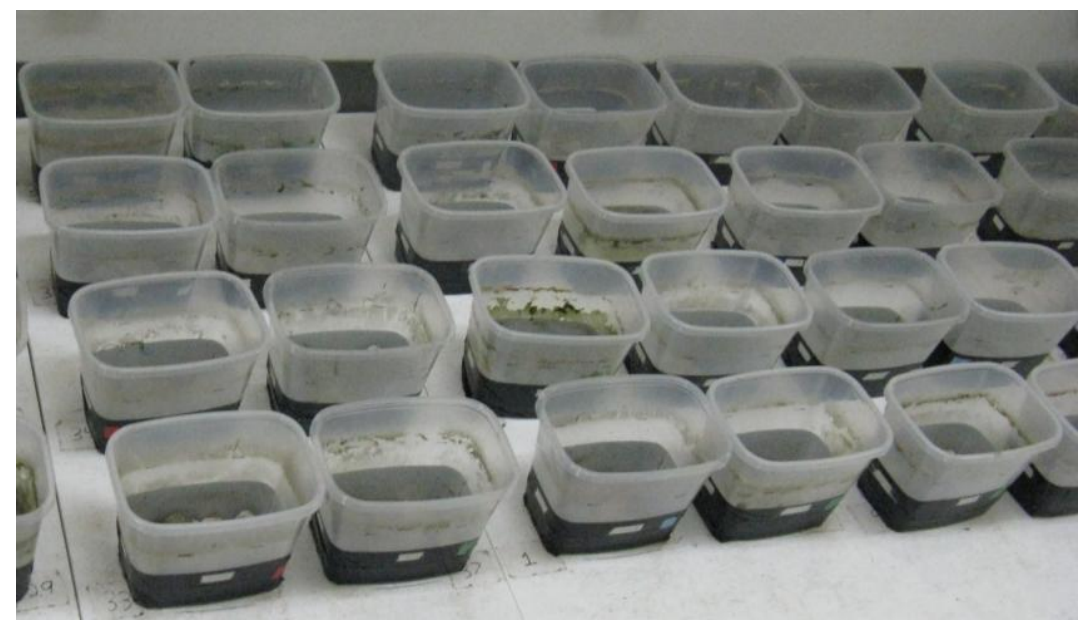

Figure 16. Microcosm vessels with black duct tape covering the lower $6 \mathrm{~cm}$ of each vessel and identifying labels after the removal of Typha latifolia shoots.

\subsubsection{Germination Lighting}

Light bank 2 (LB2) which shared the same bench as LB1 was used to confirm that viable seeds were correctly being distinguished from carpodium based on percent germination where carpodium should have 0 percent germination. As for LB1, LB2 was fitted with Dura-Test T8 Vita-Lite bulbs, two of which had been removed for the purpose of providing the correct lighting for developing algal cultures. After extensive research on commercially available light bulbs used for plant propagation, Puddephatt (2013) identified the Dura-Test T8 Vita-Lite bulb as most closely resembling natural solar irradiation and it had also previously been used by the USEPA (Lewis et al., 1994) and Environment Canada (2007). Details of the Dura-Test T8 Vita-Lite bulb are provided in Puddephatt (2013). PAR was measured directly over the middle of each Petri dish using a Spectrum Technologies Field Scout Type 2 (cable attached sensor), light meter taped to $30 \mathrm{~cm}$ ruler.

\subsubsection{Seedling Response to Phosphorus}

All sixteen bulbs installed into LB1 at the start of the seedling response to $\mathrm{P}$ were operating. Light intensity was measured at the center of each vessel with the Field Scout Type 2 light meter 
taped to one of four $2.54 \mathrm{~cm}$ ( 1 in) thick pieces of styrofoam, cleaned according to Ryerson cleaning protocol, after the addition of the $650 \mathrm{ml}$ of phosphorus treatment to document light conditions before the addition of seeds and the onset of germination. Each piece of Styrofoam was allocated to a specific treatment to avoid cross contamination between treatments. Light measurements were collected approximately three hours before seeds were added on May 25, 2012 (day 0).



Figure 17. Light sensor attached to styrofoam to determine light intensity immediately prior to seeds being added.

\subsubsection{Percent Germination of Viable Seeds.}

To ensure that all seeds added to all seedling $\mathrm{P}$ treatment replicates were potentially viable and percent germination data did not incorporate error caused by the addition of carpodium (nonviable seed), an investigation was run in parallel with the percent germination experiment (section 2.2.4) to confirm that all seeds added to reference and $\mathrm{P}$ treatments were potentially viable. If identified correctly, carpodium would have 0 percent germination. Approximately ten randomly selected seeds were then transferred to one of twelve awaiting Petri dishes containing standing MDW following the seed germination protocol (section 2.2). Twelve Petri dishes were placed under a second bench light bank (hence forth referred to as light bank 2 (LB2)). As LB2 is located within $2 \mathrm{~m}$ of LB1, air temperature and relative humidity conditions monitored under 
LB1 were considered representative of LB2 temperature and RH conditions. Petri dish locations were randomized on the first day only as the experiment was conducted over four days.

\subsubsection{Percent Germination of Seeds added to Reference and $P$ treatment Microcosms}

Three randomly selected $T$. latifolia seeds were added to each reference and phosphorus treatment microcosm ( $3 \times 40$ for a total of 120 seeds) on day 0 using the procedure following the germination protocol (section 2.2). Percent germination was monitored from day 2 to day 6 .

\subsection{Seedling Response to Phosphorus.}

To test the hypothesis that increased $\mathrm{P}$ concentrations will result in increased T. latifolia post germination seedling survival and biomass at concentrations representative of $\mathrm{P}$ concentrations observed in surface water and agricultural runoff, four treatments of $0,50,100$ and $300 \mu \mathrm{g} \mathrm{PO}_{4}-\mathrm{P} / \mathrm{L}$ were selected based on surface water P levels spanning the range of trophic levels defined by Wetzel (1983) with the 0 (no P added) treatment serving as a reference and to simulate oligotrophic (nutrient poor) sediments. A treatment of $300 \mu \mathrm{g} \mathrm{PO}_{4}-\mathrm{P} / \mathrm{L}$ was selected as $\mathrm{P}$ in agricultural runoff can exceed $300 \mu \mathrm{g} \mathrm{PO}_{4}-\mathrm{P} / \mathrm{L}$ (Yates and Prasher, 2009). The $3.1 \mathrm{~L}$ polypropylene vessels described in section 2.2.2 were used to construct microcosms.

\subsubsection{Formulated Sediment}

It was extremely crucial that the substrate used to conduct experiments testing the effects of $\mathrm{P}$ loading on T. latifolia growth, survival and biomass be low in $\mathrm{P}$ so as not to skew experimental results. Thus, an organic substrate with oligotrophic levels of $\mathrm{P}$ was crucial. Two of three commercially-available soils, including Presidents Choice Black Earth topsoil (PCTS) used in MOE experiments (Puddephatt, 2013) were considered but did not provide details on $\mathrm{P}$ availability. Thus, PCTS and Hillview Black Earth (HBE) topsoils were tested for P using the Deionized Water Extractible P Method (DWEPM) (Self-Davis et al., 2009) and the Murphy and Riley (1962) ascorbic acid method. The DWEPM procedure is summarized in Figure 18 and described below. 


\subsubsection{Deionized Water Extractible Phosphate Method}

The DWEPM described in Self-Davis et al. (2009) was modified by using a VWR orbital shaker instead of the specified reciprocating or end-to-end shaker. The orbital shaker was set at $175 \mathrm{rpm}$ which was sufficient to agitate the prescribed $2.0 \mathrm{~g}$ of sediment for one hour, oven-dried to constant weight, to $20 \mathrm{ml}$ of deionized water placed into a $40 \mathrm{ml}$ centrifuge tube. Instead of the indicated $0.45 \mu \mathrm{m}$ filter, a $0.22 \mu \mathrm{m}$ polypropylene filter was used to improve data accuracy of the phosphate analysis by removing greater amounts of microbes and colloids (Haygarth $e t$ al., 2009). Scotts Garden Essentials Soil (SGES), known to be high in P, was used as a reference to validate the modified methodology.

Three randomly selected $10 \mathrm{~g}$ samples of PCTS and SGES were dried to constant weight at $60^{\circ} \mathrm{C}$ and sieved through a $2 \mathrm{~mm}$ mesh screen. The HBE was dry weighted but not sieved. To decant the water extracted $P$ from the sediment, samples were centrifuged for 10 minutes at 6000 rpm. $15 \mathrm{ml}$ of the decanted portion of the sample was drawn by syringe with a piece of Tygon tubing attached. The Tygon tubing was then removed and a filter cartridge containing a $0.22 \mu \mathrm{m}$ filter paper previously flushed with deionized water was attached to the syringe. The sample was then filtered into a second test tube and acidified to $\mathrm{pH} 2.0$ with two drops of concentrated $\mathrm{HCl}$ to preserve the sample and prevent $\mathrm{P}$ precipitation. A small piece of Parafilm was placed over the test tube mouth to prevent evaporation or entry of airborne contaminants until all decanted samples had been filtered. $5.0 \mathrm{ml}$ of filtered samples were then transferred to a second test tube to which $0.8 \mathrm{ml}$ of ascorbic acid mixed reagent was added and absorbance determined within 30 minutes. The modified ascorbic acid procedure as described below was then followed to obtain phosphate concentrations for each brand of topsoil. 
Step 1. Sieve soil through $2 \mathrm{~mm}$ sieve and oven dry to constant weight Presidents Choice Black Earth (PCBE), Hillsview Black Earth (HBE), Scotts Garden Essentials Soil (SGES)

Step 2. Add $2.0 \mathrm{~g}$ (DW) of soil $+20 \mathrm{ml}$ of distilled water into a $40 \mathrm{ml}$ centrifuge tube and agitate for $1 \mathrm{hr}$ on orbirtal shaker set at $175 \mathrm{rpm}$.

Step 4. Using syringe with Tygon tubing, previously cleaned using Ryerson cleaning protocol, draw sample into the syringe, remove tygon tubing and attach cartridge containing $0.22 \mu \mathrm{m}$ filter and filter decanted sample into a $15 \mathrm{ml}$ test tube (test tube 1 ).

Add two drops of $\mathrm{HCl}$ to achieve a pH of 2.0 to prevent precipitation of $\mathrm{P}$. Cover with Parafilm and refrigerate for up to $24 \mathrm{hr}$ if not analyzed within $1 \mathrm{hr}$ immediately after the sample is transferred into the second test tube.

Step 5. Using a glass pipette, transfer $5.0 \mathrm{ml}$ of filtered sample into a second $15 \mathrm{ml}$ test tube (test tube 2) and add $0.8 \mathrm{ml}$ of ascorbic acid mixed reagent.

Step 6. Add two drops of $\mathrm{pH} 2.0 \mathrm{HCI}$ to prevent phosphate precipitation, cover with Parafilm and refrigerate for up to $24 \mathrm{hr}$ if not analyzed within $1 \mathrm{hr}$ after the sample is transferred.

Step 7. Determine absorbance of sample within 30 minutes of adding mixed reagent.

Figure 18. Flow chart summarizing the Deionized Water Extractible Phosphate Method.

\section{Ascorbic Acid Method}

A modified Murphy and Riley (1962) method, described as the ascorbic acid method in APHA (1998), was used to determine deionized water extractable phosphate and pore water phosphate. The ascorbic acid reagent is comprised of sulfuric acid, ammonium molybdate, potassium antimonyl tartate and ascorbic acid. A mixed reagent containing sulfuric acid, 
ammonium molybdate and antimonyl tartate was made according to APHA (1998) and stored in a glass amber jug (reagent $\mathrm{A})$. When all water sampling had been completed a mixed reagent was made by adding $0.132 \mathrm{~g}$ of ascorbic acid into a $25.0 \mathrm{ml}$ volumetric flask to which reagent $\mathrm{A}$ was added to the $25.0 \mathrm{ml}$ mark to make mixed reagent $\mathrm{B}$. The acorbic acid reduces phosphomolybdic acid and produces a blue colour proportional to the amount of phosphate in the sample. Mixed reagent B remains stable for 24 hour (hr) (APHA, 1998). The method was modified by reducing sample volume and, proportionally, reagent weights and solvent volumes by a factor of 10 to reduce reagent consumption and waste such that $0.8 \mathrm{ml}$ of mixed reagent was added to $5.0 \mathrm{ml}$ of filtered sample water instead of $8.0 \mathrm{ml}$ of reagent being added to $50.0 \mathrm{ml}$ of sample water. To improve sample accuracy a $25 \mathrm{~mm}$ diameter 0.22 micometers $(\mu \mathrm{m})$ polypropylene filter was used instead of the standard $0.45 \mu \mathrm{m}$ filter paper to increase the removal of colloids, cells and microbes $<0.45 \mu \mathrm{m}$ which are a source of $\mathrm{P}$. All other procedures were followed according to APHA (1998).

\section{$\underline{\text { Cadmium Reduction Method }}$}

For the seedling response to $\mathrm{P}$ experiment, it was desirable to have levels of $\mathrm{N}$ that were non-limiting. To determine whether bioavailable $\mathrm{N}$ levels in Presidents Choice Black Earth topsoil (PCTS) may be a limiting factor to T. latifolia seedling growth and survival, nitrate $\left(\mathrm{NO}_{3^{-}}\right.$ $\mathrm{N}+\mathrm{NO}_{2}-\mathrm{N}$ ) levels in the surface water of a $3.1 \mathrm{~L}$ microcosm containing flooded PCTS were determined by analyzing one sample collected by a $60 \mathrm{ml}$ syringe using the standard cadmium reduction method described in APHA (1998). The method was modified by reducing the sample volume and, proportionally, reagent weights and volumes by a factor of 10 to reduce $\mathrm{Cd}$ containing wastewater and reagent consumption. The City of Toronto drinking water summary reports indicated nitrate levels averaging $0.41-0.46 \mathrm{mg} \mathrm{NO}-\mathrm{N}+\mathrm{NO}_{2}-\mathrm{N} / \mathrm{L}$ from 2006 to 2012 (City of Toronto 2013b) and considered biologically significant (Dr. A. Laursen, Ryerson University, personal communication). The modified cadmium reduction method was therefore used to determine whether laboratory MDW nitrate levels were similar to the concentrations reported in City of Toronto (2013b) in order to estimate the total $\mathrm{N}$ added to grow media and the $\mathrm{N}$ : $\mathrm{P}$ ratios for each treatment. The details of the Cd reduction method are as follows: 


\section{Background}

The cadmium $(\mathrm{Cd})$ reduction method is recommended for samples with concentrations $\leq$ $1.0 \mathrm{mg} / \mathrm{L}$ (PPM) (APHA, 1998). $\mathrm{NO}_{3}{ }^{-}$is reduced to $\mathrm{NO}_{2}{ }^{-}$in the presence of $\mathrm{Cd}$. The latter reacts with colour reagent and is therefore quantifiable using colourimetric techniques.

\section{Buffer Solution}

- Dissolve $13.0 \mathrm{~g} \mathrm{NH}_{4} \mathrm{Cl}$ and $1.7 \mathrm{~g}$ Ammonium chloride disodium ethylenediamine tetraacetate (EDTA) in $900 \mathrm{ml}$ Millipore water using a clean $1000 \mathrm{ml}$ beaker. $\mathrm{NO}_{3}{ }^{-}$is reduced to $\mathrm{NO}_{2}^{-}$in the presence of $\mathrm{Cd}$, the latter reacting with colour reagent and therefore quantifiable with colourimetric technique.

- Adjust to $\mathrm{pH} 8.5$ with $\mathrm{NH}_{4} \mathrm{OH}$.

- Dilute to $1.0 \mathrm{~L}$ in a clean $1000 \mathrm{ml}$ volumetric flask

\section{Colour Reagent}

- To $800 \mathrm{ml}$ millipore water add $100 \mathrm{ml} 85 \%$ phosphoric acid and $10.0 \mathrm{~g}$ sulfanilamide.

- After dissolving sulfanilamide completely, add $1.0 \mathrm{~g}$ N-(1-naphyl)-ethylenediamine dihydrochloride. Mix to dissolve.

- Dilute to $1.0 \mathrm{~L}$.

- According to the APHA (1998) colour reagent remains chemically stable for approx. 1 month under refrigeration in a dark bottle.

\section{$\underline{N O}_{3}=-N$ Standard Curve}

- Use potassium nitrate $\left(\mathrm{KNO}_{3}\right)$ or sodium nitrite $\left(\mathrm{NaNO}_{2}\right)$ for standard curves as per APHA (1998) protocol.

- Dissolve $0.7218 \mathrm{~g} \mathrm{KNO}_{3}\left(=0.007139 \mathrm{~mol} \mathrm{KNO}_{3}=0.1 \mathrm{~g} \mathrm{~N}\right)$ dried at $80-84^{\circ} \mathrm{C}$ to constant weight (APHA recommends $60^{\circ} \mathrm{C}$ ) for $24 \mathrm{hr}$. Dilute to $1000 \mathrm{ml}$ and invert to mix to make $100 \mathrm{mg} \mathrm{NO}_{3}-\mathrm{N} / \mathrm{L}$. 
- Stock can be stored in fridge for at least 6 months with $2 \mathrm{ml} \mathrm{CHCl} / \mathrm{L}$.

- Make $10 \mathrm{mg} \mathrm{NO}-\mathrm{N}$ intermediate $\mathrm{NO}_{3}-\mathrm{N}$ solution by diluting $100 \mathrm{ml}$ of $100 \mathrm{mg} \mathrm{NO}-\mathrm{N} / \mathrm{L}$ stock solution with $900 \mathrm{ml}$ Millipore water (1:10) using a 1.0 L volumetric flask to obtain $10 \mathrm{mg} \mathrm{NO}-\mathrm{N} / \mathrm{L}$.

- Create the following standards: 0.05, 0.1, 0.2, 0.5, 0.8, and $1.0 \mathrm{mg} \mathrm{NO}-\mathrm{N} / \mathrm{L}$ by diluting the following intermediate solution to $100 \mathrm{ml}$ using $100 \mathrm{ml}$ volumetric flasks: $0.5,1.0$, 2.0, 5.0, 8.0, $10.0 \mathrm{ml}$.

\section{$\underline{\text { NO}}_{2}=\underline{N}$ Standards}

- $\mathrm{NO}_{2}{ }^{-}$standards are necessary to ensure that the column is reducing $\mathrm{NO}_{3}{ }^{-}$efficiently.

- To make a $10.0 \mathrm{mg} \mathrm{NO}_{2}{ }^{-} \mathrm{N} / \mathrm{L}$ stock, $0.0493 \mathrm{~g} \mathrm{NaNO}_{2}$ to $1.0 \mathrm{~L}$ millipore water. Preserve with $1 \mathrm{ml} \mathrm{CHCl}{ }_{3}$ (chloroform).

- Or, following APHA, add $1.232 \mathrm{~g} \mathrm{NaNO}_{2}$ to $1.0 \mathrm{~L}$ Millipore water for $250 \mathrm{mg} \mathrm{NaNO}_{3}$ $\mathrm{N} / \mathrm{L}$ or $250 \mu \mathrm{g} \mathrm{NaNO}_{2}-\mathrm{N} / \mathrm{ml}$. Preserve with $1 \mathrm{ml} \mathrm{CHCl}_{3}$ (chloroform).

- Pass same concentration of $\mathrm{NO}_{2}-\mathrm{N}$ and $\mathrm{NO}_{3}-\mathrm{N}$ standards through the column to determine the reducing efficiency of the column and to confirm colour reagent and buffer is effective.

$2.5 \mathrm{ml}$ of water sample is added to $7.5 \mathrm{ml}$ of buffer in a $15 \mathrm{ml}$ test tube and passed through a $\mathrm{Cd}$ reducing column using a pump. $0.4 \mathrm{ml}$ of colour reagent is then added to the collected sample, reduced to $\mathrm{NO}_{2}{ }^{-}$, to obtain a colour reaction, the intensity of which is proportional to the amount of $\mathrm{NO}_{2}^{-}$in the sample, and analyzed to determine absorbance.

\section{Colourimetric Sample Analysis}

A Perkin Elmer UV/VIS Lamda 20 spectrometer was used to analyze all phosphate and nitrate + nitrite samples. The spectrometer wavelength was set at $880 \mathrm{~nm}$ and $543 \mathrm{~nm}$ as specified in APHA (1998) for phosphate and nitrate analysis respectively. Six standards of known concentration and two Millipore water blanks were used to generate standard curves. In all cases, sample concentrations were within the concentration range of the standard curve except 
for deionized water extracted P from SGES. The R-squared values of the standard curves always exceeded 0.99. At least one $\mathrm{P}$ and $\mathrm{N}$ standard was analyzed to ensure data accuracy for each sample run. The same cuvette was used for all sample water analysis. To prevent sample cross contamination, the cuvette was rinsed with distilled water then rinsed with $10 \% \mathrm{HCl}$ followed by three rinses with distilled water. The cuvette was inverted and shaken to remove nearly all of the distilled water. The cuvette exterior was thoroughly wiped with Kimwipe paper before each sample analysis. The order of sample analysis was from lowest to highest colour intensity which was equivalent to analyzing from low concentration to high concentration.

\subsubsection{Formulated Sediment Top Soil Selection}

The phosphate levels in PCTS were very low at $0.03 \mu \mathrm{g} \mathrm{PO}-\mathrm{P} / \mathrm{L}$ which was less than the $10.0 \mu \mathrm{g} \mathrm{PO}_{4}-\mathrm{P}$ below which the accuracy of the ascorbic acid method is unreliable (APHA, 1998). The phosphate extracted from HVTS and SGES was $192.4 \mu \mathrm{g} \mathrm{PO}_{4}-\mathrm{P} / \mathrm{L}$ and $>2159.1 \mu \mathrm{g}$ $\mathrm{PO}_{4}-\mathrm{P} / \mathrm{L}$ respectively. A concentration of $16.2 \mathrm{mg} \mathrm{NO}_{3}-\mathrm{N}+\mathrm{NO}_{2}-\mathrm{N} / \mathrm{L}$ observed in the single sample collected from surface water with PCTS as the substrate suggested that PCTS had available $\mathrm{N}$ in sufficient quantities that would not likely be limiting to $T$. latifolia survival and growth in the event that soil $\mathrm{NH}_{4}-\mathrm{N}$ were low and added available $\mathrm{N}$ in grow media was insufficient during the early stages of the experiment.

The PCTS was therefore selected as the topsoil component of a formulated sediment recipe of $80 \%$ sand and $20 \%$ topsoil given the observed very low phosphate concentrations. The PCTS consisted of $80 \%$ organic matter (Presidents choice staff representative, personal communication) which provides a source of carbon (C) and, through microbial mineralization processes, produces electrons which are transported through microbial electron transport chains to produce adenosine triphosphate.

A high sand content was added to achieve clear water conditions, improve the detection of newly emerging ramets, and to provide a substrate commonly used in formulated sediments described in Environment Canada (1995) (e.g. 69 \% sand in Naylor and Rodriques (1994) and 25-75 \% sand in Hamr et al. (1994)). As Typha spp. can be grown hydroponically (Ye et al., 1997; Woo and Zedler, 2002), a high sand content was considered feasible despite the low 
organic matter and nutrient content and would minimize error associated with turbidity in future experiments involving colourimetric water quality analysis. As high seedling mortality can occur in flooded anoxic sediments (Stevens and Hoag, 2000), as was observed in the first preliminary propagation trial, the high porosity of sand substrate may facilitate the diffusion of oxygen into the sediments and improve seedling survival and growth. Several studies involving T. latifolia have utilized sand and/or topsoil as a rooting substrate (e.g. Wetzel and van der Valk, 1998; Kercher and Zedler, 2004; Wang et al., 2008).

\subsubsection{Sediment Preparation and Percent Moisture Content}

To ensure that all microcosms received the same weight of sediment, differences in moisture content had to be corrected for such that each microcosm received the same amount of sediment in dry weight. All sand and PCTC was sieved through an M\&L Testing Equipment Co. 2mm metal sieve. The dry weight of sand and top soil was determined separately. The moisture content of sand and PCTS was determined by first placing the empty, $18.9 \mathrm{~L}$ mixing bucket (Figure 19), cleaned according to the Ryerson cleaning protocol, on a Starfrit digital scale (11 kg capacity) and then adding sand or sediment until $5.0 \mathrm{~kg}$ had been added which was less than half the volume of the mix bucket. The custom-made mixing bucket was made of high density

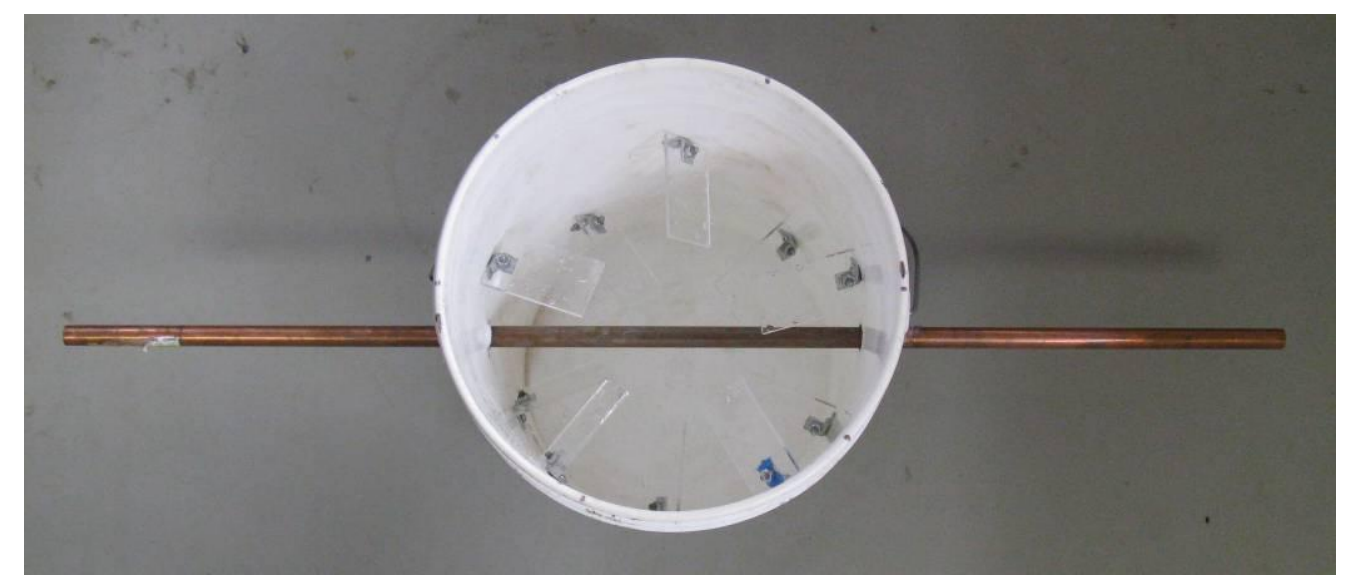

\section{Figure 19. The 18.9 L sediment mixing bucket.}

polyethylene and fitted with ten $7.8 \mathrm{~cm}$ x $5.0 \mathrm{~cm}$ baffles attached with stainless steel L brackets and bolts set at various angles. Duct tape was used to seal the holes through which a $1 / 2$ inch (in) $(1.27 \mathrm{~cm})$ I.D. copper pipe was fitted. The lid was tightly secured to the bucket and with one end 
of the copper pipe resting on an elevated solid surface and the bucket was rotated end over end 25 times. Immediately after mixing, five samples of approximately 5 to $10 \mathrm{~g}$ and were collected from different locations at the sediment surface and were placed into a pre-weighed $80 \mathrm{ml}$ glass beaker and oven dried at $60^{\circ} \mathrm{C}$ to constant weight.

To calculate percent moisture, sediment dry weight was divided by sediment wet weight $\mathrm{x}$ 100. The mean percent moisture content of the five samples was then used to convert each 5 kilogram $(\mathrm{kg})$ batch of topsoil sediment to dry weight with the total dry weight value divided by 41. An equivalent amount of sediment was added for one extra microcosm (41) to ensure that a sufficient amount of soil from each batch was available for all 40 microcosms to account for minor spills. The oven-drying of sand stored in the laboratory to constant weight indicated a moisture content of $0 \%$. Each microcosm received $1.0 \mathrm{~kg}$ as dry weight (DW) of mixed sand and topsoil (800 g sand (DW) + $200 \mathrm{~g}$ topsoil (DW)). After the sediment and sand had been added separately, each microcosm vessel, with the corresponding labeled lid firmly secured, was turned end over end 25 times to thoroughly mix the formulated sediment.

\subsubsection{Environmental Conditions}

\subsubsection{Lighting and Temperature}

The vessels were arranged in ten rows of four under light bank 1 (LB1) with individual vessel location being randomly selected every three or four days using randomizing software to eliminate photosynthetically active radiation (PAR), measured as $\mu \mathrm{E} \mathrm{m}^{-2} \mathrm{~s}^{-1}$, as a factor in $T$. latifolia response to the $\mathrm{P}$ treatments. Observed minimum and maximum temperatures and instantaneous relative humidity $(\mathrm{RH})$ measurements were recorded approximately daily using a Noma digital temperature thermometer/RH sensor. As daily temperatures were not collected over the course of $24 \mathrm{hrs}$, observed minimum and maximum values are reported and are an approximation of the true minimum and maximum temperatures. 


\subsubsection{Soil Moisture Monitoring}

Soil moisture content was monitored weekly to ensure that the watering regimen provided moist - wet soil conditions throughout the experiment. Soil moisture was monitored with a Spectrum Technologies Inc. Economy Soil Moisture Tester which provides a quantitative rank of soil moisture levels as being either dry (rank $=0)$, average dry (2-4), average (4-6), average wet (6-8) and wet (10). Six standardized sample locations considered representative of soil moisture conditions throughout a given microcosm were established (Figure 20).

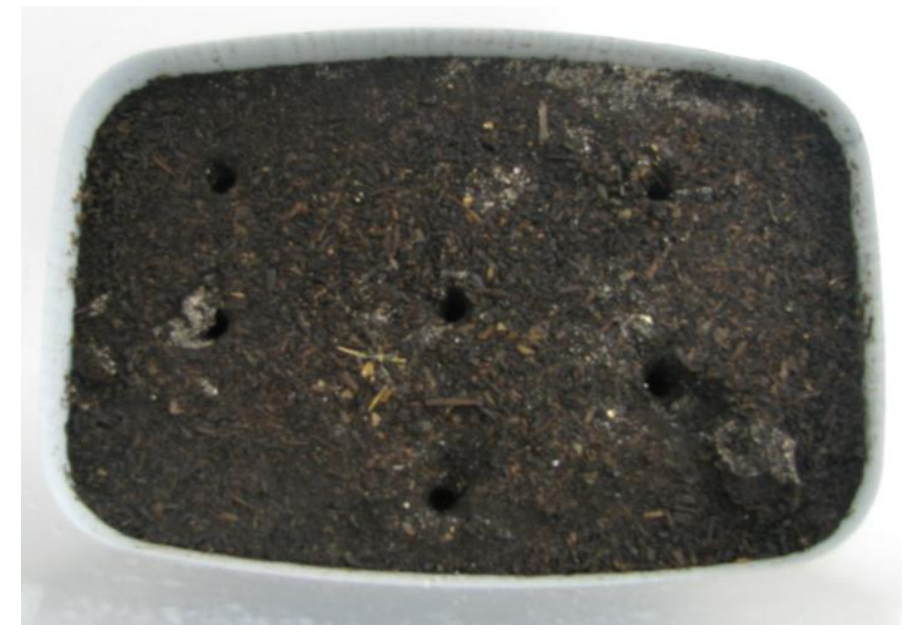

Figure 20. Soil moisture monitoring locations

Initially moisture conditions were determined immediately before and after watering. However, for moisture conditions from week 5 onwards, only sediment moisture conditions immediately prior to watering were measured. Moisture levels were measured approximately $2 \mathrm{~cm}$ below the soil surface and, with the tip of the probe in contact with the vessel bottom, at a soil depth of approximately $5.5 \mathrm{~cm}$. As soil moisture testing introduced oxygen into the sediments which may affect sediment root development, oxidation reduction potential (ORP), microbial communities and potentially damage roots, soil moisture testing was restricted to microcosms which had experienced $100 \%$ mortality after six weeks. Microcosms that had experienced $100 \%$ mortality were treated the same way as microcosms with seedlings and continued receiving the same $\mathrm{P}$ treatment throughout the experiment to serve as a physical presence and to enable soil monitoring without the risk of injury to seedling roots and the alteration of sediment redox conditions. 


\subsubsection{Seedling Addition to Experimental Vessels}

After each vessel had received $1.0 \mathrm{~kg}$ dry weight (DW) of mixed sediment, vessels were randomly assigned to one of the four treatments. A $50 \mathrm{mg} / \mathrm{L} \mathrm{PO}_{4}-\mathrm{P}$ stock solution was made according to APHA (1998) by adding $2.193 \mathrm{~g} \mathrm{KH}_{2} \mathrm{PO}_{4}$ with the modification that MDW was used as the solvent instead of Millipore water to provide the same amount of MDW constituents to each microcosm. Seven 1.0L batches for each of the 50, 100 and $300 \mu \mathrm{g} \mathrm{PO}_{4}-\mathrm{P} / \mathrm{L}$ treatments were made by adding 1.0, 2.0 and $6.0 \mathrm{ml}$ of stock solution calculated using the dilution formula $\mathrm{C}_{1} \mathrm{~V}_{1}=\mathrm{C}_{2} \mathrm{~V}_{2}$ to the $1.0 \mathrm{~L}$ mark with MDW where $\mathrm{C}_{1} \mathrm{~V}_{1}=$ initial concentration and volume and $\mathrm{C}_{2} \mathrm{~V}_{2}=$ the final concentration and volume. $650 \mathrm{ml}$ of MDW (reference water), or the appropriate phosphorus treatment, was added to each vessel to achieve approximately $1.0 \mathrm{~cm}$ of standing water. A $60 \mathrm{ml}$ syringe was used to wash all sediment off the vessel walls using some of the $650 \mathrm{ml}$ of $\mathrm{P}$ treatment water added. Calculation details for determining reagent weights and solvent volumes of grow media stocks and treatment concentrations for all grow media are provided in Appendix B.

$650 \mathrm{ml}$ of MDW/P treatment were added to each microcosm to ensure that approximately $1 \mathrm{~cm}$ of standing water was available when seeds were initially added as Sifton (1959) had observed higher germination rates with seeds submerged compared to seeds placed on a moist artificial substrate. Furthermore, the locations where germinated seeds became rooted would be randomized as there was no control over where the seeds would take root as seeds were agitated off of the dissecting needle.

\subsubsection{Grow Media Preparation}

A modified grow media used by Weng et al. (2006) (Table 5) to simulate primary and secondary waste waters was selected as it had been effective in growing T. latifolia clones in gravel and T. latifolia in preliminary trials. As done in preliminary trials, the grow media was modified by reducing the concentration of ammonium sulfate $\left(\mathrm{NH}_{4}\right)_{2} \mathrm{SO}_{4}$ used by Weng et al . (2006) by $50 \%$ to reduce the risk of ammonia toxicity to newly germinated seedlings. 
Table 5. The modified grow media used in the Typha latifolia post germination response to phosphorus loading adopted from Weng et al. (2006). Micronutrients were made and stored in $250 \mathrm{ml}$ volumes.

\begin{tabular}{|c|l|c|c|c|}
\hline Stock & \multicolumn{1}{|c|}{ Reagent } & $\mathbf{g} / \mathbf{L}$ & $\mathbf{g} / 250 \mathrm{ml}$ & $\begin{array}{c}\text { Volume of stock added } \\
\text { to each 1.0L of grow } \\
\text { media solution }\end{array}$ \\
\hline $\mathbf{1}$ & $\mathrm{MnSO}_{4} \cdot \mathrm{H}_{2} \mathrm{O}$ & 0.098 & 0.392 & 4 \\
$\mathbf{1}$ & $\mathrm{CaCl}_{2} \cdot \mathrm{H}_{2} \mathrm{O}$ & 0.256 & 1.024 & 2 \\
$\mathbf{2}$ & $\left(\mathrm{NH}_{4}\right)_{2} \mathrm{SO}_{4}$ & 5.2395 & - & $1^{\mathrm{b}}$ \\
$\mathbf{3}$ & $\mathrm{MgSO}_{4} \cdot 7 \mathrm{H}_{2} \mathrm{O}$ & 2.56 & 10.24 & 2 \\
$\mathbf{4}$ & $\mathrm{FeCI}_{3} \cdot 6 \mathrm{H}_{2} \mathrm{O}$ & 0.0512 & 0.2048 & 2 \\
\hline
\end{tabular}

b $50 \%$ of $\left(\mathrm{NH}_{4}\right)_{2} \mathrm{SO}_{4}$ used by Weng et al. (2006).

Micronutrient stock solutions were made with Millipore water as the solvent. $\mathrm{MnSO}_{4} \cdot \mathrm{H}_{2} \mathrm{O}$ and $\mathrm{CaCl}_{2} \cdot 2 \mathrm{H}_{2} \mathrm{O}$ were maintained as a single stock solution. All grow media contained $1.11 \mathrm{mg}$ $\mathrm{NH}_{4}-\mathrm{N} / \mathrm{L}$. A $50 \mathrm{mg} / \mathrm{L} \mathrm{PO}_{4}-\mathrm{P}$ stock solution was made with Millipore water as this stock solution would be used over a long-term period. All grow media were made using acid washed volumetric flasks and stored under refrigeration $\left(1-5^{\circ} \mathrm{C}\right)$.

The $\mathrm{N}$ : P ratios for each treatment after mixed grow media addition were estimated after the completion of the experiment using the $1.11 \mathrm{mg} \mathrm{NH}_{4}-\mathrm{N} / \mathrm{L}$ added to grow media as $\left(\mathrm{NH}_{4}\right)_{2} \mathrm{SO}_{4}$ in addition to the $0.43 \mathrm{mg} \mathrm{NO}_{3}-\mathrm{N} / \mathrm{L}$ indicated in the City of Toronto 2012 drinking water summary report which became available in June or July 2013 (City of Toronto, 2013b). The estimated N : $\mathrm{P}$ ratios for each treatment are provided in Table 6. The mean concentration of nine MDW samples determined usding the $\mathrm{CD}$ reduction method (APHA, 1998) was $0.36 \mathrm{mg} \pm 0.05 \mathrm{NO}_{3^{-}}$ $\mathrm{N} / \mathrm{L}$ and therefore similar to the $0.43 \mathrm{mg} \mathrm{NO}_{3}-\mathrm{N} / \mathrm{L}$ stated in City of Toronto (2013b). It is therefore likely that the estimated $\mathrm{TN}$ and $\mathrm{N}$ : P ratios are an accurate representation of the total available $\mathrm{N}$ added to each of the four grow media treatments. 
Table 6. Total N, total $P$ and $N$ : $P$ ratios for each of the four $0,50,100$ and $300 \mu \mathrm{g} \mathrm{PO}_{4}-\mathrm{P} / \mathrm{L}$ treatment grow medias

\begin{tabular}{|c|c|c|c|c|c|}
\hline $\begin{array}{c}\text { Treatment } \\
\left(\boldsymbol{\mu g} \mathbf{P O}_{\mathbf{4}} \mathbf{- P}\right)\end{array}$ & $\begin{array}{c}\mathbf{N H}_{\mathbf{4}} \mathbf{- N} \\
(\mathbf{m g} / \mathbf{L})\end{array}$ & $\begin{array}{c}\mathbf{N O}_{\mathbf{3}} \mathbf{- N} \\
(\mathbf{m g} / \mathbf{L})\end{array}$ & $\begin{array}{c}\mathbf{T N} \\
(\mathbf{m g} / \mathbf{L})\end{array}$ & $\begin{array}{c}\mathbf{P O}_{\mathbf{4}} \mathbf{- P} \\
(\mathbf{m g} / \mathbf{L})\end{array}$ & $\mathbf{N : P}$ \\
\hline 0 & 1.11 & 0.43 & 1.54 & & \\
50 & 1.11 & 0.43 & 1.54 & 0.05 & 30.80 \\
100 & 1.11 & 0.43 & 1.54 & 0.1 & 15.40 \\
300 & 1.11 & 0.43 & 1.54 & 0.3 & 5.13 \\
\hline
\end{tabular}

\subsubsection{Watering Regimen and Grow Media Addition}

Grow media was added after sufficient post-germination seedling survival was confirmed and when restarting the experiment due to low seedling survival would be unnecessary. It was not feasible to add another $650 \mathrm{ml}$ of grow media in one single addition as seedlings would potentially be drowned and the addition may possibly cause ammonia toxicity and excessive algal and bacterial growth. Thus, treatment grow media solutions were administered every two or three days to maintain the desired moist sediment conditions by adding $P$ treatment in $60 \mathrm{ml}$ volume increments using a $900 \mathrm{ml}$ polypropylene spray bottle. At the point at which the $650 \mathrm{ml}$ target was nearly reached, incremental volumes were adjusted accordingly to each microcosm to ensure all microcosms received a total of $650 \mathrm{ml}$ of grow media.

One spray bottle was allocated specifically for adding MDW to all microcosms daily. A clearly labeled separate spray bottle was allocated specifically to one of the four $\mathrm{P}$ treatments. The volume of water added to each microcosm was determined by counting the number of sprays. The volume of water produced with each spray was determined before and after each watering and grow media addition by measuring the total volume of 100 sprays aimed directly into a $250 \mathrm{ml}$ graduated cylinder tested for accuracy against a $250 \mathrm{ml}$ volumetric flask. The total volume of grow media or MDW added to each microcosm for each watering was determined as follows:

(Observed volume after 100 sprays $(\mathrm{ml}) / 100) \mathrm{X}$ total number of sprays per microcosm. 
After grow media was added, MDW was added if necessary until it was estimated visually that approximately $10 \%$ of the surface sediment was saturated as evidenced by standing water. Generally, standing water remained on the sediment surface for only a few minutes due to the high porosity associated with a high sand content. The amount of water added to each microcosm was increased to $50 \%$ saturation, also visually estimated, on week 8 by which time the majority of seedlings had grown to heights where burial by sediment was not a risk and by which time the water requirements of larger seedlings had likely increased. The $50 \%$ saturation procedure was maintained until the termination of the experiment.

\subsubsection{Pore Water Sampling}

A lack of difference between mean P treatment seedling height to tallest leaf (HTTL) by week 10 raised the question as to whether a difference in pore water $\mathrm{PO}_{4}{ }^{3-}$ concentrations differed between treatments given $\mathrm{PO}_{4}{ }^{3-}$ is readily adsorbed to sediment $\mathrm{P}$ binding sites or coprecipitated with soluble cations. Pore water was sampled on August 09, 10 and 13, seven to ten days before shoots were removed to determine microcosm biomass. Other more commonly used methods for sampling pore water were less effective in collecting representative samples from sandy sediments (Berg and McGlarthery, 2001). Dialysis cells which must remain in sediments for at least one week are representative of average conditions over time and so may not be representative of conditions at a specific point in time. The squeezing of sediment cores is not possible with sandy sediments as pore water drains out of the sample as soon as the core is sectioned (Berg and McGlarthery, 2001).

Berg and McGlathery (2001) developed a $45 \mathrm{~cm}$ long stainless steel pore water sampler $2.4 \mathrm{~mm}$ in outer diameter, $1.8 \mathrm{~mm}$ inner diameter and capped at the end with silver soldering. Four $0.38 \mathrm{~mm}$ diameter holes were drilled $2 \mathrm{~mm}$ above the pore water sampler tip. To approximate the pore water sampler designed by Berg and McGlarthery (2001), plastic disposable $2 \mathrm{ml}$ pipettes, $4.06 \mathrm{~mm}$ I.D., $6.58 \mathrm{~mm}$ O.D., $28.5 \mathrm{~cm}$ in length, were modified for sampling sandy sediments by drilling four roughly equidistant $1.18 \mathrm{~mm}$ diameter holes perpendicular to the pipette along the $0 \mathrm{ml}$ mark using a $1.18 \mathrm{~mm}(0.0465 \mathrm{in})$ drill bit. 
The main dispensing hole of the pipette was sealed by tightly wrapping Parafilm around the pipette tip. A pipette pump was used to draw pore water. Each modified pipette was tested by filling a beaker with distilled water to a depth just below the $1.18 \mathrm{~mm}$ holes and then engaging the pipette pump. The pipette was re-wrapped with Parafilm if distilled water entered the pipette. All pipettes were thoroughly flushed with distilled water and acid rinsed after each use.

Up to ten $2 \mathrm{ml}$ subsamples were collected depending upon pore water availability. The pipette was inserted into the sediment until the tip came into contact with the vessel bottom ensuring that pore water was collected from a consistent depth. In general, five subsamples were collected across one length at approximately $1 / 3$ of the width of the microcosm, spaced approximately $2-3 \mathrm{~cm}$ apart. A second set of five subsamples was collected at approximately $2 / 3$ of the width of the microcosm. Subsampling immediately adjacent to shoots was avoided to prevent root damage. Microcosms with and without plants were also sampled to determine seedling effect on pore water phosphate concentrations. Each subsample was dispensed into an $80 \mathrm{ml}$ beaker to make one composite 15 to $20 \mathrm{ml}$ sample. After pore water sampling was completed for each microcosm, approximately $20 \mathrm{ml}$ of MDW was added to replace the water removed.

After the final subsample had been collected, pore water $\mathrm{pH}$ and temperature were measured immediately with a Eutech Instruments/Oakton Multiparameter PCS tester ${ }^{\mathrm{TM}} 35$. Temperature was measured with a Sper Scientific dissolved oxygen meter. Dissolved oxygen (DO) and oxidation reduction potential (ORP) in pore water were also determined; however, several minutes could pass before the composite sample was collected which resulted in elevated ORP and DO readings. Also, oxygen would have been introduced into the sediment during the subsampling process thus the data were not used in analysis. On August 13, 2012 DO and ORP were measured immediately after subsampling to reduce error. Similarly, although DO and ORP readings were lower, the accuracy of the DO and ORP data may be erroneous thus the data collected on August 13, 2012 were also not analyzed. All meter probes were rinsed thoroughly with distilled water after use, placed into a beaker containing distilled water and then rinsed again before data were collected from the subsequent sample. 


\subsubsection{Seedling Measurements and Selection}

Seedling growth was monitored bimonthly by determining mean HTTL measured to the nearest $\mathrm{mm}$ and the mean number of leaves per microcosm. Maximum leaf width, the largest leaf width for a given shoot, was determined to the nearest mm with a flexible plastic ruler. Preliminary trials indicated that the use of a caliper was not practical for young T. latifolia due to the very soft leaf tissue and the difficulty of manipulating the caliper within the confines of the microcosm vessel which risked causing injury to seedlings. The post germination mortality rate for each microcosm was monitored throughout the study. A seedling was not considered a mortality until the entire shoot had turned completely brown.

Due to the uniformity in pore water $\mathrm{PO}_{4}{ }^{3-}$ concentration and seedling HTTL (Results, Section 3.1.5), and the decrease from 40 microcosm replicates to 29 due to mortality, it was decided to terminate the experiment on day 82 to redistribute surviving seedlings to reestablish 40 microcosm replicates in preparation for the subsequent experiment involving additions of both $\mathrm{N}$ and $\mathrm{P}$ under flooded sediment conditions. After measuring HTTL, the number of leaves and maximum leaf width for each shoot, wet weight (fresh weight, live weight) biomass was determined for shoots used in the P experiment at the end of the study on day 82, 84 and 85 using a Sartorius digital balance accurate to $0.01 \mathrm{~g}$. Prior to seedling removal, MDW was added to each microcosm to loosen soil in order to reduce damage to roots and rhizomes. Some damage however was unavoidable and major losses of root hairs occurred.

Removed seedlings were immediately rinsed with MDW to remove all traces of sediment, pat dried with paper and weighed to the nearest $0.01 \mathrm{~g}$ once the weight indicated on the balance had stabilized. Each seedling was then transferred to a previously prepared beaker of appropriate size such that the root mass could easily fit within the beaker without causing injury. The sediment was sifted through by hand to locate torn roots which were placed on a $2 \mathrm{~mm}$ sieve, rinsed over a bucket to receive sediment-laden water, pat dried, weighed to the nearest $0.01 \mathrm{~g}$ and then discarded. 


\subsection{Typha latifolia response to Phosphorus and Nitrogen Experiment}

\subsubsection{Seedling Recovery}

Immediately after weighing, the high $\mathrm{P}$ treatment grow media $\left(300 \mu \mathrm{g} \mathrm{PO}_{4}-\mathrm{P} / \mathrm{L}\right)$ was added to each recovery beaker and repeated approximately weekly until shoots were fully recovered and replanted in 3.1 L microcosms. $1.0 \mathrm{~g}$ of Plant Prod Smartcote14N-14P-14K slow release fertilizer pellets was also added to each beaker. Watering was conducted as required in order to keep the seedling root masses submerged. For the majority of seedlings one to four Parafilm strips were placed across the mouth of the beaker to enable the shoot to maintain vertical position. Beakers were then wrapped in paper to provide shade to reduce algal growth (Figure 21).

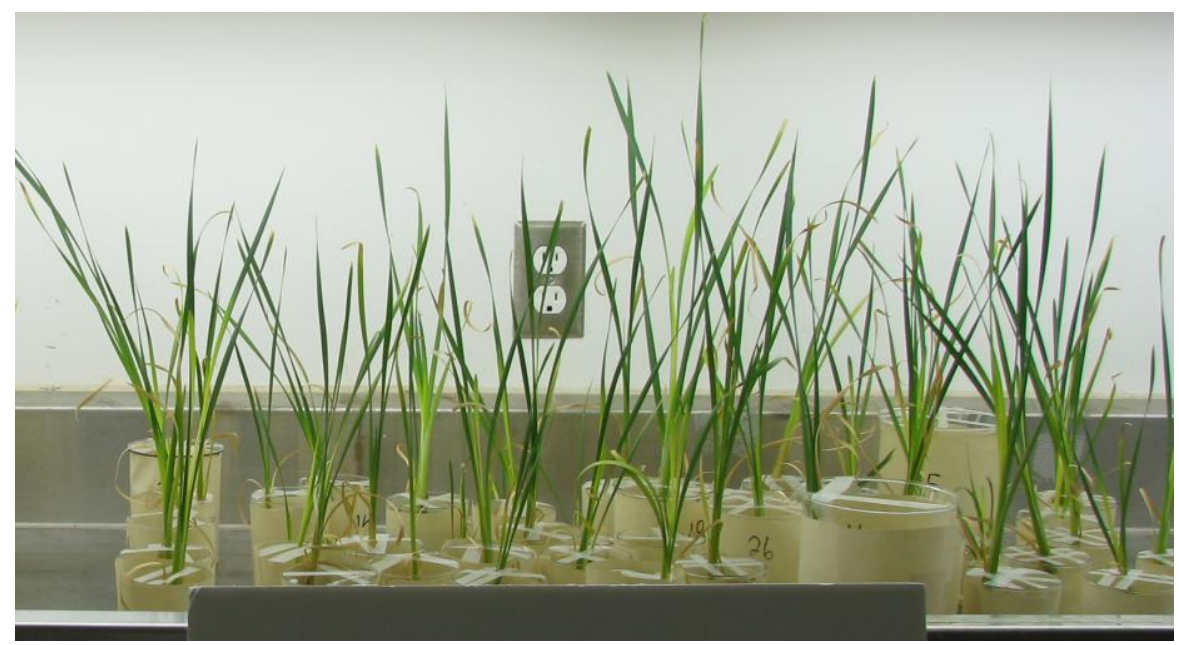

Figure 21. Typha latifolia recovering shoots being grown hydroponically in grow media on August 31, 2012 after removed from sediment, August 16 to 19, 2012.

Shoot locations were randomized every three or four days to provide approximately equal levels of PAR to each shoot during the recovery period. After approximately one to two weeks of showing signs of stress (yellowing leaves), shoots started to recover as evidenced by the production of new leaves, root hairs and ramets (vegetatively produced shoots) from rhizome. All shoots grown in SGES were unearthed on August 29 and recovered in the same manner as for the shoots used in the T. latifolia post germination response to $\mathrm{P}$ loading experiment. Lighting conditions were the same as described in Section 2.4.4. 


\subsubsection{Seedling Access}

Light bank 3 (LB3), the light bank suitable for the propagation of plants to heights of > $50.0 \mathrm{~cm}$, was necessarily situated against a wall which limited access. To fully utilize the area beneath the light bank and access microcosms with minimal risk of injury to shoots, five custombuilt mobile carts were constructed (Figure 22).

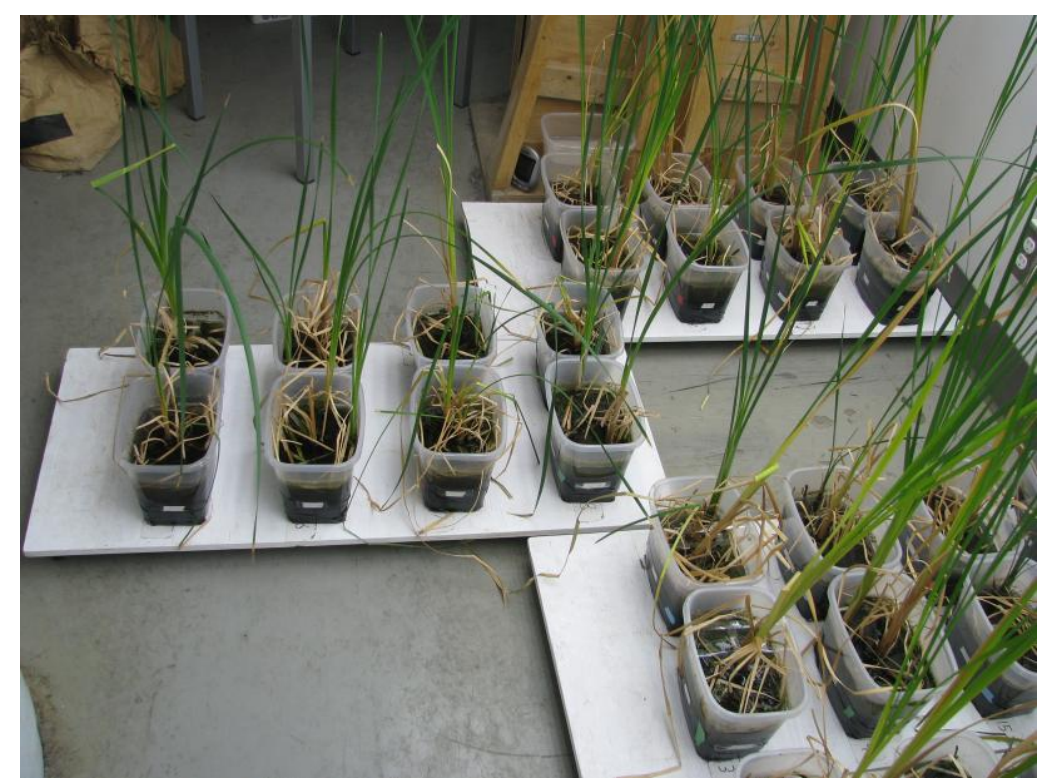

Figure 22. Cart being pulled out from underneath light bank 3 to access microcosms.

The carts were made from $5 / 8$ in $(1.6 \mathrm{~cm})$ plywood cut to $48.2 \mathrm{~cm}$ in width and $107.0 \mathrm{~cm}$ in length and painted off-site with latex anti-fungicide white paint on all sides to prevent the establishment and spread of fungus and warping of the plywood. Five caster wheels were attached to the bottom of each cart with one wheel placed at each corner of the plywood sheet and a fifth wheel being placed in the middle of the cart to prevent sagging from the weight of eight microcosms. When access was required for watering, the adding of grow media or sampling, the cart was pulled out from underneath the light bank with the individual microcosm removed and the cart promptly returned to its original position while watering, feeding or sampling was conducted 


\subsubsection{Seedling Acclimation}

\subsubsection{Formulated Sediment Preparation}

Following the termination of the T. latifolia post-germination response to $\mathrm{P}$ experiment, the remaining sediment was air-dried to facilitate mixing for reuse in the later experiment conducted to determine T. latifolia responses to oligotrophic and eutrophic $\mathrm{N}$ and $\mathrm{P}$ loading rates. The reuse of sediment was considered justifiable given that no differences in T. latifolia biomass were observed between the four treatments and that a very low amount of $\mathrm{P}$ had been added to all treatments relative to sediment P levels reported for eutrophicated wetlands (e.g. Mayer et al., 2006; Mayer et al., 2008).

To reduce variation in sediment composition between individual microcosms, sediment was air-dried and thoroughly mixed. Reference sediment was air-dried first and kept separate from $\mathrm{P}$ treatment sediments and reused as reference sediment for the subsequent experiment. All recovered reference sediment was stored in an $18 \mathrm{~L}$ food-grade bucket, cleaned following the Ryerson cleaning protocol, with the lid on until final mixing and sediment percent moisture was determined.

The 50, 100 and 300 ug $\mathrm{PO}_{4}-\mathrm{P} / \mathrm{L}$ treatment sediments were combined into three separate batches of under $10 \mathrm{~kg}$ by adding $1 / 3$ of the sediment recovered from each microcosm vessel into one of three clean plastic buckets. Before the sediment from individual vessels was combined, the sediment in each vessel was individually mixed by rotating the vessel end over end 25 times with the lid secured. The weight of sediment was divided by 3 with 1/3 of the sediment being added to one of three $18 \mathrm{~L}$ food-grade plastic buckets that were cleaned according to the glassware cleaning protocol and stored with the lid in place until percent moisture was determined.

Sediment percent moisture content for the reference sediment and the combined treatment sediment was determined three to seven days prior to the transplanting of shoots using the same procedure as described in section 2.1.4.2 with the only modification being that just over $9 \mathrm{~kg}$ wet weight (WW) of sediment was added to the mix bucket instead of the previously added $5 \mathrm{~kg}$ to 
speed the sediment preparation process and initiate the shoot acclimation process as soon as possible. The mixing bucket was cleaned following the glassware washing protocol before the reference sediment was mixed.

Preliminary trials indicated that large shoots tended to lean or topple due to either an insufficient rooting surface area and/or depth and/or loosely bound sediment. It was therefore decided to add granite stone with relatively inert chemical reactivity to the bottom of each microcosm to provide better anchoring support for shoots. Commercially available Premier beach/river granite stones were sieved through a $12.7 \mathrm{~mm}$ (1/2in) Hoskin Scientific metal sieve to remove small stones. Stones were then rinsed with MDW to remove fine particulates and washed according to the glassware cleaning protocol to remove $\mathrm{N}$ and $\mathrm{P}$ and other contaminants. As the size of individual stones differed considerably, 7 to 17 stones were added to each $3.1 \mathrm{~L}$ vessel to achieve an approximately equal weight of 412 to $427 \mathrm{~g}$ per microcosm and stored with the lids on. All microcosm vessels were washed according to the glassware washing protocol before the granite stones were added.

\subsubsection{Seedling Transplanting}

By September 12 all seedlings used in the T. latifolia response to $\mathrm{P}$ experiment, except the smallest seedlings, had recovered and many had produced new ramets. A total of 36 genets (original shoot plus newly produced ramets) that were used in the post germination T. latifolia experiment plus four seedlings of similar size that had been grown in SGES were transplanted into 3.1 L microcosm vessels containing river stone from September 12 to September 14.

Genets were gently rinsed with MDW to remove high nutrient grow media and slow release fertilizer pellets then rinsed with distilled water. Shoots were briefly placed in a beaker to allow bulk water to drain off before weighing. Roots were not pat-dried to avoid root damage. All genets were weighed to the nearest $0.01 \mathrm{~g}$ using a Sartorius digital balance. Genet roots were then gently laid on top of the granite stones (Figure 23) and, with the shoot(s) held in a vertical position, $725 \mathrm{~g}$ of formulated sediment (DW) were added on top of the root mass and around the shoot. $500 \mathrm{ml}$ of grow media were promptly added to the microcosm and placed under LB3, a 
custom-built light bank $2.4 \mathrm{~m}$ in length and $1.2 \mathrm{~m}$ in width fitted with the same $16 \mathrm{X} 121.9 \mathrm{~cm} \mathrm{~T} 8$ VitaLux light bulbs used in previous trials and experiments.

Genets were weighed to the nearest $\mathrm{g}$ (WW) using a Starfrit digital balance to determine if biomass would be a factor in genet survival during the acclimation period in the event that significant shoot mortality was observed. As shoots were not pat-dried, weights are not comparable to shoot weights obtained on August 16, 18 and 19. As substantial growth had occurred since the start of the acclimation period on September $12-14$, pre-acclimation genet biomass was not considered representative of genet biomass by the time the experiment was started on November 08. Pre-acclimation biomass was therefore not included in future analysis.



Figure 23. Genet roots being gently laid on granite stones. Note the digital balance used to measure the weight of the genet and, immediately afterward, used to add $725 \mathrm{~g}$ of formulated sediment as DW.

Three genets that were showing signs of stress (yellowing and decreasing number of leaves) acclimating in microcosms 33,17 and 11 were replaced with three genets growing under LB1 in hydroponic grow media solution on September 24, 2012. Three further genets replanted into microcosms 39, 16 and 7 died by October 25, 2012 and were replaced with recovered genets which served as a physical presence only as they were not acclimated under oligotrophic conditions sufficiently long enough to be considered representative of the other shoots. The addition of three genets on October 25 served to eliminate gaps in the canopy and therefore 
prevent unnecessary edge effect which could create a significant source of error by affecting PAR availability and competition for light between individual genets.

Each microcosm was randomly assigned to one of 40 locations under LB3 at the start of the acclimation period. Eight locations were provided on each of the five carts. As cart locations were randomized, microcosms remained on the same cart for the duration of the acclimation period and the duration of the subsequent experiment.

\subsubsection{Grow Media and Watering Regimen}

All forty microcosms were acclimated with the $10 \mu \mathrm{g} \mathrm{PO}$-P/L added to the reference grow media described in the previous experiment from September 12 until the allocation of treatment $\mathrm{P}$ and $\mathrm{N}$ levels were started on November 08. The $1.54 \mathrm{mg} \mathrm{TN} / \mathrm{L}(1.11 \mathrm{mg} \mathrm{NH}-\mathrm{N}+$ the estimated $0.43 \mathrm{mg} \mathrm{NO}_{3}-\mathrm{N}$ in $\mathrm{MDW}$ ) was within the range observed in oligotrophic lakes (Wetzel, 1983).

A large Rubbermaid plastic garbage can cleaned according to the glassware washing protocol was used to make 21.0 L of grow media as described in Table 5, Section 2.1.8 in order to provide $500 \mathrm{ml}$ of oligotrophic reference grow media for each microcosm. Using a $1.0 \mathrm{~L}$ volumetric flask, 21.0 L of grow media was made by initially adding $5.0 \mathrm{~L}$ of MDW in $5 \mathrm{X} 1.0 \mathrm{~L}$ increments to the Rubbermaid can to facilitate reagent mixing followed by the addition of $1.0 \mathrm{~L}$ containing each stock solution at $21 \mathrm{X}$ the volume added to $1.0 \mathrm{~L}\left(\right.$ e.g. $1 \mathrm{ml}$ of $\left(\mathrm{NH}_{4}\right)_{2} \mathrm{SO}_{4} / \mathrm{L} \mathrm{X}$ 21.0 L $=21 \mathrm{ml}$ of $\left.\left(\mathrm{NH}_{4}\right)_{2} \mathrm{SO}_{4}\right)$ followed by the addition of $15.0 \mathrm{~L}$ of MDW added in $15 \mathrm{X} 1.0 \mathrm{~L}$ increments. $500 \mathrm{ml}$ of grow media was added to each microcosm immediately after each seedling was re-planted into formulated sediment to ensure moist to wet sediment conditions. The grow media was stirred periodically between transplants. 200 to $300 \mathrm{ml}$ of grow media were added every 2 to 5 days thereafter as required to maintain moist soil conditions.

Subsequent batches of 2.1 to $4.1 \mathrm{~L}$ of grow media, depending on the volume needed, were made fresh from stock using 1.0 L acid rinsed volumetric flasks. The volume of stock solution added to the 1.0 volumetric flask was sufficient to provide equal volumes of grow media to 41 microcosms, with extra grow media equivalent to the volume needed for one additional 
microcosm in the event of minor spills. A $250 \mathrm{ml}$ graduated cylinder determined to be accurate by filling with a $250 \mathrm{ml}$ volumetric flask, was used to measure and dispense grow media volume. The graduated cylinder was labeled and used throughout the acclimation period and the subsequent experiment. Grow media and MDW were dispensed through a 5.0 L watering can plastic nozzle to prevent sediment scour and the exposure of roots until November 08 when microcosms were filled to the $900 \mathrm{ml}$ mark. If necessary, MDW was added in addition to grow media and, on days between grow media additions, MDW was added to maintain moist soil conditions until October 25 when microcosms were filled to the height of the black duct tape (approximately $1.0 \mathrm{~cm}$ ) until November 08 in order to acclimate seedlings to saturated soil and low sediment redox conditions. Moist soil conditions were preferred over flooded or saturated conditions initially in order to allow the sediments to compact to improve root anchoring, reduce turbidity and enable oxygen to penetrate the sediments which may be a contributing factor to shoot growth and survival in young T. latifolia shoots.

\subsubsection{Environmental Conditions}

Minimum and maximum temperature and relative humidity $(\mathrm{RH})$ were recorded every one to three days for the duration of the acclimation period using a Noma digital thermometer/RH humidity sensor and an Accutemp digital thermometer/RH sensor with the latter serving as a backup in the event of equipment failure. As daily temperatures were not collected over the course of $24 \mathrm{hrs}$, minimum and maximum values were an approximation of the true minimum and maximum value. To eliminate bias associated with edge effect and variations in light intensity, temperature and $\mathrm{RH}$, microcosm locations were randomized throughout the acclimation period every three or four days. Randomization was achieved by temporarily removing the southerly most cart from underneath the light bank, shifting the adjacent cart to the southerly most position, then shifting each microcosm position on the cart moving in a clockwise direction. The process was repeated for all five carts. The cart that was removed was moved to the northern most position. This method of randomization was repeated throughout the entire acclimation process and continued throughout the following experiment. 


\subsubsection{Biological Data}

Pretreatment data were collected to determine whether differences in growth rate as a function of change in total leaf length (TLL), defined as the sum length of all green leaves, differed significantly between genets at the time they were randomly assigned to one of three $\mathrm{N}$ and $\mathrm{P}$ treatments on November 08 , the day $\mathrm{N}$ and $\mathrm{P}$ treatments were first applied. A green leaf was defined as a leaf with any amount of green pigment capable of photosynthesis (Figure 24).

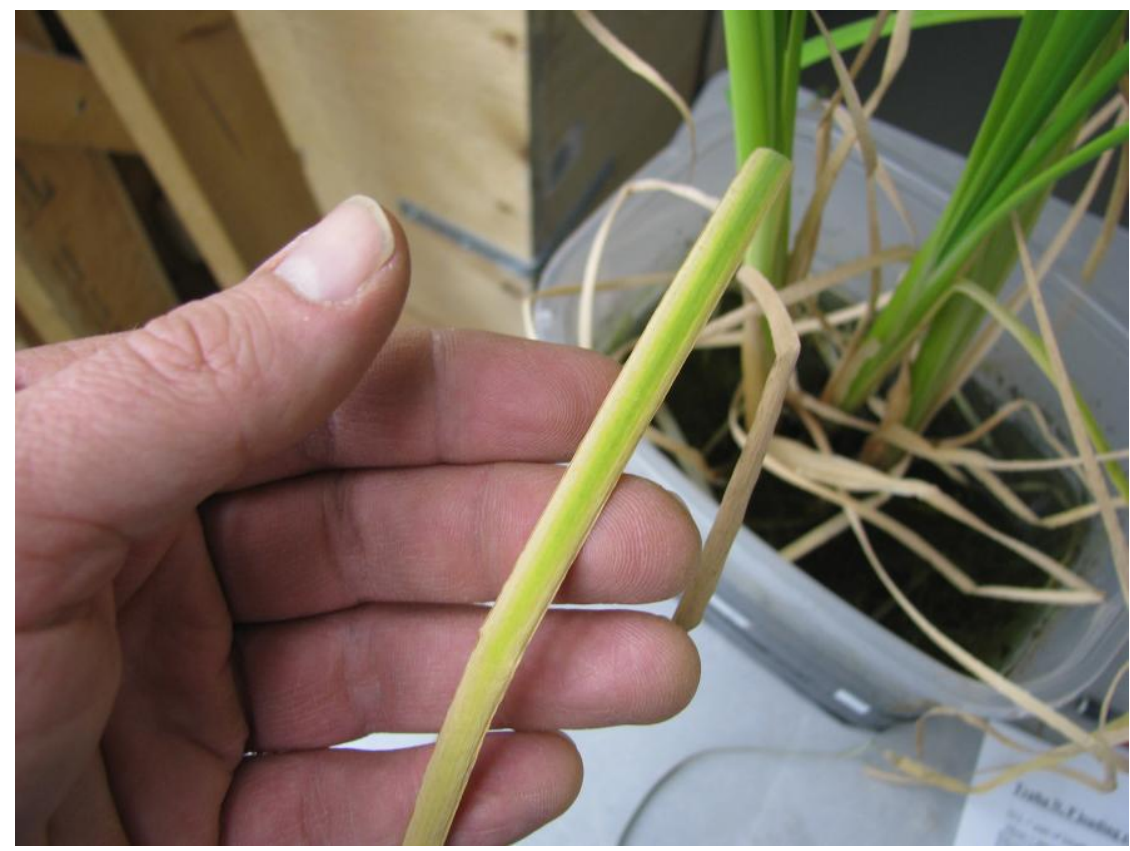

Figure 24. A representative senescent leaf showing green pigment and counted as a green leaf.

TLL was used by Woo and Zedler (2002) as a non-destructive method for monitoring T. $x$ glauca response to $\mathrm{N}$ and $\mathrm{P}$ treatments and was reported to be a highly effective indicator of genet biomass (J.B. Zedler, University of Wisconsin Botany Professor and wetland restoration ecologist, personal communication). A standard tape measure was used to measure TLL to the nearest $\mathrm{mm}$. To avoid cross-contamination between microcosms, the tape measure was cleaned before each microcosm TLL was obtained by firstly pre-rinsing in Millipore water followed by rinsing in $10 \% \mathrm{HCl}$ and lastly rinsing again with Millipore water. 
Also documented was the number of shoots per microcosm, the total number of leaves and the height to green tissue in senescent leaves. However, no studies were found in the literature that measured Typha leaves to green height as an indicator of fitness or to correlate with biomass. The number of leaves and height to green tissue were considered redundant with TLL and were therefore not analyzed but are available for comparison with future research.

\subsection{Typha latifolia Response to Oligotrophic and Eutrophic $\mathbf{N}$ and $\mathbf{P}$ Loading Rates under Laboratory Conditions.}

A full-factorial experimental design was used to test the hypothesis that environmentally

relevant (eutrophic to hypereutrophic) $\mathrm{N}$ and $\mathrm{P}$ loading rates loading would increase biomass and that high $\mathrm{N}$ availability combined with high $\mathrm{P}$ availability would result in significantly more biomass production. A reference treatment of $10 \mu \mathrm{g} \mathrm{PO}_{4}-\mathrm{P} / \mathrm{L}$ was selected as this concentration was similar to the $8.0 \mu \mathrm{g}$ TP/L mean concentration indicated in Wetzel (1983) for oligotrophic systems. A treatment of $300 \mu \mathrm{g} \mathrm{PO}$ - $\mathrm{P} / \mathrm{L}$ was selected as $>300 \mu \mathrm{g} \mathrm{PO} 4-\mathrm{P} / \mathrm{L}$ has been observed in agricultural runoff (Yates and Prasher, 2009). The $1.0 \mathrm{mg} \mathrm{TN} / \mathrm{L}(0.5 \mathrm{mg} \mathrm{NO}-\mathrm{N} / \mathrm{L}+0.5 \mathrm{mg}$ $\left.\mathrm{NH}_{4}-\mathrm{N} / \mathrm{L}\right)$ and $3.0 \mathrm{mg} \mathrm{TN} / \mathrm{L}$ treatments $(1.5 \mathrm{mg} \mathrm{NO}-\mathrm{N} / \mathrm{L}+1.5 \mathrm{mg} \mathrm{NH}-\mathrm{N} / \mathrm{L})$ as a TN loading rate were selected as $1.0 \mathrm{mg} \mathrm{TN} / \mathrm{L}$ is within the oligotrophic and $3.0 \mathrm{mg} \mathrm{TN} / \mathrm{L}$ is within the eutrophic range indicated in Wetzel (1983) respectively. The $3.0 \mathrm{mg} \mathrm{TN} / \mathrm{L}$ treatment is also a concentration in which species richness in submergent vegetation is comparatively low indicating environmental impact or possibly displacement of species adapted to $\mathrm{N}$ - poor systems by competitive species (James et al., 2005).

\subsection{Sediment}

The preparation of the sediment used in this experiment is described in Section 2.3.1.

\subsection{Environmental Conditions}

Lighting and photoperiod conditions were the same as those described for the acclimation period. A 16.0 L: 8D photoperiod was maintained throughout the experiment except for an unknown period between December 29, 2012 and January 03, 2013 during which the main 
power to the light bank was shut off for a building-wide electrical upgrade. The mean height of the light bank bulbs to the sediment surface with microcosms placed on carts was $1.73 \mathrm{~m} \pm 0.008$ $\mathrm{m}, \mathrm{n}=5$. The Field Scout Type 2 light meter was taped to an extension sufficiently long enough to determine PAR for all microcosms without having to move carts (Figure 25).

To characterize light intensity, PAR was measured at (1) sediment height adjacent to each microcosm; (2) as close to the center of each microcosm as possible with the sensor extension resting ontop of the lip and perpendicular to the vessel, and (3) at HTTL on November 09, 2012, one day after treatments were first added, and on May 08,2013, two days before the start of plant removal. Temperature and RH monitoring was continued as described in section 2.6.4.

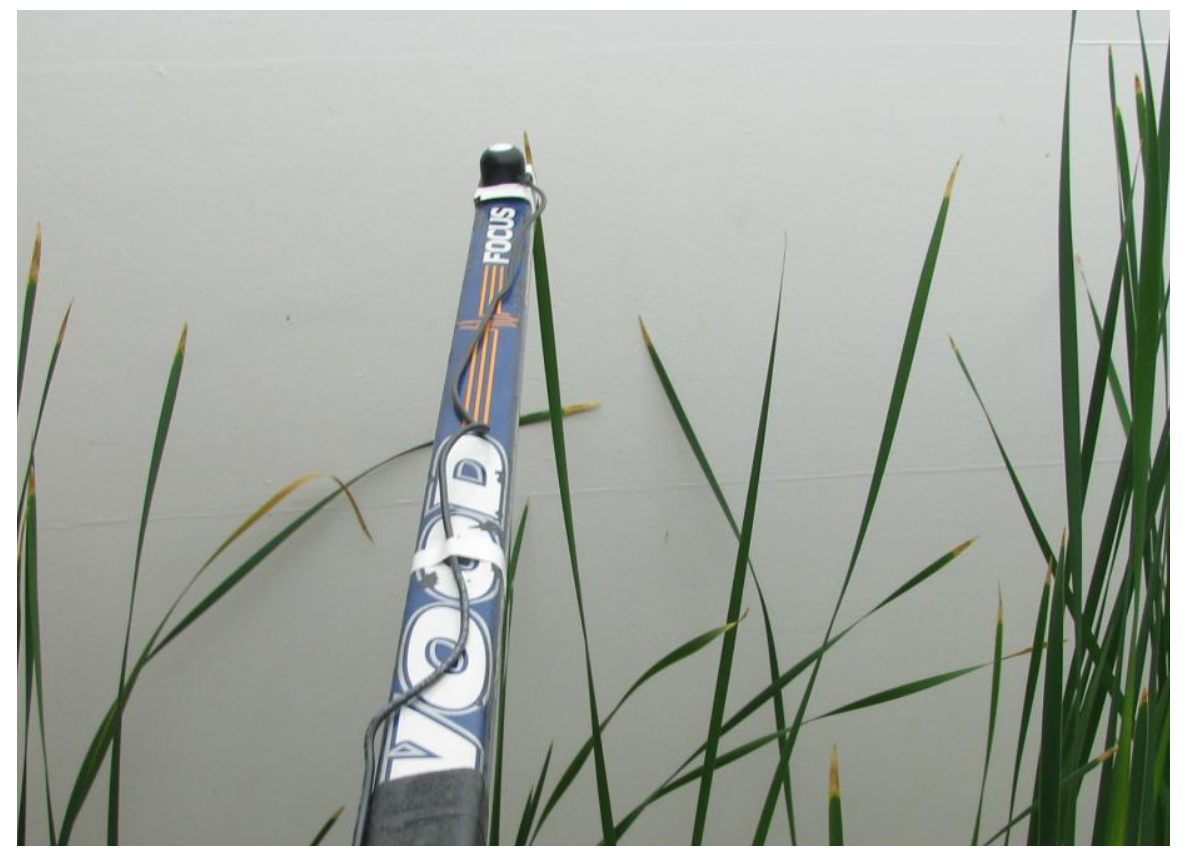

Figure 25. Measuring light intenstity under LB3 with an extension on May 08, 2013.

\subsubsection{Grow Media and Watering Regimen}

Micronutrients $\mathrm{MnSO}_{4} \cdot \mathrm{H}_{2} \mathrm{O}, \mathrm{CaCI}_{2} \cdot 2 \mathrm{H}_{2} \mathrm{O}, \mathrm{MgSO}_{4} \cdot 7 \mathrm{H}_{2} \mathrm{O}$ and $\mathrm{FeCI}_{3} \cdot 6 \mathrm{H}_{2} \mathrm{O}$ were added to each microcosm one final time on November 08 with only $\mathrm{N}$ and $\mathrm{P}$ being added thereafter. Grow media was made fresh from stock solutions on the day of addition. $\mathrm{NO}_{3}-\mathrm{N}$ stock solution was made from $\mathrm{NaNO}_{3}$. Details and calculations on stock solution reagent concentrations and grow media preparation are provided in Appendix B. 
From November 08 to December 08 either $200 \mathrm{ml}$ or $300 \mathrm{ml}$ of grow media at the desired concentration was added every six to nine days from November 08 to November 22, 2012 at treatment concentrations $(10 \mu \mathrm{g}$ TP/L or $300 \mu \mathrm{g}$ TP/L and $1.0 \mathrm{mg}$ TN/L or $3.0 \mathrm{mg} \mathrm{TN} / \mathrm{L}$ depending on treatment) with all microcosms receiving the same volume of grow media for every watering or feeding event. MDW containing a mean concentration of $0.43 \mathrm{mg} \mathrm{NO}-\mathrm{N}$ (City of Toronto, 2013b) was added to each microcosm in equal volumes between November 08 and December 08 but was discontinued thereafter due to high salinity levels in some microcosms were approaching brackish levels of $0.5 \mathrm{mg} / \mathrm{L}$.

The volume of grow media and MDW added was determined by measuring the distance between the observed water level and the full water mark of the microcosm with the greatest amount of surface water remaining since the last watering and/or grow media addition. It had previously been determined that a $1.0 \mathrm{~cm}$ decrease in water level was the close equivalent of a $200 \mathrm{ml}$ water loss to evapotranspiration. After the same volume of grow media and MDW was added, Millipore water was added until the $900 \mathrm{ml}$ mark was reached.

As the amounts of $\mathrm{N}$ and $\mathrm{P}$ being added up to December 08 may have been insufficient to obtain a detectable a response in T. latifolia biomass, $\mathrm{N}$ and $\mathrm{P}$ concentrations in grow media was increased such that, after addition, treatment concentrations were achieved at the $900 \mathrm{ml}$ volume (full water mark). The addition of grow media continued on a weekly basis. Watering with Millipore water to the $900 \mathrm{ml}$ was conducted every third or fourth day. Both feeding and watering were conducted on the same day that microcosm locations were randomized to reduce handling effect.

\subsubsection{Water Quality Monitoring}

Water temperature, dissolved oxygen, $\mathrm{pH}$, conductivity and salinity were monitored monthly to (1) determine if microcosm surface water conditions were representative of natural wetlands; (2) identify changes which may affect $\mathrm{P}$ and $\mathrm{N}$ fate and speciation and therefore explain observed T. latifolia response; (3) differences in water quality between treatments that may account for observed differences in growth and biomass and (4) to identify potential issues 
such as elevated salinity levels that may affect $T$. latifolia survival which could be rectified. Three randomly selected microcosms from each of the four treatments were used to monitor surface water dissolved oxygen, temperature, $\mathrm{pH}$, conductivity and salinity monthly. Dissolved oxygen and temperature was measured with a Sper Scientific model 850041 DO meter, pH with a Metler Toledo Five Easy pH meter and conductivity and salinity with a PCS tester ${ }^{\mathrm{TM}} 35$. All meters were calibrated before use according to manufacturer specifications. When it became apparent that salinities were high, the salinity levels in the surface water in all microcosms were sampled monthly. The water quality in all microcosms were measured in the winter, 2013 to determine if the three randomly selected microcosms were representative of water quality conditions for all treatment replicates and at the termination of the experiment.

\subsubsection{Biological Endpoints}

The determination of TLL as described under section 2.6.5 was conducted bi-monthly to monitor growth and to estimate when genet biomass for all treatments either reached a plateau or declined at which point the study would be terminated. At the end of the experiment the TLL for each microcosm was measured immediately before the microcosm was dismantled to determine the amount of variation in biomass explained by TLL. Mean growth expressed as TLL for each treatment from November 08 onwards was determined by subtracting the TLL from the preceding sample collected two weeks prior (e.g., growth between November 07 or November 08 to November $22=$ week 4 TLL - week 2 TLL). The average growth for all two week intervals for each treatment were then averaged to determine mean growth for the duriation of the experiment. The removal of shoots from all microcosms was conducted over a seven day period from May 10 to May 16. The order of microcosm removal was randomly determined. Microcosm maximum leaf width was determined at the end of the experiment using a Mastercraft digital caliper accurate to $1 / 100^{\text {th }}$ of a $\mathrm{mm}$ to potentially explain differences in above ground biomass between shoots of similar heights.

Shoot density, the number of shoots $/ \mathrm{m}^{2}$, was also determined to enable comparisons with shoot density reported in the literature. The surface area used to calculate shoot density was calculated from the mean of 18 length measurements measured every $1.0 \mathrm{~cm}$ and 11 width measurements measured every $1.0 \mathrm{~cm}$ obtained from one microcosm. The surface area value 
was also used to determine the loading rate for each treatment by summing the total weight of $\mathrm{N}$ and $\mathrm{P}$ added to each microcosm. The number of days from November 08, 2012 to May 10, 2013, the forming being the start of experiments and May 10 being the start of microcosm dismantling, was divided by 365 to convert the duration of the experiment to years to provide a loading rate to $\mathrm{g} \mathrm{N} / \mathrm{m}^{2} / \mathrm{yr}$ and $\mathrm{g} \mathrm{P} / \mathrm{m}^{2} / \mathrm{yr}$ in order to compare $\mathrm{N}$ and $\mathrm{P}$ loading rates provided in the literature.

Above ground and below ground biomass, measured as dry weight, were determined to identify differences in $\mathrm{N}$ and $\mathrm{P}$ allocation between treatment groups. Above ground biomass as was determined by cutting shoots at the soil surface. Perched shoots (shoots in which a portion of the root mass was above ground) were cut immediately above the first root or rhizome. All leaf litter was removed, rinsed with MDW, gently squeezed to remove bulk water and placed with shoots into open plastic bags. The soil mass containing roots was placed into a bucket to soak briefly to ease root removal (Figure 26). Loose roots mainly floated and could be easily

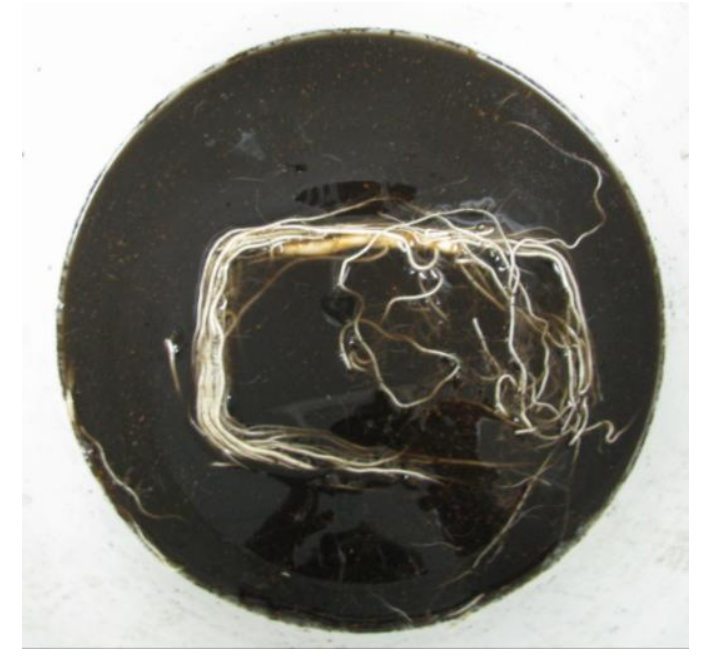

Figure 26. Root mass soaking to facilitate sediment removal.

removed. The sediment at the bottom of the receiving bucket was sifted by hand for roots. Roots gently squeezed to remove bulk water, air-dried and allowed to air dry until all shoots and roots had been removed and washed. Root masses were separated and placed in to separate paper bags from the shoots and leaf litter obtain below ground biomass (DW) and above ground biomass (DW). Paper bags containing root masses and combined shoot and leaf litter were oven-dried at $60^{\circ} \mathrm{C}$ to constant weight. Dried root masses and combined shoots and leaf litter were measured to the nearest $g$ using a Sartorius digital balance. Total biomass for each 
microcosm, measured as the sum of the below ground and above ground biomass, was used to determine the overall effect of $\mathrm{N}$ and $\mathrm{P}$ on biomass production and therefore potential invasiveness.

\subsubsection{Statistical Analysis}

All statistical analysis was performed in Systat $^{\circledR}$ version 12 statistical software. Statistical tests used were selected based on procedures described in Zar (1984). The null hypothesis rejection region was set at $\alpha=0.05$. The Levenes test was used to test each data set for equal variance. The Shapiro-Wilks test was used to determine if data residuals were normally distributed. Where parametric assumptions were met, the ONEWAY ANOVA test (referred to as ANOVA hence forward) was used to compare means between treatment groups. Where a significant difference was indicated, the post-hoc Tukey multiple range test was used to identify significant differences between individual groups. Where the assumptions of equal variance and normal distribution were violated and transformed data did not meet the parametric ANOVA test assumptions, the non-parametric Kruskal-Wallis rank sum test was used. Where significant differences were observed, the Mann -Whitney U test was used to conduct pair-wise comparisons to identify significant differences between individual groups (Dr. A. Laursen, Ryerson University, personal communication).

Tests to determine differences in pore water mean $\mathrm{PO}_{4}-\mathrm{P}$ concentrations, live shoot biomass and mean HTTL between 0, 50, 100 and $300 \mu \mathrm{g} \mathrm{PO}_{4}-\mathrm{P} / \mathrm{L}$ treatments were conducted for the first protocol examining T. latifolia seedling response to $\mathrm{P}$ treatments. For microcosms containing more than one shoot germinated from seed, the mean HTTL between two or three shoots was used in statistical analysis and figures. Biomass for a given microcosm was the sum of all live shoots, live and dead roots and leaf litter.

At the termination of the acclimation period and the start of the T. latifolia response to oligotrophic and eutrophic $\mathrm{N}$ and $\mathrm{P}$ loading rates experiment, differences between TLL, HTTL, shoot density and growth rate for each microcosm observed on November 08 was tested for to determine if statistically significant differences existed prior to the addition of $\mathrm{N}$ and $\mathrm{P}$ 
treatments. At the termination of the experiment, differences between TLL, HTTL, shoot density and shoot, root, root plus shoot biomass and root to shoot ratio were tested for. Regression-correlation was used to identify relationships between TLL and shoot, root, and root plus shoot dryweight biomass. 


\section{RESULTS}

The objectives of the experiments were to (1) establish whether T. latifolia could successfully be propagated from seed to adult under laboratory conditions and using a formulated sediment that could be effective for hypothesis testing and (2) test the hypothesis that T. latifolia is invasive under environmentally relevant high $\mathrm{N}$ and high $\mathrm{P}$ (eutrophic to hypereutrophic) concentrations.

\subsection{Typha latifolia Post Germination Response to 0, 50, 100 and 300 $\mu$ $\mathrm{PO}_{4}-\mathrm{P} / \mathrm{L}$ Treatments.}

\subsubsection{Environmental Conditions}

Laboratory air temperature fluctuated widely from May 25 to July 16, 2012 ranging from $20.8^{\circ} \mathrm{C}$ to $32.8^{\circ} \mathrm{C}$ during which period air conditioning was not operational (Figure 27).

Temperatures stabilized after air conditioning was restored with air temperatures generally remaining between 22 to $28^{\circ} \mathrm{C}$ until the termination of the experiment on August 16 .

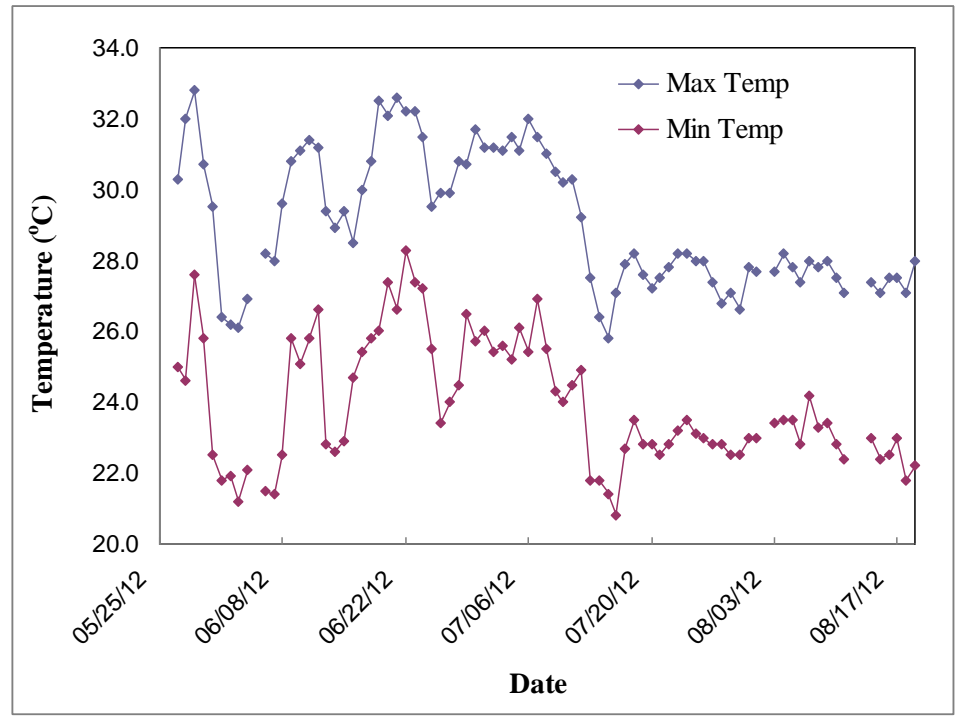

Figure 27. Observed minimum and maximum laboratory air temperatures collected beneath the light bank used to determine Typha latifolia post termination response to $P$ treatments. 
Relative humidity (RH) was monitored in order to fully describe the environmental conditions that occurred for the duration of all experiments. As the Noma digital temperature/relative humidity sensor did not record minimum and maximum $\mathrm{RH}$ as it does for temperature, an Accutemp thermometer/RH sensor was used. Observed RH ranged from $22 \%$ to $60 \% \mathrm{RH}$. The daily average minimum and maximum RH observed for the duration of the experiment was $37.6 \%$ and $46.4 \%$ respectively.

Mean PAR on May 25, 2012 at the start of the experiment approximately $5 \mathrm{~cm}$ above the soil was $144 \mu \mathrm{E} \mathrm{cm}^{-2} \mathrm{~s}^{-1}$ and ranged from 102 to $182 \mu \mathrm{E} \mathrm{cm}^{-2} \mathrm{~s}^{-1}$. Mean PAR at the end of the experiment on August 16 to August 19 was $228.6 \mu \mathrm{E} \mathrm{cm}^{-2} \mathrm{~s}^{-1}$ light measured at HTTL and ranged from 123 to $328 \mu \mathrm{E} \mathrm{cm}^{-2} \mathrm{~s}^{-1}$.

In general, a rank of 6 to 8 (average wet) was consistently observed throughout the study at approximately $2 \mathrm{~cm}$ below the soil surface. Readings below a rank 5, or average moisture conditions, were rarely observed. Similarly, the mean rank of 9 to 10 , an indication of wet sediment conditions according to manufacturer specifications, was consistently observed throughout the study at a depth of approximately $5.5 \mathrm{~cm}$ with the tip of the probe in contact with the vessel bottom.

\subsubsection{Viable Seed Identification}

Of the 82 seeds identified as nonviable seeds on May 25, three seeds had germinated by June 01 for a total percent germination of $3.4 \%$. The three seeds that germinated were not seen within the plumage and remnant flower parts attached to clusters of two or three carpodia and were the result of observational error rather than incorrect identification.

$100 \%$ germination was observed in three of the six Petri dishes into which seeds classified as viable were placed (Table 8). The overall percent germination for seeds identified as viable was $93.1 \%$ indicating that seeds added to each of the 40 microcosms were potentially viable seeds and that any differences between would not be due to experimental error. Three of the 57 germinated seeds identified as viable produced short white radicles and were considered unlikely to have survived to take root. 
Table 7. Percent germination of seeds classified as nonviable.

\begin{tabular}{cccc}
\hline \multicolumn{4}{c}{ Classified as Nonviable Seed } \\
\hline $\begin{array}{c}\text { Total number } \\
\text { of seeds } \\
\text { added May }\end{array}$ & $\begin{array}{c}\text { Number } \\
\text { germinated } \\
\text { by June 01 }\end{array}$ & $\begin{array}{c}\text { Percent } \\
\text { Germination }\end{array}$ \\
\hline Petri Dish & $\mathbf{2 5}$ & 1 & 7.7 \\
\hline 1 & 13 & 0 & 0.0 \\
2 & 12 & 0 & 0.0 \\
3 & 10 & 2 & 12.5 \\
4 & 16 & 0 & 0.0 \\
5 & 15 & 0 & 0.0 \\
6 & 16 & 3 & 3.4 \\
\hline Total & 82 & & \\
\hline \hline
\end{tabular}

Table 8. Percent germination of Typha latifolia seeds classified as viable.

\begin{tabular}{cccc}
\hline \multicolumn{4}{c}{ Classified as viable Seed } \\
\hline Petri & $\begin{array}{c}\text { Total number } \\
\text { of seeds added } \\
\text { May 25 }\end{array}$ & $\begin{array}{c}\text { Number } \\
\text { germinated } \\
\text { by June 01 }\end{array}$ & $\begin{array}{c}\text { Percent } \\
\text { Germination }\end{array}$ \\
\hline 1 & 11 & 11 & 100.0 \\
2 & 10 & 10 & 100.0 \\
3 & 10 & 8 & 80.0 \\
4 & 11 & 10 & 90.9 \\
5 & 11 & 11 & 100.0 \\
6 & 8 & 7 & 87.5 \\
\hline Total & 61 & 57 & 93.1 \\
\hline
\end{tabular}

PAR ranged from 50 to $64 \mu \mathrm{E} \mathrm{m}^{-2} \mathrm{~s}^{-1}$ with mean PAR being identical for the nonviable and viable seed groups at $62.2 \mu \mathrm{E} \mathrm{m}^{-2} \mathrm{~s}^{-1}$. Ambient air temperatures during the May 25 to June 01 germination period ranged from $21.8^{\circ} \mathrm{C}$ to $32.8^{\circ} \mathrm{C}$.

\subsubsection{Percent Germination}

The total percent germination determined from May 27 to June 01 was similar between treatments (Figure 28) with the 0 and $50 \mu \mathrm{g} \mathrm{PO}_{4}-\mathrm{P}$ treatments having the highest percent germination at 88.9 and $93.3 \%$ respectively. No newly germinated seeds were observed after 
June 01. Overall percent germination for all four treatments combined was $85 \%$. Differences in percent germination between treatments were not statistically significant $(p=0.138)$

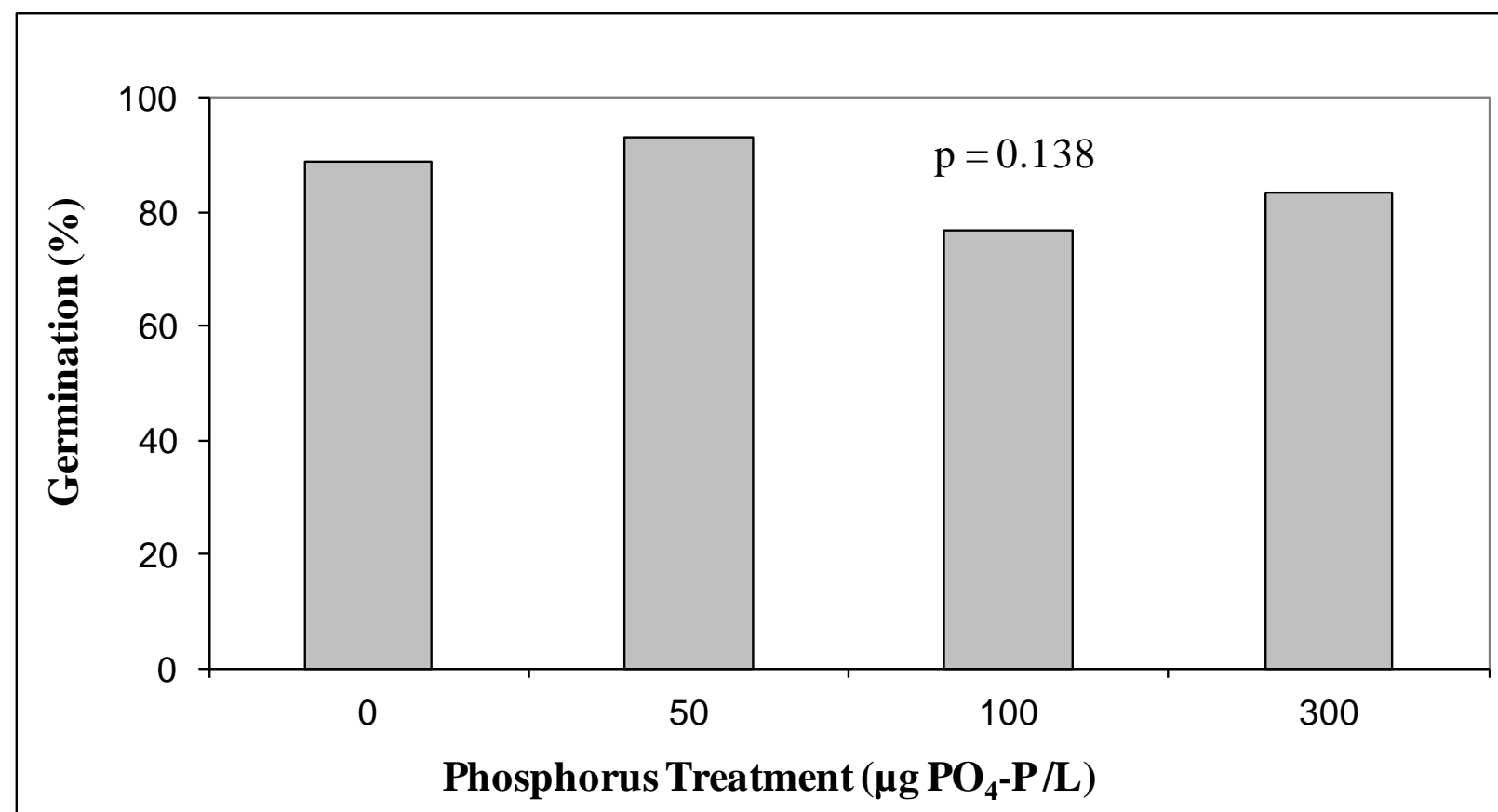

Figure 28. Total percent germination over a six day period for Typha latifolia seeds observed in each of the four $\mathrm{PO}_{4}-\mathrm{P}$ treatment microcosms.

\subsubsection{Percent Mortality}

Overall mortality of post germinated seedlings was 53.5\% from May 27 to August 16. The $300 \mu \mathrm{g} \mathrm{PO}-\mathrm{P} \mathrm{mg} / \mathrm{L}$ treatment experienced the greatest mean percent mortality from June 01 to August 16 at $62.5 \%$ with the 0,50 and $100 \mathrm{PO}_{4}-\mathrm{P} \mathrm{mg} / \mathrm{L}$ treatments experiencing 58.3, 47.7 and $41.4 \%$ mortality respectively. The differences in percent mortality were not statistically significant (Kruskal Wallis, $p=0.689$ ), Figure 29. Each treatment group included microcosms that experienced either 0 to $100 \%$ mortality. 


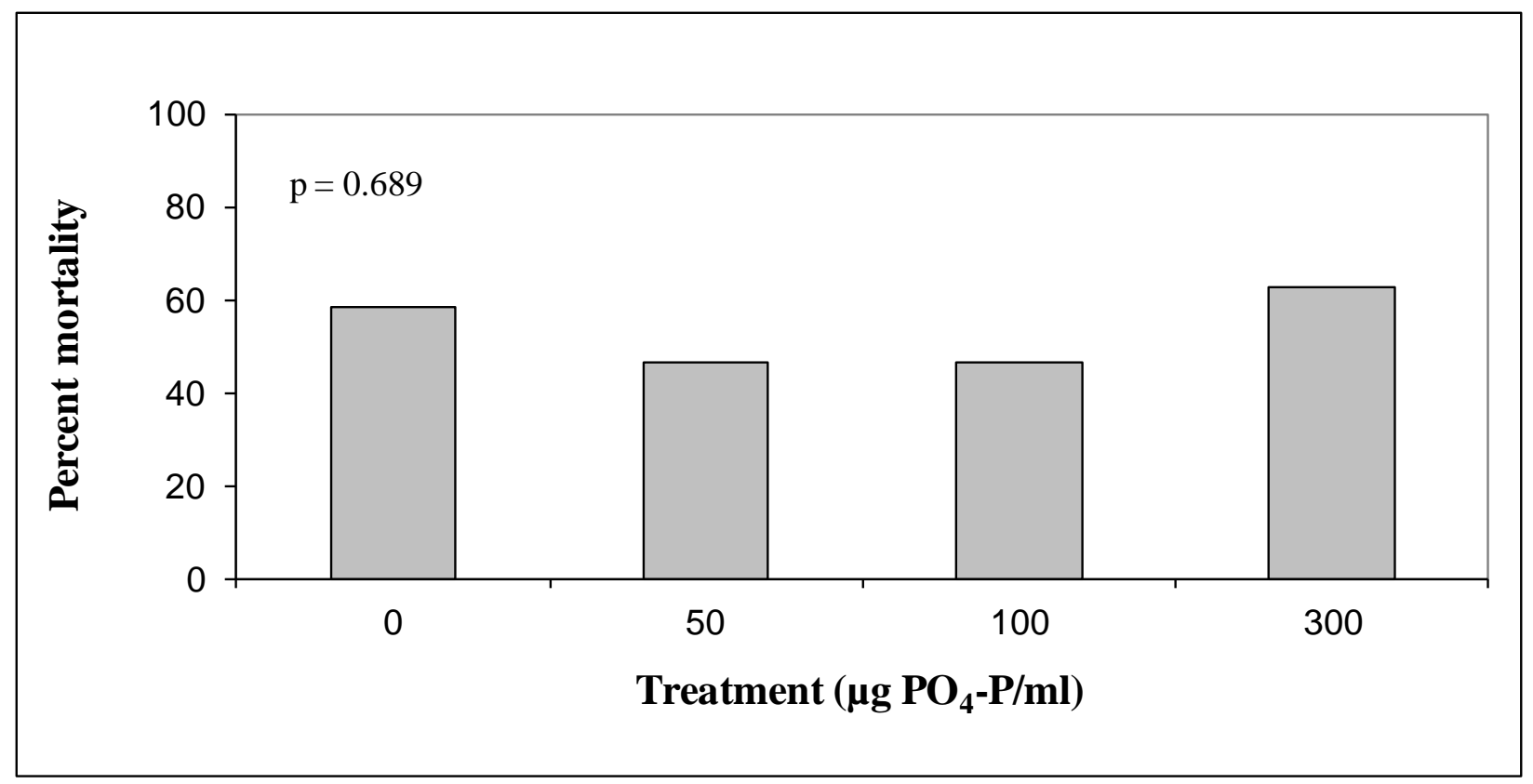

Figure 29. Post germination percent Typha latifolia mortality from June 01 to August 16, 2012.

\subsubsection{Growth and Biomass}

Mean HTTL between treatments by the date the study was terminated were not statistically significant (ANOVA, $\mathrm{p}=0.485$ ). The $300 \mu \mathrm{g} \mathrm{PO}_{4}$-P/L mean HTTL was between 43 to $55 \mathrm{~mm}$ greater than the other treatments (Figure 30); however, greater mean average height did not translate into biomass (wet weight) where the $300 \mu \mathrm{g} \mathrm{PO}$-P treatment was less than the 50 and $100 \mu \mathrm{g} \mathrm{PO}_{4}-\mathrm{P}$ treatment (Figure 31). Mean microcosm biomass for each of treatments 0, 50, 100 and $300 \mathrm{PO}_{4}-\mathrm{P} / \mathrm{L}$ differed by $<1.0 \mathrm{~g}$ and were 5.22, 5.81, 5.99 and $5.46 \mathrm{~g}$ respectively. The difference in biomass was not statistically significant (Kruskal Wallis, $\mathrm{p}=0.890$ ). As for all figures presented in this thesis representing normally distributed data, error bars indicate standard deviations. 


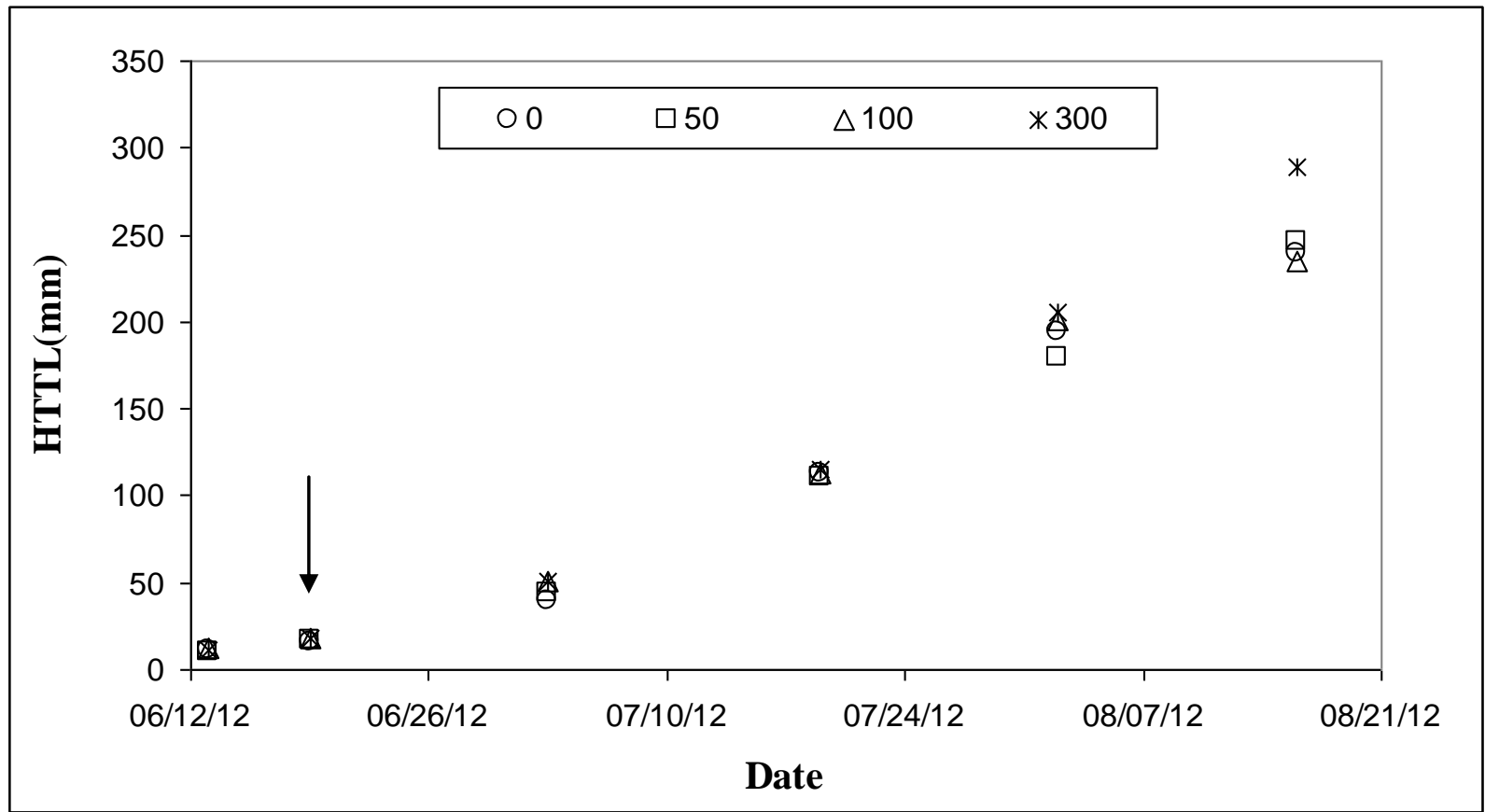

Figure 30. Typha latifolia mean height to tallest leaf over a twelve week period from the time of germination.

The arrow indicates the start of additional phosphate treatment on June 19, ending July 21.



Figure 31. Typha latifolia biomass (wet weight) after 12 weeks from germination. 


\subsubsection{Pore water}

Due to an apparent lack of difference between treatments in HTTL by August 02, pore water sampling was conducted to determine whether the $\mathrm{P}$ additions had resulted in a difference in bioavailable $\mathrm{P}$ and whether $\mathrm{P}$ may be at concentrations potentially limiting to $T$. latifolia growth. The pore water sampling conducted August 9 and 10 incorporated an error due to approximately $2.0 \mathrm{ml}$ of millipore water remaining in the filter cartridges following filter flushing. On August 13, flushed filters were transferred to a separate filter cartridge and did not include a dilution error.

The mean pore water $\mathrm{PO}_{4}-\mathrm{P}$ concentrations for treatments $0,50,100$ and $300 \mu \mathrm{g} \mathrm{PO}_{4}-\mathrm{P} / \mathrm{L}$ treatments were 19.8, 19.8, 19.0 and $22.2 \mu \mathrm{g} \mathrm{PO}_{4}-\mathrm{P} / \mathrm{L}$ respectively (Figure 32). There was no statistically significant difference between treatment pore water P (ANOVA, $\mathrm{p}=0.841$ ). However, the mean concentration of $37.2 \mu \mathrm{g} \mathrm{PO}_{4}-\mathrm{P} / \mathrm{L}$, observed in five microcosms without seedlings, one microcosm subjected to each of treatments 0,50 and $100 \mu \mathrm{g} \mathrm{PO}_{4}-\mathrm{P} / \mathrm{L}$ and two microcosms having received the $300 \mu \mathrm{g} \mathrm{PO}_{4}-\mathrm{P} / \mathrm{L}$ treatment, was significantly different from fifteen microcosms from each of the four treatments (Mann Whitney, $\mathrm{p}=0.01$ ).

A similar result was observed on August 13 when no error due to distilled water in the filter cartridge affected results. The mean $\mathrm{PO}_{4}-\mathrm{P}$ concentrations for the microcosms containing shoots from treatments 0, 50, 100 and $300 \mu \mathrm{gO}_{4} / \mathrm{P}$ not sampled on August 09 or 10 was 27.3, 28.7, 30.9 and $31.3 \mu \mathrm{g} \mathrm{PO} / \mathrm{P} / \mathrm{L}$ respectively. The $\mathrm{PO}_{4}$ concentrations did not differ between the treatment groups (ANOVA, $\mathrm{p}=0.942$ ) $($ Figure 33$)$. Whereas, the pooled $\mathrm{PO}_{4}$ concentrations for eleven microcosms with plants (all treatment groups combined) were significantly different to four microcosms without plants subjected to the 0,50 and $100 \mu \mathrm{g} \mathrm{PO} 4-\mathrm{P} / \mathrm{L}$ treatments (Mann Whitney, $\mathrm{p}=0.013$ ). These results indicated that the addition of grow media had had no effect on pore water bioavailable $\mathrm{PO}_{4}-\mathrm{P}$ which was reflected in the similarities between treatments in biomass and HTTL. 


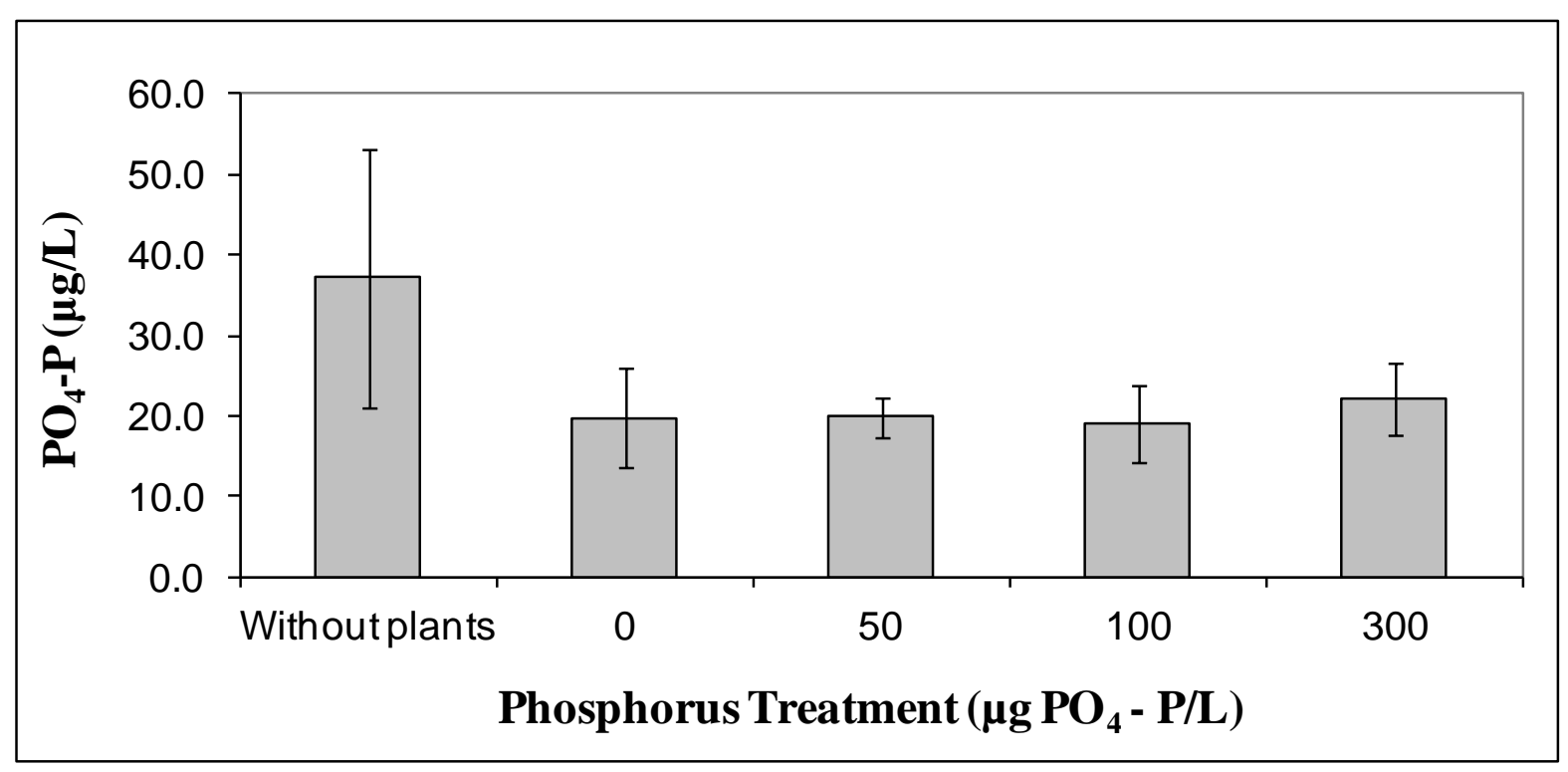

Figure 32. Microcosm pore water $\mathrm{PO}_{4}$ concentrations observed on August 09 and 10.

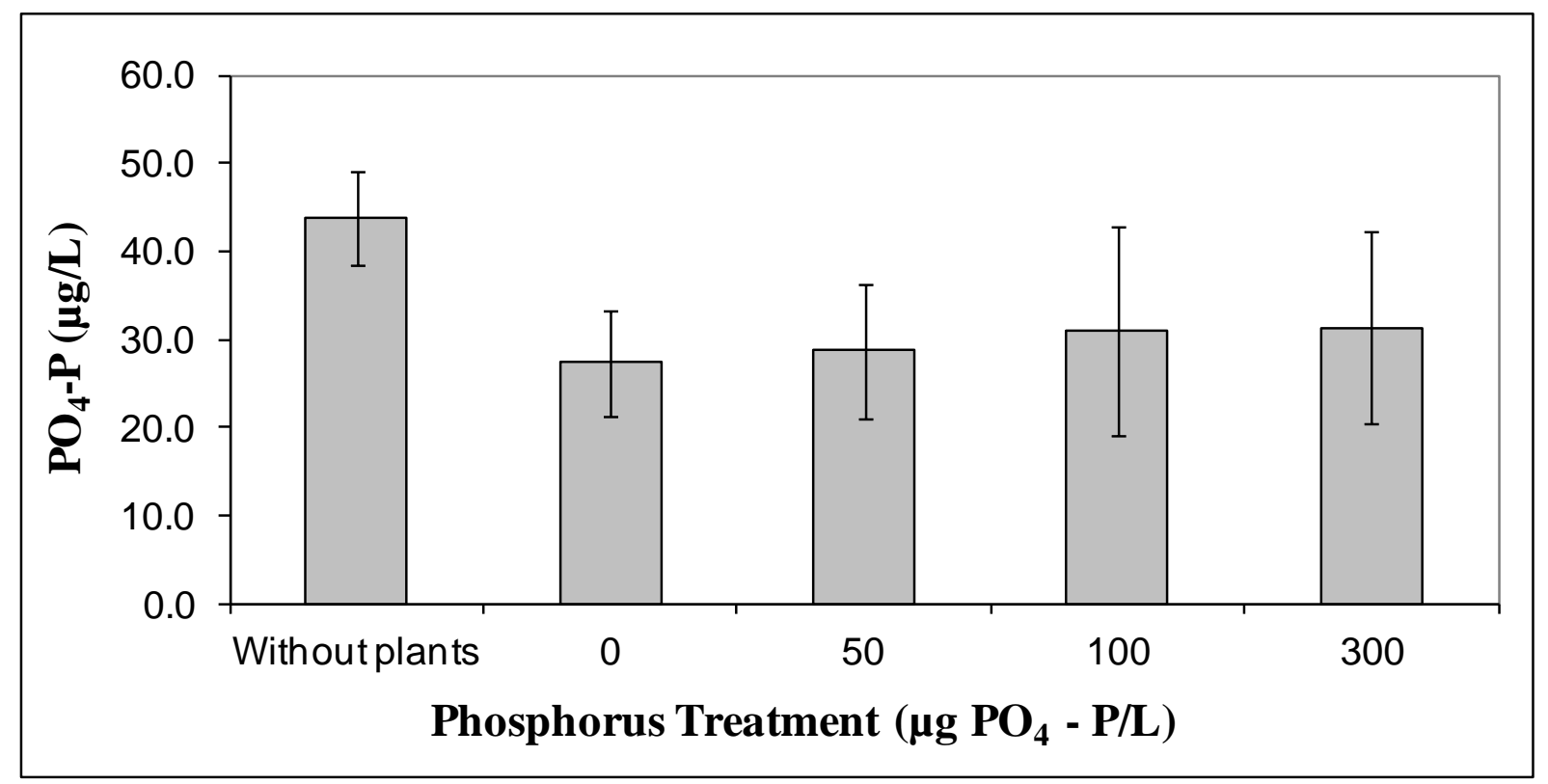

Figure 33. Pore water concentrations from microcosms sampled on August 13. 


\subsection{Typha latifolia Response to Oligotrophic and Eutrophic $\mathbf{N}$ and $\mathbf{P}$ Loading Rates.}

\subsubsection{Environmental Conditions}

The overal median temperature throughout the November 08, 2012 to May 16, 2013 was $22.4^{\circ} \mathrm{C}$ with a range of $19.0^{\circ} \mathrm{C}$ to $27.5^{\circ} \mathrm{C}$. The Accutemp sensor consistently provided very low instantaneous $\mathrm{RH}$ readings compared to that of the Noma $\mathrm{RH}$ sensor and were treated as erroneous. Mean PAR on November 09 was $67 \mu \mathrm{E} \mathrm{cm}^{-2} \mathrm{~s}^{-1} \pm 20$ measured at HTTL and ranged from $23 \mu \mathrm{E} \mathrm{cm}^{-2} \mathrm{~s}^{-1}$ measured at soil height to $90 \mu \mathrm{E} \mathrm{cm}^{-2} \mathrm{~s}^{-1}$ measured at HTTL. Mean PAR on May 08 was $80 \mu \mathrm{E} \mathrm{cm}^{-2} \mathrm{~s}^{-1} \pm 9$ and ranged from $7 \mu \mathrm{E} \mathrm{cm}^{-2} \mathrm{~s}^{-1}$ measured at soil height to $118 \mu \mathrm{E}$ $\mathrm{cm}^{-2} \mathrm{~s}^{-1}$ measured at HTTL.

\subsubsection{Basic Water Quality Parameters}

The basic water quality parameters monitored monthly are provided in

Table 9. Water temperatures generally remained slightly above $20^{\circ} \mathrm{C}$ for the majority of the experiment with water temperatures increasing to up to $25.2^{\circ} \mathrm{C}$ in April and May 2012. The loading rates for the low and high $\mathrm{N}$ treatments from November 08 to May 10 were $2.53 \mathrm{~g}$ $\mathrm{TN} / \mathrm{m}^{2} / \mathrm{yr}$ and $7.50 \mathrm{~g} \mathrm{TN} / \mathrm{m}^{2} / \mathrm{yr}$ respectively. The loading rates for the low and high $\mathrm{P}$ treatments from November 08 to May 10 were $0.03 \mathrm{~g} \mathrm{TP} / \mathrm{m}^{2} / \mathrm{yr}$ and $0.74 \mathrm{~g} \mathrm{TP} / \mathrm{m}^{2} / \mathrm{yr}$ respectively.

Table 9. Basic water quality parameters monitored monthly for the duration of the experiment.

\begin{tabular}{lccccc}
\hline Parameter & $\begin{array}{c}\text { Water } \\
\text { temperature } \\
\left({ }^{\mathbf{0}} \mathbf{C}\right)\end{array}$ & $\begin{array}{c}\text { Dissolved } \\
\text { oxygen } \\
(\mathbf{m g} / \mathbf{L})\end{array}$ & $\mathbf{p H}$ & $\begin{array}{c}\text { Conductivity } \\
(\boldsymbol{\mu S} / \mathbf{c m})\end{array}$ & $\begin{array}{c}\text { Salinity } \\
(\mathbf{m g} / \mathbf{L})\end{array}$ \\
\hline Min & 19.9 & 3.5 & 6.1 & 93.0 & 49.4 \\
Max & 25.2 & 11.5 & 8.0 & 895.0 & 453.0 \\
Mean & 22.2 & 8.5 & 6.7 & 508.3 & 248.8 \\
S.D. & 1.8 & 1.8 & 0.3 & 195.2 & 95.2 \\
\hline S.D. = standard deviation & & & &
\end{tabular}


Surface water dissolved oxygen (DO) concentrations indicated that microcosm surface water remained oxygenated throughout the experiment. Surface water $\mathrm{pH}$ was generally slightly acidic (mean $=6.7$ ), a pH characteristic of natural marsh wetlands and surface flow constructed wetlands (Kadlec and Wallace, 2009). A wide range in conductivities and salinity levels were observed. The salinity level in one microcosm reached $453 \mathrm{mg} / \mathrm{L}$ which slightly exceeded the $450 \mathrm{mg} / \mathrm{L}(0.45 \%)$ salinity concentration defined as brackish by the EPA (EPA, 2013).

\subsubsection{Pre-treatment Shoot Height, Total Leaf Length and Shoot Density Comparisons.}

TLL, HTTL and shoot density data collected on November 07 and November 08 were used to determine whether treatments differed in TLL, HHTL or shoot densities after non-reference microcosms were randomly assigned to one of the four treatment groups. There were no

statistically significant differences between mean TLL (ANOVA, $\mathrm{p}=0.167$ ) or HTTL (ANOVA, $\mathrm{p}=0.315$ ). Mean shoot density observed in the Low N-Low $\mathrm{P}$ was significantly higher than the mean shoot density observed in the High N-High P treatment (ANOVA, $p=0.04$, Tukey, $p=$ $0.028)$.

\subsubsection{Growth Expressed as Total Leaf Length in Response to $\mathbf{N}$ and $\mathbf{P}$ Treatments.}

Growth is defined here as change in TLL. All microcosms grew at a similar rate for the first eight weeks after which the Low N-Low P treatment entered into a steady decline from $796.9 \mathrm{~cm}$ until the end of the experiment on week 28 (Figure 34) by which time TLL was $558.0 \mathrm{~cm}$, resulting in an overall negative growth of $-85.8 \mathrm{~cm}$ from the $643.8 \mathrm{~cm}$ TLL observed at the start of week 2. Increase in TLL in the High N-Low P treatment was gradual after week 8 after which TLL increased to $939.5 \mathrm{~cm}$ over the following 10 weeks.

From week 18 onwards, the High N-Low P treatment entered into a steady decline with TLL decreasing to $725.7 \mathrm{~cm}$ by the week 28 . After reaching a maximum TLL of $981.6 \mathrm{~cm}$ the Low N- High P Mean TLL entered into a decline after week 10 to $797.2 \mathrm{~cm}$ at which point a plateau may have been reached. The mean TLL for microcosms allocated to the High N-High P treatment increased steadily from the beginning of the experiment until week 20 when a mean 
maximum TLL of $875.1 \mathrm{~cm}$ was reached. TLL declined to $826.6 \mathrm{~cm}$ by April 25 followed by an increase to $849.5 \mathrm{~cm}$ suggesting that a possible plateau in growth had been reached. The difference in TLL between treatments was nearly statistically significant (ANOVA, $p=0.089$ )

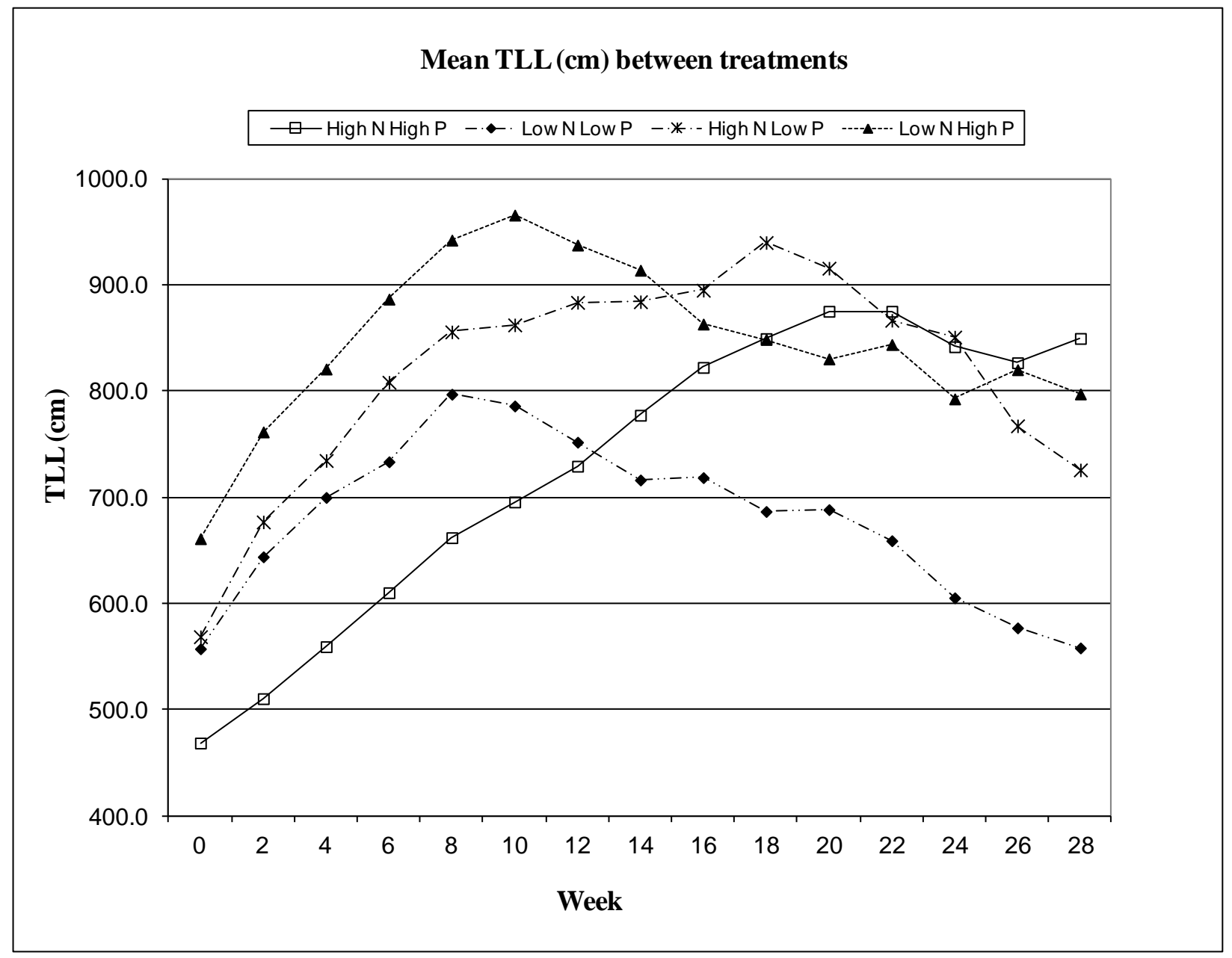

Figure 34 . Growth in response to $N$ and $P$ treatments expressed as change in TLL over time. $\mathbf{N}$ and $P$ treatment additions began at the start of week 2 .

The High N-High P treatment had the greatest mean weekly growth rate at $13.0 \mathrm{~cm}$ TLL/week compared to the other treatments (Table 10), and 10 times the weekly growth rate observed for the Low N- High P treatment. The Low N-Low P treatment experienced a mean weekly growth rate of $-3.3 \mathrm{~cm} /$ week due to week 28 TLL being less that Week 2 TLL. 
Table 10. Mean weekly growth rate expressed as change in TLL over the course of the experiment.

\begin{tabular}{ccc}
\hline & \multicolumn{2}{c}{ Mean growth/week } \\
\cline { 2 - 3 } Treatment & TLL (cm) & S.D. $(\mathbf{c m})$ \\
\hline Low N, Low P & -3.3 & 34.1 \\
High N, Low P & 1.9 & 42.6 \\
Low N, High P & 1.3 & 38.3 \\
High N, High P & 13.0 & 31.3 \\
\hline
\end{tabular}

\subsubsection{Biomass}

The Low N-Low P treatment had significantly less mean shoot biomass compared to the the Low N-High P treatment (Mann Whitney, $\mathrm{p}=0.014$ ) and the High N-High P treatment (Mann Whitney, $\mathrm{p}=0.001$ ) (Figure 35). Mean root biomass, mean root plus shoot (total) biomass and root to shoot ratio did not differ significantly (Figure 35). The Low N-Low P treatment mean HTTL was also significantly less than the Low N-High P treatment (ANOVA, p $=0.002$; Tukey, $\mathrm{p}=0.003$ ) and the High N-High P treatment (ANOVA, $\mathrm{p}=0.002$; Tukey, $\mathrm{p}=$ 0.015). Based on the Kruskal Wallis test, there were no statistically significant differences between root biomass $(p=0.173)$, root plus shoot biomass $(p=0.162)$ and root : shoot ration $(p$ $=0.165$ ) (Figure 35). These results indicate that $T$. latifolia growth and biomass production were primarily limited by phosphorus under the experimental conditions provided. 

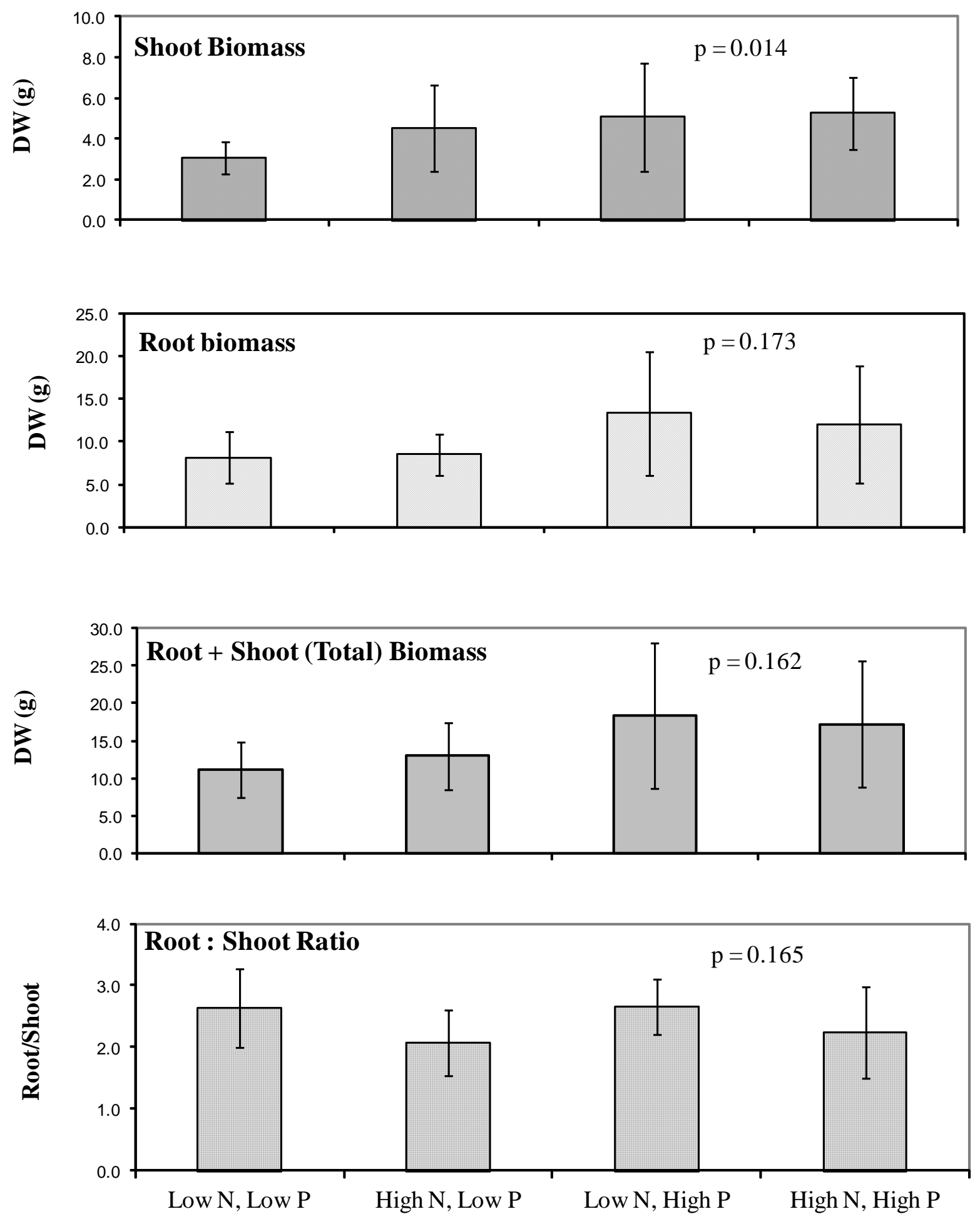

Figure 35. Shoot biomass, root biomass, total biomass and root to shoot ratio observed for low and high $\mathbf{N}$ and $P$ treatments. 


\section{DISCUSSION}

The primary objectives of the following thesis were to (1) establish a protocol for propagating T. latifolia from seed for effective hypothesis testing where individuals of equal age, fitness and genetic characteristics could be used to avoid experimental error associated with using plants of unknown origin, history, variable fitness and which could potentially introduce pests that could jeopardize study results. The majority of research reviewed involving Typha spp. has produced experimental units grown from rhizome (e.g. Weng et al., 2006) collected from locations which may be subjected to stressors, including anthropogenic contaminants, that may influence study results. Ye et al. (1997), Wetzel and van der Valk (1998) and Kercher and Zedler (2004) propagated T. latifolia from seed for research purposes; however, complete details on watering and feeding regimens, lighting conditions such as photoperiod, light intensity; soil type if used, or soil moisture content were lacking.

The second primary objective was to (2) propagate $T$. latifolia in low nutrient sediment for use as a reference treatment to effectively test the hypothesis that $T$. latifolia survival, growth and biomass is enhanced as a result of elevated but environmentally relevant concentrations of $\mathrm{N}$ and P. Previous studies that examined Typha spp. response to elevated nutrients (e.g. Shipley and Keddy, 1988; Wetzel and van der Valk, 1998; Keddy et al., 2000; Woo and Zedler, 2002) used concentrations that may be considered environmentally irrelevant and therefore are limited in terms of explaining T. latifolia invasions in areas were surface water and sediment nutrients may be far lower.

\subsection{Germination}

The overall percent germination of $85 \%$ observed in microcosms containing submerged or saturated sediment provided with various concentrations of $\mathrm{PO}_{4}$ and the $93 \%$ germination observed in Petri dishes containing MDW were similar to the percent germination observed in preliminary trials (77 to 82\%) and those reported by other authors which examined factors such as temperature, light and dissolved oxygen on T. latifolia germination (e.g. Morinaga, 1926; 
Sifton, 1959; Yeo, 1964; Bonnewell et al., 1983). There was no effect of $\mathrm{P}$ treatment on percent germination as was observed by Stewart et al. (1997).

Steps were not taken to maximize percent germination other than to minimize handling and maintain seeds in an unaltered condition to achieve as close to natural conditions as is possible in a laboratory setting. The documented optimum temperature for germinating T. latifolia seed under laboratory conditions differs between authors suggesting that preferred temperature may be population-dependant. Sifton (1959) reported the optimum temperature to range from 25 $30^{\circ} \mathrm{C}$ whereas Bonnewell et al., (1983) reported an optimum temperature of $30^{\circ} \mathrm{C}$. McNaughton (1966) reported the highest percent germination occurred between $24-30^{\circ} \mathrm{C}$ and varied between seeds collected from populations ranging from the southern tip of Texas to the Canadian border. The widely fluctuating temperatures, where temperatures ranged between $22-32^{\circ} \mathrm{C}$ during the germination phase of the seedling propagation experiment involving $\mathrm{P}$ treatments, were within the optimum temperature range indicated by the aforementioned authors. Sifton (1959) also observed enhanced germination by alternating temperatures between 15 to $30^{\circ} \mathrm{C}$. The literature therefore suggests that near optimum temperature conditions were present at the time seeds were imbibed at the beginning of the experiment and the seed viability investigation which likely contributed to the high percent germination observed.

Sifton (1959) reported a high percent germination $>80 \%$ of $T$. latifolia seeds under reduced light conditions subjected to alternating temperatures. Mean PAR measured in each of the 40 microcosms was $144 \mu \mathrm{E} \mathrm{cm}^{-2} \mathrm{~s}^{-1}$ and $62 \mu \mathrm{E} \mathrm{cm}^{-2} \mathrm{~s}^{-1}$ for the seed viability with overall percent germination being similar between the two groups of seeds suggesting that high germination can be achieved under comparatively low light conditions. In short, the seeds obtained from the single $T$. latifolia flower used for this thesis provided a similar germination rate reported in the literature indicating that the environment provided for seed germination was effective in achieving a percent germination sufficient for hypothesis testing. 


\subsection{A Protocol for Examining Typha latifolia Response to Phosphorus Loading.}

The purpose of the following experiment was to test the hypothesis that T. latifolia postgerminated seedling growth and survival is increased by $\mathrm{P}$ loading at eutrophic and hypereutrophic conditions as defined by Wetzel (1983), Environment Canada (2004) and the EPA (Wikipedia, 2013a), considered here as environmentally relevant concentrations that are typically found in natural aquatic ecosystems impacted by non-point sources of $\mathrm{P}$. The low $\mathrm{N}$ and $\mathrm{P}$ treatment loading rates added to microcosms for this experiment were $2.53 \mathrm{~g} \mathrm{TN} / \mathrm{m}^{2} / \mathrm{yr}$ and $0.03 \mathrm{~g} \mathrm{TPm}^{2} / \mathrm{yr}$ respectively and $7.50 \mathrm{~g} \mathrm{TN} / \mathrm{m}^{2} / \mathrm{yr}$ and $0.74 \mathrm{~g} \mathrm{TP} / \mathrm{m}^{2} / \mathrm{yr}$ loading rates for the high $\mathrm{N}$ and $\mathrm{P}$ treatments respectively. The TN and TP loading rates documented by Reddy et al. (1993) where no impact (T. domingensis invasion) of nutrient loading were evident in the Florida Everglades ranged from $4.7-6.4 \mathrm{~g} \mathrm{TN} / \mathrm{m}^{2} / \mathrm{yr}$ and $0.06 \mathrm{TP} / \mathrm{m}^{2} / \mathrm{yr}$ whereas the loading rates of $13.6-16.6 \mathrm{~g} \mathrm{TN} / \mathrm{m}^{2} / \mathrm{yr}$ and $0.4-0.46 \mathrm{TP} / \mathrm{m}^{2} / \mathrm{yr}$ resulted in observable impact. Similarly, Reddy et al. (1993) observed dominance of Cladium jamaicense in areas of the Florida Everglades where the $\mathrm{P}$ loading rates ranged from $0.11-0.25 \mathrm{~g} \mathrm{TP} / \mathrm{m}^{2} / \mathrm{yr}$ whereas $T$. domingensis dominated areas where loading rates ranged from $0.54-1.14 \mathrm{~g} \mathrm{TP} / \mathrm{m}^{2} / \mathrm{yr}$. The observed T. latifolia response to both the experimental high and low $\mathrm{N}$ and $\mathrm{P}$ loading rates are in close agreement to the observed distribution of T. domingensis in the Florida Everglades. Stewart et al (1997) noted that $T$. latifolia, believed to be a recent invader to the Florida Everglades, is restricted to areas impacted by nutrient loading. The environmentally relevant loading rates used by this experiment is therefore likely appropriate for conducting competitive experiments that more closely resemble non-point source $\mathrm{N}$ and $\mathrm{P}$ loading to determine T. latifolia competitiveness and potential invasiveness.

Study results did not observe an effect of $\mathrm{PO}_{4}-\mathrm{P}$ treatments added at 0, 50, 100 and $300 \mu \mathrm{g}$ $\mathrm{PO}_{4}$ - $\mathrm{P} / \mathrm{L}$ with total volume added being $1300 \mathrm{ml}$ on pore water $\mathrm{P}$ over a 10 week period. The maximum difference in pore water $\mathrm{PO}_{4}-\mathrm{P}$ between treatment mean concentrations sampled on August 09 and 10 was $3.2 \mu \mathrm{g} \mathrm{PO}_{4}-\mathrm{P} / \mathrm{L}$. The maximum difference between treatment mean concentrations collected on August 13 was $4.1 \mu \mathrm{g} \mathrm{PO}-\mathrm{P} / \mathrm{L}$. Similarly, the maximum difference between treatment mean seedling biomass was $0.77 \mathrm{~g} \mathrm{WW}$. 
These results indicated that the sediment, low in $\mathrm{P}$, adsorbed sufficient quantities of $\mathrm{P}$ to nullify the effects of each treatment. The similar pore water $\mathrm{PO}_{4}-\mathrm{P}$ concentrations in the $0 \mathrm{P}$ added compared to the 50, 100 and $300 \mu \mathrm{g} \mathrm{PO}_{4}-\mathrm{P} / \mathrm{L}$ indicated that sufficient amounts of bioavailable $\mathrm{P}$ were being generated internally through microbial decomposition of organic matter which comprised $80 \%$ of the $200 \mathrm{~g}$ of top soil added (Presidents Choice, personal communication). The total weight of $\mathrm{P}$ added to the 50, 100 and $300 \mu \mathrm{g} \mathrm{PO}_{4}-\mathrm{P} / \mathrm{L}$ treatments in the total $1300 \mathrm{ml}$ of grow media added was equivalent to $0,65,130$ and $390 \mu \mathrm{g} \mathrm{P} / \mathrm{kg}$ of sediment. $\mathrm{P}$ adsorption to sand and other types of sediments has been well documented (e.g. Richardson, 1985; Danen-Louwerse et al., 1993; White et al., 2000; Vymazal, 2007; Vohla et $a l ., 2011)$ and increasing the frequency of grow media addition from alternating days to daily additions from the start of the experiment may have resulted in a treatment effect. However, considering that sediment TP in Cootes Paradise can reach nearly $2.0 \mathrm{~g} \mathrm{TP} / \mathrm{kg}$ of sediment (Mayer et al., 2008) with a mean surface water concentration averaging $210 \mu \mathrm{g}$ TP/L (Court and Bowman, 2010), the amount P needed in order to have an observable effect would have been too high to be considered environmentally relevant and therefore counter to study objectives.

Furthermore, it cannot be determined whether the T. latifolia seedlings were limited by P. The significantly higher $\mathrm{PO}_{4}$ levels in the pore water of microcosms without seedlings compared to those with seedlings indicates that seedlings were removing $\mathrm{P}$ at a sufficiently high enough rate to have had a measurable effect on sediment $\mathrm{P}$ concentrations. Given that $>20 \mu \mathrm{g} \mathrm{PO}_{4}-\mathrm{P} / \mathrm{L}$ was detected in the pore water sediment affected by plant uptake may suggest that $\mathrm{P}$ was not limiting. Furthermore, some Low N - Low P T. latifolia genets grew to $1351.8 \mathrm{~cm}$ TLL over a three month period from September 15 through to December 20. The addition of greater amounts of $\mathrm{P}$ may therefore not have resulted in greater post-germination seedling growth. By surface water quality standards, the $300 \mu \mathrm{g} \mathrm{PO}_{4}-\mathrm{P}$ treatment is considered very high based on criteria presented in Wetzel (1983) and three times the concentration classified as hypereutrophic by Environment Canada (2004). The P requirements of T. latifolia seedlings may be sufficiently low to enable early survival and possibly recruit to adult stages in P-poor sediment. T. latifolia can occur in isolated stands in what are gernally considered to be nutrient-poor habitats (e.g., City of Toronto and the Upper Thames Conservation Authority, 2009) as can other Typha spp where they may be restricted to isolated stands (Newman et al., 1996). The precence of $T$. 
latifolia in pristine wetlands within the circumpolar boreal regions (Bourgeois et al. 2012) suggests that T. latifolia can establish in low nutrient wetland habitats. However, the presence of mesotrophic to eutrophic levels of $\mathrm{P}$ in porewater observed for the seedling response to $\mathrm{P}$ experiment including treatments that did not receive $\mathrm{P}$ additions suggests that sediment organic matter content and its rate of mineralization by mirorobes is an important factor in T. latifolia recruitment, establishment, distribution and invasiveness. Further research is need to the significance of sediment and pore water $\mathrm{P}$ on T. latifolia distribution and invasiveness.

The ability to propagate $T$. latifolia from seed in sediment low in $\mathrm{P}$ would enable future competition studies that could compare the competitiveness of T. latifolia against other native species at various $\mathrm{P}$ concentrations to determine a $\mathrm{P}$ threshold above which $T$. latifolia can become invasive. The broadly distributed but often rare species from the Class Isoetes are adapted to low nutrient conditions (Smolders et al., 2002) and may be considered as a candidate species in competition experiments. Schoenoplectus spp. are not considered to be adapted to low nutrient conditions but have proven to be effective in constructed wetlands (e.g. Tanner, 2001; Nelson and Thullen, 2008; Kadlec and Wallace 2009; Lee et al 2009; Daniels et al., 2010; Pollard, 2010). Neil and Graham (1989) observed greater N and P removal rates by wetland microcosms planted with S. tabernaemontani compared to wetlands planted with T. angustifolia. Efforts to propagate sufficient numbers of Schoenoplectus acutus and Schoenoplectus tabernaemontani from seed were unsuccessful. Continued research into developing methods for germinating noninvasive native species is recommended.

No data was found in the literature with which to compare the observed overall $53.5 \%$ seedling mortality rate, the cause of which is unknown. Qualitative observations of the surficial sediments which at times appeared dry despite registering a moist to average wet indicated a possible water limitation especially for newly germinated seedlings with limited root penetration. Wetzel and van der Valk (1998) stated that only a few seedlings died after two weeks from the time of germination. Also, the observed mortality rate was higher than compared to one preliminary propagation trial (Propagation Trial 2, Appendix E) which observed a mortality rate of 20\%. Propagation Trial 2 applied previously germinated seeds onto high nutrient Scots Garden Essentials topsoil in seed trays where soil was kept moist by placing seed trays into a reservoir containing up to $1.0 \mathrm{~cm}$ of $\mathrm{MDW}$. 
The MDW used throughout the first experiment contained chloramine which ranged from $0.29 \mathrm{mg} / \mathrm{L}$ to $0.93 \mathrm{mg} / \mathrm{L}$ (Jorge Loyo, personal communication). MDW analysis carried out by a private lab indicated elevated $\mathrm{Cu}$. Toxicity trials of unfiltered MDW VS activated carbon filtered MDW resulted in increased mortality for Daphnia magna and Hyalella azteca (M. Raby, personal communication) in unfiltered water to which chloramine and $\mathrm{Cu}$ may have been contributing factors. T. latifolia has been shown have constitutional tolerance (inherent tolerance regardless of population or exposure history) to zinc $(\mathrm{Zn})$, cadmium $(\mathrm{Cd})$ and lead $(\mathrm{Pb})$ at high concentrations (McNaugton et al., 1974; Ye et al., 1997). Tolerance of T. latifolia adults and clones to $\mathrm{Cu}$ has also been observed by Taylor and Crowder (1984) and Maddison et al. (2005). The effect of elevated $\mathrm{Cu}$ levels on newly germinated T. latifolia seedlings is unknown and may have contributed to seedling mortality.

Data on post-germination seedling growth rates were also not found in the literature. Wetzel and van der Valk (1998) began measuring seedling growth determined by HTTL and number of leaves three weeks after germination in interspecific competition experiments in soil containing 5 to $20 \mathrm{mg}$ of bioavailable $\mathrm{P} / \mathrm{g}$ of soil and $7 \mathrm{mg} / \mathrm{g}$ nitrate and at similar light intensities of up to $420 \mu \mathrm{E} \mathrm{m}^{-2} \mathrm{~s}^{-1}$. The overall mean HTTL observed in this experiment was $25.2 \mathrm{~cm}$ after twelve weeks which were highly comparable to the HTTL illustrated in the graphs presented in Wetzel and van der Valk (1998) where heights of approximately $30 \mathrm{~cm}$ or less were observed depending on the degree of competition with other species. If competition had a negligible effect

on seedlings, it would suggest that nutrient limitation may not have occurred over the first twelve week period. Wetzel and van der Valk (1998) did however observe a noticeable difference in dry weight biomass at 18 weeks. The very high production of biomass observed by Yeo (1964) where 34 aerial shoots ranging in 46 to $122 \mathrm{~cm}$ was observed further suggests that seedlings were nutrient limited.

\subsection{Typha latifolia Response to Oligotrophic and Eutrophic $N$ and $P$ Loading Rates.}

The results of the experiment conducted to determine the relative effects of $\mathrm{N}$ and $\mathrm{P}$ at oligotrophic and/or eutrophic to hypereutrophic loading rates observed significantly higher shoot 
biomass and HTTL in the Low N- High P treatment and the High N - High P treatment compared to the oligotrophic Low N - Low P supporting the hypothesis that T. latifolia biomass increases significantly under elevated yet environmentally relevant $\mathrm{P}$ loading rates. The High $\mathrm{N}$ - Low P loading rate treatment was intermediate in biomass and did not differ significantly between either. $\mathrm{N}$ was therefore a contributor to biomass suggesting $\mathrm{N}$ and $\mathrm{P}$ co-limitation at the time the experiment was terminated. These results are in agreement with Woo and Zedler (2002) who observed $\mathrm{N}$ and $\mathrm{P}$ co-limitation in T. x glauca reared under green house conditions. However, the High $\mathrm{N}$ - low P treatment (Figure 35) had exhibited a downward linear trend since week 18 at a rate more rapid than that of the Low $\mathrm{N}$ - low P treatment. Had the experiment ran longer and this trend continued, the biomass would have decreased to levels significantly different to that of the high $\mathrm{P}$ treatments, assuming that the high $\mathrm{P}$ treatments had stabilized. Based on these results, T. latifolia appears to have been primarily P-limited as was observed by Boyd and Hess (1970).

Due to the 16L: 8D photoperiod, T. latifolia growth over nearly a twelve month period was achieved since the late summer translocation of carbohydrates to the rhizome and the subsequent overwintering dormancy period that occurs under natural conditions (Garver et al., 1988) did not occur. The decline in the Low $\mathrm{N}$-Low $\mathrm{P}$ and the High $\mathrm{N}$ - Low $\mathrm{P}$ treatment raises the question as to whether T. latifolia could have persisted under low $\mathrm{N}$ and $\mathrm{P}$ conditions given that the majority of carbohydrate storage is consumed during the overwintering period with the remainder being used to generate new shoots the following spring. How the lack of a wintering period affected results is unknown but it could be assumed that a greater amount of biomass and carbohydrate storage was able to accumulate under experimental controlled conditions than would have occurred under natural conditions.

T. latifolia biomass production and shoot height under artificial light relative to natural light is unknown. The mean shoot-to- root ratios for all treatments (similar to root: shoot ratios provided in the Results section) was 0.45 and ranged from $0.22-0.77$. Reddy and Portier (1987) considered shoot: root ratios between $0.72-0.82$ to be low and, following $\mathrm{N}$ fertilization and increased temperatures to $25^{\circ} \mathrm{C}$, observed shoot: root ratios of $1.83-3.04$. Shoot production under experimental conditions was therefore relatively low and may be a reflection of reduced light intensities. However, Grace and Wetzel (1981a) observed greater heights and leaf volume 
in a natural T. latifolia stand growing under a canopy compared a T. latifolia stand occurring in an open marsh. The genets growing under canopy did not produce flowers, as was observed in this experiment, whereas genets growing in an open marsh habitat produced flowers leading Grace and Wetzel (1981a) to hypothesize that the shoots, growing under canopy, were light limited and therefore allocated resources entirely to shoot production to achieve maximum height. T. latifolia are considered to be shade tolerant (Grace and Wetzel, 1981a) and the use of artificial light may not significantly reduce biomass production but may inhibit the production of culms and inflorescence. Newly emerging ramets were observed throughout the experiment under light conditions as low as $7 \mu \mathrm{E} \mathrm{cm}^{-2} \mathrm{~s}^{-1}$. The high germination rate observed at a mean PAR of $62 \mu \mathrm{E} \mathrm{cm}^{-2} \mathrm{~s}^{-1}$ suggests that experiments carried out under artificial light can produce environmentally relevant results.

The observed shoot densities, which ranged from 53 to 481 shoots $/ \mathrm{m}^{2}$, was considerably higher than $20-40 \mathrm{shoot} / \mathrm{m}^{2}$ shoot densities typically reported in the literature (e.g. Walton $e t$ $a l ., 1990)$. This difference is likely due to methodology where stem density counted under field conditions is likely based on the number of mature or visible shoots with newly emerging shoots either being discounted or, if submerged or hidden by leaf litter, not detected. However, one shoot placed into one microcosm $\left(\right.$ area $=0.01873 / \mathrm{m}^{2}$ ) is equivalent to 53 shoots $/ \mathrm{m}^{2}$. Vessel size may therefore have restricted growth and therefore the ability to fully take advantage of the available $\mathrm{N}$ and $\mathrm{P}$. Increasing vessel size may produce a greater response to $\mathrm{N}$ and $\mathrm{P}$ loading but at the cost of the number of replicates and therefore reduced statistical power.

\subsection{Recommendations for Further Study}

For future development of T. latifolia and other wetland species propagation protocols where high survival rate is required, a rigorous evaluation of newly germinated seedling mortality and sediment moisture conditions is recommended. Given that nutrient additions were unlikely limiting, the drying of surficial sediments may contribute to seedling desiccation . The soil moisture probe was not effective in sediments above $2.0 \mathrm{~cm}$ and so sediment moisture levels may not have been an accurate reflection of sediment conditions for newly germinated seedlings.

It is recommended that competition studies be conducted to determine the $\mathrm{N}$ and $\mathrm{P}$ levels at which $\mathrm{N}$ and $\mathrm{P}$ loading rates result in T. latifolia dominance. The protocol used a low $\mathrm{P}$ 
formulated sediment which is necessary to establish a low nutrient, pre-impact reference. To provide a suitable high $\mathrm{N}$ and/or $\mathrm{P}$ comparison, the same sediment should be treated with sufficient levels of $\mathrm{P}$ prior to the addition of seedlings given that added $\mathrm{N}$ and $\mathrm{P}$ at environmentally relevant levels once seedlings are planted would not be possible due to the risk mortality caused by drowning.

The inability to germinate Schoenoplectus acutus and S. tabernaemontani indicates that established protocols for germinating a variety of native species are needed. Species that are light sensitive and which may require natural light could be germinated in cold frames (wooden boxes with a glass lid) which can easily be built to a size according to available space to establish germination protocols that will provide a sufficient number of individuals required for effective hypothesis testing.

It is further recommended that the presence and distribution of T. latifolia and other Typha spp. occurring in low nutrient wetlands and how their distributions relate to spacial differences in sediment organic matter and nutrient content to determine of isoloated Typha stands in low nutrient wetlands are restricted to microhabitats of higher nutrient availability. How Typha distribution can be predicted by more easily determined surface water nutrient levels as compared to sediment and pore water nutrient levels would (i) determine the usefulness of

surface water nutrients in predicting T. latifolia invasion and success of recovery efforts and (ii) whether pore water as observed by Angeloni et al. (2006) and sediment P may be better predictors of $\mathrm{T}$. latifolia invasion.

\subsection{Summary}

The objectives of the thesis were as follows:

1. Develop a protocol for rearing Typha latifolia from seed to adult stages under laboratory conditions to enable hypothesis testing based on data collected from plants of known history, uniform age and comparable fitness; 
2. Conduct controlled, rigorous experiments with sufficient replication to further existing knowledge on the effects of environmentally relevant $\mathrm{N}$ and $\mathrm{P}$ loading rates on T. latifolia survival, growth and biomass;

The sub-objectives were as follows:

1. Determine the feasibility of conducting future competition and nutrient removal experiments between T. latifolia and the native non-invasive species such as Schoenoplectus acutus and Schoenoplectus tabernaemontani under laboratory conditions;

2. Based on literature review, present supporting evidence for the hypothesis that native, non-invasive wetland macrophytes would provide $\mathrm{N}$ and $\mathrm{P}$ removal rates comparable to currently used invasive species and raise the issue of invasive species use in constructed wetlands to encourage research to determine the feasibility of utilizing non-invasive species in constructed wetlands for $\mathrm{N}$ and $\mathrm{P}$ removal.

\subsubsection{Typha latifolia Nitrogen and Phosphorus Limitation and Constructed Wetland Use for Ecological Protection and Restoration.}

The significant difference between the shoot biomass and maximum leaf height of microcosms exposed to oligotrophic $\mathrm{P}$ loading rates compared to eutrophic to hypereutrophic $\mathrm{P}$ loading rates supports the hypothesis that environmentally relevant levels of $\mathrm{P}$, far lower than have previously been assessed by previous studies, is supported. Increased biomass and leaf height may therefore enable T. latifolia to outcompete less competitive species or species adapted to low nutrient conditions under nutrient loading rates commonly observed in nonpoint source agricultural and stormwater runoff

Other authors have identified increased and stabilized water levels as a cause for T. latifolia invasions (e.g. Kercher and Zedler, 2004; Wilcox et al., 1985; Wilcox et al., 2008). Smolders et al. (2006) indicated that anoxic sediments created as a result of inundation can lead to the 
reduction of Fe-bound $\mathrm{P}$ and the release of bioavailable $\mathrm{P}$. Artificially high water levels and $\mathrm{P}$ availability may therefore be inextricably linked with a potentially synergistic effect that contributes to Typha invasions.

The effect of eutrophic $\mathrm{N}$ loading rates on biomass was not significant. However, other researchers have observed N limitation in T. latifolia (e.g. Grace and Wetzel, 1981a; Reddy and Portier, 1987; Grace, 1988). The management of T. latifolia and other Typha species must therefore consider both $\mathrm{N}$ and $\mathrm{P}$.

\subsubsection{The Use of Constructed Wetlands for the Protection and Restoration of Aquatic Ecosystems}

The effectiveness of constructed wetlands for the restoration of eutrophicated aquatic ecosystems appears highly limited based on the available literature. A careful mass balance estimate should be conducted, including $\mathrm{N}$ and $\mathrm{P}$ burial rate and denitrification, in order to evaluate whether the amount of $\mathrm{N}$ and $\mathrm{P}$ removed would have a beneficial biological response in terms of reduced algal biomass and increased water clarity. A risk assessment should also be conducted to determine the potential impacts of new developments involving the release of nutrients and subsequent treatment by constructed wetlands to determine (1) if a proposed constructed wetland will result in a biologically significant reduction in $\mathrm{N}$ and $\mathrm{P}$ based on changes in chlorophyll $a$ and algal biomss and (2) whether significant impact downstream as a result of ecologically impacting levels of $\mathrm{N}$ and $\mathrm{P}$ in effluent will occur. The use of $T$. latifolia and other species known to be invasive and commonly used in constructed wetlands under high nutrient loading rates would impose a significant environmental risk in watersheds that have not been impacted by invasive species. Furthermore, the false notion that wetlands are highly effective at removing $\mathrm{N}$ and $\mathrm{P}$ with the currently available constructed wetland technology needs to be addressed through a greater transfer of knowledge and appreciation of natural ecosystems and the ecological and socioeconomic impacts invasive species can incur. An objective evaluation of existing nutrient management programs and strategies should be carried out to identify potential opportunities for improving nutrient management before considering constructed wetlands for nutrient removal. 


\section{APPENDIX}

Raw data not included in this Appendix Section is available upon special request, pending purpose and approval from the author of this thesis and the authors' supervisor.

\subsection{Appendix A}

\section{Batch 1 Sediment}

\section{Table A1}

\begin{tabular}{cccc} 
Date in & Time in & Date out & Time out \\
\hline May 02,12 & 1650 & May 03,12 & 1700
\end{tabular}

Note: tests conducted on May 03, 12 at 1300 and 1900 indicated constant weight (total moisture removal) at $1300 \mathrm{hrs}$

May 02 and May 03, 2012. PCBE seived.

\begin{tabular}{|c|c|c|c|c|c|c|}
\hline \multirow{3}{*}{$\begin{array}{c}\text { Container } \\
\text { Weight } \\
\text { (g) }\end{array}$} & \multicolumn{6}{|l|}{ Container } \\
\hline & Weight + & & Container & & & \\
\hline & $\begin{array}{l}\text { PCBE WW } \\
\text { (g) }\end{array}$ & $\begin{array}{l}\text { PCBE WW } \\
\text { (g) }\end{array}$ & $\begin{array}{c}\text { Weight + PCBE } \\
\text { DW (g) }\end{array}$ & PCBE DW (g) & $\begin{array}{l}\text { Moisture } \\
\text { Content (g) }\end{array}$ & Moisture (\%) \\
\hline 58.58 & 68.94 & 10.36 & 62.64 & 4.06 & 6.30 & 60.81 \\
\hline 65.64 & 76.01 & 10.37 & 69.74 & 4.10 & 6.27 & 60.46 \\
\hline 60.31 & 70.35 & 10.04 & 64.29 & 3.98 & 6.06 & 60.36 \\
\hline 58.56 & 68.49 & 9.93 & 62.50 & 3.94 & 5.99 & 60.32 \\
\hline 58.71 & 69.28 & 10.57 & 62.95 & 4.24 & 6.33 & 59.89 \\
\hline 60.03 & 70.31 & 10.28 & 64.15 & 4.12 & 6.16 & 59.92 \\
\hline 62.49 & 72.46 & 9.97 & 66.46 & 3.97 & 6.00 & 60.18 \\
\hline 69.07 & 79.12 & 10.05 & 73.09 & 4.02 & 6.03 & 60.00 \\
\hline 63.44 & 73.41 & 9.97 & 67.42 & 3.98 & 5.99 & 60.08 \\
\hline 68.57 & 78.57 & 10.00 & 72.56 & 3.99 & 6.01 & 60.10 \\
\hline Mean & & 10.15 & & 4.04 & & 60.21 \\
\hline Std dev & & 0.22 & & 0.09 & & 0.28 \\
\hline
\end{tabular}




\section{Batch 2 Sediment}

\section{Table A3}

\begin{tabular}{cccccc}
\hline Date in & Time in & Date out & $\begin{array}{c}\text { Time out (1st } \\
\text { measurement) }\end{array}$ & Date out & $\begin{array}{c}\text { Time out (2nd } \\
\text { measurement) }\end{array}$ \\
\hline \hline May 17,12 & 2258 & May 18,12 & 1301 & May 18,12 & 1530
\end{tabular}

May 17 and May 18, 2012. PCBE unseived. Sediment mixed some what in bag by rotating

\begin{tabular}{|c|c|c|c|c|c|c|c|}
\hline \multicolumn{8}{|c|}{ Beaker } \\
\hline Glass & Weight + & & Beaker Weight & Beaker & & & \\
\hline Beaker & mixed & & + PCBE DW (g) & Weight + PCBE & & & \\
\hline Weight & sand/PCBE & PCBE WW & (1st & $\mathrm{DW}(\mathrm{g})(2 \mathrm{nd}$ & & Moisture & Moisture \\
\hline (g) & WW (g) & (g) & meaurement) & meaurement) & PCBE DW (g) & Content (g) & (\%) \\
\hline 27.7 & 33.32 & 5.62 & 29.84 & 29.85 & 2.14 & 3.48 & 61.92 \\
\hline 28.54 & 33.51 & 4.97 & 30.39 & 30.39 & 1.85 & 3.12 & 62.78 \\
\hline 26.79 & 32.51 & 5.72 & 28.92 & 28.92 & 2.13 & 3.59 & 62.76 \\
\hline 30.53 & 35.44 & 4.91 & 32.37 & 32.37 & 1.84 & 3.07 & 62.53 \\
\hline 28.5 & 33.77 & 5.27 & 30.46 & 30.45 & 1.96 & 3.31 & 62.81 \\
\hline Mean & & 5.30 & 30.40 & 30.40 & 1.98 & 3.31 & 62.56 \\
\hline Stdev & & 0.37 & 1.26 & 1.26 & 0.15 & 0.22 & 0.37 \\
\hline
\end{tabular}

Batch 2, 3 Sediment

Table A4

\begin{tabular}{cccccc}
\hline Date in & Time in & Date out & $\begin{array}{c}\text { Time out (1st } \\
\text { measurement) }\end{array}$ & Date out & $\begin{array}{c}\text { Time out (2nd } \\
\text { measurement) }\end{array}$ \\
\hline \hline May 18,12 & 1615 & May 18,12 & 2200 & May 19,12 & 1230
\end{tabular}

May 18 and May 19, 2012. PCBE seived. Topsoil mixed in mixed bucket prior to sampling.

\begin{tabular}{|c|c|c|c|c|c|c|c|c|}
\hline $\begin{array}{c}\text { Glass } \\
\text { Beaker \# }\end{array}$ & $\begin{array}{c}\text { Glass } \\
\text { Beaker } \\
\text { Weight (g) }\end{array}$ & $\begin{array}{c}\text { Beaker } \\
\text { Weight + } \\
\text { mixed } \\
\text { sand/PCBE } \\
\text { WW (g) }\end{array}$ & PCBE WW (g) & $\begin{array}{c}\text { Beaker } \\
\text { Weight + PCBE } \\
\text { DW (g) (1st } \\
\text { meaurement) }\end{array}$ & $\begin{array}{l}\text { Beaker Weight } \\
+ \text { PCBE DW (g) } \\
\text { (2nd } \\
\text { meaurement) }\end{array}$ & PCBE DW (g) & $\begin{array}{c}\text { Moisture } \\
\text { Content } \\
\text { (g) }\end{array}$ & $\begin{array}{c}\text { Moisture } \\
\text { (\%) }\end{array}$ \\
\hline 1 & 27.7 & 32.46 & 4.76 & 29.54 & 29.49 & 1.79 & 2.97 & 62.39 \\
\hline 2 & 28.54 & 33.25 & 4.71 & 30.36 & 30.33 & 1.79 & 2.92 & 62.00 \\
\hline 3 & 26.79 & 32.12 & 5.33 & 29.19 & 28.79 & 2 & 3.33 & 62.48 \\
\hline 7 & 30.53 & 35.6 & 5.07 & 32.62 & 32.44 & 1.91 & 3.16 & 62.33 \\
\hline 9 & 28.5 & 34.11 & 5.61 & 30.95 & 30.62 & 2.12 & 3.49 & 62.21 \\
\hline & Mean & & 5.10 & 30.53 & 30.33 & 1.92 & 3.17 & 62.28 \\
\hline & Stdev & & 0.38 & 1.36 & 1.38 & 0.14 & 0.24 & 0.19 \\
\hline
\end{tabular}




\section{Batch 4}

\section{Table A5}

\begin{tabular}{cccccc}
\hline Date in & Time in & Date out & $\begin{array}{c}\text { Time out (1st } \\
\text { measurement) }\end{array}$ & Date out & $\begin{array}{c}\text { Time out (2nd } \\
\text { measurement) }\end{array}$ \\
\hline \hline May 19,12 & 2138 & May 20,12 & 1123 & May 20,12 & 1421
\end{tabular}

May 19 and May 20, 2012. PCBE seived. Topsoil mixed in mixed bucket prior to sampling.

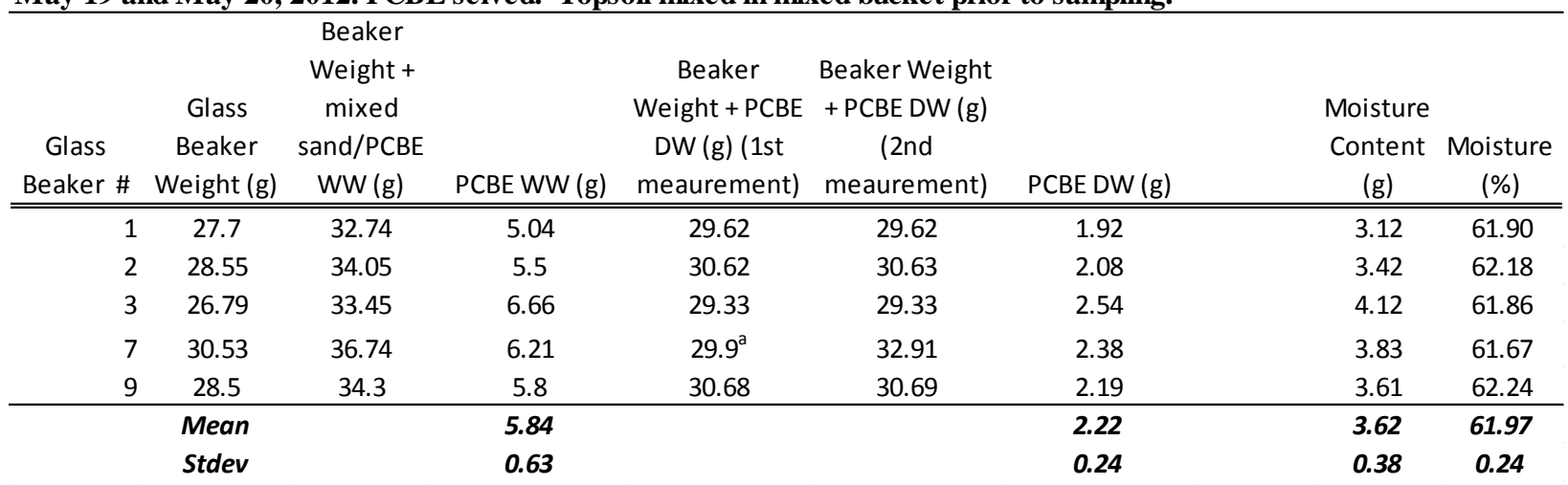

Batch 5 (1st Bag of soil seived May 03 and stored in bucket. Original moisture was 60.21\%)

\begin{tabular}{|c|c|c|c|c|c|}
\hline & & & Time out (1st & & Time out (2nd \\
\hline Marver & (1) & Date out & $\begin{array}{l}\text { measurement) } \\
\end{array}$ & $\begin{array}{l}\text { Date out } \\
\text { Mar } 12\end{array}$ & \\
\hline
\end{tabular}

May 20, 2012. PCBE seived. Topsoil mixed in mixed bucket prior to sampling. Data below fromstored in a bucket

\begin{tabular}{|c|c|c|c|c|c|c|c|c|c|c|c|c|c|c|c|c|c|c|c|}
\hline $\begin{array}{c}\text { Glass } \\
\text { Beaker \# }\end{array}$ & $\begin{array}{c}\text { Glass } \\
\text { Beaker } \\
\text { Weight (g) } \\
\end{array}$ & $\begin{array}{c}\text { Beaker } \\
\text { Weight + } \\
\text { mixed } \\
\text { sand/PCBE } \\
\text { WW (g) } \\
\end{array}$ & PCBE WW (g) & $\begin{array}{c}\text { Beaker } \\
\text { Weight + PCBE } \\
\text { DW (g) (1st } \\
\text { meaurement) } \\
\end{array}$ & $\begin{array}{c}\text { Beaker Weight } \\
+ \text { PCBE DW (g) } \\
\text { (2nd } \\
\text { meaurement) }\end{array}$ & $\begin{array}{c}\text { Beaker Weight } \\
+ \text { PCBE DW (g) } \\
\text { (3rd } \\
\text { meaurement) } \\
\end{array}$ & $\begin{array}{c}\text { Weight + } \\
\text { PCBE DW } \\
\text { (g) (4th } \\
\text { meaurem } \\
\text { ent) } \\
\end{array}$ & $\begin{array}{c}\text { PCBE DW } \\
\text { (g) }\end{array}$ & $\begin{array}{c}\text { Moisture } \\
\text { Content } \\
\text { (g) }\end{array}$ & $\begin{array}{c}\text { Moisture } \\
(\%)\end{array}$ & $\begin{array}{c}\text { Moisture } \\
\text { Content } \\
\text { (2nd } \\
\text { obs.)(g) } \\
\end{array}$ & $\begin{array}{c}\text { Moisture } \\
\begin{array}{c}\text { (\%) (2nd } \\
\text { obs. }\end{array}\end{array}$ & $\begin{array}{c}\text { Moisture } \\
(\%)(2 n d \\
\text { obs. - } 1 \text { st } \\
\text { obs.) } \\
\end{array}$ & $\begin{array}{c}\text { Moisture } \\
\text { Content } \\
\text { (3rd } \\
\text { obs.)(g) } \\
\end{array}$ & $\begin{array}{c}\text { Moisture } \\
(\%)(3 r d \\
\text { obs.) } \\
\end{array}$ & $\begin{array}{c}\text { Moisture } \\
\text { (\%) (3rd } \\
\text { obs. - } \\
\text { 2nd obs.) }\end{array}$ & $\begin{array}{c}\text { Moisture } \\
\text { Content } \\
\text { (4th rd } \\
\text { obs.)(g) } \\
\end{array}$ & $\begin{array}{c}\text { Moisture } \\
(\%)(3 r d \\
\text { obs.) } \\
\end{array}$ & $\begin{array}{c}\text { Moisture } \\
\text { (\%) (4th } \\
\text { obs. - 3rd } \\
\text { obs.) } \\
\end{array}$ \\
\hline 10 & 28.87 & 34.36 & 5.49 & 31.14 & 31.11 & 31.09 & 31.07 & 2.27 & 3.22 & 58.65 & 3.25 & 59.20 & 0.55 & 3.27 & 59.56 & 0.36 & 3.29 & 59.93 & 0.36 \\
\hline 11 & 37.01 & 42.21 & 5.2 & 39.14 & 39.11 & 39.10 & 39.09 & 2.13 & 3.07 & 59.04 & 3.1 & 59.62 & 0.58 & 3.11 & 59.81 & 0.19 & 3.12 & 60.00 & 0.19 \\
\hline 12 & 29.65 & 35.68 & 6.03 & 32.25 & 32.12 & 32.07 & 32.07 & 2.6 & 3.43 & 56.88 & 3.56 & 59.04 & 2.16 & 3.61 & 59.87 & 0.83 & 3.61 & 59.87 & 0.00 \\
\hline 15 & 30.51 & 36.54 & 6.03 & 33.09 & 33 & 32.96 & 32.95 & 2.58 & 3.45 & 57.21 & 3.54 & 58.71 & 1.49 & 3.58 & 59.37 & 0.66 & 3.59 & 59.54 & 0.17 \\
\hline 17 & 31.45 & 37.41 & 5.96 & 34.01 & 33.9 & 33.86 & 33.85 & 2.56 & 3.4 & 57.05 & 3.51 & 58.89 & 1.85 & 3.55 & 59.56 & 0.67 & 3.56 & 59.73 & 0.17 \\
\hline & Mean & & 5.74 & & & & & 2.43 & 3.31 & 57.7667 & 3.39 & 59.0902 & 1.3235 & 3.42 & 59.6343 & 0.5441 & 3.43 & 59.8123 & 0.1780 \\
\hline
\end{tabular}


Batch 6 ( Bag 2 soil only).

Table A7

\begin{tabular}{|c|c|c|c|c|c|}
\hline Date in & Time in & Date out & $\begin{array}{c}\text { Time out (1st } \\
\text { measurement) }\end{array}$ & Date out & $\begin{array}{l}\text { Time out ( } 2 \mathrm{nd} \\
\text { measurement) }\end{array}$ \\
\hline "May 20,12 & 1200 & "May 20,12 & & May 22,12 & 1058hrs \\
\hline
\end{tabular}

May 20, 2012. PCBE seived. Topsoil mixed in mixed bucket prior to sampling. Data below fromstored in a bucket soil seived May 03

\begin{tabular}{|c|c|c|c|c|c|c|c|c|c|c|c|}
\hline $\begin{array}{c}\text { Glass } \\
\text { Beaker \# }\end{array}$ & $\begin{array}{c}\text { Glass } \\
\text { Beaker } \\
\text { Weight (g) }\end{array}$ & $\begin{array}{c}\text { Beaker } \\
\text { Weight + } \\
\text { mixed } \\
\text { sand/PCBE } \\
\text { WW (g) }\end{array}$ & PCBE WW (g) & $\begin{array}{c}\text { Beaker } \\
\text { Weight + PCBE } \\
\text { DW (g) (1st } \\
\text { meaurement) }\end{array}$ & $\begin{array}{c}\text { Beaker Weight } \\
+ \text { PCBE DW (g) } \\
\text { (2nd } \\
\text { meaurement) }\end{array}$ & PCBE DW (g) & $\begin{array}{c}\text { Moisture } \\
\text { Content } \\
\text { (g) }\end{array}$ & $\begin{array}{c}\text { Moisture } \\
(\%)\end{array}$ & $\begin{array}{c}\text { Moisture } \\
\text { Content } \\
\text { (2nd } \\
\text { obs.)(g) }\end{array}$ & $\begin{array}{c}\text { Moisture } \\
\text { (\%) (2nd } \\
\text { obs. }\end{array}$ & $\begin{array}{c}\text { Moisture } \\
\text { (\%) (2nd } \\
\text { obs. - } 1 \text { st } \\
\text { obs.) }\end{array}$ \\
\hline 1 & 27.7 & 32.68 & 4.98 & 29.5 & 29.51 & 1.8 & 3.18 & 63.86 & 3.17 & 63.65 & -0.20 \\
\hline 2 & 28.55 & 33.23 & 4.68 & 30.22 & 30.24 & 1.67 & 3.01 & 64.32 & 2.99 & 63.89 & -0.43 \\
\hline 3 & 26.79 & 32.31 & 5.52 & 28.78 & 28.79 & 1.99 & 3.53 & 63.95 & 3.52 & 63.77 & -0.18 \\
\hline 7 & 30.53 & 35.35 & 4.82 & 32.27 & 32.29 & 1.74 & 3.08 & 63.90 & 3.06 & 63.49 & -0.41 \\
\hline 9 & 28.5 & 34.14 & 5.64 & 30.52 & 30.54 & 2.02 & 3.62 & 64.18 & 3.6 & 63.83 & -0.35 \\
\hline & Mean & & 5.13 & & & 1.84 & 3.28 & 64.0411 & 3.27 & 63.7254 & -0.3158 \\
\hline & Stdev & & 0.43 & & & 0.15 & 0.27 & 0.1993 & 0.28 & 0.1597 & \\
\hline
\end{tabular}

\section{Batch 7 ( Bag 3 soil only).}

\begin{tabular}{cccccc}
\hline Date in & Time in & Date out & $\begin{array}{c}\text { Time out (1st } \\
\text { measurement) }\end{array}$ & Date out & $\begin{array}{c}\text { Time out (2nd } \\
\text { measurement) }\end{array}$ \\
\hline \hline May 23,12 & 105 & May 23,12 & 1115 & May 23,12 &
\end{tabular}

\section{Table A8}

May 23, 2012. PCBE seived. Topsoil mixed in mixed bucket prior to sampling. Data below fromstored in a bucket soil seived May 03

\begin{tabular}{|c|c|c|c|c|c|c|c|c|c|c|c|}
\hline $\begin{array}{c}\text { Glass } \\
\text { Beaker \# }\end{array}$ & $\begin{array}{c}\text { Glass } \\
\text { Beaker } \\
\text { Weight (g) }\end{array}$ & $\begin{array}{c}\text { Beaker } \\
\text { Weight + } \\
\text { mixed } \\
\text { sand/PCBE } \\
\text { WW (g) }\end{array}$ & PCBE WW (g) & $\begin{array}{c}\text { Beaker } \\
\text { Weight + PCBE } \\
\text { DW (g) (1st } \\
\text { meaurement) }\end{array}$ & $\begin{array}{l}\text { Beaker Weight } \\
+ \text { PCBE DW (g) } \\
\text { (2nd } \\
\text { meaurement) }\end{array}$ & PCBE DW (g) & $\begin{array}{c}\text { Moisture } \\
\text { Content } \\
\text { (g) }\end{array}$ & $\begin{array}{c}\text { Moisture } \\
(\%)\end{array}$ & $\begin{array}{l}\text { Moisture } \\
\text { Content } \\
\text { (2nd } \\
\text { obs.)(g) }\end{array}$ & $\begin{array}{l}\text { Moisture } \\
\text { (\%) (2nd } \\
\text { obs. }\end{array}$ & $\begin{array}{l}\text { Moisture } \\
\text { (\%) (2nd } \\
\text { obs. -1st } \\
\text { obs.) }\end{array}$ \\
\hline 1 & 27.7 & 31.99 & 4.29 & 29.28 & 29.27 & 1.58 & 2.71 & 63.17 & 2.71 & 63.17 & 0.00 \\
\hline 2 & 28.55 & 33.74 & 5.19 & 30.48 & 30.47 & 1.93 & 3.26 & 62.81 & 3.26 & 62.81 & 0.00 \\
\hline 3 & 26.79 & 31.73 & 4.94 & 28.6 & 28.6 & 1.81 & 3.13 & 63.36 & 3.13 & 63.36 & 0.00 \\
\hline 7 & 30.53 & 34.48 & 3.95 & 31.99 & 31.99 & 1.46 & 2.49 & 63.04 & 2.49 & 63.04 & 0.00 \\
\hline 9 & 28.5 & 33.68 & 5.18 & 30.42 & 31.41 & 1.92 & 3.26 & 62.93 & 3.26 & 62.93 & 0.00 \\
\hline Mean & & & 4.71 & & 30.35 & 1.74 & 2.97 & 63.0632 & 2.97 & 63.0632 & 0.0000 \\
\hline Stdev & & & 0.56 & & 1.42 & 0.21 & 0.35 & 0.2118 & 0.35 & 0.2118 & \\
\hline
\end{tabular}




\section{Table A9. Sediment Percent Moisture Summary Table}

Sediment moisture content for Batches 1 to 7

\begin{tabular}{cccc}
\hline & $\begin{array}{c}\text { Mean } \\
\text { moisture } \\
\text { content } \\
(\boldsymbol{\%})\end{array}$ & $\mathbf{n}$ & $\mathbf{s}$ \\
\hline \hline 1 & 60.21 & 10.00 & 0.28 \\
2 & 62.56 & 5.00 & 0.37 \\
2,3 & 62.28 & 5.00 & 0.19 \\
4 & 61.97 & 5.00 & 0.24 \\
5 & 59.81 & 5.00 & 0.18 \\
6 & 63.73 & 5.00 & 0.16 \\
7 & 63.06 & 5.00 & 0.21 \\
\hline Mean & 61.95 & & 0.23 \\
\hline
\end{tabular}

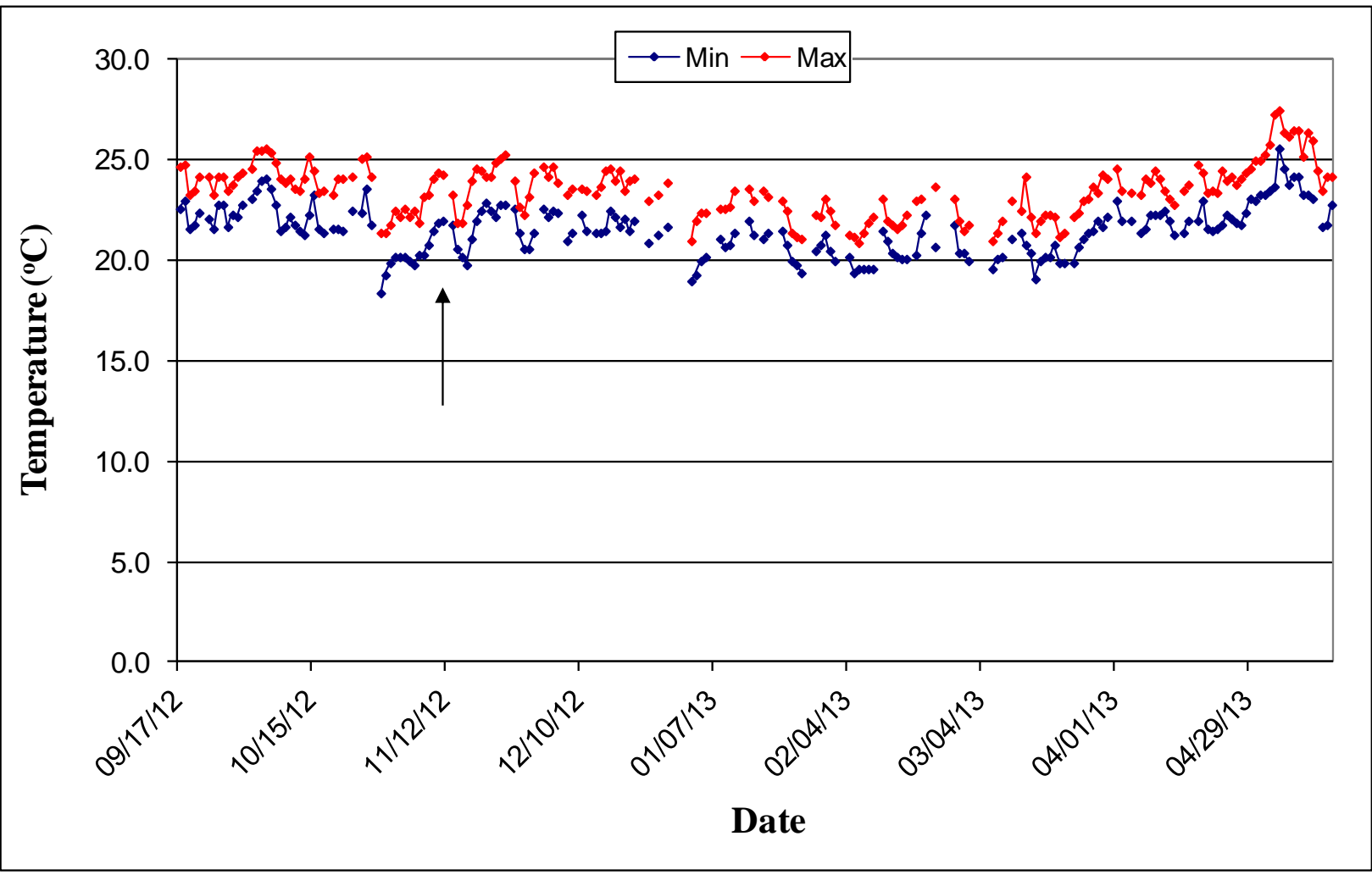

Figure B1. Temperature data from light bank 3 for the acclimation and entire study period from November 08, 2012, indicated by the arrow, to May 16, 2013. 


\subsection{Appendix B}

Typha latifolia protocol development and Seedling Response To Phosphorus

Table B.1 Total P added (approximate)

\begin{tabular}{|c|cccc|}
\hline Total Votal volume & \multicolumn{4}{|c|}{ P Treament $(\mu \mathrm{g} / \mathrm{L})$} \\
\hline \hline 1.3 & 0 & 50 & 100 & 300 \\
Total P added & 0 & 65 & 130 & 390 \\
\hline
\end{tabular}

Table B2. Typha latifolia grow media reagents modified from Weng et al., 2006.

Table B2. Reagent molar mass for Chlorella and Typha grow medium culture

Molar mass obtained from: Mortimer. CE. 1971. Chemistry, a conceptual approach. 2nd edition. Litton Educational Publishing Inc.

\begin{tabular}{|c|c|c|c|c|c|c|c|c|}
\hline Element & $\mathrm{g} / \mathrm{mol}$ & Reagent & Media/Source & Molar mass (g) & $\begin{array}{c}\text { Weight } \\
\text { needed (g) }\end{array}$ & $\begin{array}{l}\text { Molarity } \\
\text { (mol/L) }\end{array}$ & $\begin{array}{c}\% \text { active } \\
\text { ingredient }\end{array}$ & $\begin{array}{c}\text { Weight of } \\
\text { Active } \\
\text { Ingredient }(\mathrm{g}) \\
\end{array}$ \\
\hline $\mathrm{H}$ & \multicolumn{3}{|c|}{$1.008 \mathrm{MnSO}_{4}$} & 150.9956 & & & & \\
\hline $\mathrm{N}$ & \multicolumn{2}{|c|}{ 14.0067 $\mathrm{MnSO}_{4}{ }^{*} \mathrm{H}_{2} \mathrm{O}$} & Alternative & 169.011 & 0.098110505 & 0.000580498 & 0.893406938 & 0.087652605 \\
\hline $\mathrm{O}$ & \multicolumn{2}{|c|}{ 15.9994 $\mathrm{MnSO}_{4} * 6 \mathrm{H}_{2} \mathrm{O}$} & Weng et al. & 259.088 & 0.1504 & 0.000580498 & 0.582796579 & 0.087652605 \\
\hline$P$ & \multicolumn{2}{|c|}{$30.9738 \mathrm{CaCl}_{2}$} & Alternative & 110.986 & 0.193259655 & 0.001741298 & 1 & 0.193259655 \\
\hline S & \multicolumn{2}{|c|}{$32.06 \mathrm{CaCl}_{2} * 2 \mathrm{H}_{2} \mathrm{O}$} & Weng et al. & 147.0168 & 0.256 & 0.001741298 & 0.754920526 & 0.193259655 \\
\hline $\mathrm{Cl}$ & \multicolumn{2}{|c|}{$35.453\left(\mathrm{NH}_{4}\right)_{2} \mathrm{SO}_{4}$} & Alternative & 132.135 & 5.239497093 & 0.039652606 & 1 & 5.239497093 \\
\hline $\mathrm{Ca}$ & \multicolumn{2}{|c|}{$40.08\left(\mathrm{NH}_{4}\right)_{2} \mathrm{SO}_{4} * 7 \mathrm{H}_{2} \mathrm{O}$} & Weng et al. & 258.2428 & 10.24 & 0.039652606 & 0.511669638 & 5.239497093 \\
\hline $\mathrm{Fe}$ & \multicolumn{2}{|c|}{$55.847 \mathrm{MgSO}_{4} * 7 \mathrm{H}_{2} \mathrm{O}$} & Weng et al. & 246.4704 & 2.56 & 0.010386643 & & \\
\hline $\mathrm{Mg}$ & \multicolumn{2}{|c|}{$24.305 \mathrm{FeCl}_{3} * 6 \mathrm{H}_{2} \mathrm{O}$} & Weng et al. & 270.2984 & 0.0128 & 4.73551E-05 & & \\
\hline $\mathrm{Mn}$ & \multicolumn{2}{|c|}{$54.938 \mathrm{KH}_{2} \mathrm{PO}_{4}$} & Weng et al. & 136.0894 & 2.193 & 0.016114407 & & \\
\hline K & & $P$ & & 30.9738 & 0.499124424 & 0.016114407 & 0.227598917 & 0.499124424 \\
\hline $\mathrm{Na}$ & \multicolumn{2}{|c|}{22.9898} & & & & & & \\
\hline $\mathrm{H}_{2} \mathrm{O}$ & \multicolumn{2}{|c|}{18.0154} & & & & & & \\
\hline
\end{tabular}

$22.76 \%$ of weight $\mathrm{KH} 2 \mathrm{PO} 4$ is $\mathrm{P}$ or $0.499 \mathrm{~g}$ of $2.193 \mathrm{~g} \mathrm{KH} 2 \mathrm{PO} 4$ is $\mathrm{P}$ 
Table B3. Typha stock solution per $1000 \mathrm{ml}$ of Distilled water

\begin{tabular}{|c|c|c|c|c|c|c|}
\hline Reagent & Weight (g) & Molarity (Mol/L) & Volume (ml) & $\mu \mathrm{g} / \mathrm{L}$ & $\begin{array}{c}\text { Dilution } \\
\text { volume to } \\
200 \text { ug/L (L) } \\
\end{array}$ & Comments \\
\hline $\mathrm{MnSO}_{4}{ }^{*} \mathrm{H}_{2} \mathrm{O}$ & 0.098 & 0.000580498 & 1000 & & & Alternative \\
\hline $\mathrm{CaCl}_{2}$ & 0.193 & 0.001741298 & 1000 & & & Alternative \\
\hline $\mathrm{CaCl}_{2} * 2 \mathrm{H}_{2} \mathrm{O}$ & 0.256 & 0.001741298 & 1000 & & & \\
\hline$\left(\mathrm{NH}_{4}\right)_{2} \mathrm{SO}_{4}$ & 5.239 & 0.039652606 & 1000 & & & Alternative \\
\hline $\mathrm{MgSO}_{4} * 7 \mathrm{H}_{2} \mathrm{O}$ & 2.56 & 0.010386643 & 1000 & & & \\
\hline $\mathrm{FeCl}_{3} * 6 \mathrm{H}_{2} \mathrm{O}$ & 0.0128 & 4.73551E-05 & 1000 & & & \\
\hline $\mathrm{KH}_{2} \mathrm{PO}_{4}$ & 2.193 & 0.016114407 & 1000 & & & $0.499 \mathrm{~g}$ is $\mathrm{P}$ \\
\hline $\mathrm{P}$ in $\mathrm{KH}_{2} \mathrm{PO}_{4}$ & 0.499124424 & 0.016114407 & 1000 & 499124.4241 & 2495.62212 & \\
\hline Total weight & 10.5518 & & & & & \\
\hline $\mathrm{P}$ to total ratio & 0.047302301 & & & & & \\
\hline
\end{tabular}




\subsection{Appendix C}

Table C. 1. T. latifolia Germination lighting Conditions

\begin{tabular}{|c|c|c|c|}
\hline Date & Mesocosm & $\begin{array}{l}\text { Old meter } \\
\text { Light } \\
\text { Intensity } \\
(\mu \mathrm{E})\end{array}$ & $\begin{array}{c}\text { New meter } \\
\text { Light } \\
\text { Intensity } \\
(\mu \mathrm{E}) \\
\end{array}$ \\
\hline $05 / 25 / 12$ & 1 & & 116 \\
\hline $05 / 25 / 12$ & 2 & & 131 \\
\hline $05 / 25 / 12$ & 3 & & 140 \\
\hline $05 / 25 / 12$ & 4 & & 127 \\
\hline $05 / 25 / 12$ & 5 & & 120 \\
\hline $05 / 25 / 12$ & 6 & & 166 \\
\hline $05 / 25 / 12$ & 7 & & 164 \\
\hline $05 / 25 / 12$ & 8 & & 156 \\
\hline $05 / 25 / 12$ & 9 & & 156 \\
\hline $05 / 25 / 12$ & 10 & & 182 \\
\hline $05 / 25 / 12$ & 11 & & 180 \\
\hline $05 / 25 / 12$ & 12 & & 156 \\
\hline $05 / 25 / 12$ & 13 & & 147 \\
\hline $05 / 25 / 12$ & 14 & & 169 \\
\hline $05 / 25 / 12$ & 15 & & 169 \\
\hline $05 / 25 / 12$ & 16 & & 143 \\
\hline $05 / 25 / 12$ & 17 & & 134 \\
\hline $05 / 25 / 12$ & 18 & & 161 \\
\hline $05 / 25 / 12$ & 19 & & 155 \\
\hline $05 / 25 / 12$ & 20 & & 143 \\
\hline $05 / 25 / 12$ & 21 & & 138 \\
\hline $05 / 25 / 12$ & 22 & & 149 \\
\hline $05 / 25 / 12$ & 23 & & 144 \\
\hline $05 / 25 / 12$ & 24 & & 128 \\
\hline $05 / 25 / 12$ & 25 & & 140 \\
\hline $05 / 25 / 12$ & 26 & & 153 \\
\hline $05 / 25 / 12$ & 27 & & 146 \\
\hline $05 / 25 / 12$ & 28 & & 129 \\
\hline $05 / 25 / 12$ & 29 & & 142 \\
\hline $05 / 25 / 12$ & 30 & & 155 \\
\hline $05 / 25 / 12$ & 31 & & 148 \\
\hline $05 / 25 / 12$ & 32 & & 144 \\
\hline $05 / 25 / 12$ & 33 & & 135 \\
\hline $05 / 25 / 12$ & 34 & & 153 \\
\hline
\end{tabular}




\begin{tabular}{lrr}
$05 / 25 / 12$ & 35 & 154 \\
$05 / 25 / 12$ & 36 & 132 \\
$05 / 25 / 12$ & 37 & 121 \\
$05 / 25 / 12$ & 38 & 127 \\
$05 / 25 / 12$ & 39 & 123 \\
$05 / 25 / 12$ & 40 & 102 \\
\hline Mean & & 144.45 \\
Stddev & & 17.44287 \\
Min & & 102 \\
Max & & 182
\end{tabular}

Table C2. Light intensity observed within microcosms at different locations and conditions under light bank 1 .

\begin{tabular}{|c|c|c|c|c|c|}
\hline Date & Microcosm & $\begin{array}{c}\text { Light } \\
\text { Bank } \\
\text { Location }\end{array}$ & $\begin{array}{l}\text { Transect } \\
\text { location }\end{array}$ & $\begin{array}{c}\text { New } \\
\text { meter } \\
\text { Light } \\
\text { Intensity } \\
(\mu \mathrm{E})\end{array}$ & Comments \\
\hline $06 / 28 / 12$ & 9 & 19 & 1 & 139 & Surrounded by other mesocosms \\
\hline $06 / 28 / 12$ & 9 & 19 & 2 & 142 & Surrounded by other mesocosms \\
\hline $06 / 28 / 12$ & 9 & 19 & 3 & 135 & Surrounded by other mesocosms \\
\hline $06 / 28 / 12$ & 9 & 19 & 4 & 146 & Surrounded by other mesocosms \\
\hline $06 / 28 / 12$ & 9 & 19 & 5 & 150 & Surrounded by other mesocosms \\
\hline $06 / 28 / 12$ & 9 & 19 & 6 & 140 & Surrounded by other mesocosms \\
\hline $06 / 28 / 12$ & 9 & 19 & 7 & 141 & Surrounded by other mesocosms \\
\hline $06 / 28 / 12$ & 9 & 19 & 8 & 144 & Surrounded by other mesocosms \\
\hline $06 / 28 / 12$ & 9 & 19 & 9 & 138 & Surrounded by other mesocosms \\
\hline $06 / 28 / 12$ & 10 & 19 & 1 & 141 & Surrounded by other mesocosms \\
\hline $06 / 28 / 12$ & 10 & 19 & 2 & 136 & Surrounded by other mesocosms \\
\hline $06 / 28 / 12$ & 10 & 19 & 3 & 134 & Surrounded by other mesocosms \\
\hline $06 / 28 / 12$ & 10 & 19 & 4 & 145 & Surrounded by other mesocosms \\
\hline $06 / 28 / 12$ & 10 & 19 & 5 & 150 & Surrounded by other mesocosms \\
\hline $06 / 28 / 12$ & 10 & 19 & 6 & 141 & Surrounded by other mesocosms \\
\hline $06 / 28 / 12$ & 10 & 19 & 7 & 142 & Surrounded by other mesocosms \\
\hline $06 / 28 / 12$ & 10 & 19 & 8 & 144 & Surrounded by other mesocosms \\
\hline $06 / 28 / 12$ & 10 & 19 & 9 & 137 & Surrounded by other mesocosms \\
\hline
\end{tabular}




$\begin{array}{ll}06 / 28 / 12 & 3 \\ 06 / 28 / 12 & 3 \\ 06 / 28 / 12 & 3 \\ 06 / 28 / 12 & 3 \\ 06 / 28 / 12 & 3 \\ 06 / 28 / 12 & 3 \\ 06 / 28 / 12 & 3 \\ 06 / 28 / 12 & 3 \\ 06 / 28 / 12 & 3\end{array}$

$06 / 28 / 12 \quad 21$

$06 / 28 / 12 \quad 21$

$06 / 28 / 12 \quad 21$

$06 / 28 / 12 \quad 21$

$06 / 28 / 12 \quad 21$

$06 / 28 / 12 \quad 21$

$06 / 28 / 12 \quad 21$

$06 / 28 / 12 \quad 21$

$06 / 28 / 12 \quad 21$

$\begin{array}{ll}19 & 1 \\ 19 & 2 \\ 19 & 3 \\ 19 & 4 \\ 19 & 5 \\ 19 & 6 \\ 19 & 7 \\ 19 & 8 \\ 19 & 9\end{array}$

19

19

19

19

19

19

19

19

19

19

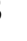

$\begin{array}{ll}06 / 28 / 12 & 22 \\ 06 / 28 / 12 & 22 \\ 06 / 28 / 12 & 22 \\ 06 / 28 / 12 & 22 \\ 06 / 28 / 12 & 22 \\ 06 / 28 / 12 & 22 \\ 06 / 28 / 12 & 22 \\ 06 / 28 / 12 & 22 \\ 06 / 28 / 12 & 22\end{array}$

19

19

19

19

19

19

19

19

19

$06 / 28 / 12 \quad 9$

$06 / 28 / 12 \quad 9$

$06 / 28 / 12 \quad 9$

$06 / 28 / 12 \quad 9$

$06 / 28 / 12 \quad 9$

$06 / 28 / 12 \quad 9$

$06 / 28 / 12 \quad 9$

$06 / 28 / 12 \quad 9$

$06 / 28 / 12 \quad 9$

$06 / 28 / 12$
13

1

2

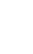

5

6

8

9

135

138

133

144

150

142

138

142

141

136

135

132

144

149

142

135

138

137

140

137

138

146

151

144

141

140

136

143

143

139

150

153

145

143

142

140
Surrounded by other mesocosms

Surrounded by other mesocosms

Surrounded by other mesocosms

Surrounded by other mesocosms

Surrounded by other mesocosms

Surrounded by other mesocosms

Surrounded by other mesocosms

Surrounded by other mesocosms

Surrounded by other mesocosms

Surrounded by other mesocosms

Surrounded by other mesocosms

Surrounded by other mesocosms

Surrounded by other mesocosms

Surrounded by other mesocosms

Surrounded by other mesocosms

Surrounded by other mesocosms

Surrounded by other mesocosms

Surrounded by other mesocosms

Surrounded by other mesocosms

Surrounded by other mesocosms

Surrounded by other mesocosms

Surrounded by other mesocosms

Surrounded by other mesocosms

Surrounded by other mesocosms

Surrounded by other mesocosms

Surrounded by other mesocosms

Surrounded by other mesocosms

Surrounded by other mesocosms

Not Surrounded

Difference_light btwn surrouned and not surrouned $=2.6 \mu \mathrm{E}$

Not Surrounded

Not Surrounded

Not Surrounded

Not Surrounded

Not Surrounded

Not Surrounded

Not Surrounded 


\begin{tabular}{|c|c|c|c|c|}
\hline 06/28/12 & 13 & 15 & 2 & 156 \\
\hline $06 / 28 / 12$ & 13 & 15 & 3 & 159 \\
\hline 06/28/12 & 13 & 15 & 4 & 163 \\
\hline $06 / 28 / 12$ & 13 & 15 & 5 & 168 \\
\hline $06 / 28 / 12$ & 13 & 15 & 6 & 163 \\
\hline $06 / 28 / 12$ & 13 & 15 & 7 & 154 \\
\hline 06/28/12 & 13 & 15 & 8 & 147 \\
\hline $06 / 28 / 12$ & 13 & 15 & 9 & 152 \\
\hline $06 / 28 / 12$ & 33 & 31 & 1 & 145 \\
\hline $06 / 28 / 12$ & 33 & 31 & 2 & 143 \\
\hline $06 / 28 / 12$ & 33 & 31 & 3 & 140 \\
\hline $06 / 28 / 12$ & 33 & 31 & 4 & 149 \\
\hline $06 / 28 / 12$ & 33 & 31 & 5 & 154 \\
\hline $06 / 28 / 12$ & 33 & 31 & 6 & 157 \\
\hline $06 / 28 / 12$ & 33 & 31 & 7 & 137 \\
\hline $06 / 28 / 12$ & 33 & 31 & 8 & 140 \\
\hline $06 / 28 / 12$ & 33 & 31 & 9 & 135 \\
\hline 07/05/12 & 3 & 12 & 1 & 122 \\
\hline 07/05/12 & 3 & 12 & 2 & 125 \\
\hline 07/05/12 & 3 & 12 & 3 & 120 \\
\hline 07/05/12 & 3 & 12 & 4 & 137 \\
\hline 07/05/12 & 3 & 12 & 5 & 147 \\
\hline 07/05/12 & 3 & 12 & 6 & 141 \\
\hline 07/05/12 & 3 & 12 & 7 & 157 \\
\hline 07/05/12 & 3 & 12 & 8 & 160 \\
\hline 07/05/12 & 3 & 12 & 9 & 156 \\
\hline 07/05/12 & 9 & 23 & 1 & 122 \\
\hline 07/05/12 & 9 & 23 & 2 & 123 \\
\hline 07/05/12 & 9 & 23 & 3 & 124 \\
\hline 07/05/12 & 9 & 23 & 4 & 133 \\
\hline 07/05/12 & 9 & 23 & 5 & 138 \\
\hline 07/05/12 & 9 & 23 & 6 & 132 \\
\hline 07/05/12 & 9 & 23 & 7 & 123 \\
\hline 07/05/12 & 9 & 23 & 8 & 130 \\
\hline 07/05/12 & 9 & 23 & 9 & 124 \\
\hline 07/05/12 & 10 & 8 & 1 & 115 \\
\hline 07/05/12 & 10 & 8 & 2 & 116 \\
\hline 07/05/12 & 10 & 8 & 3 & 117 \\
\hline 07/05/12 & 10 & 8 & 4 & 135 \\
\hline
\end{tabular}




$\begin{array}{lllll}07 / 05 / 12 & 10 & 8 & 5 & 137 \\ 07 / 05 / 12 & 10 & 8 & 6 & 132 \\ 07 / 05 / 12 & 10 & 8 & 7 & 143 \\ 07 / 05 / 12 & 10 & 8 & 8 & 142 \\ 07 / 05 / 12 & 10 & 8 & 9 & 143\end{array}$

\section{Typha latifolia response to oligotrophic and eutrophic $\mathrm{N}$ and $\mathrm{P}$ loading rates under laboratory conditions}

Table D.1. Light intensity (PAR) characteristics for experimental unit microcosms observed on 11/09/12 and 05/08/13.

Each cart has two rows for four microcosm locations. Locations are in order of $\mathrm{W}$ to $\mathrm{E}$ for locations $1-4,5-8,9-12$ ect. HTTL = height to tallest leaf

Soil Level measured outside of microcosm adjacent to vessel height of black duct tape which indicated soil height Measurement at microcosm center collected by resting extension on vessel lip, prependicular to soil level, as close to the middle of the microcosm as possible without physically contacting ramets (shoots)

\begin{tabular}{|c|c|c|c|c|c|c|}
\hline \multirow[b]{2}{*}{$\begin{array}{c}\text { Date } \\
(\mathrm{mm} / \mathrm{dd} / \mathrm{yy})\end{array}$} & \multirow[b]{2}{*}{ Location } & \multirow[b]{2}{*}{ Cart } & \multirow[b]{2}{*}{ Microcosm } & \multicolumn{3}{|c|}{ Measurement Location } \\
\hline & & & & 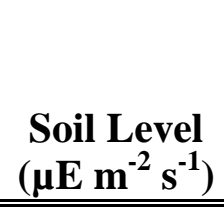 & $\begin{array}{c}\text { HHTL } \\
\left(\mu \mathrm{E} \mathrm{m} \mathbf{m}^{-2} \mathbf{s}^{-1}\right) \\
\end{array}$ & 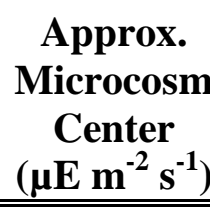 \\
\hline $111 / 09 / 12$ & 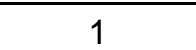 & 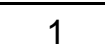 & 11 & 23 & 52 & 33 \\
\hline $11 / 09 / 12$ & 2 & 1 & 32 & 24 & 57 & 23 \\
\hline $11 / 09 / 12$ & 3 & 1 & 20 & 26 & 55 & 32 \\
\hline $11 / 09 / 12$ & 4 & 1 & 2 & 24 & 53 & 31 \\
\hline $11 / 09 / 12$ & 5 & 1 & 22 & 30 & 59 & 28 \\
\hline $11 / 09 / 12$ & 6 & 1 & 12 & 31 & 60 & 30 \\
\hline $11 / 09 / 12$ & 7 & 1 & 10 & 34 & 55 & 40 \\
\hline $11 / 09 / 12$ & 8 & 1 & 4 & 32 & 64 & 33 \\
\hline $11 / 09 / 12$ & 9 & 2 & 8 & 30 & 74 & 32 \\
\hline $11 / 09 / 12$ & 10 & 2 & 24 & 31 & 69 & 38 \\
\hline $11 / 09 / 12$ & 11 & 2 & 31 & 34 & 74 & 40 \\
\hline $11 / 09 / 12$ & 12 & 2 & 34 & 32 & 62 & 40 \\
\hline $11 / 09 / 12$ & 13 & 2 & 27 & 31 & 77 & 37 \\
\hline $11 / 09 / 12$ & 14 & 2 & 15 & 27 & 75 & 42 \\
\hline $11 / 09 / 12$ & 15 & 2 & 7 & 29 & 75 & 38 \\
\hline $11 / 09 / 12$ & 16 & 2 & 29 & 28 & 76 & 38 \\
\hline $11 / 09 / 12$ & 17 & 3 & 6 & 31 & 70 & 41 \\
\hline $11 / 09 / 12$ & 18 & 3 & 37 & 27 & 81 & 42 \\
\hline $11 / 09 / 12$ & 19 & 3 & 28 & 29 & 90 & 37 \\
\hline
\end{tabular}




\begin{tabular}{|c|c|c|c|c|c|c|}
\hline $11 / 09 / 12$ & 20 & 3 & 23 & 28 & 68 & 37 \\
\hline $11 / 09 / 12$ & 21 & 3 & 18 & 35 & 69 & 39 \\
\hline $11 / 09 / 12$ & 22 & 3 & 17 & 37 & 75 & 43 \\
\hline $11 / 09 / 12$ & 23 & 3 & 9 & 37 & 78 & 42 \\
\hline $11 / 09 / 12$ & 24 & 3 & 16 & 36 & 71 & 42 \\
\hline $11 / 09 / 12$ & 25 & 4 & 35 & 35 & 78 & 43 \\
\hline $11 / 09 / 12$ & 26 & 4 & 40 & 37 & 58 & 44 \\
\hline $11 / 09 / 12$ & 27 & 4 & 1 & 37 & 72 & 47 \\
\hline $11 / 09 / 12$ & 28 & 4 & 19 & 36 & 75 & 42 \\
\hline $11 / 09 / 12$ & 29 & 4 & 13 & 28 & 66 & 43 \\
\hline $11 / 09 / 12$ & 30 & 4 & 25 & 29 & 61 & 44 \\
\hline $11 / 09 / 12$ & 31 & 4 & 38 & 33 & 73 & 38 \\
\hline $11 / 09 / 12$ & 32 & 4 & 36 & 31 & 69 & 39 \\
\hline $11 / 09 / 12$ & 33 & 5 & 26 & 28 & 66 & 39 \\
\hline $11 / 09 / 12$ & 34 & 5 & 5 & 29 & 64 & 36 \\
\hline $11 / 09 / 12$ & 35 & 5 & 3 & 33 & 59 & 40 \\
\hline $11 / 09 / 12$ & 36 & 5 & 14 & 31 & 61 & 28 \\
\hline $11 / 09 / 12$ & 37 & 5 & 21 & 26 & 57 & 34 \\
\hline $11 / 09 / 12$ & 38 & 5 & 30 & 26 & 51 & 36 \\
\hline $11 / 09 / 12$ & 39 & 5 & 39 & 23 & 57 & 34 \\
\hline $11 / 09 / 12$ & 40 & 5 & 33 & 27 & 68 & 28 \\
\hline 05/08/13 & 1 & 1 & 4 & 7 & 59 & 26 \\
\hline 05/08/13 & 2 & 1 & 11 & 10 & 88 & 32 \\
\hline $05 / 08 / 13$ & 3 & 1 & 32 & 8 & 32 & 31 \\
\hline 05/08/13 & 4 & 1 & 2 & 7 & 54 & 29 \\
\hline 05/08/13 & 5 & 1 & 20 & 18 & 72 & 34 \\
\hline 05/08/13 & 6 & 1 & 22 & 22 & 59 & 36 \\
\hline 05/08/13 & 7 & 1 & 10 & 26 & 70 & 36 \\
\hline 05/08/13 & 8 & 1 & 12 & 21 & 56 & 30 \\
\hline $05 / 08 / 13$ & 9 & 2 & 15 & 12 & 83 & 28 \\
\hline $05 / 08 / 13$ & 10 & 2 & 8 & 15 & 72 & 36 \\
\hline 05/08/13 & 11 & 2 & 31 & 15 & 101 & 37 \\
\hline 05/08/13 & 12 & 2 & 24 & 14 & 83 & 34 \\
\hline $05 / 08 / 13$ & 13 & 2 & 27 & 23 & 108 & 35 \\
\hline $05 / 08 / 13$ & 14 & 2 & 7 & 22 & 112 & 35 \\
\hline 05/08/13 & 15 & 2 & 29 & 20 & 110 & 31 \\
\hline $05 / 08 / 13$ & 16 & 2 & 34 & 21 & 75 & 38 \\
\hline 05/08/13 & 17 & 3 & 23 & 22 & 86 & 38 \\
\hline 05/08/13 & 18 & 3 & 6 & 20 & 84 & 38 \\
\hline 05/08/13 & 19 & 3 & 16 & 19 & 108 & 34 \\
\hline $05 / 08 / 13$ & 20 & 3 & 9 & 19 & 41 & 40 \\
\hline $05 / 08 / 13$ & 21 & 3 & 28 & 20 & 118 & 34 \\
\hline 05/08/13 & 22 & 3 & 37 & 22 & 89 & 40 \\
\hline 05/08/13 & 23 & 3 & 18 & 20 & 93 & 38 \\
\hline $05 / 08 / 13$ & 24 & 3 & 17 & 22 & 76 & 29 \\
\hline $05 / 08 / 13$ & 25 & 4 & 36 & 19 & 86 & 36 \\
\hline 05/08/13 & 26 & 4 & 1 & 22 & 96 & 36 \\
\hline $05 / 08 / 13$ & 27 & 4 & 19 & 22 & 89 & 34 \\
\hline $05 / 08 / 13$ & 28 & 4 & 13 & 22 & 84 & 35 \\
\hline $05 / 08 / 13$ & 29 & 4 & 38 & 18 & 78 & 36 \\
\hline
\end{tabular}




$\begin{array}{lllcccc}05 / 08 / 13 & 30 & 4 & 40 & 14 & 94 & 37 \\ 05 / 08 / 13 & 31 & 4 & 35 & 19 & 70 & 30 \\ 05 / 08 / 13 & 32 & 4 & 25 & 18 & 84 & 37 \\ 05 / 08 / 13 & 33 & 5 & 21 & 22 & 71 & 32 \\ 05 / 08 / 13 & 34 & 5 & 3 & 19 & 77 & 31 \\ 05 / 08 / 13 & 35 & 5 & 14 & 19 & 77 & 33 \\ 05 / 08 / 13 & 36 & 5 & 33 & 22 & 112 & 28 \\ 05 / 08 / 13 & 37 & 5 & 5 & 10 & 65 & 28 \\ 05 / 08 / 13 & 38 & 5 & 26 & 10 & 77 & 28 \\ 05 / 08 / 13 & 39 & 5 & 30 & 11 & 47 & 30 \\ 05 / 08 / 13 & 40 & 5 & 39 & 10 & 64 & 26\end{array}$

\subsection{Appendix D}

\section{Table D1. Typha Latifolia Seed Germination}

Three seeds were added to each microcosm

\begin{tabular}{|c|c|c|c|c|c|c|c|c|}
\hline Microcosm & Treat. & Date & $\begin{array}{c}\text { Number } \\
\text { Germinated }\end{array}$ & $\begin{array}{c}\text { Volume of } \\
\text { water } \\
\text { added post } \\
\text { assessment } \\
(\mathrm{ml}) \\
\end{array}$ & $\begin{array}{c}\text { Standing } \\
\text { water (\% } \\
\text { surface area) }\end{array}$ & $\begin{array}{c}\text { Wet } \\
\text { sediment } \\
\text { (\% surface } \\
\text { area) }\end{array}$ & $\begin{array}{c}\text { Moist } \\
\text { sediment (\% } \\
\text { surface } \\
\text { area) }\end{array}$ & $\begin{array}{c}\text { Germ. } \\
\text { Rate }\end{array}$ \\
\hline 4 & 1 & $05 / 27 / 12$ & 1 & 15 & 100 & & & 0.333 \\
\hline 5 & 1 & $05 / 27 / 12$ & 1 & 15 & 100 & & & 0.333 \\
\hline 8 & 1 & $05 / 27 / 12$ & 1 & 15 & 40 & 60 & & 0.333 \\
\hline 12 & 1 & $05 / 27 / 12$ & none obser. & 15 & 25 & 75 & & 0.000 \\
\hline 13 & 1 & $05 / 27 / 12$ & 1 & 15 & 5 & 95 & & 0.333 \\
\hline 19 & 1 & $05 / 27 / 12$ & 2 & 15 & & 100 & & 0.667 \\
\hline 31 & 1 & $05 / 27 / 12$ & 3 & 15 & & & 100 & 1.000 \\
\hline 33 & 1 & $05 / 27 / 12$ & 1 & 15 & & 100 & & 0.333 \\
\hline 35 & 1 & $05 / 27 / 12$ & 1 & 15 & & & 100 & 0.333 \\
\hline 37 & 1 & $05 / 27 / 12$ & none obser. & 15 & & 100 & & 0.000 \\
\hline 4 & 1 & $05 / 28 / 12$ & 2 & 15 & 60 & 40 & & 0.667 \\
\hline 5 & 1 & $05 / 28 / 12$ & 3 & 15 & & 100 & & 1.000 \\
\hline 8 & 1 & $05 / 28 / 12$ & 2 & 15 & & 100 & & 0.667 \\
\hline 12 & 1 & $05 / 28 / 12$ & 2 & 15 & & 100 & & 0.667 \\
\hline 13 & 1 & $05 / 28 / 12$ & 2 & 15 & & 100 & & 0.667 \\
\hline 19 & 1 & $05 / 28 / 12$ & 3 & 15 & & & 100 & 1.000 \\
\hline 31 & 1 & $05 / 28 / 12$ & 3 & 15 & & & 100 & 1.000 \\
\hline 33 & 1 & $05 / 28 / 12$ & 2 & 15 & & 100 & & 0.667 \\
\hline 35 & 1 & $05 / 28 / 12$ & 3 & 15 & & & 100 & 1.000 \\
\hline 37 & 1 & $05 / 28 / 12$ & none obser. & 15 & & 100 & & 0.000 \\
\hline
\end{tabular}




$\begin{array}{rrrcc}4 & 1 & 05 / 29 / 12 & 2 & 15 \\ 5 & 1 & 05 / 29 / 12 & 3 & 15 \\ 8 & 1 & 05 / 29 / 12 & 2 & 15 \\ 12 & 1 & 05 / 29 / 12 & 3 & 15 \\ 13 & 1 & 05 / 29 / 12 & 2 & 14.5 \\ 19 & 1 & 05 / 29 / 12 & 3 & 15 \\ 31 & 1 & 05 / 29 / 12 & 3 & 15 \\ 33 & 1 & 05 / 29 / 12 & 3 & 15.5 \\ 35 & 1 & 05 / 29 / 12 & 3 & 15 \\ 37 & 1 & 05 / 29 / 12 & \text { none obser. } & 15\end{array}$

$\begin{array}{ccc}100 & & 0.667 \\ 50 & 50 & 1.000 \\ 100 & & 0.667 \\ 100 & & 1.000 \\ 50 & 50 & 0.667 \\ & 100 & 1.000 \\ & 100 & 1.000 \\ 100 & & 1.000 \\ & 100 & 1.000 \\ 100 & & 0.000\end{array}$

$\begin{array}{rrcc}13 & 1 & 06 / 01 / 12 & 2 \\ 8 & 1 & 06 / 01 / 12 & 2 \\ 4 & 1 & 06 / 01 / 12 & 2 \\ 35 & 1 & 06 / 01 / 12 & 3 \\ 33 & 1 & 06 / 01 / 12 & 3 \\ 31 & 1 & 06 / 01 / 12 & 3 \\ 19 & 1 & 06 / 01 / 12 & 3 \\ 12 & 1 & 06 / 01 / 12 & 3 \\ 5 & 1 & 06 / 01 / 12 & 3 \\ 37 & 1 & 06 / 01 / 12 & \text { none obser }\end{array}$

\begin{tabular}{|c|c|c|c|c|c|c|c|}
\hline 2 & $05 / 27 / 12$ & 1 & 15 & & 100 & & 0.333 \\
\hline 3 & $05 / 27 / 12$ & 3 & 15 & & 100 & & 1.000 \\
\hline 7 & $05 / 27 / 12$ & 1 & 15 & 100 & & & 0.333 \\
\hline 14 & $05 / 27 / 12$ & 2 & 15 & 40 & 60 & & 0.667 \\
\hline 17 & $05 / 27 / 12$ & 1 & 15 & 30 & 70 & & 0.333 \\
\hline 21 & $05 / 27 / 12$ & none obser. & 15 & 95 & 5 & & 0.000 \\
\hline 23 & $05 / 27 / 12$ & 1 & 15 & 95 & 5 & & 0.333 \\
\hline 34 & $05 / 27 / 12$ & none obser. & 15 & 100 & & & 0.000 \\
\hline 36 & $05 / 27 / 12$ & 1 & 15 & 70 & 30 & & 0.333 \\
\hline 39 & $05 / 27 / 12$ & 3 & 15 & & & 100 & 1.000 \\
\hline 2 & $05 / 28 / 12$ & 3 & 15 & & & 100 & 1.000 \\
\hline 3 & $05 / 28 / 12$ & 3 & 15 & & & 100 & 1.000 \\
\hline 7 & $05 / 28 / 12$ & 2 & 15 & 25 & 100 & & 0.667 \\
\hline 14 & $05 / 28 / 12$ & 3 & 15 & & 100 & & 1.000 \\
\hline 17 & $05 / 28 / 12$ & 2 & 15 & & 100 & & 0.667 \\
\hline 21 & $05 / 28 / 12$ & 3 & 15 & & 100 & & 1.000 \\
\hline 23 & $05 / 28 / 12$ & none obser. & 15 & & 100 & & 0.000 \\
\hline 34 & $05 / 28 / 12$ & 2 & 15 & 100 & & & 0.667 \\
\hline 36 & $05 / 28 / 12$ & 2 & 15 & 10 & 90 & & 0.667 \\
\hline 39 & $05 / 28 / 12$ & 3 & 15 & & 100 & & 1.000 \\
\hline
\end{tabular}




\begin{tabular}{|c|c|c|c|c|c|c|c|c|}
\hline 2 & 2 & $05 / 29 / 12$ & 3 & 15 & & & 100 & 1.000 \\
\hline 3 & 2 & $05 / 29 / 12$ & 3 & 15 & & & 100 & 1.000 \\
\hline 7 & 2 & $05 / 29 / 12$ & 3 & 15.5 & & 50 & 50 & 1.000 \\
\hline 14 & 2 & $05 / 29 / 12$ & 3 & 15 & & & 100 & 1.000 \\
\hline 17 & 2 & $05 / 29 / 12$ & 3 & 15 & & 100 & & 1.000 \\
\hline 21 & 2 & $05 / 29 / 12$ & 2 & 15 & & 100 & & 0.667 \\
\hline 23 & 2 & $05 / 29 / 12$ & 3 & 15 & & 100 & & 0.000 \\
\hline 34 & 2 & $05 / 29 / 12$ & 3 & 15 & 30 & 70 & & 1.000 \\
\hline 36 & 2 & $05 / 29 / 12$ & 2 & 15 & & 100 & & 0.667 \\
\hline 39 & 2 & $05 / 29 / 12$ & 3 & 15 & & & 100 & 1.000 \\
\hline 36 & 2 & $06 / 01 / 12$ & 2 & & & & & 0.667 \\
\hline 21 & 2 & $06 / 01 / 12$ & 2 & & & & & 0.667 \\
\hline 39 & 2 & $06 / 01 / 12$ & 3 & & & & & 1.000 \\
\hline 34 & 2 & $06 / 01 / 12$ & 3 & & & & & 1.000 \\
\hline 23 & 2 & $06 / 01 / 12$ & 3 & & & & & 1.000 \\
\hline 17 & 2 & $06 / 01 / 12$ & 3 & & & & & 1.000 \\
\hline 14 & 2 & $06 / 01 / 12$ & 3 & & & & & 1.000 \\
\hline 7 & 2 & $06 / 01 / 12$ & 3 & & & & & 1.000 \\
\hline 3 & 2 & $06 / 01 / 12$ & 3 & & & & & 1.000 \\
\hline 2 & 2 & $06 / 01 / 12$ & 3 & & & & & 1.000 \\
\hline 1 & 3 & $05 / 27 / 12$ & 1 & 15 & 100 & & & 0.333 \\
\hline 6 & 3 & $05 / 27 / 12$ & 1 & 15 & 100 & & & 0.333 \\
\hline 9 & 3 & $05 / 27 / 12$ & none obser. & 15 & 15 & 85 & & 0.000 \\
\hline 10 & 3 & $05 / 27 / 12$ & 2 & 15 & & & 100 & 0.667 \\
\hline 11 & 3 & $05 / 27 / 12$ & none obser. & 15 & 25 & 75 & & 0.000 \\
\hline 20 & 3 & $05 / 27 / 12$ & none obser. & 15 & & 100 & & 0.000 \\
\hline 25 & 3 & $05 / 27 / 12$ & 3 & 15 & 50 & 50 & & 1.000 \\
\hline 29 & 3 & $05 / 27 / 12$ & none obser. & 15 & 95 & 5 & & 0.000 \\
\hline 30 & 3 & $05 / 27 / 12$ & 1 & 15 & 60 & 40 & & 0.333 \\
\hline 40 & 3 & $05 / 27 / 12$ & 2 & 15 & 60 & 40 & & 0.667 \\
\hline 1 & 3 & $05 / 28 / 12$ & 2 & 15 & 95 & 5 & & 0.667 \\
\hline 6 & 3 & $05 / 28 / 12$ & 3 & 15 & & 100 & & 1.000 \\
\hline 9 & 3 & $05 / 28 / 12$ & 3 & 15 & & 100 & & 1.000 \\
\hline 10 & 3 & $05 / 28 / 12$ & 2 & 15 & & & 100 & 0.667 \\
\hline 11 & 3 & $05 / 28 / 12$ & 2 & 15 & & 100 & & 0.667 \\
\hline 20 & 3 & $05 / 28 / 12$ & 2 & 15 & 50 & 50 & & 0.667 \\
\hline 25 & 3 & $05 / 28 / 12$ & 3 & 15 & & 100 & & 1.000 \\
\hline 29 & 3 & $05 / 28 / 12$ & 3 & 15 & & 100 & & 1.000 \\
\hline 30 & 3 & $05 / 28 / 12$ & 2 & 15 & & 100 & & 0.667 \\
\hline
\end{tabular}




\begin{tabular}{|c|c|c|c|c|c|c|c|c|}
\hline 40 & 3 & $05 / 28 / 12$ & 2 & 15 & & 100 & & 0.667 \\
\hline 1 & 3 & $05 / 29 / 12$ & 2 & 15 & 100 & & & 0.667 \\
\hline 6 & 3 & $05 / 29 / 12$ & 3 & 15 & & & 100 & 1.000 \\
\hline 9 & 3 & $05 / 29 / 12$ & 3 & 15 & & & 100 & 1.000 \\
\hline 10 & 3 & $05 / 29 / 12$ & 2 & 15 & & & 100 & 0.667 \\
\hline 11 & 3 & $05 / 29 / 12$ & 2 & 15 & & & 100 & 0.667 \\
\hline 20 & 3 & $05 / 29 / 12$ & 3 & 15 & & 100 & & 1.000 \\
\hline 25 & 3 & $05 / 29 / 12$ & 3 & 15 & & 100 & & 1.000 \\
\hline 29 & 3 & $05 / 29 / 12$ & 2 & 15 & & 100 & & 0.667 \\
\hline 30 & 3 & $05 / 29 / 12$ & 2 & 15 & & 100 & & 0.667 \\
\hline 40 & 3 & $05 / 29 / 12$ & 2 & 15 & & 100 & & 0.667 \\
\hline 40 & 3 & $06 / 01 / 12$ & 2 & & & & & 0.667 \\
\hline 30 & 3 & 06/01/12 & 2 & & & & & 0.667 \\
\hline 29 & 3 & $06 / 01 / 12$ & 2 & & & & & 0.667 \\
\hline 25 & 3 & $06 / 01 / 12$ & 2 & & & & & 0.667 \\
\hline 11 & 3 & $06 / 01 / 12$ & 2 & & & & & 0.667 \\
\hline 10 & 3 & $06 / 01 / 12$ & 2 & & & & & 0.667 \\
\hline 1 & 3 & $06 / 01 / 12$ & 2 & & & & & 0.667 \\
\hline 20 & 3 & $06 / 01 / 12$ & 3 & & & & & 1.000 \\
\hline 9 & 3 & $06 / 01 / 12$ & 3 & & & & & 1.000 \\
\hline 6 & 3 & $06 / 01 / 12$ & 3 & & & & & 1.000 \\
\hline 15 & 4 & $05 / 27 / 12$ & 1 & 15 & & 100 & & 0.333 \\
\hline 16 & 4 & $05 / 27 / 12$ & none obser. & 15 & 40 & 60 & & 0.000 \\
\hline 18 & 4 & $05 / 27 / 12$ & 1 & 15 & 5 & 95 & & 0.333 \\
\hline 22 & 4 & $05 / 27 / 12$ & 1 & 15 & & 100 & & 0.333 \\
\hline 24 & 4 & $05 / 27 / 12$ & 1 & 15 & & & 100 & 0.333 \\
\hline 26 & 4 & $05 / 27 / 12$ & none obser. & 15 & 10 & 90 & & 0.000 \\
\hline 27 & 4 & $05 / 27 / 12$ & 1 & 15 & 20 & 80 & & 0.333 \\
\hline 28 & 4 & $05 / 27 / 12$ & 2 & 15 & 40 & 60 & & 0.667 \\
\hline 32 & 4 & $05 / 27 / 12$ & 2 & 15 & 10 & 90 & & 0.667 \\
\hline 38 & 4 & $05 / 27 / 12$ & 3 & 15 & & 100 & & 1.000 \\
\hline 15 & 4 & $05 / 28 / 12$ & 2 & 15 & & & 100 & 0.667 \\
\hline 16 & 4 & $05 / 28 / 12$ & 3 & 15 & & 100 & & 1.000 \\
\hline 18 & 4 & $05 / 28 / 12$ & 3 & 15 & & & 100 & 1.000 \\
\hline 22 & 4 & $05 / 28 / 12$ & 2 & 15 & & 100 & & 0.667 \\
\hline 24 & 4 & $05 / 28 / 12$ & 2 & 15 & & & 100 & 0.667 \\
\hline 26 & 4 & $05 / 28 / 12$ & 2 & 15 & & & 100 & 0.667 \\
\hline 27 & 4 & $05 / 28 / 12$ & 3 & 15 & & 100 & & 1.000 \\
\hline 28 & 4 & $05 / 28 / 12$ & 2 & 15 & & 100 & & 0.667 \\
\hline
\end{tabular}




\begin{tabular}{|c|c|c|c|c|c|c|c|}
\hline 32 & 4 & $05 / 28 / 12$ & 2 & 15 & 100 & & 0.667 \\
\hline 38 & 4 & $05 / 28 / 12$ & 4 & 15 & 100 & & 0.667 \\
\hline 15 & 4 & $05 / 29 / 12$ & 2 & 15 & & 100 & 0.667 \\
\hline 16 & 4 & $05 / 29 / 12$ & 3 & 15 & 50 & 50 & 1.000 \\
\hline 18 & 4 & $05 / 29 / 12$ & 3 & 15 & & 100 & 1.000 \\
\hline 22 & 4 & $05 / 29 / 12$ & 3 & 15 & & 100 & 1.000 \\
\hline 24 & 4 & $05 / 29 / 12$ & 2 & 30 & & 100 & 0.667 \\
\hline 26 & 4 & $05 / 29 / 12$ & 2 & 15 & & 100 & 0.667 \\
\hline 27 & 4 & $05 / 29 / 12$ & 3 & 15 & & 100 & 1.000 \\
\hline 28 & 4 & $05 / 29 / 12$ & 3 & 15 & 100 & & 1.000 \\
\hline 32 & 4 & $05 / 29 / 12$ & 2 & 15 & 100 & & 0.667 \\
\hline 38 & 4 & $05 / 29 / 12$ & 4 & 15 & & 100 & 0.667 \\
\hline 32 & 4 & $06 / 01 / 12$ & 2 & 3 & & & 0.667 \\
\hline 26 & 4 & $06 / 01 / 12$ & 2 & 3 & & & 0.667 \\
\hline 24 & 4 & $06 / 01 / 12$ & 2 & 3 & & & 0.667 \\
\hline 15 & 4 & 06/01/12 & 2 & 3 & & & 0.667 \\
\hline 28 & 4 & $06 / 01 / 12$ & 3 & 3 & & & 1.000 \\
\hline 27 & 4 & $06 / 01 / 12$ & 3 & 3 & & & 1.000 \\
\hline 22 & 4 & $06 / 01 / 12$ & 3 & 3 & & & 1.000 \\
\hline 18 & 4 & $06 / 01 / 12$ & 3 & 3 & & & 1.000 \\
\hline 16 & 4 & $06 / 01 / 12$ & 3 & 3 & & & 1.000 \\
\hline 38 & 4 & $06 / 01 / 12$ & 4 & 6 & & & 0.667 \\
\hline
\end{tabular}

\section{Table D2. Typha latifolia Seedling Biomass}

\begin{tabular}{|c|c|c|c|c|c|c|c|c|}
\hline Micro. & $\mathrm{N}$ & Treat. & $\begin{array}{c}\text { Sample } \\
\text { Date } \\
\end{array}$ & $\begin{array}{c}\text { P1 } \\
\text { biomass } \\
\text { (g) } \\
\end{array}$ & $\begin{array}{c}\text { P2 } \\
\text { biomass } \\
(\mathrm{g}) \\
\end{array}$ & $\begin{array}{c}\text { P3 } \\
\text { biomass } \\
\text { (g) } \\
\end{array}$ & $\begin{array}{c}\text { Root } \\
\text { Biomass } \\
(\mathrm{g}) \\
\end{array}$ & $\begin{array}{c}\text { Total } \\
\text { biomass } \\
(\mathrm{g}) \\
\end{array}$ \\
\hline 4 & & 1 & $08 / 18 / 12$ & 7.3 & & & & 7.3 \\
\hline 5 & & 1 & $08 / 18 / 12$ & 6.11 & & & 1.82 & 7.93 \\
\hline 8 & & 1 & $08 / 18 / 12$ & 3.83 & 0.07 & & 0.42 & 4.32 \\
\hline 12 & & 1 & $08 / 18 / 12$ & 0.41 & & & & 0.41 \\
\hline 19 & & 1 & $08 / 18 / 12$ & 2.12 & 1.1 & & 1.58 & 4.8 \\
\hline 31 & & 1 & $08 / 16 / 12$ & 4.93 & 0.44 & & 1.46 & 6.83 \\
\hline 37 & 7 & 1 & $08 / 18 / 12$ & 0.34 & 3.71 & & 0.9 & 4.95 \\
\hline 2 & & 2 & $08 / 18 / 12$ & 2.73 & 1.07 & & 1.29 & 5.09 \\
\hline 7 & & 2 & $08 / 16 / 12$ & 1.03 & 1.47 & 1.67 & 2.29 & 6.46 \\
\hline 14 & & 2 & $08 / 18 / 12$ & 2.95 & 0.1 & & 1.09 & 4.14 \\
\hline 17 & & 2 & $08 / 18 / 12$ & 2.34 & 0.31 & 2.43 & 1.83 & 6.91 \\
\hline 34 & & 2 & $08 / 16 / 12$ & 1.56 & 0.27 & 3.23 & 2.57 & 7.63 \\
\hline
\end{tabular}




\begin{tabular}{|c|c|c|c|c|c|c|c|c|}
\hline 36 & & 2 & $08 / 18 / 12$ & 3.42 & 1.24 & & 1.05 & 5.71 \\
\hline 39 & 7 & 2 & $08 / 18 / 12$ & & 4.12 & & 0.62 & 4.74 \\
\hline 1 & & 3 & $08 / 16 / 12$ & 2.61 & 2.53 & & 0.52 & 5.66 \\
\hline 6 & & 3 & $08 / 18 / 12$ & 0.33 & 3.5 & & 1.15 & 4.98 \\
\hline 11 & & 3 & $08 / 19 / 12$ & 0.54 & 6.08 & & 0.2 & 6.82 \\
\hline 20 & & 3 & 08/19/12 & 0.54 & 6.08 & & 0.2 & 6.82 \\
\hline 29 & & 3 & $08 / 16 / 12$ & 0 & 4.15 & & 1.56 & 5.71 \\
\hline 30 & & 3 & 08/19/12 & 5.1 & & & 0.11 & 5.21 \\
\hline 40 & 7 & 3 & $08 / 19 / 12$ & 5.63 & 0.54 & & 0.58 & 6.75 \\
\hline 15 & & 4 & 08/19/12 & 5.36 & 1.02 & & & 6.38 \\
\hline 16 & & 4 & $08 / 19 / 12$ & 0.29 & 1.73 & & 0.06 & 2.08 \\
\hline 24 & & 4 & $08 / 19 / 12$ & 3.95 & & & 0.79 & 4.74 \\
\hline 26 & & 4 & 08/19/12 & 4.27 & & & 0.89 & 5.16 \\
\hline 27 & & 4 & 08/19/12 & 0.42 & 5.47 & 0.8 & 0.19 & 6.88 \\
\hline 28 & & 4 & 08/19/12 & 6.75 & & & 0.74 & 7.49 \\
\hline 38 & 7 & 4 & $08 / 16 / 12$ & 2.2 & & & & 2.2 \\
\hline
\end{tabular}

\section{Typha latifolia response to $\mathbf{N}$ and $\mathbf{P}$}

Standard Deviations for mean TLL biweekly measurements

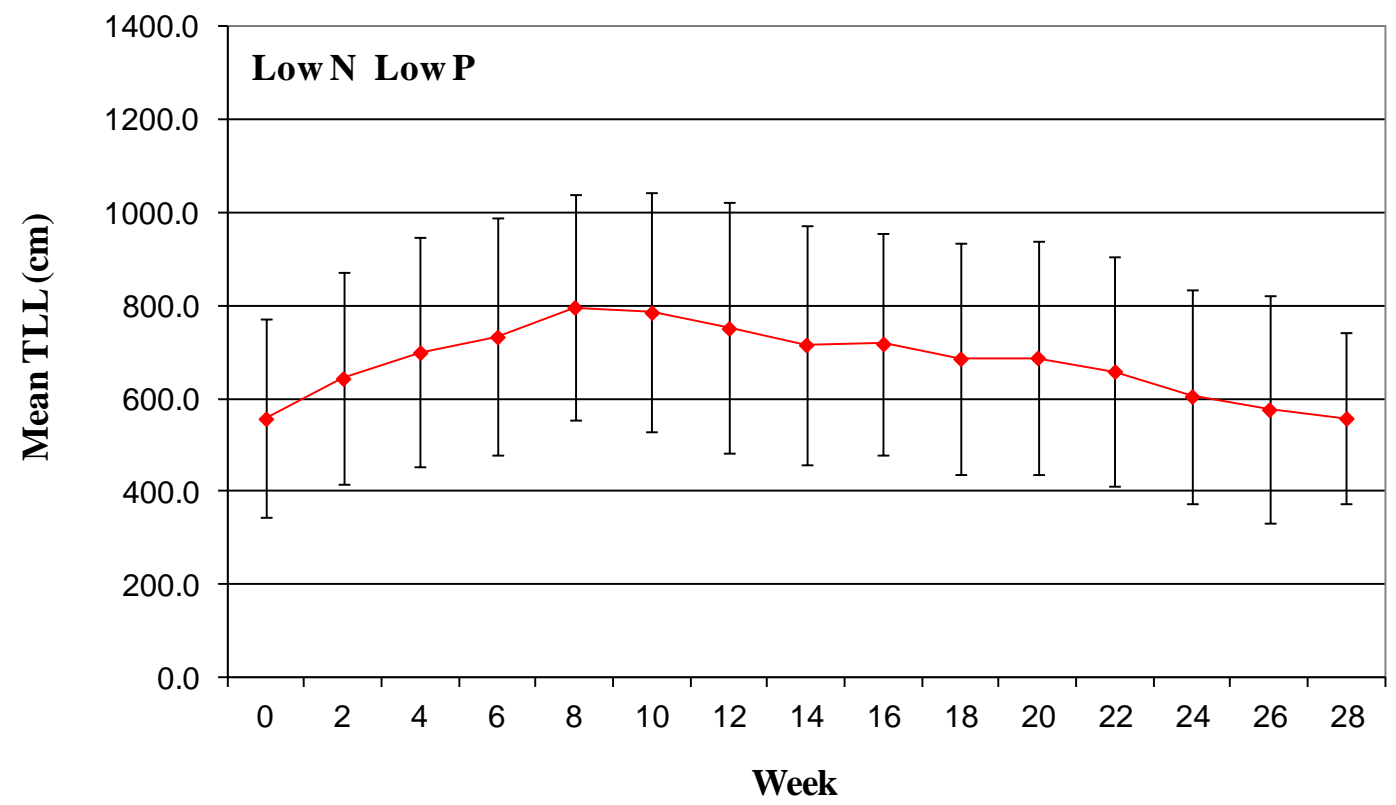


Figure D1. Mean TLL and standard deviations Typha latifolia reared in Low N and Low P.

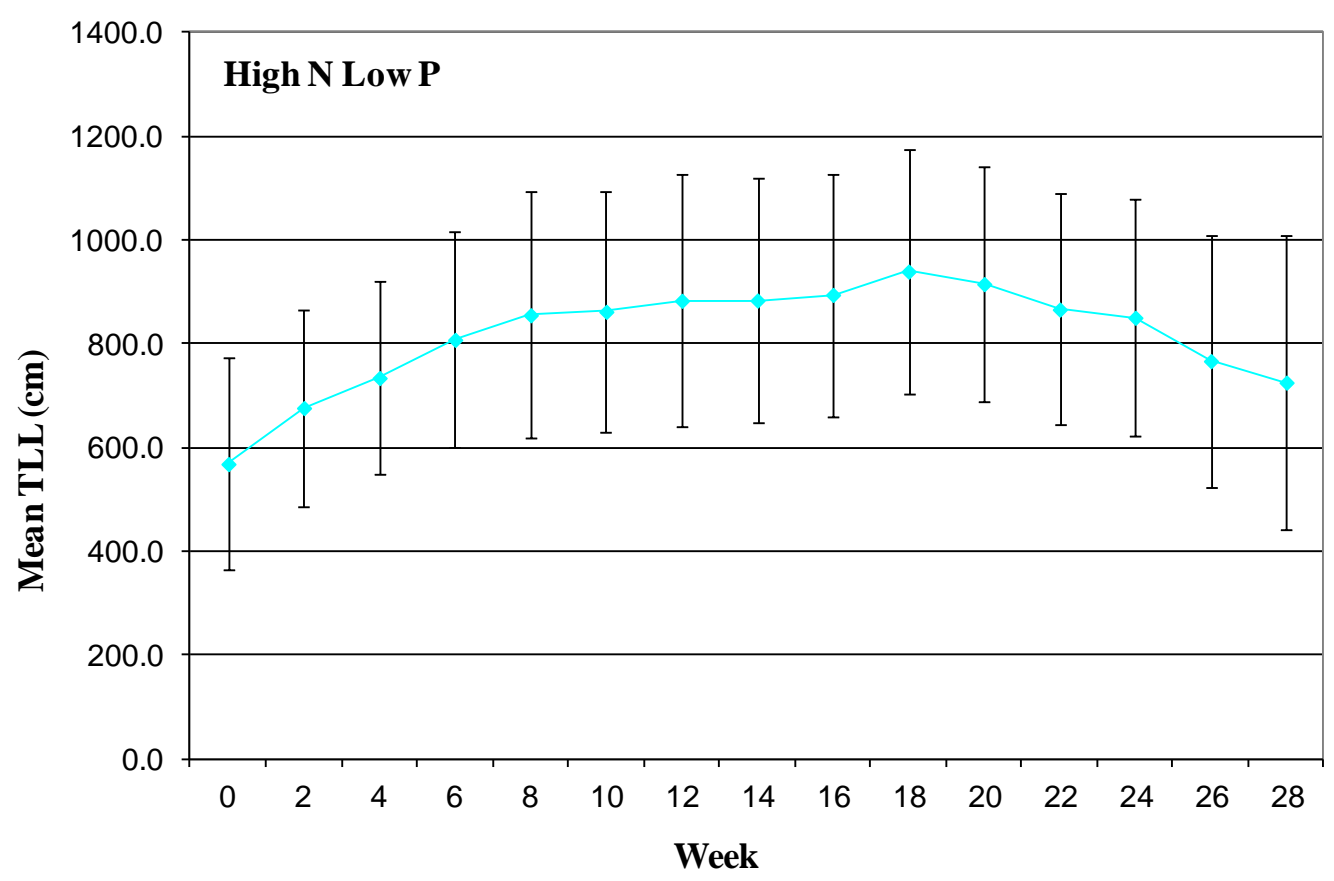

Figure D2. Mean TLL and standard deviations Typha latifolia reared in High N and Low $\mathbf{P}$.

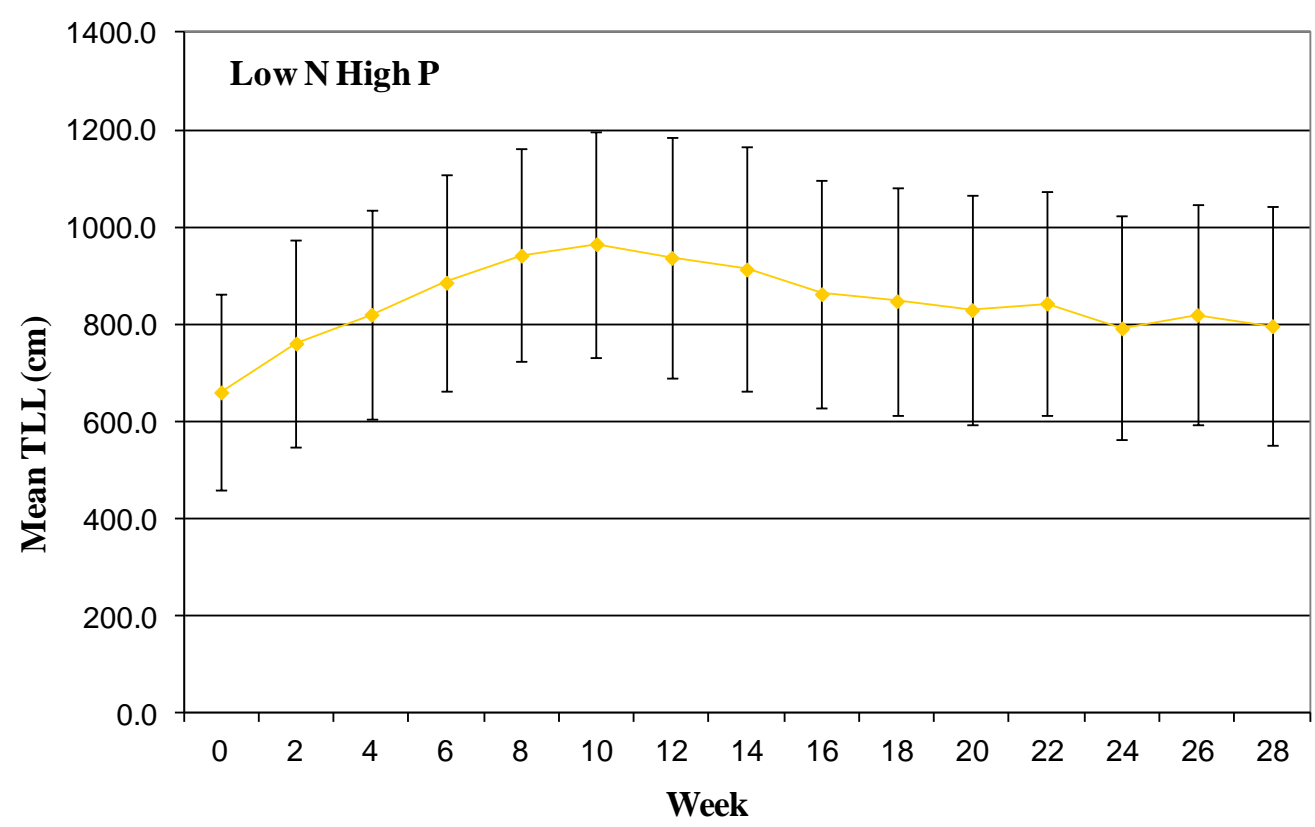


Figure D3. Mean TLL and standard deviations Typha latifolia reared in Low $\mathbf{N}$ and High P.

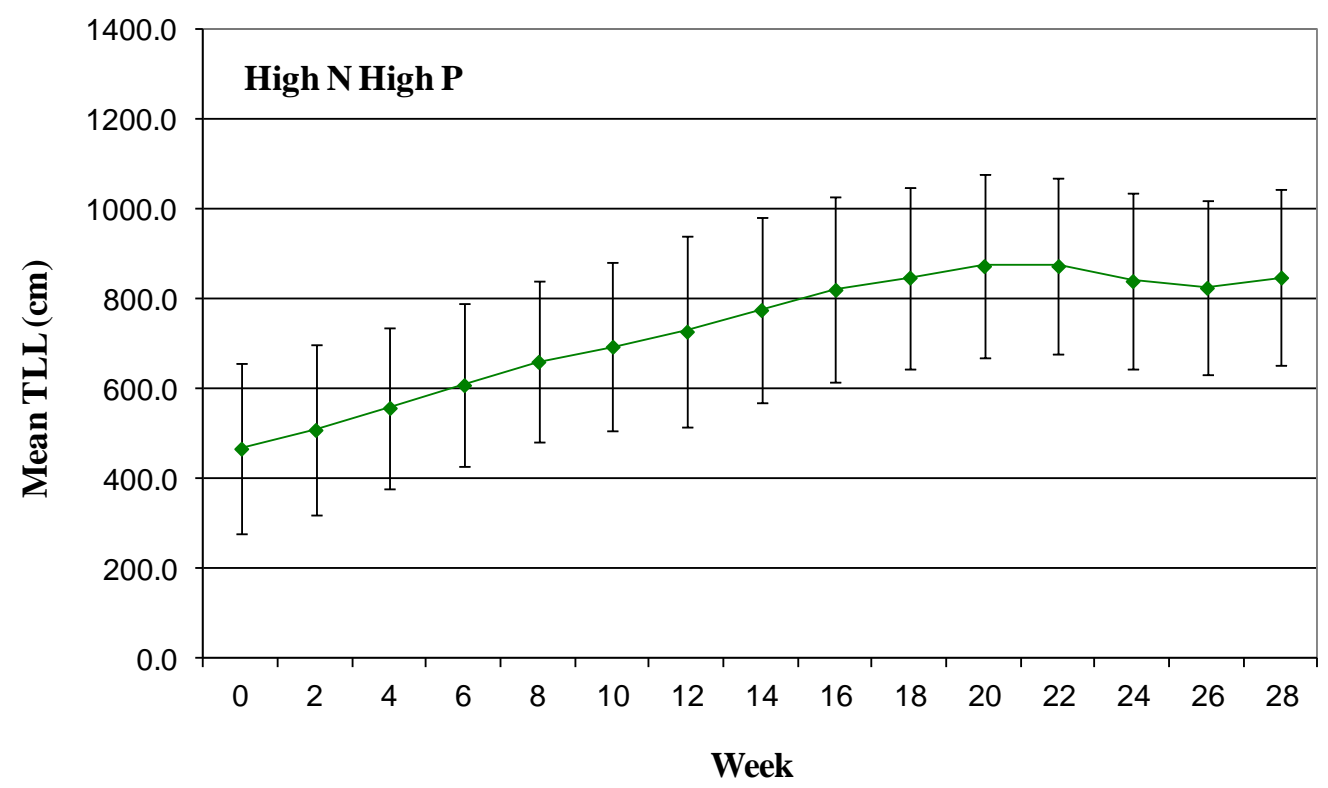

Figure D4. Mean TLL and standard deviations Typha latifolia reared in High $\mathbf{N}$ and High P. 


\subsection{Appendix E}

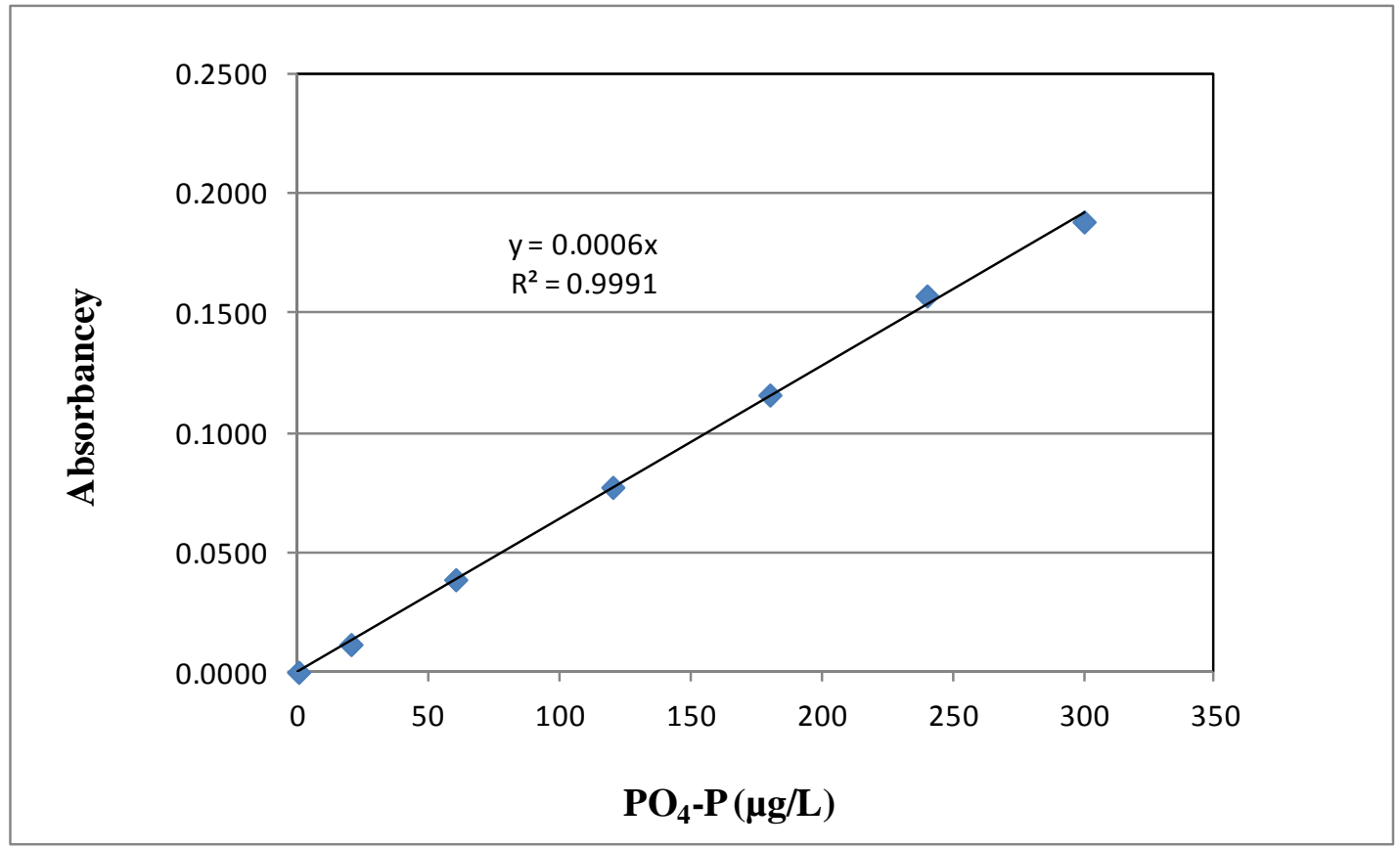

Figure E1. Phosphate standard curve used to estimate the porewater phosphate concentrations in sediments used to propagate Typha latifolia seedling.

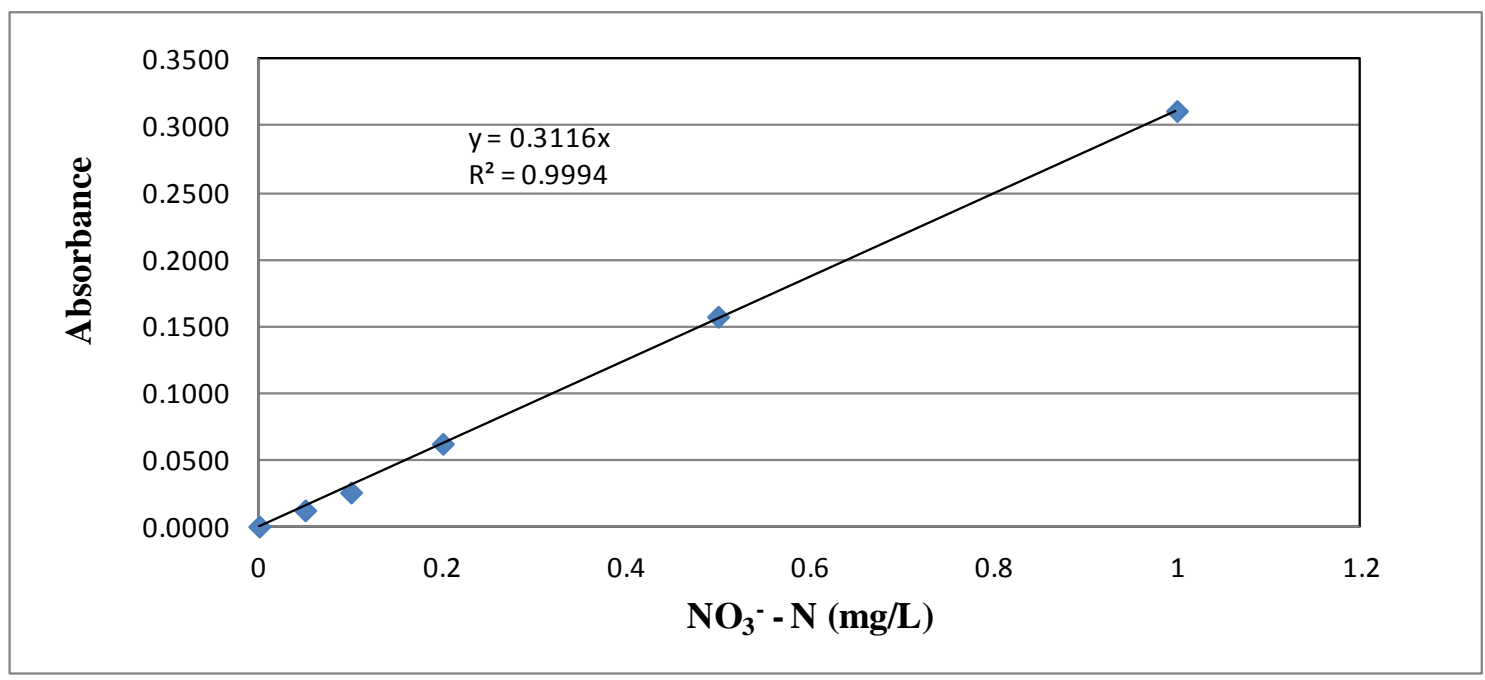

Figure E2. Nitrate standard curve used to estimate the nitrate concentration in City of Toronto Municipal drinking water provided to microcosms for the Typha latifolia seedling propagation and response to $\mathrm{N}$ and $\mathrm{P}$ for the acclimation period and first month of the Typha latifolia response to $\mathrm{N}$ and $\mathrm{P}$ loading. 


\section{Water Quality: Typha latifolia response to oligotrophic and eutrophic $\mathbf{N}$ and $\mathbf{P}$ loading rates under laboratory conditions}

All water samples collected before watering/grow media additions except in some cases salinity was measured before and after watering/grow media additions.

\section{Table E. 1. Supporting water quality data for Typha latifolia response to $\mathbf{N}$ and $\mathbf{P}$ treatments.}

$\mathrm{Wk}=$ week $\mathrm{M} .=$ microcosm $; \mathrm{T} .=$ treatment $\mathrm{DO}=$ dissolved oxygen; $\mathrm{PSC}=$ water conductivity meter; cond $=$ conductivity

\begin{tabular}{|c|c|c|c|c|c|c|c|c|c|c|c|}
\hline $\mathbf{N}$ & $\begin{array}{c}\text { Date } \\
(\mathrm{mm} / \mathrm{dd} / \mathbf{y y}) \\
\end{array}$ & Wk & M. & T. & $\begin{array}{c}\text { DO } \\
\text { meter } \\
\left({ }^{\circ} \mathrm{C}\right) \\
\end{array}$ & $\begin{array}{c}\text { PCS } \\
\text { meter } \\
\left({ }^{\circ} \mathrm{C}\right) \\
\end{array}$ & $\begin{array}{c}\text { DO } \\
(\mathrm{mg} / \mathrm{L}) \\
\end{array}$ & pH & $\begin{array}{c}\text { Cond. } \\
(\mu \mathrm{S} / \mathrm{cm}) \\
\end{array}$ & $\begin{array}{c}\text { Salinity } \\
(\mathrm{mg} / \mathrm{L})\end{array}$ & $\begin{array}{c}\text { TDS } \\
(\mathrm{mg} / \mathrm{L}) \\
\end{array}$ \\
\hline 1 & $12 / 06 / 12$ & 6 & 3 & 2 & 22.5 & 22.4 & 6.89 & 6.49 & 698.0 & 332.0 & 495 \\
\hline 2 & $12 / 06 / 12$ & 6 & 4 & 1 & 22.4 & 22.1 & 6.92 & 6.69 & 445.0 & 200.0 & 306 \\
\hline 3 & $12 / 06 / 12$ & 6 & 20 & 4 & 21.3 & 22.8 & 5.66 & 6.26 & 677.0 & 325.0 & 486 \\
\hline 4 & $12 / 06 / 12$ & 6 & 2 & 4 & 22.4 & 22.8 & 9.02 & 7.10 & 342.0 & 161.0 & 243 \\
\hline 5 & $12 / 06 / 12$ & 6 & 32 & 1 & 22.2 & 22.5 & 10.54 & 7.36 & 662.0 & 315.0 & 471 \\
\hline 6 & $12 / 06 / 12$ & 6 & 11 & 3 & 22.3 & 22.4 & 8.99 & 7.05 & 429.0 & 201.0 & 305 \\
\hline 7 & $12 / 06 / 12$ & 6 & 22 & 2 & 23.3 & 22.4 & 11.29 & 7.81 & 580.0 & 267.0 & 393 \\
\hline 8 & $12 / 06 / 12$ & 6 & 12 & 1 & 22.4 & 21.1 & 7.44 & 6.62 & 332.0 & 158.0 & 245 \\
\hline 9 & $12 / 06 / 12$ & 6 & 31 & 3 & 22.3 & 22.6 & 7.74 & 6.84 & 690.0 & 331.0 & 493 \\
\hline 10 & $12 / 06 / 12$ & 6 & 9 & 3 & 22.2 & 22.5 & 7.47 & 6.80 & 441.0 & 207.0 & 313 \\
\hline 11 & $12 / 06 / 12$ & 6 & 36 & 4 & 22.2 & 22.5 & 10.51 & 7.62 & 684.0 & 324.0 & 488 \\
\hline 12 & $12 / 06 / 12$ & 6 & 38 & 2 & 21.9 & 22.2 & 11.03 & 8.02 & 462.0 & 218.0 & 328 \\
\hline 1 & $01 / 10 / 13$ & 11 & 3 & 2 & 20.4 & 21.2 & 7.47 & 6.40 & 607.0 & 292.0 & 430 \\
\hline 2 & $01 / 10 / 13$ & 11 & 4 & 1 & 20.4 & 21.2 & 9.51 & 6.45 & 401.0 & 192.0 & 285 \\
\hline 3 & $01 / 10 / 13$ & 11 & 20 & 4 & 20.5 & 21.4 & 7.86 & 6.25 & 661.0 & 317.0 & 471 \\
\hline 4 & $01 / 10 / 13$ & 11 & 2 & 4 & 20.3 & 21.1 & 10.15 & 6.78 & 429.0 & 203.0 & 305 \\
\hline 5 & $01 / 10 / 13$ & 11 & 32 & 1 & 20.5 & 21.2 & 11.38 & 7.35 & 713.0 & 321.0 & 506 \\
\hline 6 & $01 / 10 / 13$ & 11 & 11 & 3 & 20.4 & 21.2 & 11.28 & 7.11 & 450.0 & 214.0 & 315 \\
\hline 7 & $01 / 10 / 13$ & 11 & 22 & 2 & 20.3 & 21.2 & 10.16 & 7.01 & 585.0 & 283.0 & 418 \\
\hline 8 & 01/10/13 & 11 & 12 & 1 & 20.4 & 21.1 & 9.33 & 7.23 & 301.0 & 144.0 & 213 \\
\hline 9 & $01 / 10 / 13$ & 11 & 31 & 3 & 20.4 & 21.2 & 10.84 & 6.99 & 588.0 & 286.0 & 404 \\
\hline 10 & $01 / 10 / 13$ & 11 & 33 & 3 & 20.4 & 21.1 & 7.16 & 6.38 & 258.0 & 123.0 & 183 \\
\hline 11 & $01 / 10 / 13$ & 11 & 36 & 4 & 20.4 & 21.2 & 6.94 & 6.65 & 646.0 & 310.0 & 458 \\
\hline 12 & $01 / 10 / 13$ & 11 & 38 & 1 & 20.6 & 21.3 & 10.73 & 7.09 & 447.0 & 214.0 & 318 \\
\hline 1 & $01 / 11 / 13$ & 15 & 1 & 2 & & 22.0 & & & & 342.0 & \\
\hline 2 & $01 / 11 / 13$ & 15 & 2 & 4 & & 22.1 & & & & 216.0 & \\
\hline 3 & $01 / 11 / 13$ & 15 & 3 & 2 & & 22.1 & & & & 316.0 & \\
\hline 4 & $01 / 11 / 13$ & 15 & 4 & 1 & & 22.0 & & & & 206.0 & \\
\hline 5 & $01 / 11 / 13$ & 15 & 5 & 1 & & 21.9 & & & & 332.0 & \\
\hline 6 & $01 / 11 / 13$ & 15 & 6 & 3 & & 21.9 & & & & 250.0 & \\
\hline 7 & $01 / 11 / 13$ & 15 & 7 & 4 & & 22.2 & & & & 186.0 & \\
\hline 8 & $01 / 11 / 13$ & 15 & 8 & 1 & & 22.1 & & & & 341.0 & \\
\hline
\end{tabular}




\begin{tabular}{|c|c|c|c|c|c|c|c|c|c|c|c|}
\hline 9 & $01 / 11 / 13$ & 15 & 9 & 3 & & & & & & & \\
\hline 10 & $01 / 11 / 13$ & 15 & 10 & 4 & & 22.3 & & & & 316.0 & \\
\hline 11 & $01 / 11 / 13$ & 15 & 11 & 3 & & 21.9 & & & & 238.0 & \\
\hline 12 & $01 / 11 / 13$ & 15 & 12 & 1 & & 21.9 & & & & 157.0 & \\
\hline 13 & $01 / 11 / 13$ & 15 & 13 & 1 & & 21.5 & & & & 272.0 & \\
\hline 14 & $01 / 11 / 13$ & 15 & 14 & 3 & & 22.0 & & & & 343.0 & \\
\hline 15 & $01 / 11 / 13$ & 15 & 15 & 2 & & 22.1 & & & & 215.0 & \\
\hline 16 & $01 / 11 / 13$ & 15 & 16 & 2 & & 21.8 & & & & 181.0 & \\
\hline 17 & $01 / 11 / 13$ & 15 & 17 & 2 & & & & & & & \\
\hline 18 & $01 / 11 / 13$ & 15 & 18 & 4 & & 22.1 & & & & 220.0 & \\
\hline 19 & $01 / 11 / 13$ & 15 & 19 & 1 & & 21.6 & & & & 220.0 & \\
\hline 20 & $01 / 11 / 13$ & 15 & 20 & 4 & & 22.0 & & & & 287.0 & \\
\hline 21 & $01 / 11 / 13$ & 15 & 21 & 3 & & 21.9 & & & & 79.5 & \\
\hline 22 & $01 / 11 / 13$ & 15 & 22 & 2 & & 22.0 & & & & 295.0 & \\
\hline 23 & $01 / 11 / 13$ & 15 & 23 & 3 & & 21.9 & & & & 175.0 & \\
\hline 24 & $01 / 11 / 13$ & 15 & 24 & 1 & & 22.0 & & & & 265.0 & \\
\hline 25 & $01 / 11 / 13$ & 15 & 25 & 1 & & 21.8 & & & & 385.0 & \\
\hline 26 & $01 / 11 / 13$ & 15 & 26 & 4 & & 21.9 & & & & 101.0 & \\
\hline 27 & $01 / 11 / 13$ & 15 & 27 & 2 & & 20.0 & & & & 172.0 & \\
\hline 28 & $01 / 11 / 13$ & 15 & 28 & 3 & & 21.8 & & & & 59.3 & \\
\hline 29 & $01 / 11 / 13$ & 15 & 29 & 4 & & 22.1 & & & & 80.6 & \\
\hline 30 & $01 / 11 / 13$ & 15 & 30 & 1 & & 21.9 & & & & 315.0 & \\
\hline 31 & $01 / 11 / 13$ & 15 & 31 & 3 & & 22.0 & & & & 300.0 & \\
\hline 32 & $01 / 11 / 13$ & 15 & 32 & 1 & & 22.0 & & & & 359.0 & \\
\hline 33 & $01 / 11 / 13$ & 15 & 33 & 3 & & 21.8 & & & & 144.0 & \\
\hline 34 & $01 / 11 / 13$ & 15 & 34 & 2 & & 22.1 & & & & 337.0 & \\
\hline 35 & $01 / 11 / 13$ & 15 & 35 & 4 & & 22.1 & & & & 381.0 & \\
\hline 36 & $01 / 11 / 13$ & 15 & 36 & 4 & & 22.0 & & & & 327.0 & \\
\hline 37 & $01 / 11 / 13$ & 15 & 37 & 2 & & 22.1 & & & & 201.0 & \\
\hline 38 & $01 / 11 / 13$ & 15 & 38 & 2 & & 21.9 & & & & 230.0 & \\
\hline 39 & $01 / 11 / 13$ & 15 & 39 & 3 & & 21.9 & & & & 123.0 & \\
\hline 40 & $01 / 11 / 13$ & 15 & 40 & 4 & & 22.1 & & & & 404.0 & \\
\hline 1 & 02/12/13 & 15 & 1 & 2 & 20.3 & 21.0 & 10.02 & 6.93 & 694.0 & 332.0 & $\begin{array}{l}\text { Not } \\
\text { done }\end{array}$ \\
\hline 2 & $02 / 12 / 13$ & 15 & 2 & 4 & 20.4 & 21.3 & 9.22 & 6.99 & 543.0 & 259.0 & done \\
\hline 3 & $02 / 12 / 13$ & 15 & 3 & 2 & 21.1 & 20.4 & 7.94 & 6.32 & 623.0 & 301.0 & $\begin{array}{l}\text { done } \\
\text { Not }\end{array}$ \\
\hline 4 & $02 / 12 / 13$ & 15 & 4 & 1 & 20.4 & 21.0 & 9.27 & 6.69 & 545.0 & 288.0 & $\begin{array}{c}\text { done } \\
\text { Not }\end{array}$ \\
\hline 5 & $02 / 12 / 13$ & 15 & 5 & 1 & 20.6 & 20.7 & 10.09 & 6.47 & 704.0 & 361.0 & $\begin{array}{c}\text { done } \\
\text { Not }\end{array}$ \\
\hline 6 & $02 / 12 / 13$ & 15 & 6 & 3 & 20.2 & 20.7 & 10.42 & 6.70 & 583.0 & 272.0 & $\begin{array}{c}\text { done } \\
\text { Not }\end{array}$ \\
\hline 7 & $02 / 12 / 13$ & 15 & 7 & 4 & 20.4 & 21.3 & 7.67 & 6.55 & 326.0 & 161.0 & $\begin{array}{c}\text { done } \\
\text { Not }\end{array}$ \\
\hline 8 & $02 / 12 / 13$ & 15 & 8 & 1 & 20.3 & 21.0 & 9.48 & 6.60 & 837.0 & 400.0 & done \\
\hline 9 & $02 / 12 / 13$ & 15 & 9 & 3 & & & & & & & \\
\hline 10 & $02 / 12 / 13$ & 15 & 10 & 4 & 20.4 & 20.9 & 10.35 & 6.67 & 570.0 & 273.0 & $\begin{array}{l}\text { Not } \\
\text { done }\end{array}$ \\
\hline 11 & $02 / 12 / 13$ & 15 & 11 & 3 & 20.6 & 20.9 & 11.07 & 6.94 & 484.0 & 245.0 & Not \\
\hline
\end{tabular}




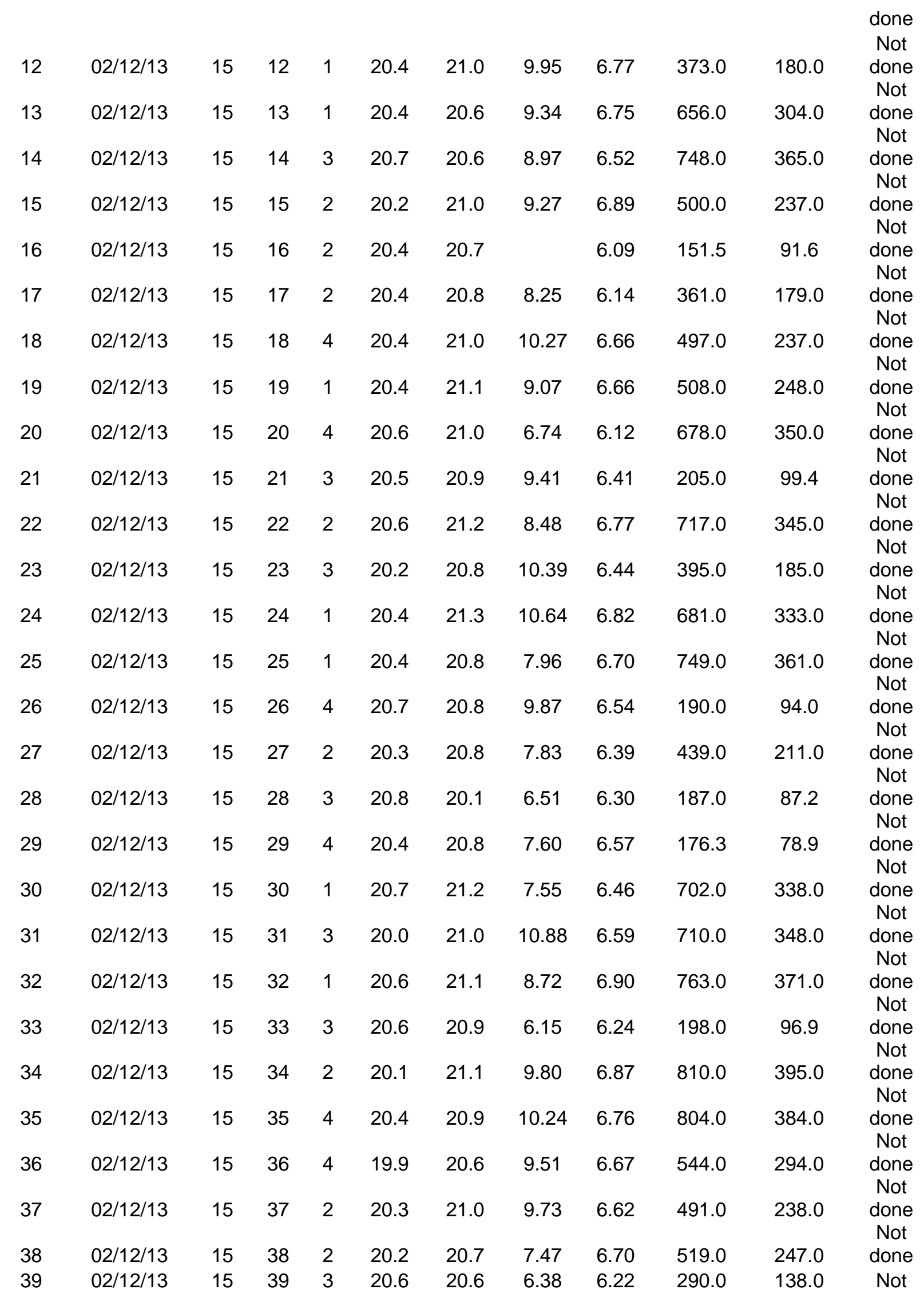









\begin{tabular}{|c|c|c|c|c|c|c|c|c|c|c|c|}
\hline 37 & $04 / 16 / 13$ & 24 & 37 & 2 & & 22.0 & & & & 312.0 & \\
\hline 38 & 04/16/13 & 24 & 38 & 2 & & 22.3 & & & & 242.0 & \\
\hline 39 & 04/16/13 & 24 & 39 & 3 & & 22.2 & & & & 128.0 & \\
\hline 40 & 04/16/13 & 24 & 40 & 4 & & 22.4 & & & & 282.0 & \\
\hline 1 & 04/18/13 & 25 & 3 & 2 & 23.4 & 23.7 & 8.24 & 6.30 & 582.0 & 276.0 & 419 \\
\hline 2 & 04/18/13 & 25 & 4 & 1 & 23.0 & 23.5 & 8.55 & 6.57 & 623.0 & 289.0 & 441 \\
\hline 3 & 04/18/13 & 25 & 20 & 4 & 23.2 & 23.7 & 4.88 & 6.49 & 389.0 & 183.0 & 227 \\
\hline 4 & 04/18/13 & 25 & 2 & 4 & 23.3 & 23.6 & 6.68 & 6.56 & 354.0 & 168.0 & 254 \\
\hline 5 & $04 / 18 / 13$ & 25 & 32 & 1 & 23.0 & 23.6 & 7.16 & 6.49 & 794.0 & 381.0 & 570 \\
\hline 6 & 04/18/13 & 25 & 11 & 3 & 23.1 & 23.4 & 10.45 & 6.71 & 410.0 & 194.0 & 293 \\
\hline 7 & 04/18/13 & 25 & 22 & 2 & 23.2 & 23.6 & 9.46 & 6.64 & 849.0 & 410.0 & 608 \\
\hline 8 & 04/18/13 & 25 & 12 & 1 & 23.6 & 23.7 & 8.81 & 6.38 & 483.0 & 229.0 & 347 \\
\hline 9 & 04/18/13 & 25 & 31 & 3 & 23.4 & 23.4 & 10.13 & 6.94 & 614.0 & 297.0 & 447 \\
\hline 10 & 04/18/13 & 25 & 33 & 3 & 23.4 & 23.7 & 3.45 & 6.36 & 129.6 & 65.2 & 94.9 \\
\hline 11 & 04/18/13 & 25 & 36 & 4 & 23.4 & 23.7 & 9.14 & 6.74 & 419.0 & 198.0 & 299 \\
\hline 12 & 04/18/13 & 25 & 38 & 2 & 23.5 & 23.7 & 8.77 & 6.53 & 437.0 & 208.0 & 311 \\
\hline 1 & $5 / 08 / / 2013$ & 28 & 1 & 2 & 23.9 & 24.6 & 9.75 & 6.64 & 353.0 & 166.0 & 252 \\
\hline 2 & $5 / 08 / / 2013$ & 28 & 2 & 4 & 24.4 & 24.6 & 3.94 & 6.45 & 349.0 & 162.0 & 247 \\
\hline 3 & $5 / 08 / / 2013$ & 28 & 3 & 2 & 24.1 & 24.8 & 8.30 & 6.62 & 565.0 & 267.0 & 404 \\
\hline 4 & $5 / 08 / / 2013$ & 28 & 4 & 1 & 24.7 & 25.0 & 7.70 & 6.78 & 399.0 & 198.0 & 295 \\
\hline 5 & $5 / 08 / / 2013$ & 28 & 5 & 1 & 24.4 & 24.6 & 7.68 & 6.54 & 555.0 & 259.0 & 388 \\
\hline 6 & $5 / 08 / / 2013$ & 28 & 6 & 3 & 24.8 & 25.0 & 9.84 & 6.71 & 691.0 & 329.0 & 497 \\
\hline 7 & $5 / 08 / / 2013$ & 28 & 7 & 4 & 24.6 & 24.9 & 6.04 & 6.49 & 206.0 & 96.2 & 131 \\
\hline 8 & $5 / 08 / / 2013$ & 28 & 8 & 1 & 24.5 & 24.9 & 7.79 & 6.63 & 801.0 & 378.0 & 570 \\
\hline 9 & $5 / 08 / / 2013$ & 28 & 9 & 3 & & & & & & & \\
\hline 10 & $5 / 08 / / 2013$ & 28 & 10 & 4 & 24.4 & 24.8 & 9.92 & 6.68 & 483.0 & 229.0 & 345 \\
\hline 11 & $5 / 08 / / 2013$ & 28 & 11 & 3 & 24.3 & 24.6 & 8.27 & 6.40 & 445.0 & 197.0 & 318 \\
\hline 12 & $5 / 08 / / 2013$ & 28 & 12 & 1 & 23.9 & 24.3 & 7.52 & 6.56 & 604.0 & 284.0 & 420 \\
\hline 13 & $5 / 08 / / 2013$ & 28 & 13 & 1 & 24.6 & 25.0 & 8.38 & 6.56 & 680.0 & 330.0 & 510 \\
\hline 14 & $5 / 08 / / 2013$ & 28 & 14 & 3 & 23.3 & 24.7 & 8.77 & 6.70 & 526.0 & 260.0 & 406 \\
\hline 15 & $5 / 08 / / 2013$ & 28 & 15 & 2 & 24.9 & 24.9 & 7.90 & 6.78 & 576.0 & 271.0 & 407 \\
\hline 16 & $5 / 08 / / 2013$ & 28 & 16 & 2 & 24.6 & 24.7 & 5.89 & 6.31 & 157.9 & 74.7 & 115 \\
\hline 17 & $5 / 08 / / 2013$ & 28 & 17 & 2 & 24.6 & 24.6 & 7.01 & 6.60 & 431.0 & 204.0 & 309 \\
\hline 18 & $5 / 08 / / 2013$ & 28 & 18 & 4 & 24.7 & 25.0 & 7.70 & 6.78 & 399.0 & 198.0 & 295 \\
\hline 19 & $5 / 08 / / 2013$ & 28 & 19 & 1 & 23.7 & 25.0 & 8.26 & 6.65 & 541.0 & 316.0 & 389 \\
\hline 20 & $5 / 08 / / 2013$ & 28 & 20 & 4 & 25.2 & 24.8 & 4.54 & 6.33 & 357.0 & 164.0 & 260 \\
\hline 21 & $5 / 09 / / 2013$ & 28 & 21 & 3 & 24.4 & 24.7 & 7.79 & 6.92 & 252.0 & 118.0 & 178 \\
\hline 22 & $5 / 09 / / 2013$ & 28 & 22 & 2 & 24.1 & 24.6 & 8.37 & 6.66 & 895.0 & 426.0 & 890 \\
\hline 23 & $5 / 09 / / 2013$ & 28 & 23 & 3 & 24.8 & 24.8 & 7.59 & 6.45 & 531.0 & 247.0 & 379 \\
\hline 24 & $5 / 09 / / 2013$ & 28 & 24 & 1 & 24.9 & 24.9 & 8.92 & 6.75 & 575.0 & 273.0 & 414 \\
\hline 25 & $5 / 09 / / 2013$ & 28 & 25 & 1 & 23.4 & 24.7 & 9.57 & 6.54 & 507.0 & 240.0 & 360 \\
\hline 26 & $5 / 09 / / 2013$ & 28 & 26 & 4 & 23.7 & 24.7 & 7.13 & 7.14 & 99.4 & 49.4 & 67.2 \\
\hline 27 & $5 / 09 / / 2013$ & 28 & 27 & 2 & 24.7 & 25.2 & 7.31 & 6.76 & 340.0 & 159.0 & 236 \\
\hline 28 & $5 / 09 / / 2013$ & 28 & 28 & 3 & 24.2 & 24.5 & 6.26 & 6.62 & 109.2 & 53.7 & 74.6 \\
\hline 29 & $5 / 09 / / 2013$ & 28 & 29 & 4 & 23.9 & 24.8 & 6.63 & 6.11 & 93.0 & 50.0 & 70.5 \\
\hline 30 & $5 / 09 / / 2013$ & 28 & 30 & 1 & 24.8 & 24.9 & 7.23 & 6.45 & 706.0 & 339.0 & 496 \\
\hline 31 & $5 / 09 / / 2013$ & 28 & 31 & 3 & 24.8 & 25.1 & 10.30 & 6.85 & 590.0 & 277.0 & 415 \\
\hline 32 & $5 / 09 / / 2013$ & 28 & 32 & 1 & 24.7 & 24.9 & 7.37 & 6.20 & 799.0 & 383.0 & 569 \\
\hline 33 & $5 / 09 / / 2013$ & 28 & 33 & 3 & 24.9 & 24.7 & 3.47 & 6.42 & 119.1 & 58.3 & 85.9 \\
\hline 34 & $5 / 09 / / 2013$ & 28 & 34 & 2 & 24.7 & 25.0 & 9.07 & 6.68 & 864.0 & 367.0 & 611 \\
\hline
\end{tabular}




$\begin{array}{cccccccccccc}35 & 5 / 09 / / 2013 & 28 & 35 & 4 & 24.9 & 24.9 & 7.97 & 6.47 & 541.0 & 263.0 & 395 \\ 36 & 5 / 09 / / 2013 & 28 & 36 & 4 & 24.5 & 24.7 & 7.78 & 6.60 & 433.0 & 206.0 & 312 \\ 37 & 5 / 09 / / 2013 & 28 & 37 & 2 & 24.9 & 24.8 & 8.92 & 6.50 & 545.0 & 255.0 & 390 \\ 38 & 5 / 09 / / 2013 & 28 & 38 & 2 & 24.8 & 25.0 & 7.80 & 6.64 & 513.0 & 239.0 & 365 \\ 39 & 5 / 09 / / 2013 & 28 & 39 & 3 & 24.8 & 25.0 & 6.11 & 6.55 & 227.0 & 107.0 & 159 \\ 40 & 5 / 09 / / 2013 & 28 & 40 & 4 & 24.7 & 24.8 & 7.25 & 6.55 & 425.0 & 198.0 & 297 \\ & & & & & & & & & & & \\ \text { Min } & & & & & 19.9 & 20.0 & 3.5 & 6.1 & 93.0 & 49.4 & 67.2 \\ \text { Max } & & & & & 25.2 & 25.2 & 11.5 & 8.0 & 895.0 & 453.0 & 890.0 \\ \text { Mea } & & & & & 22.2 & 22.4 & 8.5 & 6.7 & 508.3 & 248.8 & 356.2 \\ \text { n } & & & & & 1.8 & 1.4 & 1.8 & 0.3 & 195.2 & 95.2 & 152.4 \\ \text { S.D. } & & & & & & & & & & & \end{array}$




\section{LITERATURE CITED}

Addy, C.E. and L.G. MacNamara. 1948. Waterfowl management on small areas. Wildlife Management Institute. Washington, D.C. 80pp.

Agricultural Wetlands Research Network. 2011. Netley-Libau Marsh. From http://www.iisd.org/pdf/2011/netleylibau_marsh.pdf. Accessed February 25, 2013.

American Public Health Association (APHA), American Water Works Association and the Water Environment Federation. 1998. Standard methods for the examination of water and wastewater. $20^{\text {th }}$ Edition. United Book Press Inc. Baltimore, Maryland.

Angeloni, N.L., Jankowski, K.J., Tuchman, N.C. and J.J. Kelly. 2006. Effects of an invasive cattail species (Typha x glauca) on sediment nitrogen and microbial community composition in a freshwater wetland. FEMS Microbiology Letters. 263: 86-92.

Arheimer, B. and H. B. Wittgren. 2002. Modelling nitrogen removal in potential wetlands at the catchment scale. Ecological Engineering. 19: 63-80

Asomoah, S. A. and E.W. Bork. 2010. Drought tolerance thresholds in cattail (Typha latifolia): A test using controlled hydrologic treatments. Wetlands. 30: $99-110$.

Austin, A. 2011. Manitoba researchers convert cattails into pellets. Printed courtesy of Biomass Power and Thermal.

Batty, L., Baker, A.J.M. and B. D. Wheeler. 2002. Aluminum and phosphate uptake by Phragmites australis: the role of Fe, Mn and Al root plaques. Annals of Botany. 89: 443 449.

Bedish, J.W. 1967. Cattail moisture requirements and their significance to marsh management. American Midland Naturalist. 78: 288-300.

Beining, B. and M.L. Otte. 1996. Retention of metals and longevity of a wetland receiving mine leachate. In: Brandt, J.E., Galevotic, J.R., Kost, L., and J. Trouart (Eds.). Proceedings of $14^{\text {th }}$ Annual National Meeting - Vision 2000. An environmental commitment. American Society for Surface Mining and Reclamation, Austin Texas. Pp 43 - 46.

Berg, P and K.J. McGlarthery. 2001. A high-resolution pore water sampler for sandy sediments. Limnology and Oceanography. 46: $203-210$.

Beule, J. D. 1979. Control and management of cattails in southeastern Wisconsin wetlands. Technical Bulletin No. 112. Department of Natural Resources. Madison Wisconsin. 
Beule, J.D. and T. Janisch. 1973. Experimental control of cattail to improve wetland habitat. Annual Progress Report, Department of Natural Resources, Madison, Wisconsin (mimeo).

Boers, A.M., and J. B. Zedler. 2008. Stabilized water levels and Typha invasiveness. Wetlands. 28: 676-685

Boers, A.M., Veltman, R.L.D. and J. B. Zedler. 2007. Typha x glauca dominance and extended hydroperiod constrain restoration of wetland diversity. Ecological Engineering. 29: 232244.

Bole, J.B and J.R. Allan. Uptake of phosphorus from sediment by aquatic plants, Myriophyllum spicatum and Hydrilla verticillata. Water Research. 12: 353 - 358.

Bonnell J. and M. Fortin. 2009. Don Valley Historical Mapping Project. http://maps.library.utoronto.ca/dvhmp/index.html

Bonnewell, V., Koukka, W.L. and D. C. Pratt. 1983. Light, oxygen, and temperature requirements for Typha latifolia seed germination. Canadian Journal of Botany. 61: 13301336.

Borealis. 2001. Polypropylene: Chemical resistance table. http://www.borealisgroup. com/pdf/chemical-resistance/chemtab_PP.pdf. Downloaded June 30, 2013.

Bostrom, B., Persson, G. and B. Broberg. 1988. Bioavailability of different phosphorus forms in freshwater systems. Hydrobiologia. 170: 133-155.

Bourgeois, B., Hugron, S. and M. Poulin. 2012. Establishing a moss cover inhibits the germination of Typha latifolia, an invasive species, in restored peatlands. Aquatic Botany. 100: $76-79$

Boyd, C.E. 1970. Production, mineral accumulation and pigment concentrations in Typha latifolia. Ecology. 51: 285-290.

Boyd, C.E, and L.W. Hess. 1970. Factors influencing shoot production and mineral nutrient levels in Typha latifolia. Ecology. 51: 296-300.

Bradley M. H. and A. T. Wolf. 2005. Invasive Plant Species in Diked vs. Undiked Great Lakes Wetlands. Journal of Great Lakes Research. 31:277-287

Brisson, J and F. Chazarenc. 2009. Maximizing pollutant removal in constructed wetlands: Should we pay more attention to macrophyte species selection? Science of the Total Environment. 407: 3923 - 3930 . 
Brix, H. 1997. Do macrophytes play a role in constructed treatment wetlands? Water Science and Technology. 35: $11-17$.

Brix, H. 1994. Functions of macrophytes in constructed wetlands. Water Science and Technology. 29: $71-78$.

Brix, H. and H. H. Schierup. 1989. The use of aquatic macrophytes in water-pollution control. Ambio. 18: 100 - 107.

Calheiros, S.C., Rangel, A.O.S.S. and P.M.L. Castro. 2009. Treatment of industrial waste with two-stage constructed wetlands planted with Typha latifolia and Phragmites australis. Bioresource Technology. 100. 3205 - 3213.

Cameron, K., Madramootoo, C., Crollac, A. and C. Kinsley. 2003. Pollutant removal from municipal sewage lagoon effluents with a free-surface wetland. Water Research. 37: 28032812.

Carignan, R. and J. Kalff. 1980. Phosphorus sources for aquatic weeds: Water or sediments? Science. 207: 987-989.

Casey, P.A. 2010. Plant Fact Sheet for Sago Pondweed (Stuckenia pectinata (L.) Böerner). USDA-Natural Resources Conservation Service, Kansas Plant Materials Center. Manhattan, KS 66502.

Casselman, J.M. and C. A. Lewis. 1996. Habitat requirements of northern pike (Esox lucius). Canadian Journal of Fisheries and Aquatic Sciences. 53(Suppl.1): 161-174.

Chow-Fraser, P. 2005. Ecosystem response to changes in water level of Lake Ontario marshes: lessons learned from the restoration of Cootes Paradise Marsh. Hydrobiologia. 539: 189204.

Chow-Fraser, P., Lougheed, V., LeThiec, V., Crosbie, R., Simser, L., and J. Lord 1998. Longterm response of the biotic community to fluctuating water levels and changes to water quality in Cootes Paradise Marsh, a degraded coastal wetland of Lake Ontario. Wetland Ecology and Management. 6:19-42.

City of London and the Upper Thames River Conservation Authority. 2009. Sifton Bog environmentally significant area conservation master plan 2009 - 2019. ISBN 1 - 894329$10-4$.

City of Toronto. 2013a. http://www.toronto.ca/water/wastewater_treatment/history.htm. Accessed June 6, 2013. 
City of Toronto. 2013b. Drinking water analysis summary. Drinking Water Analysis Summary for All Plants and Distribution for the years 2006 - 2012. http://www.toronto.ca /water/publications/summary.htm and at distribution monitoring locations. Accessed July 9, 2013.

Cooke, G.W. and R. J. B.Williams. 1973. Significance of man-made sources of phosphorus: fertilizers and farming. Water Research. 7: 19-33.

Cooper, J.E., Mead, J.V., Farrell, J.M. and R.G. Werner. 2008. Potential effects of spawning habitat changes on the segregation of northern pike (Esox lucius) and muskellunge (E. masquinongy) in the upper St. Lawrence River. Hydrobiologia. 601: 41-53.

Cordell, D., Drangert, J.O. and S. White. 2009. The story of phosphorus: Global food security and food for thought. Global Environmental Change. 19: 292-305.

Court, A. and J. Bowman. 2011. Project Paradise Season Summary Report 2010. RBG Report No. 2011-05. Royal Botanical Gardens. Hamilton, Ontario.

Craft, C.B. and C.J. Richardson. 1998. Recent and long-term organic soil accretion and nutrient accumulation in the Everglades. Soil Science Society of America Journal. 62: 834-843.

Craft, C.B. and C.J. Richardson. 1993. Peat accretion and N, P, and organic C accumulation in nutrient-enriched and unenriched everglades peatlands. Ecological Applications. 3: 446 458.

Curtis, J.T. 1959. The vegetation of Wisconsin. University of Wisconsin press, Madison, Wisconsin. 657p. P. 390, 392, 393.

D'Antonio, C. and L.A.Meyerson. 2002. Exotic Plant Species as Problems and Solutions in Ecological Restoration: A Synthesis. Restoration Ecology. 10: 703-713

Dahl, T. E. and C. E. Johnson. 1991. Wetland status and trends in the conterminous United States, mid 1970's to mid 1980's: first update of the national wetlands status report. US Fish and Wildlife Service Report. U.S. Fish and Wildlife Service, Washington, DC, USA.

Danen-Louwerse, H., Lijklema, L. and M. Coenraats. 1993. Iron content of sediment and phosphate adsorption properties. Hydrobiologia. 253: 311-317.

Daniels, J.S.(T)., Cade, B.S. and J.J. Sartoris. 2010. Measuring bulrush culm relationships to estimate plant biomass within a Southern California treatment wetland. Wetlands. 30:231239 
Davis, C.B. and van der Valk. 1983. Uptake and release of nutrients by living and decomposing Typha gluaca Godr. tissues at Eagle Lake, Iowa. Aquatic Botany. 16: 75-89.

Davis, S.M. 1991. Growth, decomposition, and nutrient retention of Cladium Jamaicense Crantz and Typha domingensis Pers. in the Florida Everglades. Aquatic Botany. 40. 203-224.

de Szalay, F.A. and W. Cassidy. 2001. Effects of Muskrat (Ondatra zibethicus) lodge construction on invertebrate communities in a Great Lakes coastal wetland. American Midland Naturalist. 146: 300-310.

Drexler, J.Z. and B. L. Bedford. 2002. Pathways of nutrient loading and impacts on plant diversity in a New York Peatland. Wetlands. 22: 263-281

Donk, van E., Grimm, M.P., Gulati, R.D. and J.P.G. Klein Breteler. 1990. Whole-lake food-web manipulation as a means to study community interactions in a small ecosystem. Hydrobiologia. 200/2001: 275 - 289.

Drizzo, A., Frost, C.A., Grace, J. and K.A. Smith. 1999. Pysio-chemical screening of phosphate removing substrates for use in constructed wetland systems. Water Research. 33: 3595 3602.

Dubbe, D.R., Garver, E.G. and D.C. Pratt. 1988. Production of cattail (Typha spp.) biomass in Minnesota, USA. Biomass. 17: 79 - 104.

Elser, J. and E. Bennett. 2011. Phosphorus cycle: A broken biogeochemical cycle. Nature. 478: 29-31.

Elser, J.J., Marzolf, E.R and C.R. Goldman. 1990. Phosphorus and nitrogen limitation of phytoplankton growth in the freshwaters of North America: A review and critique of experimental enrichments. Canadian Journal of Fisheries and Aquatic Sciences. 47: 1468 1477.

Engineering Toolbox. 2013. http://www.engineeringtoolbox.com/polypropylene-pp-chemicalresistance-d_435.html. Accessed June 30, 2013.

Environment Canada. 2013. Regional Criteria for Ecological Sensitivity. Regional Ecological Sensitivity Criteria - Ontario. http://www.ec.gc.ca/pde-egp/default.asp? lang=En\&n =75F19FC6-1\#_on. Accessed August 05, 2013.

Environment Canada. 2007. Biological Test Method: Test for Measuring Emergence and Growth of Terrestrial Plants Exposed to Contaminants in Soils. EPS 1/RM/45 February 2005 (with June 2007 amendments). Method Development and Applications Sections, Environmental Technology Centre, Environment Canada. Ottawa, Ontario 
Environment Canada. 2004. National Guidelines and Standards Office. Water Policy and

Coordination Directorate. Canadian Guidance Framework for the Management of Phosphorus in Freshwater system.Report No. 1-18.

Environment Canada 1995 Guidance document on measurement of toxicity test precision using controlled sediments spiked with reference toxicant. Report EPS 1/RM/30. September 1995.

Environmental Protection Agency (EPA). 2013. Definition of brackish water. http://www.epa.gov/superfund/training/hrstrain/htmain/glossal.htm. Accessed April 18, 2013.

Environmental Protection Agency (EPA). 2000. Manual: Constructed wetlands treatment of Municipal wastewaters. Office of Research and Development. Cincinnati, Ohio. 45268. EPA/625/R-99/010.

Errington, P.L., Siglin R.J. and R. C. Clark. 1963. The decline of a muskrat population. The Journal of Wildlife Management. 27: 1-8.

Favorite, J. 2002. United States Department of Agriculture Natural Resources Conservation Service (USDA NRCS). Plant Guide. Softstem bulrush. Shoenoplectus tabernaemontani (K.C. Gmel.) Palla.

Fieswyk, C.B. and J. B. Zedler. 2007 Vegetation change in Great Lakes coastal wetlands: Deviation from the historical cycle: Journal of Great Lakes Research. 33: 366-380.

Fraser, L.H., Carty, S.M. and D. Steer. 2004. A test of four plant species to reduce total nitrogen and total phosphorus from soil leachate in subsurface wetland microcosms. Bioresource Technology. 94: 185-192

Fraser, L.H. and P. Keddy. 1997. The role of experimental microcosms in ecological research. Trends in Ecology and Evolution. 12: 478 - 481.

Galatowitsch, S.M., Anderson, N.O. and P.D. Ascher. 1999. Invasiveness in wetland plants in temperate North America. Wetlands. 19(4): 733 - 755.

Galiano, M.I. and A.G. van der Valk. 1986. Seed germination traits in drawdowns in the delta marsh, Manitoba, Canada. Aquatic Botany. 26: 89 - 102.

Garver, E.G., Dubbe, D.R. and D.C. Pratt. 1988. Seasonal patterns in accumulation and partitioning of biomass and macronutrients in Typha spp. Aquatic Botany. 32: 115 - 127. 
Grace, J.B. 1988. The effects of nutrient additions on mix-tures of Typha latifolia L. and Typha domingensis Pers. along a water-depth gradient. Aquatic Botany. 31: 83-92.

Grace, J.B. 1987. The impact of preemption on the zonation of two Typha species along lakeshores. Ecological Monographs. 57: 283 - 303.

Grace, J.B. 1983. Autotoxic inhibition of seed germination by Typha latifolia: an evaluation. Oecologia. 59: 366 - 369 .

Grace, J.B. and J.S. Harrison. 1986. The biology of Canadian weeds. 73. Typha latifolia L. and Typha angustifolia L. and Typha x glauca Godr. Canadian Journal of Plant Science. 66: 361-379.

Grace J.B. and R.G. Wetzel, 1981a. Phenotypic and genotypic components of growth and reproduction in Typha latifolia: experimental studies in marshes of differing successional maturity. Ecology. 62: $789-801$.

Grace J.B. and R.G. Wetzel, 1981b. Habitat partitioning and competitive displacement in cattails (Typha): Experimental field studies. American Naturalist. 118: 463 - 474.

Grace J.B. and R.G. Wetzel, 1981c. Effects of size and growth rate on vegetative reproduction in Typha. Oecologia. 50: $158-161$.

Gren, I-M. 2010. Resilience value of constructed coastal wetlands for combating eutrophication. Ocean \& Coastal Management 53: 358-365.

Gurevitch, J and D. K. Padilla. 2004. Are invasive species a major cause of extinctions? Trends in Ecology and Evolution.19: 470-474.

Ham, J., Chun G. Yoon, C.G., Kim, H-J and H-C Kim. 2010. Modeling the effects of constructed wetland on nonpoint source pollution control and reservoir water quality improvement. Journal of Environmental Sciences in China. 22: 834-839.

Hammer, D.A. 1989. Constructed wetlands for wastewater treatment: Municipal, industrial and agricultural. Lewis Publishers Inc. Chelsea, Michigan. 831 pp.

Hamr, P., Kirby, R.S., Gillis, P. and K.E. Day. 1994. Development of methodologies for the whole-sediment toxicity tests with benthic invertebrates: a) optimum age for initiation and duration of the Hyalella azteca survival and growth test, b) formulation of artificial sediment(s) for use in reference toxicity tests with benthic invertebrates. Prepared for Technology Development Directorate, Environment Canada, Ottawa, ON. 28p. 
Haygarth, P.M. and A.C. Edwards. 2009. Water sample collection, handling, preparation and storage. In Methods for phosphorus analysis in soils, sediments, residuals and waters Kover, J.L. and G.M. Pierzynski (eds). Southern Cooperative Series. Bulletin No. 408. $122 \mathrm{pp}$.

Heath, R.G. and C.R. Lewis. 1957. Aerial control of cattail with Radapon. The Dow Chemical Company. Midland, Michigan. Down to Earth. Winter, 1957.

Hirel, B. and P.J. Lea. 2001. Ammonia assimilation. In Lea, P.J. and J. F. Morot-Gaudry (Eds.). Plant Nitrogen. Springer - Verlag Berlin, Heidelberg, INRA, Paris. 411 pp.

Hotchkiss, N. and H. L. Dozier. 1949. Taxonomy and Distribution of N. American Cat-Tails. American Midland Naturalist. 41: 237-254

Houlahan, J.E. and C.S. Findlay. 2004. Effect of invasive plant species on temperate wetland plant diversity. Conservation Biology. 18: 1132 - 1138.

Invasive Species Specialist Group. 2013. Global Invasive Species Database. http://www.issg.org/database/species/ ecology.asp?si=895\&fr=1\&sts=\&lang=EN.

Accessed May 31, 2013, June 28, 2013.

Ip, Y.K., Chew, S.F. and D.J. Randall. 2001. Ammonia toxicity, tolerance and excretion. Fish Physiology. 20: 109 - 148.

Ipex Inc. 2001. Chemical Resistance Guide. http://www.google.ca/url?sa=t\&rct= $\mathrm{j} \& \mathrm{q}=\&$ esrc $=\mathrm{s} \& \mathrm{frm}=1 \&$ source $=$ web $\& \mathrm{~cd}=1 \& \mathrm{sq} \mathrm{i}=2 \& \mathrm{ved}=0 \mathrm{CDUQFjAA} \& u r l=\mathrm{http} \% 3 \mathrm{~A} \% 2 \mathrm{~F}$ $\%$ Fwww.ipexinc.com\%2FContent\%2FProducts\%2FProduct.aspx\%3FIsDownload\%3Dtru e\%26FileId\%3D1899\&ei=8qzRUdOBDoThyQHTnIGACQ\&usg=AFQjCNHM50Ec7EXI wgGWWjcn191pUR-8Gw\&sig2=kOceGIoObNZkWTP bvh7i2Q. Downloaded on June $30,2013$.

James, C., Fisher, J., Russell, V., Collings, S. and B. Moss. 2005. Applied Issues: nitrate availability and hydrophyte species richness in shallow lakes. Freshwater Biology. 50: 1049-1063.

Jarvie, H.P., Neal, C. and J.A. Withers. 2006. Sewage effluent phosphorus: A greater risk to river eutrophication than agricultural phosphorus? Science of the Total Environment. 360: 246253.

Jeppensen, E., Kristensen, P., Jensen, J.P., Sondergaard, M., Mortensen, E. And T. Lauridsen. 1991. Recovery resilience following a reduction in external phosphorus loading of shallow 
eutrophic Danish lakes: duration, regulating factors and methods for overcoming resilience. In Memorie Dell intituto Italiano di idrobiologia Dott. Marco Ed Marchi. Ecosystem research in freshwater environment recovery (III International Workshop, Pallaonza, $26^{\text {th }}$ $29^{\text {th }}$ September, 1990. Giussani, G., Van Liere, L., and B. Moss. Editors. Consiglio Nazionale delle Ricerche Instituto Italiano di Idrobiologia - Verbania Pallanza. (An international journal of Limnology). 48: 127 - 148.

http://books.google.ca/books?hl=en\&lr=\&id=tz1RAAAAMAAJ\&oi=fnd\&pg=PA127\&dq =phosphorus+loading+in+lakes\&ots=w7OIIGfPcw\&sig=2Dput3ygzLIMDFhtfMfwuya0tg $\mathrm{k \# v}=$ onepage \&q=phosphorus\%20loading\%20in\%20lakes\&f=false. Accessed August 03, 2013.

Kadlec, R.H. and S.D. Wallace. 2009. Treatment Wetlands. Second Edition. CRC Press LLC. Boca Raton, FL. 1016 pp.

Keddy, P.A. and A. A. Reznicek. 1986. Great Lakes vegetation dynamics: the role of fluctuating water levels and buried seeds. Journal of Great Lakes Research. 12: 25-36

Keddy, P., Gaudet, G. and L.H. Fraser. 2000. Effects of low and high nutrients on the competitive hierarchy of 26 shoreline plants. Journal of Ecology. 88: 413 - 423.

Kelly, C.A., Rudd, J.W.M. and D.W. Schindler. 1990. Acidification by nitric acid - future considerations. Water, Air and Soil Pollution. 50: 49-61.

Kercher, M. S. and J. B. Zedler. 2004. Flood tolerance in wetland angiosperms: a comparison of invasive and noninvasive species. Aquatic Botany. 80: 89-102.

Kirk, H., Connolly, C. and J. R. Freeland. 2011. Molecular genetic data reveal hybridization between Typha angustifolia and Typha latifolia across a broad spatial scale in eastern North America. Aquatic Botany. 95:189-193.

Krattinger, K. 1975. Genetic mobility in Typha. Aquatic Botany. 1: 57-70.

Kuehen, M.M. and B.N. White. 1999. Morphological analysis of genetically identified cattails Typha latifolia, Typha angustifolia and Typha x glauca. Canadian Journal of Botany. 77: 906-912.

Lee, C.-g., Fletcher, T.D. and G. Sun. 2009. Review: Nitrogen removal in constructed wetland systems. Engineering Life Science. 9: 11-22.

Lewis P, Klemm, D., Lazorchak J., Norberg-King, T, Peltier W., Herber M. Editors. 1994. ShortTerm Methods for Estimating the Chronic Toxicity of Effluents and Receiving Waters to 
Freshwater Organisms. Third Edition. Report No. EPA/600/4-91/002. July 1994.

Environmental Monitoring Systems Laboratory (Cincinnati, Ohio), Environmental Research Laboratory (Duluth, Minnesota), Region 4 Environmental Services Division (Athens, Georgia), Office of Water (Washington, D.C.).

Li, L., Li, Y., Biswas, K.D., Nian, Y. and G. Jiang. 2008. Potential of constructed wetlands in treating the eutrophic water: Evidence from Taihu Lake of China. Bioresource Technology. 99: 1656-1663.

Linde, A. F.; Thomas, J., Smith, H., Dale. Hine, D. and L. Ruth Editor. 1976. Cattail: the significance of its growth, phenology and carbohydrate storage to its control and management. (Technical bulletin. (Wisconsin Deptartment of Natural Resources), No. 94) Wisconsin Department of Natural Resources. 27 pp.

Linz, G. M. and H. J. Homan. 2011. Use of glyphosate for managing invasive cattail (Typha spp.) to disperse blackbird (Icteridae) roosts. Crop Protection. 30:98 - 104.

Livingston, E.H. 1989. Use of wetlands for urban stormwater management. Pp. 253-262. in Hammer, D.A. (Editor). Constructed wetlands for wastewater treatment: Municipal, industrial and agricultural. Lewis Publishers Inc. Chelsea, Michigan. 831 pp.

Lougheed, V.L., Theÿsmeÿer, T., Smith, T. and P. Chow-Fraser. 2004. Carp exclusion, food-web interactions, and the restoration of Cootes Paradise. Journal of Great Lakes Research. 30: $44-57$.

Maddison, M., Mauring, T., Remm, K., Lesta, M. and Ülo Mander. 2009. Dynamics of Typha latifolia L. populations in treatment wetlands in Estonia. Ecological Engineering. 35: 258264.

Maddison, M., Soosarr, K., Lohumus, K. and U. Mander. 2005. Cattail population in wastewater treatment wetlands in Estonia: biomass production, retention of nutrients and heavy metals in phytomass. Journal of Environmental Science and Health. 40: 1157-1166.

Maine, M.A., Su ne, N., Hadad, H., Sa'nchez, G. and C. Bonetto. 2009. Influence of vegetation on the removal of heavy metals and nutrients in a constructed wetland. Journal of Environmental Management. 90: 355 -363

Mal, T. K. and L. Narine. 2004. The biology of Canadian weeds. 129. Phragmites australis (Cav.) Trin. ex Steud. Canadian Journal of Plant Science. 84: 365-396 
Martín, I. and J. Fernández. 1992. Nutrient dynamics and growth of a cattail crop (Typha latifolia L.) developed in effluent with high eutrophic potential-application to wastewater purification. Bioresource Technology. 42: 7-12.

Martina, J.P and C.N. von Ende. 2008. Correlation of soil nutrient characteristics and reed canarygrass (Phalaris arundinacea: Poaceae) abundance in Northern Illinois (USA). American Midland Naturalist. 160: 430-437

Mayer, T., Bennie, D., Rosa, F., Palabrica, V., Rekas, G., Schachtschneider, J., and C. Marvin. 2008. Dispersal of contaminants from municipal discharges as evidenced from sedimentary records in a Great Lakes coastal wetland, Cootes Paradise, Ontario. Journal of Great Lakes Research. 34:544-558.

Mayer, T., Rosa, F., Mayer, R. and M. Charlton. 2006. Relationship between the sediment geochemistry and phosphorus fluxes in a Great Lakes coastal marsh, Cootes Paradise, Ontario, Canada. Water, Air, and Soil Pollution: Focus: 6: 495-503

McJannet, C.L., Keddy, P.A. and F.R. Pick. 1995. Nitrogen and phosphorus tissue concentrations in 41 wetland plants: a comparison across habitats and functional groups. Functional Ecology. 9: 231- 238.

McNaughton, S. J. 1968. Autotoxic feedback in relation to germination and seedling growth in Typha Latifolia. Ecology. 49: 367-369.

McNaughton, S. J. 1966. Ecotype Function in the Typha Community. Ecological Monographs. 36: 297 -325.

McNaughton, J.S., Folsom, T.C., Lee, T., Park, F., Price, C., Roeder, D., Schmitz, J. and C. Stockwell. 1974. Heavy Metal Tolerance in Typha Latifolia without the Evolution of Tolerant Races. Ecology. 55: 1163-1165.

Meijer, M-L., Lammens, E.H.R.R., Raat, A.J.P., Klein Breteler, J.G.P. and M.P.Grimm. 1995. Development of fish communities in lakes after biomanipulation. Netherlands Journal of Aquatic Ecology. 29: 91-101.

Meyer, S.W., Badzinski, S.S., Petrie, S.A. and C.D. Ankney. 2010. Seasonal abundance and species richness of birds in common reed habitats in Lake Erie. Journal of Wildlife Management. 74, 1559-1567.

Mitch, L.M. 2000. Common Cattail, Typha latifolia L.1. Weed Technology. 14:446-450 
Moore, D.R.J., Keddy, P.A., Gaudet, C.L. and I.C. Wisheu. 1989. Conservation of wetlands: do infertile wetlands deserve a higher priority? Biological Conservation. 47: 203 - 217.

Morinaga, T. 1926. The favorable effect of reduced oxygen supply upon the germination of certain seeds. American Journal of Botany.13: 159-166

Murphy, J. and J.P. Riley. 1962. A modified single solution method for the determination of phosphate in natural waters. Analytical Chimica Acta. 27: 31-36.

Naylor, C. and Q.C.J. Rodrigues. 1994. The use of the OECD earthworm soil (a formulated sediment) in tests with Chironomous riparius. SETAC abstract, $15^{\text {th }}$ Annual Meeting of The Society for Environmental Toxicology and Chemistry. Denver, CO.

Neil, J.H. and J.T. Graham. 1989. The evaluation of native marsh plants for the treatment of domestic sewage. Environment Ontario, Water Resources Branch. 48pp.

Nelson, S.M. and J. S. Thullen. 2008. Aquatic macroinvertebrates associated with Schoenoplectus litter in a constructed wetland in California (USA). Ecological Engineering 33: 91-101.

Newman, S., Grace, J.B., and J.W. Koebel. 1996. Effects of nutrients and hydroperiod on Typha, Cladium, and Eleocharis: Implications for Everglades Restoration. Ecological Applications. 6: 774-783.

Nichols, D. S. 1983. Capacity of natural wetlands to remove nutrients from wastewater. WPCF. 55: $495-505$.

Noe, G.B., Childers, D.L. and R.D. Jones. 2001. Phosphorus biogeochemistry and the impact of phosphorus enrichment: why is the Everglades so unique? Ecosystems. 2001. 4: 603 - 624 .

Olson, A., Paul, J and J.R. Freeland. 2009. Habitat preferences of cattail species and hybrids (Typha spp.) in eastern Canada. Aquatic Botany. 91: 67-70.

Otis, C.H. 1914. The transpiration of emersed water plants: Its measurements and its relationships. Botanical Gazette. 58: 457-494.

Painter, D.S., K.J. McCabe and W.L. Simser. 1988. Past and present limnological conditions in Cootes Paradise affecting aquatic vegetation. NWRI contribution No. 88-47.

Patrick, Jr. W.H. and R.A. Khalid. 1974. Phosphate release and sorption by soils and sediments: effect of anaerobic and anaerobic conditions. Science. 186: 53-55.

Peer, B.D., Homan, H.J., Linz, G.M. and W.J. Bleier. 2003. Impact of black-bird damage to sunflower: bioenergetic and economic models. Ecological Applications. 13: 248 - 256. 
Pollard, P. C. 2010. Bacterial activity in plant (Schoenoplectus validus) biofilms of constructed wetlands. Water Research. 44: 5939 - 5948.

Pote, D.H., Daniel, T.C. and P.B. DeLaune. 2009. Total phosphorus and total dissolved phosphorus in water samples. In Methods for phosphates analysis in soils, sediments, residuals and waters Kover, J.L. and G.M. Pierzynski (eds). Southern Cooperative Series. Bulletin No. 408. 122pp.

Puddephatt, J.K. 2013. Determining the sustainability of land-applying biosolids to a agricultural lands using environmentally-relevant terrestrial biota. M.Sc. Thesis. Ryerson University.

Ray, A. M. and R. S. Inouye. 2006. Effects of water-level fluctuations on the arbuscular mycorrhizal colonization of Typha latifolia L. Aquatic Botany. 84 (2006) 210-216

Reddy, K.R. and E.M. D'Angelo. 1997. Biochemical indicators to evaluate pollution removal efficiency in constructed wetlands. Water Science and Technology. 35: 1- 10.

Reddy, K.R., Delaune, R.D., DeBusk, W.F. and M.S. Koch. 1993. Long-term nutrient accumulation rates in the Everglades. Soil Science Society of America Journal. 1993. 57: $1147-1155$.

Reddy, K. R., Kadlec, R.H., Flaig, E. and P. M. Gale (1999): Phosphorus retention in streams and wetlands: A Review. Critical Reviews in Environmental Science and Technology. 29: 83-146.

Reddy, K. R. and K. M. Portier, 1987. Nitrogen utilization by T. latifolia as affected by temperature and rate of nitrogen application. Aquatic Botany. 27: $127-138$.

Richardson, C.J. 1985. Mechanisms controlling phosphorus retention capacity in freshwater wetlands. Science. 228:1424-1427.

Rigler, F.H. 1964. The phosphorus fractions and the turnover time of inorganic phosphorus in different types of lakes. Limnology and Oceanography. 9: 511-518.

Sakadevan, K. and H. J. Bavor. 1998. Phosphate adsorption characteristics of soils, slags and zeoplite to be used as substrates in constructed wetland systems. Water Research. 32: 393399.

Sale, P.J.M. and R.G. Wetzel. 1983. Growth and Metabolism of Typha species in relation to cutting treatments. Aquatic Botany. 15: $321-334$. 
Self-Davis, M.L., Moore jr., P.A. and B.C. Joern. 2009. Water- or dilute salt-extractable phosphorus in soil. In Methods for phosphorus analysis in soils, sediments, residuals and waters Kover, J.L. and G.M. Pierzynski (eds). Southern Cooperative Series. Bulletin No. 408. 122pp.

Shapiro, J. 1990. Biomanipulation: the next phase - making it stable. Hydrobiologia. 200/2001: 13-27.

Schindler, D.W. 1977. The evolution of phosphorus limitation in lakes: Natural mechanisms compensate for nitrogen and carbon in eutrophied lakes. Science. 195: 260 - 262.

Schindler, DW. 1974. Eutrophication and recovery in eutrophic lakes: Implications for lake management. Science. 184: 897-899.

Scholtz, M. 2006. Wetland Systems to Control Urban Runoff. $1^{\text {st }}$ Edition. Elsevier. Oxford, UK. pp.103, 104, 105.

Selbo, S. M. and A. A. Snow. 2004. The potential for hybridization between Typha angustifolia and Typha latifolia in a constructed wetland. Aquatic Botany. 78: 361-369.

Sheoran, A.S. and V. Sheoran. 2006. Heavy metal removal mechanisms of acid mine drainage in wetlands: A critical review. Minerals Engineering. 19: 105-116.

Shih, J.G. and S.A. Finkelstein. 2008. Range Dynamics and invasive tendencies in Typha latifolia and Typha angustifolia in Eastern North America derived from herbarium and pollen records. Wetlands: 28: 1-16.

Sifton, H.B. 1959. The germination of light-sensitive seeds of Typha latifolia L. ${ }^{1}$. Canadian Journal of Botany. 37: 719 - 739.

Slayton, K. 2009. Orlando Easterly Wetlands compliance and performance review for the City of Orlando's Easterly Wetlands Treatment System 2008 Annual Report. Prepared for: Florida Department of Environmental Protection.

Smith, S.G. 1967. Experimental and natural hybrids in North American Typha (Typhaceae). The American Midland Naturalist. 78: 257-287.

Smith, V.H. and D. W. Schindler 2009. Eutrophication science: where do we go from here? Trends in Ecology and Evolution. 24:201-207.

Smolders, A.J.P., Lamers, L.P.M., Lucassen, E.C.H.E.T., Van der Velde, G. and J.G.M. Roelofs. 2006. Internal eutrophication: How it works and what to do about it - a review. Chemistry and Ecology. 22: 93-111. 
Snell, E.A. 1987. Recent wetland losses in southern Ontario. Pp. 183 - 197 in Wetlands, inertia or momentum. In M.J. Bardecki and N. Patterson, Editors. Federation of Ontario Naturalists, Don Mills, Ontario.

Song, Z., Zheng, Z., Li, J., Sun, X, Han, X., Wang, W. and M. Xu. 2006. Seasonal and annual performance of a full-scale constructed wetland system for sewage treatment in China. Ecological Engineering. 26: 272-282

Steens, J.H., Smith, L.P. and H.P. Cofer. 1959. Studies on cattail management in the Northeast. Transactions of the Northeast Wildlife Confederation. 10: 149 - 155.

Stevens, M. and C. Hoag. 2000. United States Department of Agriculture Natural Resources Conservation Service (USDA NRCS). Plant Guide. Broad-leaved cattail. Typha latifolia $L$.

Stevens, M. and C. Hoag. 2003. United States Department of Agriculture Natural Resources Conservation Service (USDA NRCS). Plant Guide. Hardstem bulrush. Shoenoplectus acutus (Muhl. Ex Bigelow) A. \& D. Love var. occidentalis (S. Wats.) S.G. Sm.

Steward, K.K., and H. Ornes. 1975. The autoecology of sawgrass in the Florida Everglades. Ecology. 56: $162-171$.

Sullivan, L., Wildova, R., Goldberg, D. and C. Vogel. 2010. Growth of three cattail (Typha) taxa in response to elevated $\mathrm{CO}_{2}$. Plant Ecology. 207:121-129

Szögi, A.A., Hunt, P.G., Sadler, E.J. and D.E. Evans. 2004. Characterization of oxidizationreduction processes in constructed wetlands for swine wastewater treatment. Applied Engineering in Agriculture. 20: 189 - 200.

Tanner, C.C. 1996. Plants for the constructed wetland treatment systems - A comparison of the growth and nutrient upatake of eight emergent species. Ecological Engineering. 7: 59 - 83.

Taylor, G.J. and Crowder, A.A. 1984. Copper and nickel tolerance in Typha latifolia clones from contaminated and uncontaminated environments. Canadian Journal of Botany. 61: $1825-1830$.

Taylor, M.E. 1992. Constructed wetlands for stormwater management: a review. The Queen's Printer, Toronto, Ontario. 63 pp.

Theÿsmeÿer, T., Smith, T. and L. Simser. 1999. West Pond 1999 study. Royal Botanical Gardens. 
Tilley, D., Ogle, D., and L. St. John. 2011. Plant guide for hardstem bulrush (Schoenoplectus acutus). United States Department of Agriculture -Natural Resources Conservation Service (USDA-NRCS), Idaho Plant Materials Center. Aberdeen, ID.

Tornbjerg, T., Bendix, M. and H. Brix. 1994. Internal gas transport in Typha latifolia L. and Typha angustifolia L.2. convective tissue throughflow pathways and ecological significance. Aquatic Botany. 49: 91-105.

van der Valk, A.G. and C.B. Davis. 1978. The role of seed banks in the vegetation dynamics of prairie glacial marshes. Ecology. 59: 322-335.

van Kessel, J.K. 1978. The relation between redox potential and denitrification in a watersediment system. Water Research. 12: 285-290.

Verhoeven, J. T. A. and A. F.M. Meuleman. 1999. Wetlands for wastewater treatment:

Opportunities and limitations. Ecological Engineering. 12: 5-12

Vohla, C., K õiv, M., Bavor, H.J., Chazarenc, F and Ülo Mander. 2011. Filter materials for phosphorus removal from wastewater in treatment wetlands - A review. Ecological Engineering. 37: 70-89.

United States Department of Agriculture -Natural Resources Conservation Service (USDANRCS). 2013a. Plants Profile. Schoenoplectus acutus. (Muhl. ex Bigelow) Á. Löve \& D. Löve var. acutus. Hardstem bulrush. http://plants.usda.gov/java/ profile?symbol=scaca. Accessed June 28, 2013.

United States Department of Agriculture -Natural Resources Conservation Service (USDANRCS). 2013b. Plants Profile. Schoenoplectus tabernaemontani. (C.C. Gmel.) Palla. Softstem bulrush. http://plants.usda.gov/java/profile?symbol=scta2. Accessed June 28, 2013.

United States Department of Agriculture -Natural Resources Conservation Service (USDANRCS). 1997. Wetland plant fact sheet. Hardstem Bulrush (Scirpus acutus). USDA-NRCS Interagency Riparian/wetland project. Plant Materials Center, Aberdeen, Idaho 83210. Vymazal, J. 2007. Removal of nutrients in various types of constructed wetlands. Science of the Total Environment. 380: 48 -65.

Wang, S-C, Jurik, T.W. and A.G. van der Valk. 1994. Effects of sediment load on various stages in the life and death of cattail (Typha x glauca). Wetlands. 14: 166-173. 
Wang, Z., Wen, S., Xing, B., Gao, D., and F. Li. 2008. Rhizosphere effect of different aquatic plants on phosphorus depletion. Frontiers of Environmental Science and Engineering in China. 2(3): 274-279.

Waters, I. and J.M. Shay. 1992. Effect of water depth on population parameters of a Typha glauca stand. Canadian Journal of Botany. 70: 349-51.

Waters, I. and J.M. Shay. 1990. A field study of the morphometric response of Typha glauca shoots to a water depth gradient. Canadian Journal of Botany. 68: 2339-2343

Wei, A. and P. Chow-Fraser. 2006. Synergistic impact of water level fluctuation and invasion of Glyceria on Typha in a freshwater marsh of Lake Ontario. Aquatic Botany. 84: 63-69

Weisner, S.E.B. 1993. Long-term competitive displacement of Typha latifolia by Typha angustifolia in a eutrophic lake. Oecologia. 94:451-456.

Weng, S., Putz, G. and J.A. Kells. 2006. Phosphorus uptake by cattail plants in a laboratory-scale experiment related to constructed wetlands. Journal of Environmental Engineering and Science. 5: 295-308.

Wetzel, R.G. 1983. Limnology. Second Edition. 767 pp.

Wetzel, R.G. and A.G. van der Valk. 1998. Effects of nutrient and soil moisture on competition between Carex stricta, Phalaris ardundinacea and Typha latifolia. Plant Ecology. 138: 179-190.

White, J.S., Bayley, S. E. and P. J. Curtis. 2000. Sediment storage of phosphorus in a northern prairie wetland receiving municipal and agro-industrial wastewater. Ecological Engineering 14: $127-138$.

Whillans, T.H. 1982. Changes is marsh area along the Canadian shore of Lake Ontario. Journal of Great Lakes Research. 8: 570-577.

Walton, W.E., Schreiber, E.T. and M.R. Mulla. 1990. Distribution of Culex trasalis larvae in a freshwater marsh in Orange County, California. Journal of the American Mosquito Control Association. 6: 539 - 543.

Wikipedia, 2013a. http://en.wikipedia.org/wiki/Trophic_state_index. Accessed July 23, 2013.

Wikipedia, 2013b. Cold frame. http://en.wikipedia.org/wiki/Cold_frame. Accessed June 30, 2013

Wikipedia, 2013c. Einstein unit. http://en.wikipedia.org/wiki/Einstein_(unit). Accessed July 14, 2013 
Wilcove, D. S., and L. Y. Chen. 1998. Management costs for endangered species. Conservation Biology. 12:1405-1407.

Wilcox, D.A., Kowalski, K.P., Hoare, H.L., Carlson, M.L. and H.N. Morgan. 2008. Cattail invasion of sedge/grass meadows in Lake Ontario: photointerpretation analysis of sixteen wetlands over five decades. Journal of Great Lakes Research. 34, 301-323.

Wilcox, D.A., Apfelbaum, S.I. and R.D. Hiebert. 1985. Cattail invasion of sedge meadows following hydrological disturbance in the Cowles Bog wetland complex, Indiana Dunes National Lakeshore. Wetlands. 4: 115 - 128.

Wisconsin Department of Natural Resources. 2011. Website accessed on October 10, 2011. http://dnr.wi.gov/invasives/fact/com_cattail.htm.

Woo, I. and J.B. Zedler. 2002. Can nutrients alone shift a sedge meadow towards dominance by the invasive Typha x glauca? Wetlands. 22: $509-521$.

Woo, K.H. 2009. Evaluation of hydrology in an agricultural watershed and nitrogen removal by constructed wetlands (under the direction of Dr. Stephen W. Broome and Dr. Devendra M. Amatya.). A dissertation submitted to the Graduate Faculty of North Carolina State University in partial fulfillment of the requirements for the Degree of Doctor of Philosophy. Soil Science. Raleigh, North Carolina.

Yalcuk, A., Pakdil, N.B. and S.Y. Turan. 2010. Performance evaluation on the treatment of olive mill wastewater in vertical subsurface flow constructed wetlands. Desalination. 262: 209-214.

Yates, C.R., and S. O. Prasher. 2009. Phosphorus reduction from agricultural runoff in a pilotscale surface-flow constructed wetland. Ecological Engineering 35: 1693-1701.

Ye, Z.H., Baker, A.J.M., Wong, M.H. and A.J. Willis. 1997. Zinc, lead and cadmium tolerance, uptake and accumulation by Typha latifolia. New Phytologist. 136: 469 - 480.

Ye, Z.H., Whiting, S.N., Qian, J.H., Lytle, C.M., Lin, Z.-Q. and N. Terry. 2001. Trace element removal from a 10-year-old constructed wetland. Journal of Environmental Quality. 30: $1710-1719$.

Yount, J.L. and R.A. Crossman Jr. 1970. Eutrophication control by plant harvesting. Water Pollution Control Federation. 42(5): R173-R183.

Zar, J.H. 1984. Biostatistical Analysis. Second edition. Prentice-Hall, Inc. 717pp. 
Zedler, J. B. 2003. Wetlands at your service: reducing impacts of agriculture at the watershed scale. Frontiers in Ecology and the Environment 1:65-72.

Zhang, Z., Rengel, Z. and K. Meney. 2008. Interactive effects of nitrogen and phosphorus loadings on nutrient removal from simulated wastewater using Schoenoplectus validus in wetland microcosms. Chemosphere 72: 1823-1828. 